Volnei Tita

\title{
CONTRIBUIÇÃO AO ESTUDO DE DANOS E FALHAS PROGRESSIVAS EM ESTRUTURAS DE MATERIAL COMPÓSITO POLIMÉRICO
}

Tese de doutorado apresentada à Escola de Engenharia de São Carlos da Universidade de São Paulo, como parte dos requisitos para obtenção do título de Doutor em Engenharia Mecânica

ORIENTADOR: Prof. Dr Jonas de Carvalho

São Carlos

2003 
Ao meu pai (in memoriun) e a minha mãe por tudo e em especial a minha esposa, Sandra, por ser a minha grande companheira nesta difícil caminhada. 


\section{AGRADECIMENTOS}

Ao Prof. Dr Jonas de Carvalho pelo desafio lançado, pela amizade e pelos momentos de discussão sobre o projeto de pesquisa.

Ao Prof. Dr Sergio Persival Baroncini Proença da Escola de Engenharia de São Carlos (Departamento de Engenharia de Estruturas) e ao Prof. Dr Marcílio Alves da Escola Politécnica da Universidade de São Paulo (Departamento de Engenharia Mecatrônica e de Sistemas Mecânicos) por auxiliar e contribuir com importantes sugestões para o enriquecimento do trabalho.

Aos companheiros do LTC (Laboratório de Tribologia e Compósitos) pelos momentos de alegria e descontração, mas principalmente pelas incansáveis discussões sobre Mecânica dos Sólidos, Mecânica dos Materiais, Materiais Compósitos e outros tantos assuntos de suma importância para o nosso amadurecimento como pesquisadores na área de Ciências Mecânicas.

Ao Prof. Dr. Ir. Dirk Vandepitte do Departamento de Engenharia Mecânica da Katholieke Universiteit Leuven (Belgium) bem como ao Prof. Dr. Ir. Ignaas Verpoest do Departamento de Engenharia de Materiais da Katholieke Universiteit Leuven (Belgium) por permitirem a fabricação bem como a realização de ensaios experimentais em compósitos poliméricos reforçados no LCPC (Leuven Composites Processing Centre - Belgium).

À Dr. Ir. Mieke Lossie e ao técnico Paul Van Cauwenbergh do Departamento de Engenharia Mecânia da Katholieke Universiteit Leuven e ao Dr. Ir. Bart Vangrimde do Departamento de Engenharia de Materiais da Katholieke Universiteit Leuven pelo grande apoio dado durante a fabricação, a realização dos ensaios mecânicos bem como a análise dos resultados experimentais. 
Ao Prof. Dr. Ir. Stepan Lomov do Departamento de Engenharia de Materiais da Katholieke Universiteit Leuven por ter contribuído com alguns aspectos teóricos associados ao trabalho.

Aos técnicos do Departamento de Engenharia Mecânia da Katholieke Universiteit Leuven e aos técnicos do Departamento de Engenharia de Materiais da Katholieke Universiteit Leuven pelo grande apoio dado durante a fabricação das amostras.

Ao Prof. Dr João Lirani do LAMAQ (Departamento de Engenharia Mecânica USP/São Carlos) por conceder uma licença de utilização do pacote computacional DYNA $^{\circledR}$.

Ao Prof. Dr Elias Hage Jr. (DEMA - Departamento de Engenharia de Materiais - UFSCar) por ceder a máquina de testes para a realização de ensaios quase-estáticos (tração e flexão).

Ao Departamento de Engenharia de Materiais (USP/São Carlos) por ceder a máquina de testes de impacto instrumentada (Charpy) e por permitir a utilização de uma prensa hidraulica para confecção de amostras.

Aos companheiros do Departmento de Engenharia Mecânica (USP/S. Carlos) por momentos agradáveis.

Aos funcionários do Departamento de Engenharia Mecânica (USP/S. Carlos) pelo auxílio nas questões burocráticas.

À FAPESP pelo financiamento concedido ao presente projeto de pesquisa.

E principalmente a Deus pelos momentos de inspiração, determinação e entendimento nas fases mais críticas do desenvolvimento do projeto. 
"...meu propósito não é ensinar aqui o método que cada um deve seguir para bem conduzir sua razão, mas somente mostrar de que modo procurei conduzir a minha."

(René Descartes) 


\section{RESUMO}

TITA, V. (2003). Contribuição ao estudo de danos e falhas progressivas em estruturas de material compósito polimérico. São Carlos, 2003. Tese de Doutorado Escola de Engenharia de São Carlos, Universidade de São Paulo, São Carlos, 2003.

Neste trabalho buscou-se propor e implementar um modelo de material capaz de prever o comportamento mecânico de estruturas em compósitos poliméricos reforçados (CPR). Inicialmente fez-se um levantamento bibliográfico sobre os modos de danificação intralaminar e falhas interlaminares bem como sobre formas de abordagem (analítica e numérica) para tratar esses problemas. Em seguida, foram apresentadas em detalhes as etapas experimentais executadas, descrevendo todo o procedimento de fabricação dos corpos-de-prova e os resultados obtidos a partir dos ensaios quase-estáticos de tração, compressão, cisalhamento e flexão. Com base nesses resultados e em informações provenientes da literatura, propõem-se alguns modelos de material que foram implementados em sub-rotinas FORTRAN. Tais modelos são posteriormente compilados em conjunto com um programa de elementos finitos $\left(A B A Q U S^{\circledR}\right)$ a fim de serem avaliados e terem seus parâmetros calibrados. Numa primeira fase, através de simulações computacionais dos ensaios de tração e compressão avaliou-se os modelos de material implementados. Numa segunda fase, os parâmetros foram calibrados tomando como base três estudos de caso (flexão, endentação e teste de impacto) envolvendo seqüências de empilhamento distintas. Após a simulação computacional desses estudos, apresentou-se a proposta de uma metodologia para avaliar problemas de impacto a baixa velocidade em estruturas laminadas. Conclui-se assim que o presente projeto de pesquisa traz contribuições inovadoras, mas também apresenta várias perspectivas de trabalhos futuros.

Palavras-chave: compósitos poliméricos, comportamento mecânico, modelo de material, ensaios quase-estáticos, testes de impacto, simulação computacional. 


\section{ABSTRACT}

TITA, V. (2003). Contribution to the study of damage and progressive failure on composite structures. São Carlos, 2003. Ph.D. Thesis - Escola de Engenharia de São Carlos, Universidade de São Paulo, São Carlos, 2003.

In this work, material models were proposed to predict the mechanical behavior of composite structures. First of all, it was done a study about damage intra-ply and inter-ply (delamination) on composite materials and about analytical and numerical approaches to solve problems of progressive damage on composite structures was performed. After, many specimens were manufactured and experimental tests (tensile, compression, shear and flexural tests) were carried out. Experimental results and information from literature were used to develop some material models, which were implemented using FORTRAN compiler. These material models were compiled with a commercial finite element program $\left(\mathrm{ABAQUS}^{\circledR}\right)$ in order to evaluate and calibrate parameters of the models. In the first step, computational simulations of tensile and compression test were carried out to evaluate material models implemented. In the second step, the parameters of the material models were calibrated using three case studies (flexural, indentation and impact test) with some staking sequences. After that, a methodology was proposed to evaluate impact problems on composite structures under low velocity. Therefore, this research project not only shows new contributions but also suggests many future investigations.

Keywords: composites, mechanical behavior, material model, quasi-static tests, impact test, computational simulations. 


\section{LISTA DE FIGURAS}

FIGURA 1.1-1 - Esquema de classificação para materiais compósitos (CALLISTER, 1985)

FIGURA 1.1-2 - Compósitos estruturais laminados (VINSON;

SIERAKOWSKI, 1987)

FIGURA 2.1-1 - Mecanismos de danificação/falha para um CPR:

Fenômenos intra e interlaminares

FIGURA 2.1.1-1 - Mecanismos da fibra sob compressão:

(a) Microflambagem; (b) Cisalhamento

(AGARWAL; BROUTMAN, 1990)

FIGURA 2.1.1-2 - Mecanismos de danificação em CPR: fenômenos intralaminares (ANDERSON, 1995)

FIGURA 2.1.2-1 - Mecanismos de danificação/falha em CPR:

(a) processo de evolução da falha (AGARWAL;

BROUTMAN, 1990);(b) amostra de CPR

delaminada

FIGURA 2.1.2-2 - "Formas características" de falha interlaminar em estruturas impactadas: (a) laminado espesso;

(b) laminado fino (ABRATE, 1998)

FIGURA 2.2-1 - Estado de tensões num dado ponto material

FIGURA 2.2-2 - Lâmina ortotrópica: sistema global de coordenadas e sistema local de coordenadas (eixos principais do material)

FIGURA 2.2-3 - Superfície definida pelo Critério da Máxima Tensão (HYER, 1998)

FIGURA 2.2-4 - Vista isométrica da superfície definida pelo Critério de Hoffman considerando estado plano de tensões (MAGAGNIN FILHO, 1996)

FIGURA 2.2-5 - Franjas isocromáticas de tensão para um CPR sob a ação de carregamento transversal (HULL, 1981) 
FIGURA 2.2-6 - Superfície definida pelo Critério de Tsai-Wu

(HYER, 1998)

FIGURA 2.2-7 - Porcentagem de contribuição na degradação:

(a) laminados unidirecionais; (b) laminados do tipo

“angle-ply”(SANDHU, 1976)

FIGURA 2.2-8 - Esquema cronológico de trabalhos científicos relevantes

FIGURA 2.2-9 - Mecanismo de delaminação: Modos de Fratura (MAGAGNIN FILHO, 1996)

FIGURA 2.2-10 - Fluxograma de análise de uma estrutura laminada 32

FIGURA 2.2.1-1 - (a) Estrutura laminada; (b) Esforços atuantes 33

FIGURA 2.2.1-2 - Aproximações cinemáticas de Kirchhoff

FIGURA 2.2.2-1 - Deformação de um corpo elástico num sistema cartesiano de coordenadas

FIGURA 2.2.2-2 - Procedimento de avaliação do Modelo de Material

FIGURA 3.1-1 - Tecido pré-impregnado (“prepreg”): (a) Bobina de "prepreg"; (b) Empilhamento de lâminas unidirecionais

FIGURA 3.2-1 - Fase de preparação para efetuar moldagem do prepreg 46

FIGURA 3.2-2 - Ciclo de cura ideal para o M10 (Hexcel ${ }^{\circledR}$ )

FIGURA 3.3.1-1 - Amostras para ensaios de tração: (a) lâminas empilhadas a $0^{\circ}$; (b) lâminas empilhadas a $90^{\circ}$

FIGURA 3.3.1-2 - Curvas tensão-deformação dos corpos-de-prova a $0^{\circ}$ sob teste de tração: (a) Gráfico obtido pelo extensômetro; (b) Gráfico obtido pelo cross head da máquina

FIGURA 3.3.1-3 - Curvas tensão-deformação dos corpos-de-prova a $90^{\circ}$ sob teste de tração:(a) Corpo de prova número 1; (b) Corpo de prova número 6

FIGURA 3.3.1-4 - Gráfico da deformação transversal em função da deformação axial 
FIGURA 3.3.1-5 - Modos de falha de CPR a compressão

(a) Flambagem local das fibras; (b) Falha por

cisalhamento (CARLSSON; PIPES, 1987)

FIGURA 3.3.1-6 - Resistência à compressão em função da razão comprimento de flambagem pela espessura da amostra (CARLSSON; PIPES, 1987)

FIGURA 3.3.1-7 - Ensaios utilizando "strain gauges back-to-back":

(a)Amostra carregada excentricamente; (b) Amostra carregada uniformemente (adaptado de Carlsson;

Pipes (1987)) 58

FIGURA 3.3.1-8 - Dispositivo IITRI para ensaio de compressão 59

FIGURA 3.3.1-9 - Amostras para ensaios de compressão:

(a) lâminas empilhadas a $0^{\circ}$ (amostra fraturada com

"strain-gauge"); (b) lâminas empilhadas a $90^{\circ}$

FIGURA 3.3.1-10 - Curvas tensão-deformação dos corpos-de-prova a $0^{\circ}$ sob teste de compressão: (a) carregamentos combinados (b) carregamento uniforme

FIGURA 3.3.1-11 - Curvas tensão-deformação dos corpos-de-prova a $90^{\circ}$ sob teste de compressão: (a) carregamentos combinados (b) carregamento uniforme

FIGURA 3.3.2-1 - Teste de Cisalhamento: (a) Curva de tensão de cisalhamento em função das distorções angulares;

(b) Campo de tensões no corpo de prova para cisalhamento 62

FIGURA 3.3.2-2 - Amostras para ensaios de cisalhamento 63

FIGURA 3.3.2-3 - Curvas dos corpos-de-prova a +/-45 ${ }^{\circ}$ sob tração:

(a) Tensão de cisalhamento-distorções angulares;

(b) Deformações permanentes-tensão de cisalhamento 64

FIGURA 3.3.2-4 - Determinação do parâmetro de não-linearidade $\alpha$ 65

FIGURA 3.3.3-1 - Amostras para ensaios de flexão 3-pontos:(a) norma ASTM D790-96a; (b) norma ASTM D2344-84 
FIGURA 3.3.3-2 - Curvas força-deflexão obtidas do teste de flexão 3pontos (ASTM D790-96a): (a) Amostra com lâminas a $0^{\circ}$; (b) Amostra com lâminas a $90^{\circ}$

FIGURA 3.3.3-3 - Curvas tensão-deformação obtidas do teste de flexão 3-pontos (ASTM D790-96a): (a) Amostra com lâminas a $0^{\circ}$; (b) Amostra com lâminas a $90^{\circ}$

FIGURA 3.3.3-4 - Distribuição das tensões de cisalhamento transversal para uma viga de carbono grafite e resina epóxi $($ span/espessura $=4)$ sob flexão 3-pontos (WHITNEY; DANIEL; PIPES, 1984)

FIGURA 3.3.3-5 - Gráfico força-deflexão para amostras orientadas a $0^{\circ}$ (ASTM D2344)

FIGURA 3.3.3-6 - Resultados dos testes de flexão 3-pontos (ASTM D2344): (a) Lâminas orientadas a $[0 / 90 / 0 / 90 / 0 / 90 / 0]_{s}$;(b) Lâminas orientadas a [+45/$\left.45 /+45 / 0_{2} / 90_{2}\right]_{\mathrm{s}}$

FIGURA 4.1-1 - Fluxograma de análise progressiva de danificação e falha em laminados

FIGURA 4.1-2 - Processo de degradação das propriedades de um CPR:

(a) Proposto por Hahn e Tsai (HAHN; TSAI, 1974);

(b) Proposto no presente trabalho.

FIGURA 4.2.2-1 - Degradação do módulo de Young $\mathrm{E}_{11}$ 88

FIGURA 4.4-1 - Fluxograma do algoritmo da sub-rotina USDFLD 94

FIGURA 4.4-2 - Fluxograma do algoritmo das sub-rotinas UMAT 95

FIGURA 4.5-1 - Modelos do ensaio de tração (a) e do ensaio de compressão (b)

FIGURA 4.5-2 - Calibração dos parâmetros H e B para o modelo do ensaio de tração $[0]_{5}$

FIGURA 4.5-3 - Influência do número de incrementos na solução do modelo do ensaio de tração [0]5

FIGURA 4.5-4 - Influência da densidade de malha na solução do modelo do ensaio de tração [0]5 
FIGURA 4.5-5 - Avaliação da sensibilidade da resposta ao módulo de Young para modelos dos ensaios de compressão:

(a) amostras a a $[0]_{15} ;$ (b) amostras a $[90]_{15}$ 101

FIGURA 5.2.1-1 - Gráfico força-deflexão para amostras orientadas a $0^{\circ}$ 104 FIGURA 5.2.1-2 - Gráfico força-deflexão para amostras orientadas a $[0 / 90 / 0 / 90 / 0]_{\mathrm{s}}$

FIGURA 5.2.1-3 - Gráfico força-deflexão para amostras orientadas a $[+45 /-45 /+45 / 0 / 90] \mathrm{s}$

FIGURA 5.2.2-1 - Modelos do teste de flexão 3-pontos: (a) Modelo em

Casca (Elemento S8R); (b) Modelo Sólido

(Elemento C3D8R)

FIGURA 5.2.3-1 - Curvas força-deflexão para lâminas orientadas a

$[0]_{10}$ : Modelo I (sub-rotina USDFLD)

FIGURA 5.2.3-2 - Curvas força-deflexão para lâminas orientadas a

$[0]_{10}$ : Modelo II (sub-rotina UMAT)

FIGURA 5.2.3-3 - Representação dos primeiros elementos que danificam para um total de 29 incrementos (lâminas orientadas a $[0]_{10}$ - Modelo II)

FIGURA 5.2.3-4 - Dependência do tamanho do incremento (lâminas orientadas a $[0]_{10}$ - Modelo II

FIGURA 5.2.3-5 - Curvas força-deflexão para lâminas orientadas a

$[0]_{10}$ : Modelo III (sub-rotina UMAT)

FIGURA 5.2.3-6 - Curvas força-deflexão para lâminas orientadas a

$[0]_{10}$ : Elemento S8R (Modelo II) x Elemento C3D8R

(Modelo III)

FIGURA 5.2.3-7 - Modelo sólido deformado

FIGURA 5.2.3-8 - Curvas força-deflexão para lâminas orientadas a [0/90/0/90/0 $]_{\mathrm{s}}$ : Modelo I (sub-rotina USDFLD)

FIGURA 5.2.3-9 - Curvas força-deflexão para lâminas orientadas a [0/90/0/90/0 $]_{s}$ : Modelo II (sub-rotina UMAT)

FIGURA 5.2.3-10 - Curvas força-deflexão para lâminas orientadas a

$$
\text { [0/90/0/90/0]s: Modelo III (sub-rotina UMAT) }
$$


FIGURA 5.2.3-11 - Curvas força-deflexão para lâminas orientadas a [0/90/0/90/0 $]_{\mathrm{s}}$ : Elemento S8R (Modelo II) $\mathrm{x}$ Elemento C3D8R (Modelo III)

FIGURA 5.2.3-12 - Influência da densidade de malha na simulação do teste de flexão 3-pontos para lâminas orientadas a [0/90/0/90/0 $]_{s}$ : Modelo III (sub-rotina UMAT)

FIGURA 5.2.3-13 - Curvas força-deflexão para lâminas orientadas a [0/90/0/90/0 $]_{\mathrm{s}}$ : Modelo III x Modelo IV

FIGURA 5.2.3-14 - Curvas força-deflexão para lâminas orientadas a [+45/-45/+45/0/90]s: Modelo I (sub-rotina USDFLD)

FIGURA 5.2.3-15 - Curvas força-deflexão para lâminas orientadas a [+45/-45/+45/0/90] $]_{\mathrm{s}}$ : Modelo II (sub-rotina UMAT)

FIGURA 5.2.3-16 - Curvas força-deflexão para lâminas orientadas a $[+45 /-45 /+45 / 0 / 90]_{s}$ : Modelo III (sub-rotina UMAT)

FIGURA 5.2.3-17 - Curvas força-deflexão para lâminas orientadas a [+45/-45/+45/0/90]s: Elemento S8R (Modelo II) x Elemento C3D8R (Modelo III)

FIGURA 5.2.3-18 - Avaliação da sensibilidade da resposta ao módulo de cisalhamento $G_{12}$ para lâminas orientadas a $[+45 /-45 /+45 / 0 / 90]_{\mathrm{s}}$ (Modelo III)

FIGURA 5.3-1 - Condições para o "indentation test": (a) Geometria do impactador (endentador); (b) Engastamento das amostras

FIGURA 5.3-2 - Torre de impacto (“drop-tower") e dispositivos utilizados no teste

FIGURA 5.3-3 - Amostras utilizadas durante o "indentation test" e o "drop-test"

FIGURA 5.3.1-1 - Históricos para lâminas orientadas a $[0]_{10}$ :
(a) Históricos de força
(b) Históricos de deslocamento 
FIGURA 5.3.1-2 - Históricos de energia para lâminas orientadas a $[0]_{10}$ :

(a) Energia de impacto igual a 5,91 J; (b) Energia de impacto igual a $2,36 \mathrm{~J}$

FIGURA 5.3.1-3 - Mapas de falha obtidos através da técnica de ultrasom $C$-Scan para lâminas orientadas a $[0]_{10}$

FIGURA 5.3.1-4 - Históricos para lâminas orientadas a [0/90/0/90/0]s:

(a) Históricos de força; (b) Históricos de deslocamento

FIGURA 5.3.1-5 - Históricos de energia para lâminas orientadas a [0/90/0/90/0 $]_{\mathrm{s}}$ : (a) Energia de impacto igual a 5,91 J;

(b) Energia de impacto igual a 2,36 J

FIGURA 5.3.1-6 - Forma ("peanut shape") e orientação das delaminações (ABRATE, 1998)

FIGURA 5.3.1-7 - Mapas de falha obtidos através da técnica de ultrasom C-Scan para lâminas orientadas a [0/90/0/90/0 $]_{\mathrm{s}}$

FIGURA 5.3.1-8 - Históricos para lâminas orientadas a [+45/45/+45/0/90] $]_{\mathrm{s}}$ : (a) Históricos de força; (b) Históricos de deslocamento

FIGURA 5.3.1-9 - Históricos de energia para lâminas orientadas a [+45/-45/+45/0/90 $]_{\mathrm{s}}$ : (a) Energia de impacto igual a $5,91 \mathrm{~J}$; (b) Energia de impacto igual a 2,36 J;

(c) Energia de impacto igual a 10,82 J; (d) Energia de impacto igual a 4,33 J

FIGURA 5.3.1-10 - Mapas de falha obtidos através da técnica de ultrasom $C$-Scan para lâminas orientadas a $[+45 /-$ $45 /+45 / 0 / 90]_{\mathrm{s}}$

FIGURA 5.3.1-11 - Energia absorvida em função da energia de impacto

FIGURA 5.3.1-12 - Gráficos de força-deslocamento para lâminas orientadas a $[0]_{10}$ : (a) Valor da força de $2.250 \mathrm{~N}$;

(b) Valor da força de $1.300 \mathrm{~N}$ 
FIGURA 5.3.1-13 - Gráficos de força-deslocamento para lâminas orientadas a [0/90/0/90/0 $]_{\mathrm{s}}$ : (a) Valor da força de $3.000 \mathrm{~N}$; (b) Valor da força de $1.750 \mathrm{~N}$

FIGURA 5.3.1-14 - Gráficos de força-deslocamento para lâminas orientadas a $[+45 /-45 /+45 / 0 / 90]_{\mathrm{s}}$ :(a) Valor da força de $3.300 \mathrm{~N}$; (b) Valor da força de $1.900 \mathrm{~N}$

FIGURA 5.3.2-1 - Problema de contato entre dois corpos (BATHE, 1996)

FIGURA 5.3.2-2- Modelos do teste de endentação: (a) Modelo em Casca (Elemento S8R); (b) Modelo Sólido (Elemento C3D8R)

FIGURA 5.3.2-3 - Modelo do teste de impacto: programa DYNA ${ }^{\circledR}$

FIGURA 5.3.3-1 - Avaliação dos modelos de contato para o teste de endentação com lâminas orientadas a $[0]_{10}$

FIGURA 5.3.3-2 - Avaliação dos modelos de material para o teste de endentação com lâminas orientadas a $[0]_{10}$ : Modelo II (sub-rotina UMAT)

FIGURA 5.3.3-3 - Concentração de tensões próxima ao endentador para

o teste com lâminas orientadas a $[0]_{10}$

FIGURA 5.3.3-4 - Avaliação dos modelos de material para o teste de endentação com lâminas orientadas a $[0]_{10}$ : Critério de Hill x Modelo II (sub-rotina UMAT)

FIGURA 5.3.3-5 - Avaliação dos modelos de material para o teste de endentação com lâminas orientadas a [0/90/0/90/0 $]_{\mathrm{s}}$ : Modelo II (sub-rotina UMAT)

FIGURA 5.3.3-6 - Avaliação dos modelos de material para o teste de endentação com lâminas orientadas a [0/90/0/90/0 $]_{\mathrm{s}}$ : Critério de Hill x Modelo II (sub-rotina UMAT)

FIGURA 5.3.3-7 - Avaliação dos modelos de material para o teste de endentação com lâminas orientadas a [0/90/0/90/0 $]_{s}$ : Modelo II x Modelo III 
FIGURA 5.3.3-8 - Avaliação dos modelos de material para o teste de endentação com lâminas orientadas a [+45/45/+45/0/90]s: Critério de Hill x Modelo II

FIGURA 5.3.3-9 - Avaliação dos modelos de material para o teste de endentação com lâminas orientadas a [+45/45/+45/0/90]s: Modelo II x Modelo III

FIGURA 5.3.3-10 - Avaliação dos modelos de material para o teste de impacto com lâminas orientadas a $[0]_{10}$ : DYNA ${ }^{\circledR}$

(a) Energia de impacto igual a 2,36 J; (b) Energia de impacto igual a $5,91 \mathrm{~J}$.

FIGURA 5.3.3-11 - Avaliação dos modelos de material para o teste de impacto com lâminas orientadas a $[0]_{10}$ : $\mathrm{DYNA}^{\circledR} \mathrm{x}$ $\operatorname{ABAQUS}^{\circledR}$ (a) Energia de impacto igual a 2,36 J;

(b) Energia de impacto igual a 5,91 J

FIGURA 5.3.3-12- Avaliação dos modelos de material para o teste de impacto com lâminas orientadas a [0/90/0/90/0 $]_{\mathrm{s}}$ : $\operatorname{ABAQUS}^{\circledR}$ (a) Energia de impacto igual a 2,36 J;

(b) Energia de impacto igual a 5,91 J.

FIGURA 5.3.3-13- Avaliação dos modelos de material para o teste de impacto com lâminas orientadas a $[+45 / 45 /+45 / 0 / 90]_{\mathrm{s}}:$ ABAQUS $^{\circledR}$ (a) Energia de impacto igual a 2,36 J; (b) Energia de impacto igual a $5,91 \mathrm{~J}$

FIGURA 5.3.3-14- Avaliação dos modelos de material para o teste de impacto com lâminas orientadas a [+45/45/+45/0/90 $]_{\mathrm{s}}$ : Modelo II (VUMAT)

(Energia de impacto igual a 5,91 J)

FIGURA 6.2-1 - Tipos de resposta de impacto em função do tempo de contato: (a) curtíssimo tempo; (b) curto tempo; (c) longo tempo (OLSSON, 2000) 


\section{LISTA DE TABELAS}

TABELA 3.2-1 - Propriedades, valores de resistência e de deformação da resina epóxi do M10 para o ciclo de cura ideal $\left(\mathrm{Hexcel}^{\circledR}\right)$

TABELA 3.2-2 - Alternativas de ciclo de cura para o M10 (Hexcel ${ }^{\circledR}$ )

TABELA 3.2-3 - Corpos-de-prova obtidos utilizando o "prepreg" M10 $\left(\right.$ Hexcel $\left.^{\circledR}\right)(\mathrm{L}=$ comprimento; $\mathrm{W}=$ largura; $\mathrm{H}=$ espessura $)$

TABELA 3.3-1 - Valores de fração volumétrica de fibra para alguns corposde-prova (“prepreg” M10 - Hexcel ${ }^{\circledR}$ )

TABELA 3.3-2 - Propriedades elásticas e valores de resistência mecânica para compósitos em resina epóxi reforçados com fibra de carbono unidirecional.

TABELA 3.3.3-1 - Especificações para os testes de flexão três-pontos

$$
\text { ( } \mathrm{L}=\text { comprimento; } \mathrm{W}=\text { largura; } \mathrm{H}=\text { espessura) }
$$

TABELA 3.3.4-1 - Comparação dos resultados experimentais do prepreg M10 com valores da literatura

TABELA 4.2.2-1 - Ajuste das propriedades do ponto material devido à danificação da matriz

TABELA 4.2.2-2 - Ajuste das propriedades do ponto material devido à danificação da fibra

TABELA 5.2-1 - Especificações para os testes de flexão três-pontos

$$
\text { ( } \mathrm{L}=\text { comprimento; } \mathrm{W}=\text { largura; } \mathrm{H}=\text { espessura) }
$$

TABELA 5.2.2-1 - Propriedades elásticas e valores de resistência empregados nas simulações computacionais

TABELA 5.2.2-2 - Tipos modelos avaliados e calibrados

TABELA 5.3-1 - Especificações para os testes de endentação

$$
\text { ( } \mathrm{L}=\text { comprimento; } \mathrm{W}=\text { largura; } \mathrm{H}=\text { =espessura) }
$$

TABELA 5.3-2 - Especificações para os testes de impacto

$$
\text { ( } \mathrm{L}=\text { comprimento; } \mathrm{W}=\text { largura; } \mathrm{H}=\text { =spessura) }
$$

TABELA 5.3.1-1 - Valores de força para os testes de endentação ( $\mathrm{L}=$ comprimento; $\mathrm{W}=$ largura; $\mathrm{H}=$ espessura) 


\section{SUMÁRIO}

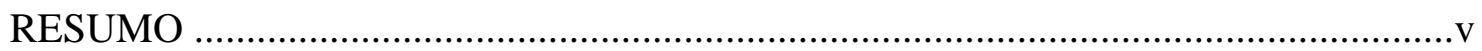

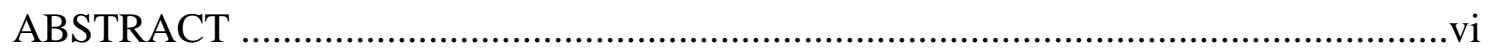

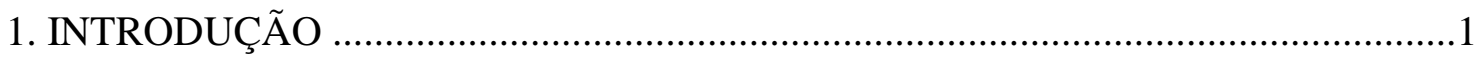

1.1 Materiais Compósitos .....................................................................................

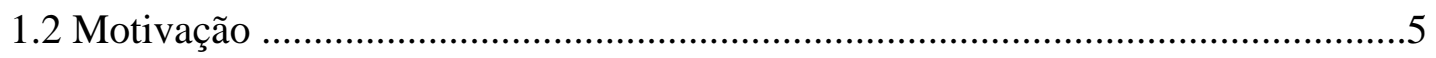

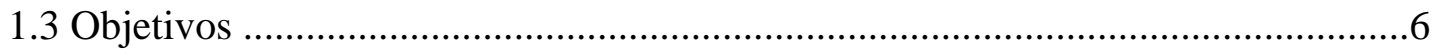

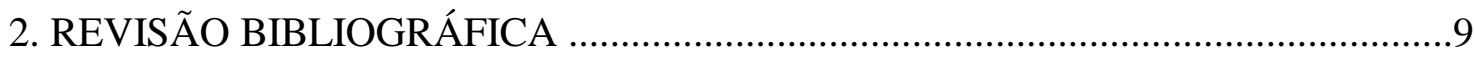

2.1 Comportamento Mecânico dos Compósitos Poliméricos Reforçados Laminados 9

2.1.1 Fenômenos Intralaminares .......................................................................10

2.1.2 Fenômenos Interlaminares .................................................................13

2.2 Análise Estrutural de Compósitos Poliméricos Reforçados Laminados ...............16

2.2.1 Abordagem Analítica .................................................................................33

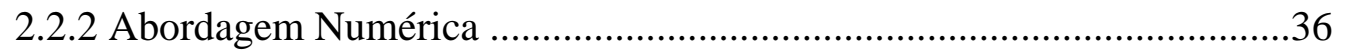

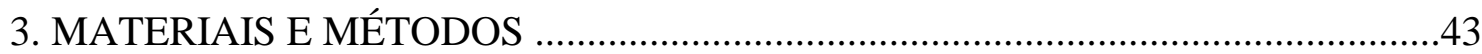

3.1 Materiais Compósitos Poliméricos ...............................................................43

3.2 Fabricação das Amostras ..............................................................................44

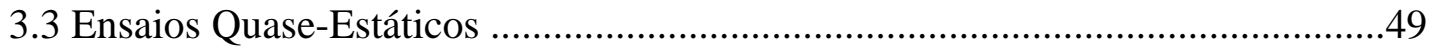

3.3.1 Ensaios de Tração e Compressão .............................................................53

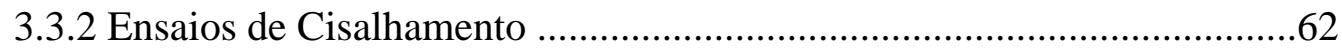

3.3.3 Ensaios de Flexão 3-Pontos ...............................................................66

3.3.4 Síntese dos Resultados dos Ensaios Quase-Estáticos .............................74 
4.1 Análise Progressiva de Danificação e Falha ........................................................76

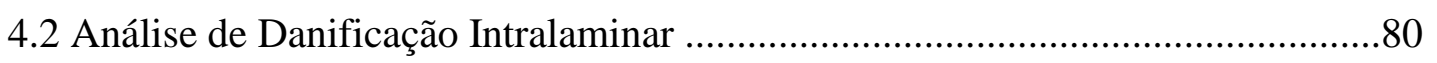

4.2.1 Critérios de Danificação Intralaminar ....................................................80

4.2.2 Leis de Evolução de Dano Intralaminar ..................................................83

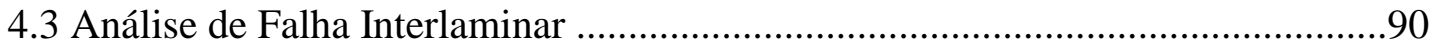

4.3.1 Critério de Falha Interlaminar ..............................................................90

4.3.2 Lei de Evolução de Falha Interlaminar ..................................................91

4.4 Implementação do Modelo Proposto .................................................................93

4.5 Análise de Testes de Tração e Compressão ..........................................................96

5. APLICAÇÃO DO MODELO DE MATERIAL ….................................................. 102

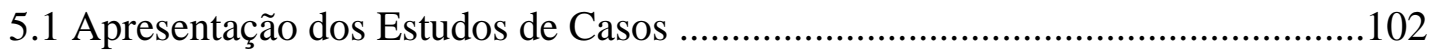

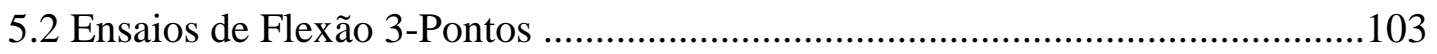

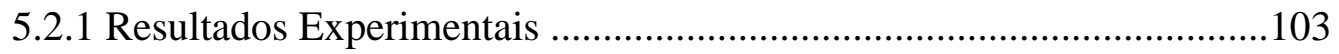

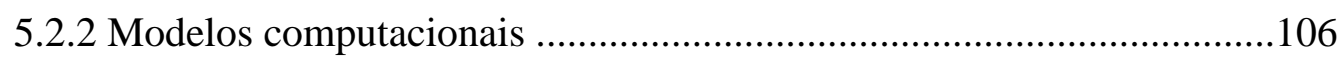

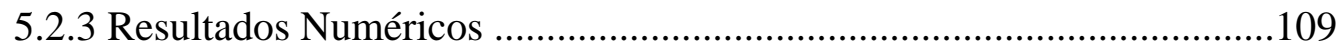

5.3 Testes de Endentação e Impacto ....................................................................127

5.3.1 Resultados Experimentais ..............................................................131

5.3.2 Modelos computacionais ................................................................. 146

5.3.3 Resultados Numéricos ...........................................................................155

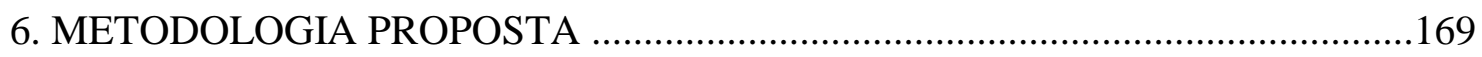

6.1 Metodologias Empregadas para Avaliar Impacto em Compósitos Poliméricos 169

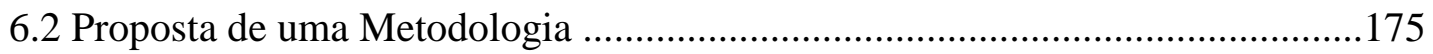

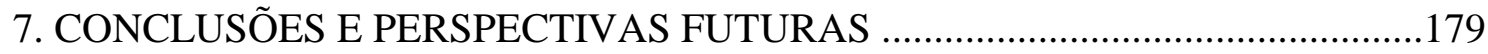

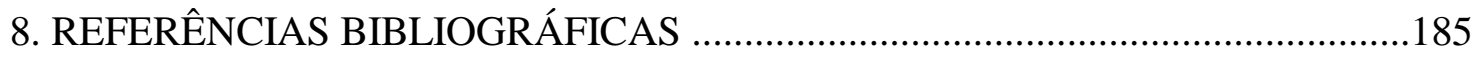

APÊNDICE A - SUBROTINAS UMAT E USDFLD ..........................................A1 


\section{Capítulo 1}

\section{INTRODUÇÃO}

\subsection{MATERIAIS COMPÓSITOS}

Muitos componentes mecânicos utilizados atualmente requerem materiais com combinações de propriedades não usualmente satisfeitas pelas ligas de metais convencionais, cerâmicas e materiais poliméricos. Várias estruturas do setor aeronáutico, automobilístico e aeroespacial necessitam possuir baixo peso, alta resistência, alta rigidez e resistência à abrasão e ao impacto. $\mathrm{O}$ acelerado desenvolvimento de materiais compósitos reforçados, ocorrido acentuadamente nos últimos anos, tem propiciado aos projetistas novas alternativas para solucionar tais problemas, fornecendo-lhes um novo leque de possibilidades.

\section{Definiç̃ão e Classificação}

Um compósito pode ser considerado um material multifase que exibe uma combinação de propriedades, possibilitando assim, um desempenho melhor desse material frente a cada fase da sua composição, caso essas fossem empregadas individualmente (CALLISTER, 1985).

De acordo com esse princípio de ação combinada, procura-se moldar os melhores arranjos de propriedades por uma combinação criteriosa de dois ou mais materiais distintos. Esses materiais que formam o compósito podem ser classificados como aglomerante (fase contínua ou matriz) ou reforço (fase dispersa). O aglomerante tem como função manter os reforços unidos, transmitindo a estes o carregamento aplicado. Os reforços têm como função suportar os carregamentos transmitidos pelo aglomerante. 
Devido à grande variedade de compósitos, Callister (1985) os classifica como: compósitos reforçados por partículas, compósitos reforçados por fibras e compósitos estruturais (FIGURA 1.1-1). Neste trabalho serão abordados especificamente os compósitos estruturais laminados, que possuem uma resina como matriz e fibras longas como reforços. Dessa forma, o texto irá geralmente referenciar os compósitos poliméricos reforçados laminados com a sigla CPR.

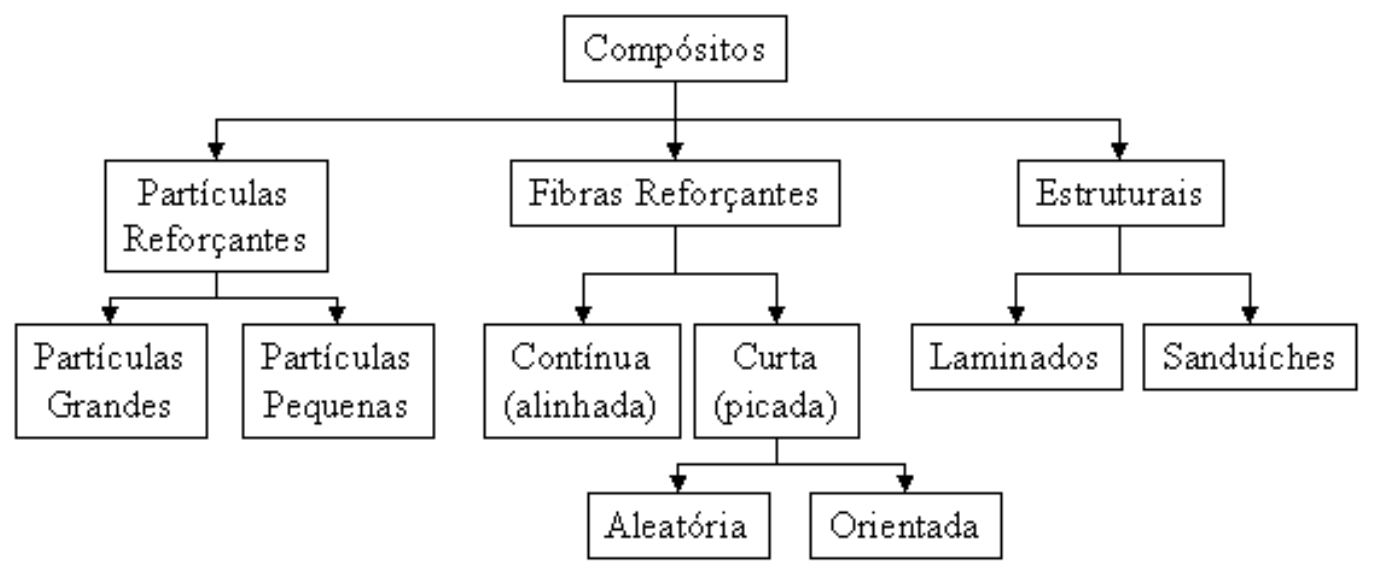

FIGURA 1.1-1 - Esquema de classificação para materiais compósitos

(CALLISTER, 1985)

Segundo Vinson e Sierakowski (1987), os materiais compósitos estruturais laminados podem ser abordados de duas formas: abordagem micromecânica e abordagem macromecânica.

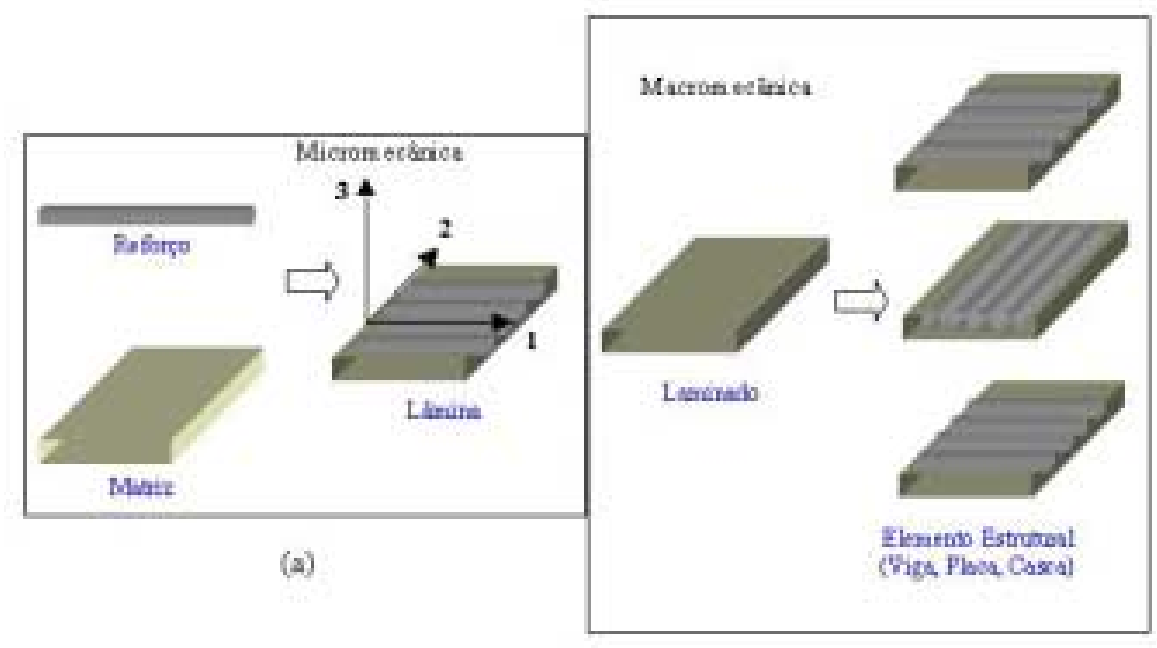

(b)

FIGURA 1.1-2 - Compósitos estruturais laminados 
A abordagem micromecânica busca analisar a lâmina constituída por: reforço, matriz e interface fibra-matriz. Apesar da lâmina ser anisótropa (ortotrópica) e heterogênea, vários autores consideram seus constituintes (fibra e resina polimérica) como sendo isótropos e homogêneos a fim de facilitar o procedimento de análise. No entanto, vale ressaltar que há casos onde os pesquisadores optam por tratar os constituintes como materiais anisótropos e heterogêneos, requisitando assim uma análise estatística das propriedades. Por outro lado, a abordagem macromecânica busca analisar o comportamento da estrutura, ou seja, o comportamento mecânico do laminado que é constituído por uma sequiência de lâminas empilhadas.

\section{Aplicação em Projetos Mecânicos}

Há muitos anos o homem combina propriedades de materiais diferentes para atingir seus objetivos, como exemplo tem-se os Sumerianos que em 4000 A.C. (Antes de Cristo) adicionavam palha ao barro para aumentar a resistência de seus tijolos. Embora esses benefícios sejam conhecidos há milhares de anos, apenas há alguns anos é que se desenvolveu a tecnologia desses materiais para a fabricação de componentes mecânicos (TSAI, 1986). O avião F.111 foi um dos primeiros modelos a incorporar esta tecnologia. As características que combinam alta resistência estrutural e baixa densidade (redução de peso) chamaram também a atenção da indústria automobilística, uma vez que essas características possibilitam o desenvolvimento de veículos mais leves com menor consumo de combustível sem comprometer a eficiência estrutural. A Ford Motor Company em 1979 desenvolveu um protótipo de carro com alguns componentes feitos em material compósito (carbono e epóxi). O protótipo simplesmente pesava $570 \mathrm{~kg}$ a menos que a versão em aço e só o eixo de transmissão sofreu uma redução de $57 \%$ do seu valor original (DHARAM, 1979). Atualmente a Chrysler vem desenvolvendo um projeto baseado na aplicação de compósitos em seus veículos; tal projeto é conhecido como CCV (Composite Concept Vehicle). Em 1997, a companhia americana apresentou um protótipo a base de compósitos na feira internacional de veículos em Frankfurt (BUCHHOLZ, 1997).

Essa busca pela aplicação de materiais compósitos em projetos mecânicos é parcialmente explicada por Hollmann (1986). Para ele, a eficiência estrutural de componentes mecânicos está associada diretamente ao material, ou seja, sua relação resistência ou rigidez contra peso deverá ser alta para os mais eficientes e baixa para os menos eficientes. Segundo a literatura, compósitos com $70 \%$ de epóxi e $30 \%$ em fibra 
de carbono ou $60 \%$ em fibra de vidro e $40 \%$ em epóxi possuem uma rigidez muito próxima da rigidez do alumínio, que é um material mais pesado do que ambos os compósitos citados (ENGINEERED MATERIALS HANDBOOK, 1987). Um comentário análogo pode ser feito em relação a alguns compósitos com $60 \%$ de fibra de carbono e $40 \%$ de epóxi quando comparado aos aços (ENGINEERED MATERIALS HANDBOOK, 1987). Além da alta resistência específica, os compósitos são requisitados pelo bom desempenho frente a carregamentos dinâmicos. Em alguns projetos, o maior objetivo é evitar danos estruturais causados por vibrações indesejáveis. Para tal, é possível empilhar as lâminas segundo uma seqüência adequada a fim de obter um laminado com freqüências naturais diferentes da freqüência de excitação, como demonstrado por Tita; Carvalho e Lirani (2001).

Nas últimas duas décadas, os materiais compósitos estão sendo utilizados para garantir não apenas a eficiência estrutural, mas também a segurança de passageiros, nas indústrias automobilística, aeronáutica, naval, de trens e até mesmo de elevadores. Dessa forma busca-se um projeto estrutural de componentes que absorvam a máxima quantidade de energia proveniente de um impacto sob um certo controle do colapso, sem ocasionar riscos para a vida humana ou então gerar altas desacelerações na estrutura. Neste caso, o uso de materiais compósitos poliméricos reforçados é aconselhável, pois estes são capazes de dissipar grande quantidade de energia, sem comprometer a resistência da estrutura. Reindl (1987) relatou que Henry Ford já estudava a resistência frente ao impacto e a durabilidade de componentes automotivos. Com o passar dos anos, as normas para projeto e fabricação de automóveis e aeronaves foram ficando cada vez mais rigorosas e começaram a exigir como requisito essencial de alguns componentes a capacidade de absorção de energia frente a carregamentos de impacto ("structural crashworthiness"). Componentes mecânicos da parte dianteira, traseira e lateral de veículos terrestres ou então componentes de aeronaves ("subfloor" de helicópteros e aviões) são alguns exemplos que se enquadram neste tipo de exigência (KINDERVATER; GEORGI, 1993) (MAMALIS, 1997). Vale ressaltar que o conceito de projeto desses componentes mecânicos está associado ao conceito de resistência ao impacto ("crash resistence”) descrito por Kindervater e Georgi (1993). Segundo esses pesquisadores, a resistência ao impacto inclui a capacidade de absorção de energia por parte do componente e a integridade estrutural do mesmo. Para desenvolver um projeto que atenda tais requisitos, altera-se o material ou sua geometria. Um exemplo com relação à mudança de geometria é o cone frontal de um carro de F-1 (“nose cone”) que 
devido à sua forma, apresenta um colapso progressivo durante um processo de impacto. No entanto, alterações bruscas na geometria de um componente podem causar um aumento de custo do componente, optando-se assim por uma mudança no material empregado.

\subsection{MOTIVAÇÃO}

De acordo com o que foi apresentado no item 1.1, tem-se que os materiais compósitos poliméricos reforçados laminados (CPR) possuem uma excelente combinação de rigidez, resistência e baixo peso que são características muito atrativas para o desenvolvimento de componentes mecânicos. Além dessas características devese ressaltar a sua inerente anisotropia que permite ao projetista desenvolver as propriedades do material juntamente com as características geométricas e funcionais da peça, de maneira a se obter o desempenho desejado. Por exemplo, os componentes fabricados em CPR podem ser reforçados com fibras nas direções mais solicitadas em função dos carregamentos atuantes. No entanto, a anisotropia presente nos materiais compósitos pode ser vista como um fator positivo ou negativo. Pois, se por um lado, ela concede ao engenheiro a possibilidade de não apenas selecionar o material, mas também projetá-lo em conjunto com o componente visando uma alta eficiência estrutural, por outro lado, a anisotropia associada à heterogeneidade faz com que haja uma grande dificuldade em se prever com precisão o modo de falha da estrutura. Essa dificuldade de prever o modo de falha exato do material reflete diretamente na confiabilidade dos componentes fabricados, e torna-se ainda mais sério para componentes de alta responsabilidade, onde a combinação de fadiga, de danos por impacto e de efeitos do meio ambiente pode causar falha catastrófica. Isto obriga os engenheiros a utilizarem nos cálculos, elevados coeficientes de segurança que evidenciam a sub-utilização das potencialidades desses materiais, acarretando assim um custo mais elevado para o produto final.

É diante desse contexto que várias contribuições científicas estão sendo apresentadas nas últimas décadas com o intuito de minimizar o problema da subutilização dos CPR, visando o desenvolvimento de componentes mecânicos que possuam uma combinação de bom desempenho com viabilidade de fabricação e custos aceitáveis para um mercado competitivo. Esse panorama motivou a realização do presente trabalho que busca contribuir para o projeto de componentes mecânicos sob 
solicitações quase-estáticas bem como para o projeto de componentes que devam absorver energia ao serem solicitados por carregamentos de impacto. Para que tais contribuições possam ser concretizadas, deve-se realizar os objetivos propostos a seguir.

\subsection{OBJETIVOS}

O objetivo geral deste trabalho consiste em propor e implementar computacionalmente um modelo de material para compósitos poliméricos capaz de representar de forma coerente os mecanismos de danificação/falha de uma estrutura laminada que venha sofrer uma dada solicitação.

Devido à amplitude do objetivo proposto, optou-se por dividi-lo em objetivos específicos, tais como:

1. Apresentar um levantamento bibliográfico sobre o comportamento mecânico de materiais compósitos poliméricos bem como sobre formas de abordagem analítica e numérica para prever tal comportamento;

2. Fabricar amostras em compósito polimérico (resina epóxi reforçada por fibra de carbono unidirecional) baseando-se em normas técnicas adequadas;

3. Realizar ensaios experimentais quase-estáticos normalizados, como: testes de tração, de compressão, de cisalhamento e de flexão, visando obter as propriedades e os valores de resistência mecânica bem como um melhor entendimento do comportamento mecânico das amostras fabricadas;

4. Propor um modelo de material para compósitos poliméricos que seja capaz de representar de forma coerente os fenômenos físicos intralaminares e interlaminares decorrentes da ação de carregamentos quase-estáticos;

5. Implementar computacionalmente o modelo de material proposto;

6. Aplicar o modelo proposto para simular o comportamento mecânico de estruturas, utilizando assim três estudos de caso distintos: teste de flexão, teste de endentação e teste de impacto ;

7. Apresentar a proposta de uma metodologia que seja capaz de avaliar problemas de impacto de componentes mecânicos em CPR quando solicitados por um carregamento de impacto sob baixa velocidade;

Tomando como referência os objetivos descritos acima, tem-se que o presente trabalho está organizado de tal forma que haja primeiramente um entendimento global 
dos fenômenos físicos ocorridos quando um CPR é solicitado por um dado tipo de carregamento. Em seguida, são relatadas algumas abordagens contidas na literatura que visam prever o comportamento mecânico dessas estruturas laminadas. Posteriormente, fez-se assim, alguns ensaios mecânicos (tração, compressão, flexão e cisalhamento) a fim de obter parâmetros de material e de entender melhor o comportamento mecânico do CPR utilizado no presente trabalho. Com base nos resultados experimentais obtidos e com informações provenientes da literatura, apresenta-se um modelo de material que seja capaz de prever danos intralaminares e falhas interlaminares. A fim de avaliar as potencialidades e limitações do modelo de material proposto, aplica-se o mesmo em alguns estudos de caso (testes de flexão, endentação e impacto) para diferentes seqüências de empilhamento. Por fim, propõe-se uma metodologia que seja capaz de quantificar a capacidade de absorção de energia de impacto de componentes mecânicos em CPR. Sendo assim, os capítulos do presente trabalho estão divididos da seguinte forma:

\section{- Capítulo 2 - Revisão Bibliográfica}

Está dividido em dois itens. O primeiro item mostra um estudo detalhado dos fenômenos envolvidos no problema de impacto em CPR. Dessa forma, são demonstrados os fenômenos de danos intralaminares e de falhas interlaminares. $\mathrm{O}$ segundo item relata abordagens analíticas e numéricas empregadas para a análise desses problemas.

\section{- Capítulo 3 - Materiais e Métodos}

Está dividido em três partes. A primeira parte descreve o material compósito polimérico laminado utilizado no presente trabalho. A segunda apresenta todo processo de fabricação das amostras. Por fim, na terceira parte, descreve-se todas as condições em que foram realizados os ensaios quase-estáticos (tração, compressão, cisalhamento e flexão) bem como todos os resultados experimentais obtidos em cada tipo de teste.

\section{- Capítulo 4 - Modelo de Material Proposto}

Está dividido em quatro partes. A primeira parte aborda de uma maneira geral como são resolvidos os problemas de dano/falha progressiva empregando o Método dos Elementos Finitos. A segunda parte apresenta os modelos de material utilizados para prever danos intralaminares. Por outro lado, a terceira parte descreve os modelos de 
material utilizados para detectar falhas interlaminares. Por fim, o presente capítulo traz na sua última parte, a calibração dos parâmetros do modelo de material proposto tomando como referência os ensaios de tração e compressão.

\section{- Capítulo 5 - Aplicação do Modelo de Material}

Está dividido em três partes. A primeira parte apresenta os três estudos de casos (flexão, endentação e impacto) que serão empregados para avaliar e calibrar o modelo de material proposto. A segunda parte descreve em detalhes sobre a modelagem computacional dos testes de flexão bem como todo processo de calibração dos parâmetros associados aos modelos de material. A terceira parte relata inicialmente sobre os ensaios de impacto e endentação, mostrando os resultados experimentais e os mapas de falha obtidos através da técnica de ultra-som C-Scan. Posteriormente são demonstrados os resultados computacionais, discutindo-se assim os problemas numéricos bem como as potencialidades e limitações do modelo de material empregado.

\section{- Capítulo 6 - Metodologia Proposta}

Está dividido em 2 partes. A primeira contém uma revisão bibliográfica de trabalhos que contribuíram para o estudo de impacto em estruturas de CPR, focalizando principalmente metodologias que foram desenvolvidas para tratar tal tipo de problema. Com base nesta revisão e nos resultados obtidos ao longo do desenvolvimento do presente trabalho propõe-se uma nova metodologia a fim de que possa quantificar a quantidade de energia que será absorvida por um componente mecânico em CPR ao sofrer um carregamento de impacto.

\section{- Capítulo 7 - Conclusões e Perspectivas Futuras}

Este capítulo contém algumas conclusões tomando como referência todos os ensaios experimentais realizados bem como todas as simulações computacionais empregadas. Além disso, é possível encontrar algumas perspectivas concretas para trabalhos futuros.

\section{- Capítulo 8 - Referências Bibliográficas}

Contém as fontes das referências bibliográficas utilizadas ao longo do desenvolvimento do projeto de pesquisa. 


\section{Capítulo 2}

\section{REVISÃO BIBLIOGRÁFICA}

\subsection{COMPORTAMENTO MECÂNICO DOS COMPÓSITOS POLIMÉRICOS REFORÇADOS LAMINADOS}

A resposta de um material compósito polimérico reforçado laminado frente a um dado tipo de carregamento deverá expressar o comportamento mecânico do mesmo. Essa resposta em algumas situações pode ser linear com ruptura frágil ou altamente nãolinear apresentando perda gradativa de rigidez e perda de resistência mecânica. A esses diferentes tipos de respostas estão associados fenômenos físicos localizados em três diferentes níveis: 1) nível micro-mecânico; 2) nível meso-mecânico; 3) nível macromecânico. Para um CPR, tem-se que no primeiro nível de abordagem, avaliam-se os fenômenos que podem ocorrer no nível micro-estrutural dos materiais constituintes (fibra e matriz). No segundo, avaliam-se os fenômenos que podem ocorrer no interior das lâminas bem como entre lâminas adjacentes. Por fim, no terceiro nível de abordagem, avaliam-se os fenômenos que ocorrem na estrutura como um todo. Vale ressaltar que todo o estudo a ser realizado na presente tese irá concentrar-se no chamado nível meso-mecânico.

Com base na literatura (AGARWAL; BROUTMAN, 1990), sabe-se que componentes mecânicos fabricados em CPR apresentam basicamente dois tipos de fenômenos em nível meso-mecânico:

$\checkmark$ Danos Intralaminares: ocorrem dentro das lâminas;

$\checkmark$ Falhas Interlaminares: ocorrem entre as lâminas. 
Os mecanismos de dano intralaminares correspondem basicamente a danos da matriz, da fibra ou da interface fibra-matriz que são claramente visíveis. Por outro lado, as falhas interlaminares correspondem especificamente ao fenômeno conhecido por delaminação que se caracteriza pela separação de duas lâminas adjacentes e ocorre repentinamente quando o estado de tensão atuante entre essas lâminas supera a resistência interlaminar.

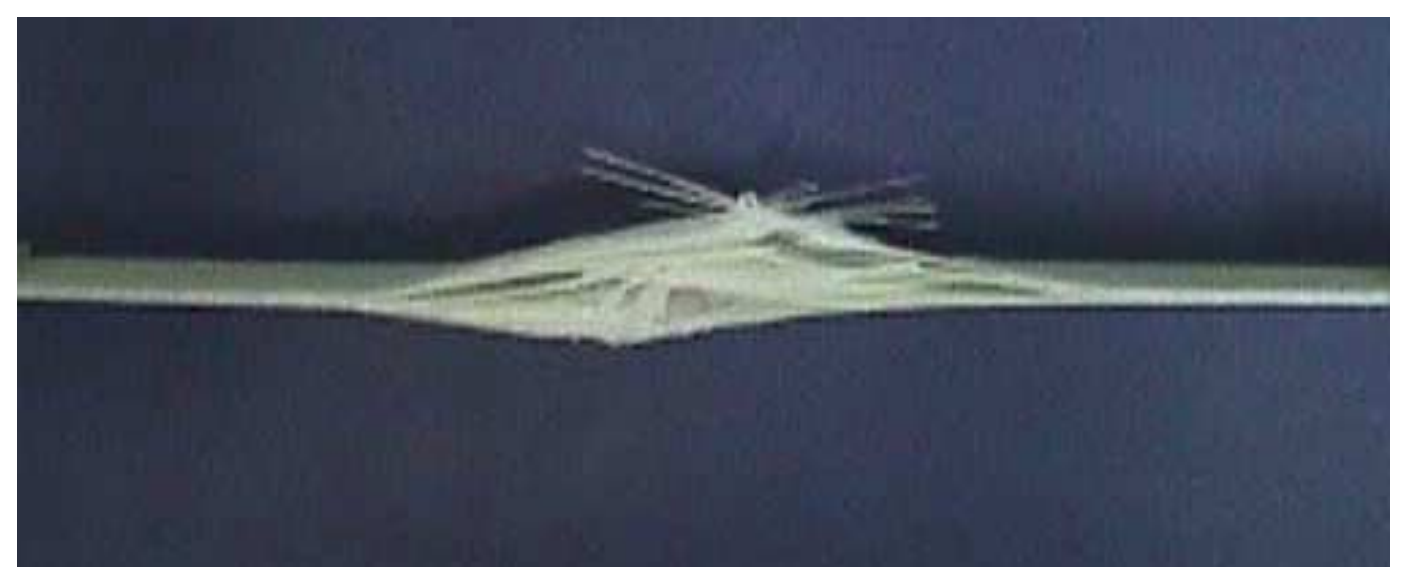

FIGURA 2.1-1 - Mecanismos de danificação/falha para um CPR:

Fenômenos intra e interlaminares

\subsubsection{Fenômenos Intralaminares}

Quanto ao modo de ruptura da fibra, tem-se que o mesmo depende de uma série de fatores, tais como: diâmetro e comprimento da fibra, fração volumétrica, orientação das fibras na lâmina entre outros. Entretanto, os seus modos de ruptura estão associados também aos carregamentos aplicados. Carregamentos de compressão podem induzir a falha da fibra através de microflambagem ou então cisalhamento das mesmas (FIGURA 2.1.1-1). Por outro lado, carregamentos de tração podem provocar ruptura das fibras, dependendo assim, sensivelmente do grau de adesão entre as fibras e a matriz polimérica.

Quanto ao modo de ruptura da matriz, tem-se que a resposta da resina polimérica pode ser frágil ou dúctil, linear elástica ou até mesmo visco-elastoplástica (McCRUM; BUCKLEY; BUCKNALL, 1992). Tudo isso depende principalmente da sua composição química e da temperatura do meio. No entanto, a literatura tem demonstrado que de uma maneira geral, independente do tipo de carregamento aplicado, a ruptura da matriz ocorre na vizinhança de uma fibra rompida ou na vizinhança de um vazio criado por uma bolha de ar durante a moldagem. Essas regiões são concentradoras 
de tensão e tendem redistribuir os carregamentos para o volume de resina mais próximo, levando muitas vezes ao fraturamento precoce da matriz.

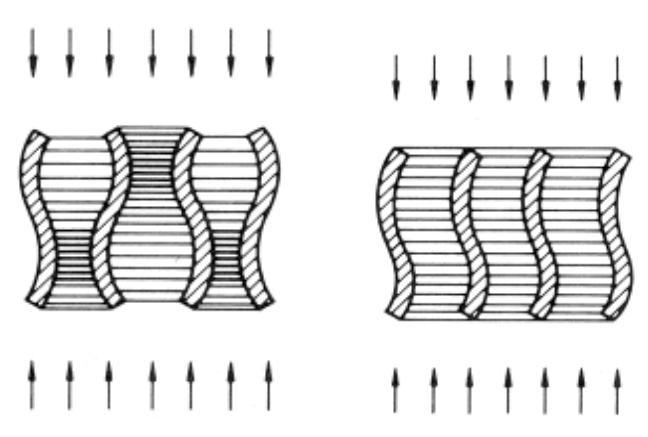

(a)

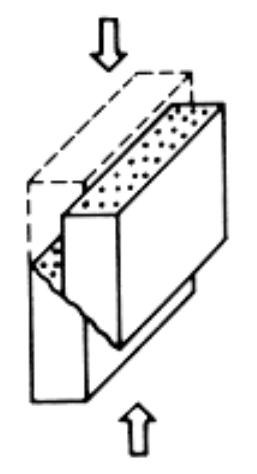

(b)

FIGURA 2.1.1-1 - Mecanismos da fibra sob compressão:

(a) Microflambagem; (b) Cisalhamento

(AGARWAL; BROUTMAN, 1990)

Quanto aos modos de falha da interface, tem-se que os mesmos dependem da interação físico-química entre a fibra e a matriz. Vale ressaltar que este aspecto da interface foi explorado no trabalho apresentado por Dotan (1997). Segundo Hull (1981), a interface é um parâmetro dominante para a avaliação da tenacidade à fratura em materiais compósitos, pois elas definem qual será o modo de danificação/falha. Assim, os compósitos que possuem uma fraca interação fibra-matriz sofrerão a quebra da interface, proporcionando o descolamento entre a fibra e matriz ("debonding") como mostra a FIGURA 2.1.1-2 (mecanismo (3)). No entanto, para os compósitos com uma forte interação, haverá provavelmente o rompimento da fibra que produzirá assim o mecanismo de "Pull-Out" como evidencia a FIGURA 2.1.1-2 (mecanismo (1)). Tal mecanismo caracteriza-se pelo arrancamento da fibra de dentro da matriz que geralmente ocorre após a propagação de uma fissura. Antes da ocorrência do "Pull-Out" pode haver a formação do mecanismo de "Fiber Bridging" (mecanismo (2)), desde que o compósito possua fibras frágeis de alta resistência, matrizes dúcteis e interface forte. Sendo assim, a fissura se propaga pela matriz e a fibra forma uma ponte interligando as duas superfícies da matriz fraturada. Por outro lado, a fronteira da fissura dá origem a regiões com concentração de tensão até mesmo fora do plano de propagação. A região localizada à frente da fissura, que está se propagando, concentra altas tensões, podendo 
também levar à "Fratura da Fibra" (4) devido a sua alta fragilidade, ou à "Danificação da Matriz" (5).

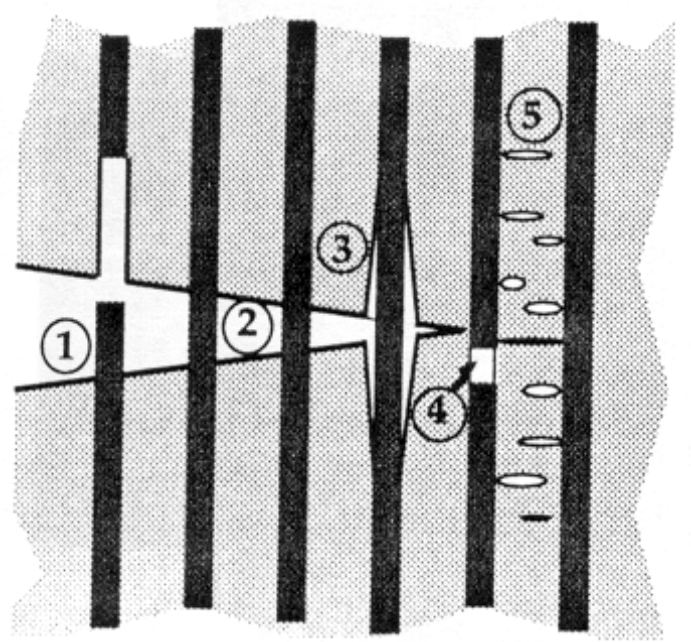

FIGURA 2.1.1-2 - Mecanismos de danificação em CPR: fenômenos intralaminares (ANDERSON, 1995)

Além dos modos de ruptura da fibra e da matriz bem como dos modos de falha da interface fibra-matriz, Hahn e Tsai (1973) verificaram a formação de deformações permanentes intralaminares devido à ação das tensões de cisalhamento atuantes no plano da lâmina. Os pesquisadores observaram uma resposta praticamente linear para as lâminas com o ângulo de orientação das fibras próximo de $0^{\circ}$ ou de $90^{\circ} \mathrm{em}$ relação ao carregamento aplicado, devido à predominância das tensões normais. Entretanto, quando o ângulo de orientação das fibras em relação ao carregamento se aproximava de $15^{\circ}$ havia uma resposta não-linear com predominância das tensões de cisalhamento. Tal fenômeno foi posteriormente confirmado através de experimentos realizados por Sandhu (1976). 


\subsubsection{Fenômenos Interlaminares}

Estudos demonstram que o mecanismo de falha dos compósitos se assemelha ao dos metais no que diz respeito à evolução do processo. Ou seja, assim como nos metais, a falha nos materiais compósitos inicia-se por pequenos mecanismos (danos intralaminares) para depois então ocorrer os mecanismos mais visíveis (falha interlaminar) (ANDERSON, 1995).

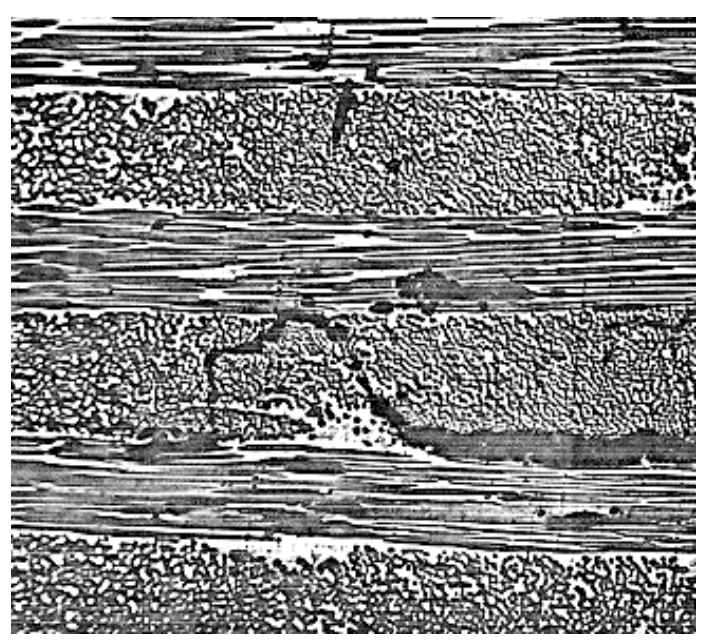

(a)

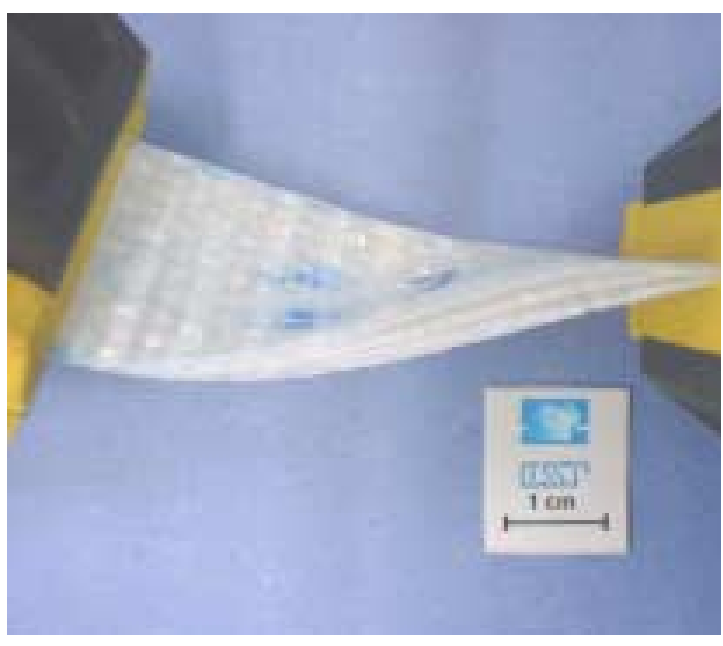

(b)

FIGURA 2.1.2-1 - Mecanismos de danificação/falha em CPR:

(a) processo de evolução da falha (AGARWAL; BROUTMAN, 1990);

(b) amostra de CPR delaminada

Normalmente o processo de danificação inicia-se em lâminas que tenham orientação de fibra próxima a $90^{\circ}$ em relação aos carregamentos. Após o aparecimento do primeiro dano, o carregamento na estrutura tende a ser re-distribuído vindo a provocar o aparecimento de mais regiões danificadas na mesma lâmina ou em outras lâminas. Esse processo ocorre sucessivamente até que essas regiões danificadas se unem, formando assim uma fissura discreta. As fronteiras das fissuras que se formaram numa determinada lâmina encontram lâminas adjacentes com ângulos de orientação diferente (FIGURA 2.1.2-1(a)). Neste momento, as tensões de cisalhamento interlaminares crescem abruptamente e levam o laminado a iniciar o processo de delaminação (FIGURA 2.1.2-1(b)).

É interessante ressaltar que o número de delaminações aumenta em quantidade e se propaga pela estrutura com o incremento dos carregamentos. Isto pode ser verificado através de um teste de flexão sob 3-pontos. Neste caso, as delaminações ocorrem com 
facilidade entre lâminas com grandes diferenças entre orientações de fibras, por exemplo, entre lâminas orientadas a $0^{\circ}$ e a $90^{\circ}$. Isto é explicado porque as lâminas possuem diferentes rigidezes de flexão, apresentando assim diferentes respostas, o que proporciona um estado de tensões interlaminares muito favorável para a separação. Tal tipo de fenômeno também ocorre em estruturas que são impactadas. Segundo Abrate (1998), o processo de danificação/falha dos compósitos poliméricos é dominado basicamente por três fenômenos: danos na matriz, falha por delaminação e fraturamento da fibra. Sendo assim, para testes com baixos níveis de energia cinética de impacto (próximo a $2 \mathrm{~J}$ ) tem-se a presença apenas da danificação da matriz polimérica. Se esse nível de energia aumentar, as delaminações passam a ser visíveis e também passam a evoluir dentro da estrutura, produzindo assim uma das duas "formas características" de falha interlaminar.

De acordo com Abrate (1998), a "forma característica" de falha depende da espessura do laminado, portanto, haverá uma forma específica para laminados espessos e outra para laminados finos. Para laminados espessos, as danificações na matriz polimérica estão localizadas no lado onde ocorreu o impacto. Isto se deve a ação localizada das tensões de contato, entre o impactador e a amostra. Esses danos intralaminares progridem para a interface criando as delaminações que reduzem drasticamente a rigidez do laminado e promovem um estado crítico de tensão nas camadas imediatamente abaixo. Isso gera novos danos intralaminares e consequentemente novas delaminações, formando uma árvore tipo pinus (FIGURA 2.1.2-2 (a)).

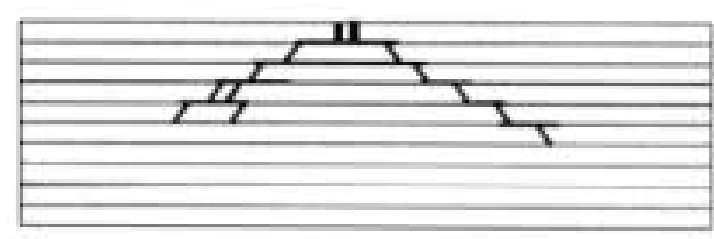

(a)

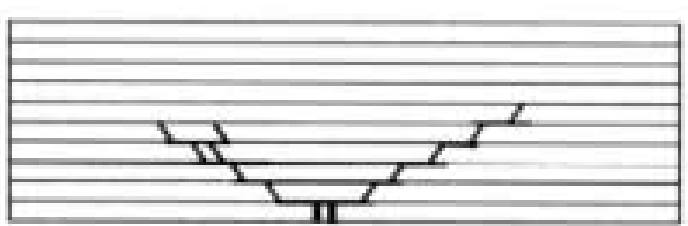

(b)

FIGURA 2.1.2-2 - "Formas características" de falha interlaminar em estruturas impactadas: (a) laminado espesso; (b) laminado fino

(ABRATE, 1998)

Por outro lado, para laminados finos, as tensões são maiores no lado oposto ao impacto, causando a danificação da matriz nas lâminas inferiores. Esses danos 
intralaminares progridem para a interface criando as delaminações que reduzem drasticamente a rigidez do laminado e promovem um estado crítico de tensão nas camadas imediatamente acima. Isso gera novos danos intralaminares e consequentemente novas delaminações, formando uma árvore tipo pinus invertida (FIGURA 2.1.2-2 (b)). Porém, vale destacar que se o nível de energia de impacto aumentar razoavelmente, é possível notar a predominante ocorrência do rompimento das fibras. Com isso, tem-se que grande parte da energia de impacto passa a ser absorvida por esse tipo de mecanismo. 


\subsection{ANÁlISE ESTRUTURAL DE COMPÓSITOS POLIMÉRICOS REFORÇADOS LAMINADOS}

De acordo com a literatura, tem-se que os materiais compósitos poliméricos reforçados laminados (CPR) possuem uma excelente eficiência estrutural. No entanto, a anisotropia presente nesses materiais causa aspectos negativos ou positivos durante o desenvolvimento de um projeto. Se por um lado, torna-se possível projetar o material em conjunto com o componente mecânico, por outro, a anisotropia associada à heterogeneidade faz com que haja uma grande dificuldade em se prever com precisão o modo de falha da estrutura. Vale ressaltar que o grau de anisotropia e de heterogeneidade desses materiais está associado a uma série de parâmetros, tais como: módulo de elasticidade da fibra; efeitos visco-elastoplásticos presentes na matriz polimérica; orientação e/ou entrelaçamento das fibras; grau de interação entre as fibras e a matriz polimérica (resistência da interface) e fração volumétrica de fibras (porcentagem de fibra em volume existente no laminado). É importante destacar que todos esses parâmetros podem influenciar o comportamento mecânico de uma dada estrutura, proporcionando alterações significativas nos modos de danificação/falha do laminado e dificultando assim uma previsão de resposta que seja confiável. Isto pode ser confirmado através de ensaios experimentais que demonstram para algumas amostras a predominância de danificações na matriz, e em outras a predominância de fraturas em fibras ou delaminações.

Essa dificuldade de prever o comportamento mecânico do material reflete diretamente na confiabilidade dos componentes fabricados, obrigando muitas vezes a utilização de elevados coeficientes de segurança durante a fase de desenvolvimento do projeto. Segundo Matthews e Rawlings (1994), a falha de um componente ocorre no momento em que o mesmo não pode mais satisfazer a função para o qual foi projetado. Sendo assim, durante a fase de desenvolvimento do projeto torna-se necessário o emprego de um critério de danificação/falha que seja capaz de identificar a ocorrência de um dano intralaminar ou então de uma falha interlaminar. Tal critério pode ser expresso matematicamente na forma de uma função relacionando as tensões atuantes com valores limites de resistência determinados experimentalmente. No entanto, o caráter anisótropo intrínseco aos materiais compósitos faz com que a determinação das tensões atuantes não seja uma tarefa simples, sendo necessário recorrer a alguns fundamentos da Mecânica dos Sólidos. 
Segundo Malvern (1969), um sólido (meio contínuo) carregado externamente produzirá tensões internas para equilibrar tais carregamentos como mostra a FIGURA 2.2-1.

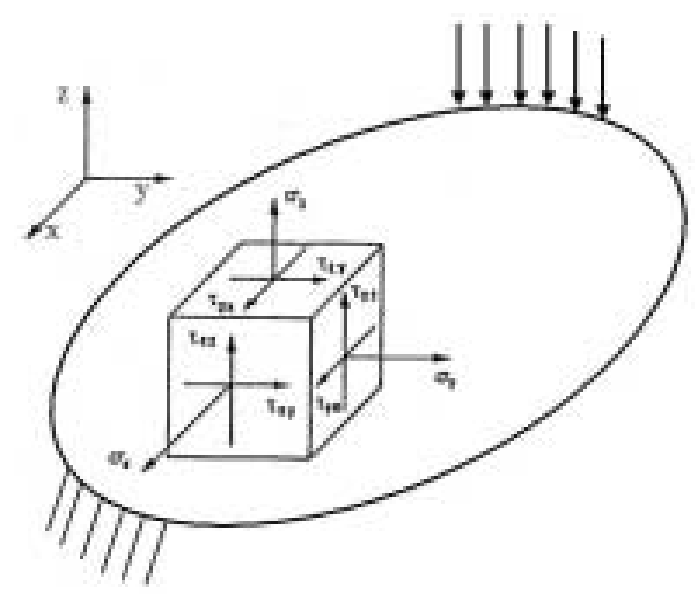

FIGURA 2.2-1 - Estado de tensões num dado ponto material

As tensões produzidas podem ser representadas por um tensor de segunda ordem (Tensor das Tensões) que, devido ao estado de equilíbrio do ponto material, tem algumas componentes iguais, ou seja: $\tau_{\mathrm{xy}}=\tau_{\mathrm{yx}} ; \tau_{\mathrm{xz}}=\tau_{\mathrm{zx}}$ e $\tau_{\mathrm{yz}}=\tau_{\mathrm{zy}}$. Dessa forma, $\mathrm{o}$ Tensor das Tensões será simétrico e poderá ser simplesmente representado por um vetor de seis componentes:

$$
\sigma_{\text {Global }}=\left[\begin{array}{llllll}
\sigma_{\mathrm{x}} & \sigma_{\mathrm{y}} & \sigma_{\mathrm{z}} & \tau_{\mathrm{xy}} & \tau_{\mathrm{xz}} & \tau_{\mathrm{yz}}
\end{array}\right]^{\mathrm{T}}
$$

É importante ressaltar que o tensor $\sigma_{\text {Global }}$ contém as componentes de tensão do ponto material em relação ao sistema global de coordenadas (x, y, z). No entanto, para uma estrutura laminada, deve-se lembrar que o meio material é formado por um conjunto de lâminas empilhadas que possuem diferentes orientações de fibra. Sendo assim, sob cada lâmina há um sistema local de coordenadas baseado nos eixos de ortotropia $(1,2,3)$ (FIGURA 2.2-2). 


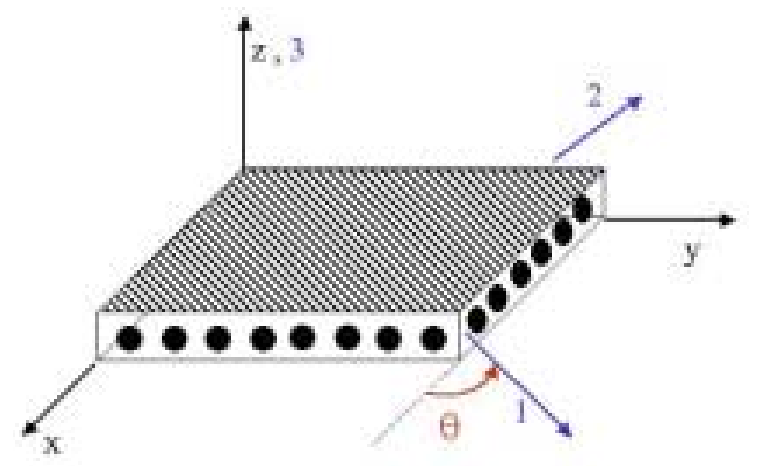

FIGURA 2.2-2 - Lâmina ortotrópica: sistema global de coordenadas e sistema local de coordenadas (eixos principais do material)

Na FIGURA 2.2-2, a direção 1 é paralela à fibra, a direção 2 é perpendicular à fibra e pertence ao plano da lâmina $1-2$ e a direção 3 é perpendicular à fibra, sendo normal ao plano da lâmina 1-2.

Segundo Keunings (1992), num material ortotrópico segundo as direções de ortotropia, não há acoplamentos entre tensões normais e distorções angulares bem como não há acoplamentos entre tensões de cisalhamento e deformações normais. Sendo assim, tensões normais não produzem distorções angulares e tensões de cisalhamento não produzem deformações normais. Com base nessa afirmação e com base em estudos que demonstram a simetria do tensor constitutivo para materiais ortotrópicos, tem-se que a Lei de Hooke assumirá a forma dada pela equação 2.2-2, demonstrando que as componentes da rigidez são diretamente calculadas a partir das propriedades elásticas tomadas sob uma lâmina (VINSON; SIERAKOWSKI, 1986). Dessa forma, torna-se possível o cálculo do tensor $\sigma_{\text {Local }}$ que contém as componentes de tensão do ponto material em relação ao sistema local de coordenadas $(1,2,3)$.

$$
\begin{gathered}
\sigma_{\text {Local }}=\left[\begin{array}{c}
\sigma_{1} \\
\sigma_{2} \\
\sigma_{3} \\
\sigma_{12} \\
\sigma_{13} \\
\sigma_{23}
\end{array}\right]=\left[\begin{array}{cccccc}
\mathrm{Q}_{11} & \mathrm{Q}_{12} & \mathrm{Q}_{13} & 0 & 0 & 0 \\
\mathrm{Q}_{21} & \mathrm{Q}_{22} & \mathrm{Q}_{23} & 0 & 0 & 0 \\
\mathrm{Q}_{31} & \mathrm{Q}_{32} & \mathrm{Q}_{33} & 0 & 0 & 0 \\
0 & 0 & 0 & 2 \mathrm{Q}_{44} & 0 & 0 \\
0 & 0 & 0 & 0 & 2 \mathrm{Q}_{55} & 0 \\
0 & 0 & 0 & 0 & 0 & 2 \mathrm{Q}_{66}
\end{array}\right]\left[\begin{array}{c}
\varepsilon_{1} \\
\varepsilon_{2} \\
\varepsilon_{3} \\
\varepsilon_{12} \\
\varepsilon_{13} \\
\varepsilon_{23}
\end{array}\right] \\
\text { ou } \sigma_{\text {Local }}=[\mathrm{Q}] \varepsilon_{\text {Local }}
\end{gathered}
$$


onde:

$$
\begin{array}{cc}
\mathrm{Q}_{11}=\frac{\mathrm{E}_{11}\left(1-v_{23} v_{32}\right)}{\Delta} & \mathrm{Q}_{12}=\frac{\mathrm{E}_{11}\left(v_{21}+v_{31} v_{23}\right)}{\Delta}=\frac{\mathrm{E}_{22}\left(v_{12}+v_{32} v_{13}\right)}{\Delta} \\
\mathrm{Q}_{22}=\frac{\mathrm{E}_{22}\left(1-v_{31} v_{13}\right)}{\Delta} & \mathrm{Q}_{13}=\frac{\mathrm{E}_{11}\left(v_{31}+v_{21} v_{32}\right)}{\Delta}=\frac{E_{22}\left(v_{13}+v_{12} v_{23}\right)}{\Delta} \\
\mathrm{Q}_{33}=\frac{\mathrm{E}_{33}\left(1-v_{12} v_{21}\right)}{\Delta} & \mathrm{Q}_{23}=\frac{E_{22}\left(v_{32}+v_{12} v_{31}\right)}{\Delta}=\frac{E_{33}\left(v_{23}+v_{21} v_{13}\right)}{\Delta} \\
\Delta=1-v_{12} v_{21}-v_{23} v_{32}-v_{31} v_{13}-2 v_{21} v_{32} v_{13}
\end{array}
$$

Vale ressaltar que as propriedades elásticas utilizadas na equação (2.2-2) estão especificadas na TABELA 2.2-1.

TABELA 2.2-1 - Propriedades elásticas de uma lâmina ortotrópica

\begin{tabular}{cr}
\hline Símbolo & Propriedade Elástica \\
\hline $\mathrm{E}_{11}$ & Módulo de elasticidade na direção da fibra (direção 1) \\
$\mathrm{E}_{22}$ & Módulo de elasticidade perpendicular à fibra (direção 2) \\
$\mathrm{E}_{33}$ & Módulo de elasticidade normal ao plano da lâmina (direção3) \\
$\mathrm{G}_{12}$ & Módulo de cisalhamento no plano da lâmina (plano 1-2) \\
$\mathrm{G}_{13}$ & Módulo de cisalhamento no plano 1-3 \\
$\mathrm{G}_{23}$ & Módulo de cisalhamento no plano 2-3 \\
$v_{12}$ & Coeficiente de Poisson medido no plano 1-2 \\
$v_{13}$ & Coeficiente de Poisson medido no plano 1-3 \\
$v_{23}$ & Coeficiente de Poisson medido no plano 2-3 \\
\hline
\end{tabular}

Todavia, deve-se destacar que uma lâmina ortotrópica unidirecional é também transversalmente isótropa o que acarreta em:

$$
\mathrm{E}_{22}=\mathrm{E}_{33} ; \quad \mathrm{G}_{12}=\mathrm{G}_{13} \text { e } v_{12}=v_{13}
$$

Além disso, devido ao Teorema da Reciprocidade de Maxwell tem-se que:

$$
\frac{v_{i j}}{E_{i i}}=\frac{v_{j i}}{E_{j j}} \text { para } i, j=1,2 \text { e } 3
$$


Para que se possa finalmente calcular a matriz de rigidez da lâmina em relação ao sistema global de coordenadas é necessário aplicar uma transformação de coordenadas:

$$
[\bar{Q}]=[\mathrm{T}]^{-1}[\mathrm{Q}][\mathrm{T}]
$$

onde:

$$
\begin{array}{rl}
{[\mathrm{T}]=\left[\begin{array}{cccccc}
\mathrm{m}^{2} & \mathrm{n}^{2} & 0 & 0 & 0 & 2 \mathrm{mn} \\
\mathrm{n}^{2} & \mathrm{~m}^{2} & 0 & 0 & 0 & -2 \mathrm{mn} \\
0 & 0 & 1 & 0 & 0 & 0 \\
0 & 0 & 0 & \mathrm{~m} & -\mathrm{n} & 0 \\
0 & 0 & 0 & \mathrm{n} & \mathrm{m} & 0 \\
-\mathrm{mn} & \mathrm{mn} & 0 & 0 & 0 & \left(\mathrm{~m}^{2}-\mathrm{n}^{2}\right)
\end{array}\right]} \\
\mathrm{m}=\cos \theta \quad \mathrm{e} & \mathrm{n}=\operatorname{sen} \theta
\end{array}
$$

Com isso, torna-se possível o cálculo do tensor $\sigma_{\mathrm{Global}}$ que contém as componentes de tensão do ponto material em relação ao sistema global de coordenadas $(\mathrm{x}, \mathrm{y}, \mathrm{z})$ :

$$
\sigma_{\text {Global }}=[\overline{\mathrm{Q}}] \varepsilon_{\text {Global }}
$$

A mesma matriz de transformação também relaciona a tensão global com a local da seguinte forma:

$$
\sigma_{\text {Local }}=[\mathrm{T}] \sigma_{\text {Global }}
$$

Portanto, sob posse das deformações globais e da matriz de rigidez da lâmina em relação ao sistema global de coordenadas pode-se determinar o tensor $\sigma_{\text {Global }}$ e então finalmente obter as componentes de tensão do ponto material em relação ao sistema local de coordenadas $(1,2,3)$. Essas componentes de tensão do tensor local é que serão aplicadas ao critério de danificação ou falha escolhido. No entanto, a escolha de um critério para compósitos é algo complexo, pois necessita satisfazer três requisitos:

Ser o mais geral possível, podendo assim avaliar vários estudos de caso;

$\checkmark$ Ser capaz de representar de forma consistente os fenômenos físicos envolvidos;

$\checkmark$ Não necessitar de muitos experimentos para estabelecer uma superfície no espaço das tensões. 
Devido principalmente à complexidade de previsão dos fenômenos físicos, tem-se na literatura a descrição de inúmeras contribuições. Somente no trabalho de Rowlands (1985) foram apresentados e comentados 21 critérios e no relatório de París (2001) há 53 referências sob a aplicação de critérios de danificação/falha para CPR.

De acordo com Rowlands (1985), muitas teorias desenvolvidas para materiais compósitos são baseadas em teorias previamente desenvolvidas para materiais isótropos. Assim, o Critério da Máxima Tensão Normal para materiais isótropos foi estendido por Jenkins em 1920 para identificar danos intralaminares em materiais ortotrópicos (ROWLANDS, 1985) (FIGURA 2.2-3).

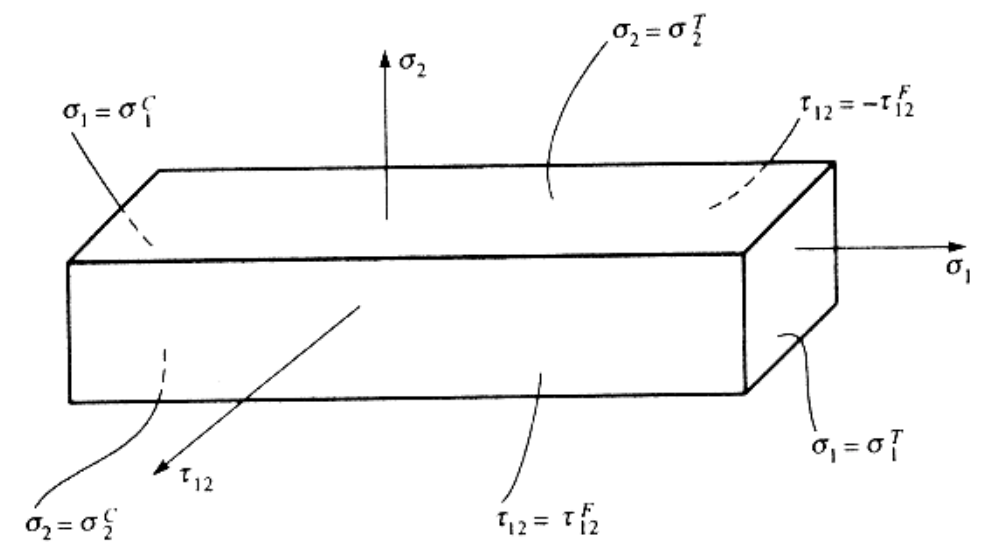

(onde: T indica o limite sob tração; $C$ indica o limite sob compressão e F o limite sob cisalhamento)

FIGURA 2.2-3 - Superfície definida pelo Critério da Máxima Tensão (HYER, 1998)

De maneira análoga ao Critério da Máxima Tensão desenvolveu-se o Critério da Máxima Deformação para materiais ortotrópicos. Posteriormente, em 1950, Hill (1950) estabeleceu um dos primeiros critérios para materiais completamente anisótropos. Este critério é na verdade uma generalização do Critério de von Mises de 1920 (Critério da Energia de Distorção) que tinha sido formulado para analisar plastificação em materiais isótropos. Apesar de ser um critério mais geral, tem-se o inconveniente da necessidade da determinação de vários parâmetros a fím de estabelecer a equação completa do modelo. No mesmo ano, Norris associou o Critério da Máxima Tensão ao Critério de Hill, fazendo com que o dano fosse identificado caso uma das equações do critério fosse satisfeita (ROWLANDS, 1985). Em 1957, Marin modificou o Critério da Energia de 
Distorção ao introduzir alguns parâmetros, sendo assim, o critério passou a diferenciar o comportamento a tração e a compressão na direção longitudinal. Além disso, o autor adotou que os eixos principais deveriam coincidir com os eixos de ortotropia (ROWLANDS, 1985). Em 1959, Ashkenazi também se baseou no Critério de von Mises para estabelecer seu critério. Neste trabalho, o autor introduziu um parâmetro de anisotropia o qual poderia ser medido utilizando corpos de prova com fibras orientadas a $45^{\circ}$ (ROWLANDS, 1985). Em 1962, Griffith e Baldwin assumiram que o dano poderia ser independente das tensões hidrostáticas, e estenderam também o conceito da energia de distorção para problemas com presença de ortotropia (ROWLANDS, 1985). Em 1965, Gol'denblat e Kopnov propuseram que o critério deveria ser independente do sistema de coordenadas (ROWLANDS, 1985). Neste mesmo ano, Tsai propôs um critério de Hill modificado ao qual foi chamado de Critério de Tsai-Hill. Este critério é uma extensão do Critério de Hill para quantificar a desigualdade em tração e compressão para materiais anisótropos especificamente ortotrópicos (ROWLANDS, 1985). Vale ressaltar que este critério, embora ainda hoje seja utilizado, não é invariante em relação ao sistema de coordenadas, ou seja, o resultado do critério depende do sistema adotado. Sendo assim, o Critério de Tsai-Hill é aplicado apenas aos materiais com presença de eixos de ortotropia.

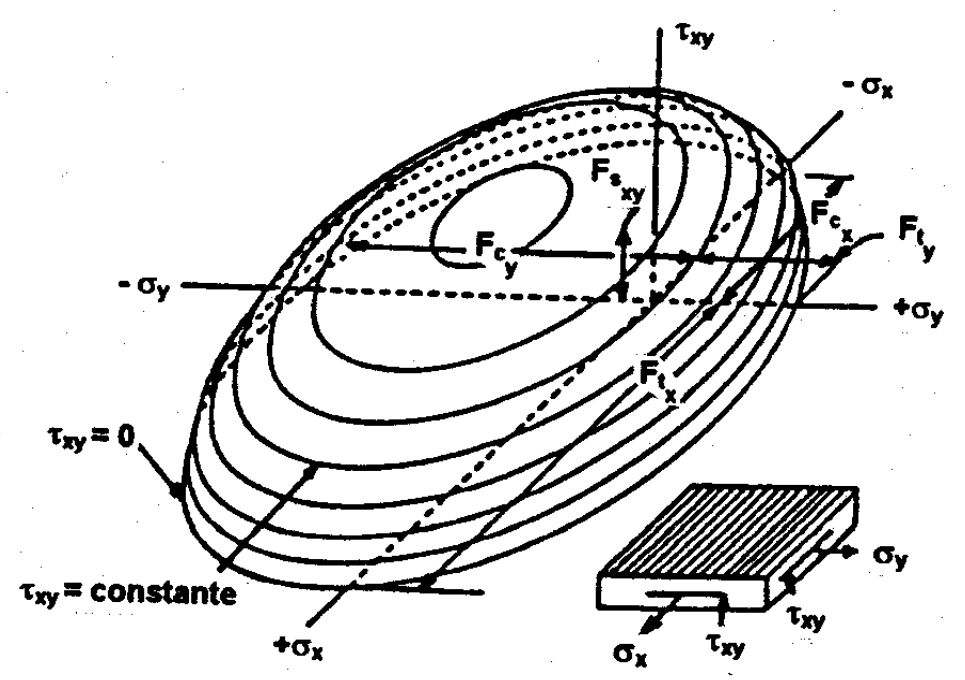

FIGURA 2.2-4 - Vista isométrica da superfície definida pelo Critério de Hoffman considerando estado plano de tensões

(MAGAGNIN FILHO, 1996) 
Com o objetivo de diferenciar a resposta sob tração e sob compressão em CPR, Malmeister em 1966 e Hoffman em 1967 propuseram os seus respectivos critérios (ROWLANDS, 1985). Tais critérios possuem parâmetros que consideram a diferença de resposta sob tração e sob compressão a fim de tornar o critério mais geral (FIGURA 2.2-4). Por outro lado, outros pesquisadores apresentavam critérios mais específicos, como o caso de Fisher que em 1967 apresentou um critério aplicado apenas para materiais ortotrópicos baseando-se nas teorias de Hill e Norris (ROWLANDS, 1985). Em 1968, Franklin modificou o Critério de Marin, criando assim o Critério FranklinMarin (THOM, 1998). Este critério passou a contabilizar a diferença de resistência sob tração e sob compressão na direção transversal. Além disso, Franklin acrescentou um parâmetro que considerava carregamentos biaxiais, podendo este ser calibrado experimentalmente. A partir de 1969, começaram a surgir critérios que consideravam fatores relacionados ao processo de fabricação (tensões residuais de cura) que viessem afetar o desempenho em serviço do componente fabricado. Dentre esses, destaca-se o Critério de Chamis de 1969 ao qual possuía parâmetros relacionados a vazios, orientação das fibras, distribuição das propriedades, interface fibra-matriz e tensões residuais (ROWLANDS, 1985). Porém tão importante quanto contabilizar as tensões residuais provenientes dos processos de fabricação, era apresentar um critério que fosse mais rigoroso ao representar o comportamento de um CPR quando solicitado por um carregamento transversal. Neste caso as fibras, que possuem um alto módulo de rigidez, fazem uma espécie de barreira, impedindo a deformação da matriz. Devido a essa restrição imposta pelas fibras, surgem pontos de concentração de tensão entre fibras e matriz polimérica, ocasionando danos localizados (FIGURA 2.2-5). Isso faz com que a resposta da estrutura seja dominada pela matriz que muitas vezes pode possuir um comportamento visco-elastoplático. Dessa forma, Petit e Waddoups (1969) acrescentaram os efeitos de não-linearidade ao Critério da Máxima Deformação para materiais compósitos, pois todos os critérios apresentados previamente, consideravam que a resposta para qualquer tipo de carregamento seria linear elástica até a identificação do dano. Conseqüentemente, os autores propuseram também uma estratégia de solução incremental a fim de representar os efeitos de não-linearidade desses materiais. 


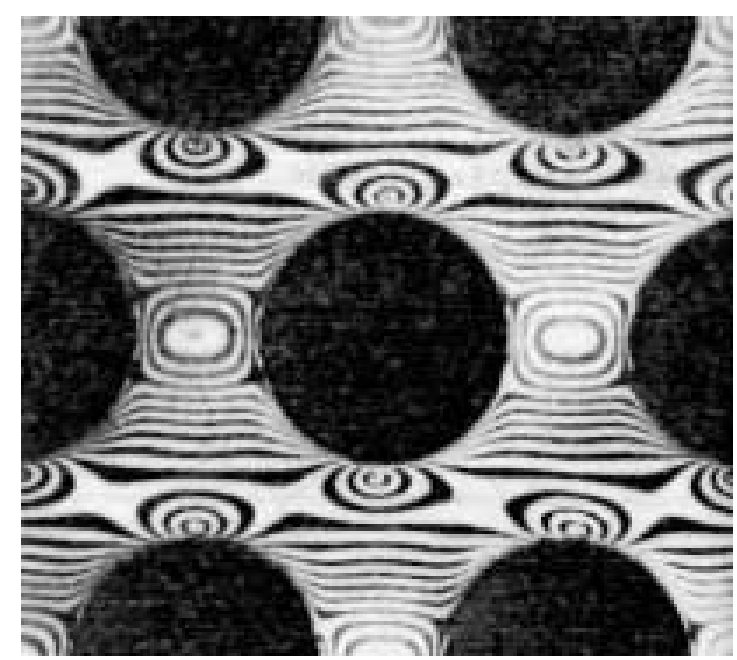

FIGURA 2.2-5 - Franjas isocromáticas de tensão para um CPR sob a ação de carregamento transversal

(HULL, 1981)

Posteriormente, Hahn e Tsai (1973) realizaram um estudo onde abordaram o comportamento não-linear dos CPR sob tensões de cisalhamento. Os autores concluíram que a não-linearidade de resposta devido à ação de carregamentos transversais à fibra é muito pequena quando comparada com a não-linearidade de resposta sob a ação das tensões de cisalhamento no plano da lâmina. A contribuição mais importante deste trabalho foi que os autores conseguiram formular uma relação constitutiva onde se expressa a não-linearidade devido ao cisalhamento através de um tensor de $4^{\mathrm{a}}$ ordem.

Tsai e Wu (1971) apresentaram um critério com vantagens sobre o Critério de Tsai-Hill, pois o mesmo passou a ser invariante sob a rotação dos eixos coordenados. Sendo assim, todas as transformações passaram a ser realizadas de acordo com as leis tensoriais conhecidas. Com isso, a superfície proposta por Tsai-Wu começou a ser uma das mais utilizadas e até hoje vários trabalhos são desenvolvidos com base na mesma (FIGURA 2.2-6). Vale ressaltar que o Critério de Tsai-Wu possui uma forma polinomial ao qual considera também a possibilidade de danos causados por carregamentos combinados. 


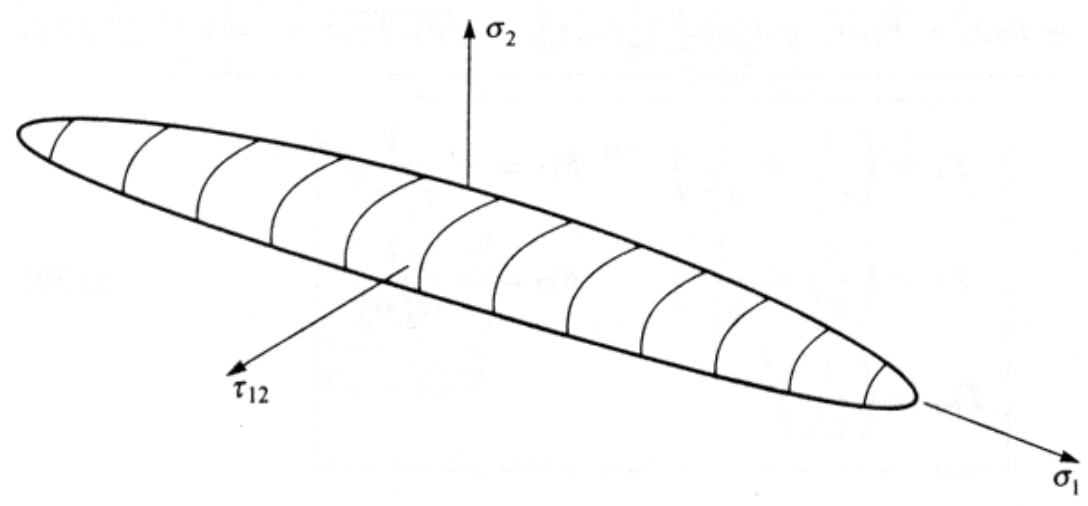

FIGURA 2.2-6 - Superfície definida pelo Critério de Tsai-Wu (HYER, 1998)

Posteriormente, em 1974, Wu e Scheublein estenderam o Critério de Tsai-Wu, adicionando os termos cúbicos (THOM, 1998). Porém devido à complexidade de solução, esta forma do critério é menos utilizada. Neste mesmo ano, baseando-se no Critério de Hill, foi estabelecido um critério de plastificação conhecido como Lei Generalizada de Huber-Mises (MAGAGNIN FILHO, 1996). Esse critério pode ser empregado para compósitos poliméricos com baixa fração volumétrica de fibra e que possuam uma matriz com características elasto-plásticas, ou então, numa análise termoestrutural quando o gradiente de temperatura modifica o comportamento do laminado em questão (MAGAGNIN FILHO, 1996). Sendo assim, pode-se tratar tal problema recorrendo a uma solução elasto-plástica baseada no algoritmo de Newton-Raphson. No entanto, para grande maioria dos compósitos poliméricos ocorre um processo de danificação e falha gradual ao invés de um processo de plastificação. Diante disso, Hahn e Tsai (1974) apresentaram uma discussão preliminar sobre alguns modelos de falha gradual. De acordo com esses pesquisadores, as lâminas com reforço unidirecional orientado a $90^{\circ}$ devem apresentar uma falha mais abrupta, relaxando as tensões atuantes de uma única vez assim que ocorrer a primeira incidência de dano. Porém, para as lâminas com reforço bidirecional, as tensões devem ser relaxadas gradativamente.

Posteriormente, Sandhu (1976) confirmou todas as observações previamente feitas por Hahn e Tsai. A FIGURA 2.2-7(a) mostra que para compósitos unidirecionais, a formulação obtida por Hahn e Tsai em 1973 é válida, pois indica que os laminados a $15^{\circ}$ sob tração possuem uma maior parcela de degradação devido à ação das tensões de cisalhamento. Entretanto, os laminados a $0^{\circ}$ possuem uma maior parcela de degradação devido às tensões normais longitudinais (paralela às fibras) e os laminados a $90^{\circ}$ 
possuem uma maior degradação devido às tensões normais transversais (transversal às fibras). Com relação aos compósitos do tipo "angle-ply", ou seja, empilhados a $+/-\alpha$, a danificação predominante por cisalhamento é constatada nos laminados a $+/-45^{\circ}$ como mostra a FIGURA 2.2-7(b). É importante ressaltar também que Sandhu (1976) estendeu o Critério de Petit e Waddoups, incluindo a possibilidade de representar a resposta nãolinear da lâmina sob carregamento transversal ou cisalhamento.

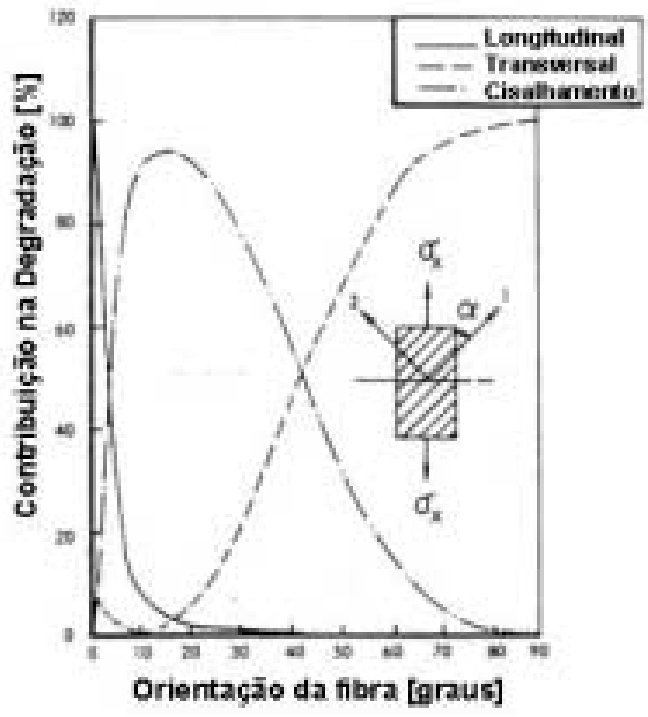

(a)

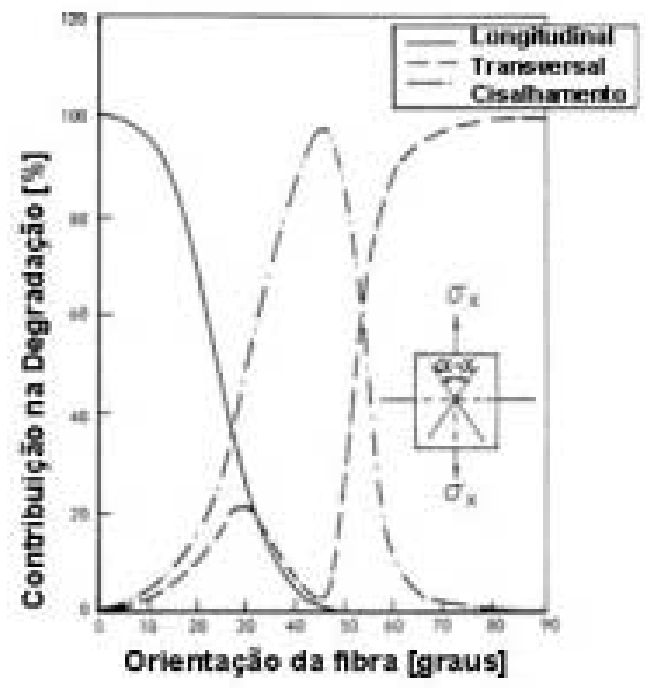

(b)

FIGURA 2.2-7 - Porcentagem de contribuição na degradação:

(a) laminados unidirecionais; (b) laminados do tipo "angle-ply"

(SANDHU, 1976)

Yamada e Sun (1978) propuseram um critério e ampliaram a discussão feita por Hahn e Tsai (1974) ao considerar que devido à fratura das fibras, as propriedades da lâmina danificada deveriam ser degradas segundo uma distribuição estatística de Weibull.

Em 1979, Cowin formulou uma teoria similar à de Tsai-Wu, expressando os parâmetros em termos das resistências normais e de cisalhamento (ROWLANDS, 1985). Neste mesmo ano, Hashin (1979) apresentou uma proposta de determinação das propriedades elásticas de CPR e no ano seguinte, apresentou um critério quadrático polinomial para laminados unidirecionais transversalmente isótropos considerando os modos de danificação intralaminar (HASHIN, 1980). Essa contribuição foi 
extremamente relevante, pois até então, apenas alguns critérios, tal como o Critério da Máxima Tensão e da Máxima Deformação, distinguiam os cinco modos de danificação:

\section{$\checkmark$ Danificação da matriz sob carregamento de tração; \\ $\checkmark$ Danificação da matriz sob carregamento de compressão; \\ $\checkmark$ Danificação da fibra sob carregamento de tração; \\ $\checkmark$ Danificação da fibra sob carregamento de compressão; \\ $\checkmark$ Danificação da lâmina por cisalhamento.}

No entanto, tais critérios eram incapazes de contabilizar efeitos de carregamentos combinados, sendo necessário recorrer ao Critério de Tsai-Wu. Porém a determinação de alguns parâmetros através de ensaios biaxiais, associados a esse critério, foi muitas vezes criticada por alguns pesquisadores. Dessa forma, o Critério de Hashin passou a ser um dos mais utilizados, pois o mesmo permite avaliar danos intralaminares, sem que haja a necessidade de realizar ensaios biaxiais, mesmo quando o laminado sofre a ação de carregamentos combinados. A expressão geral do critério é escrita em termos dos invariantes de tensão e cada termo que não contribui ao respectivo modo de danificação é anulado. O Critério de Hashin é capaz de identificar os modos de danificação da fibra e da matriz sob carregamento de tração e compressão. Com isso, o critério consiste de quatro equações distintas que podem ser entendidas como quatro sub-critérios e será melhor detalhado no Capítulo 4. Atualmente vários estudos demonstram a eficiência do Critério de Hashin e vários trabalhos são extensões do mesmo (PARÍS, 2001). Por exemplo, em 1984, Chang; Scott e Springer (1984a e 1984b) baseando-se no trabalho de Hahn e Tsai (1973) bem como no trabalho desenvolvido por Hashin (1980) apresentaram um modelo que não apenas contabilizava os modos de danificação, mas também adicionava os efeitos de não-linearidade devido às tensões de cisalhamento. Além disso, com base no trabalho de Yamada e Sun (1978), os autores postularam que a degradação das propriedades $E_{11}$ e $G_{12}$ seguiria uma função de descaimento exponencial devido ao processo de danificação da fibra.

Em 1990, Hart-Smith criaram um critério simples baseando-se no Critério de Tresca. Entretanto, sua aplicação ficou limitada a laminados finos, sendo válido apenas para casos envolvendo estado plano de tensões (THOM, 1998). Em 1996, Puck utilizando-se das hipóteses de Mohr estabeleceu que apenas as tensões atuantes no plano 
de propagação da fissura é que irão promover o dano. Porém devido à complexidade de solução desse critério, tem-se que o mesmo é pouco utilizado (THOM, 1998).

Na FIGURA 2.2-8 é possível observar um esquema indicando cronologicamente a contribuição de cada trabalho bem como a relação de interdependência entre eles.

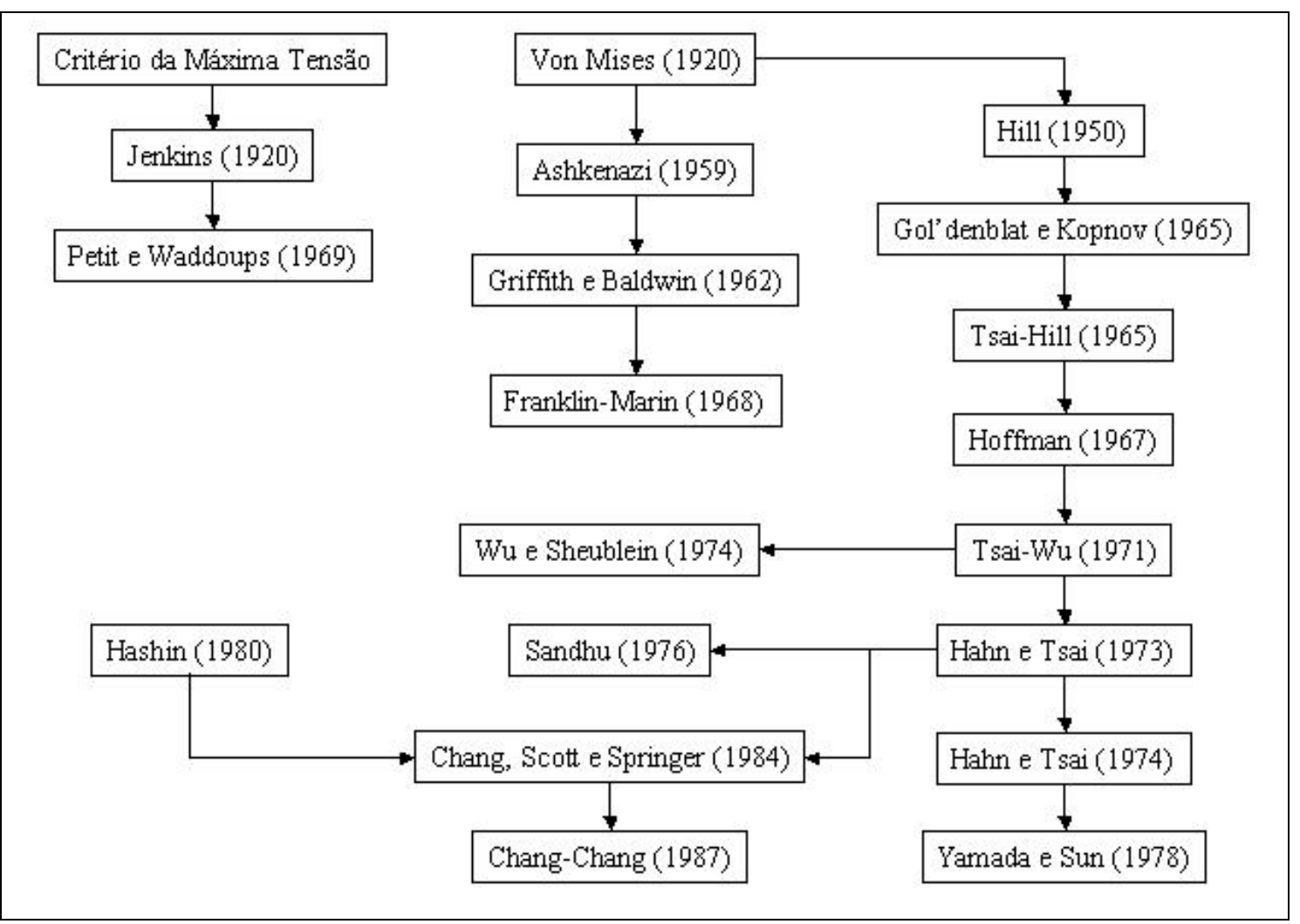

FIGURA 2.2-8 - Esquema cronológico de trabalhos científicos relevantes

Echaabi; Trochu e Gauvin (1996) descreveram os chamados Critérios Paramétricos. Neste caso, a função que representa o envelope do critério deve ser escolhida tal que o erro entre o resultado experimental e a curva parametrizada seja minimizado. Tal envelope é constituído por diferentes formas em cada quadrante do espaço das tensões ou deformações, permitindo uma boa representação dos fenômenos físicos para um determinado laminado. No entanto, este procedimento exige muitos ensaios experimentais e é válido apenas para um laminado específico, não constituindo um critério geral. Nesse mesmo trabalho, os autores comentaram sobre uma técnica estatística conhecida como KRIGIN, onde se faz um vasto levantamento experimental a fim de se ajustar uma curva que determinará o envelope do critério. Novamente tem-se um envelope capaz de representar de forma coerente o comportamento mecânico do 
CPR. Porém, tal envelope é obtido a partir de vários ensaios experimentais sendo apenas para um laminado específico.

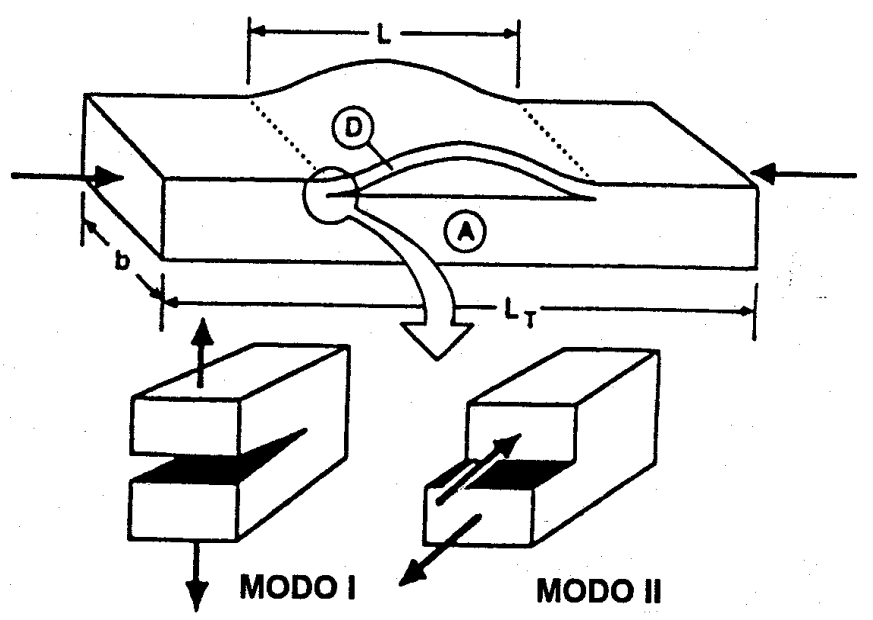

FIGURA 2.2-9 - Mecanismo de delaminação: Modos de Fratura (MAGAGNIN FILHO, 1996)

Além dos danos intralaminares, as falhas interlaminares mais conhecidas como delaminações foram objetos de estudo de vários pesquisadores. Em 1982, Lee definiu um critério de falha interlaminar, onde as tensões normais ao plano da lâmina $\left(\sigma_{3}\right)$ e as tensões de cisalhamento transversais $\left(\sigma_{13}\right.$ e $\left.\sigma_{23}\right)$ eram tomadas no centro da interface entre duas lâminas adjacentes. Essas tensões, juntamente com valores limites de tensões determinados experimentalmente, eram aplicadas ao critério que determinava a ocorrência ou não de uma delaminação. No entanto, o fenômeno de delaminação está intimamente associado ao processo de propagação de uma fissura interlaminar. Dessa forma, o mesmo geralmente é tratado com base em fundamentos provenientes da Mecânica da Fratura. Nota-se com base em ensaios experimentais que os compósitos poliméricos reforçados apresentam dois modos de fratura: Modo I (modo de abertura) e Modo II (modo de cisalhamento). Tais modos são responsáveis pelo aparecimento e propagação das fissuras ao longo do laminado. Segundo Matthews e Rawlings (1994), as fissuras podem surgir na matriz caracterizando o Modo I para carregamentos de tração e o Modo II para carregamentos de cisalhamento. Entretanto, as fissuras que surgem na interface, devido à delaminação, possuem os dois modos acoplados, pois, há uma abertura em forma de cunha caracterizando o Modo I e há o deslizamento entre duas camadas adjacentes caracterizando o Modo II (FIGURA 2.2-9). Na literatura é possível encontrar uma gama de trabalhos que tratam o problema da delaminação 
através da Mecânica da Fratura (JANG, 1994). Dentre esses, destacam-se atualmente os trabalhos de Dávila e Camanho (2001) bem como Dávila; Camanho e Moura (2001).

Enfim, até nos trabalhos mais recentes da literatura sob materiais compósitos é possível encontrar muitas contribuições que visam apresentar um novo critério de danificação ou falha para esses materiais. Porém, o desenvolvimento atual do projeto de componentes mecânicos fabricados a partir de um CPR exige uma análise estrutural que especifique não apenas a danificação ou falha da primeira lâmina ("first ply failure"), mas também que seja capaz de determinar todo o processo de degradação da estrutura ("last ply failure"). Sendo assim, alguns pesquisadores têm procurado novas alternativas para solucionar tal problema. Williams e Vaziri (2001), baseando-se em fundamentos da Mecânica do Dano (“Continuum Damage Mechanics”), implementaram no pacote comercial ANSYS/DYNA ${ }^{\circledR}$ o modelo de danificação proposto por Matzenmiller, Lubliner e Taylor (1995). Apesar de terem obtido um certo ganho de qualidade de resposta para alguns casos, os autores declararam que houve uma grande dificuldade em se determinar os parâmetros requisitados pela lei de evolução de dano. Além disso, torna-se necessário o emprego de um tensor de dano de quarta ordem escrito para o estado plano de tensões que possui 21 variáveis independentes para ser determinado. Tal questão foi reforçada por Alves (1997) ao demonstrar que os modelos de dano anisótropos são potencialmente mais precisos, porém as dificuldades experimentais associadas à medição dos vários parâmetros intrínsecos a estes modelos, restringem a sua aplicabilidade. Isto pode ser constatado através do trabalho de Allix et al (2000) onde foi demonstrado o desenvolvimento de um transmissor ultra-sônico especial com controle de varredura para calibrar os parâmetros de um modelo de danificação baseado nos fundamentos da Mecânica do Dano. Dessa forma, uma solução adotada para modelar esses problemas é empregar um Procedimento de Análise de Danificação/Falha Progressiva. Esse procedimento pode ser analítico como demonstrado por Agarwal e Broutman (1990) ou numérico como demonstrado em vários trabalhos da literatura (PARÍS, 2001).

O Procedimento de Análise de Danificação/Falha Progressiva consiste em associar ao Critério de Danificação/Falha do material uma Lei de Evolução de Dano/Falha, mais conhecida como Lei de Degradação do Material ("Property Degradation Model'). Com isso, o critério informará se há incidência de dano ou falha ao passo que a Lei de Evolução determinará a degradação das propriedades. Com base 
na literatura, tem-se basicamente o emprego de dois métodos para realizar o processo de degradação do material:

$\checkmark$ Método do Desconto Total ("Total Discount Method"): a propriedade associada ao ponto material que danificou é reduzida a zero;

$\checkmark$ Método do Desconto Limitado ("Limited Discount Method"): a redução da propriedade associada ao ponto material depende do tipo de dano ocorrido. Para danificação da fibra somente o módulo de elasticidade longitudinal $\mathrm{E}_{11}$ é anulado já para danificação da matriz anula-se o módulo de elasticidade transversal $\mathrm{E}_{22}$.

Nota-se assim que o Método do Desconto Total é mais conservador, pois desconsidera que o ponto material danificado possa ainda suportar determinados carregamentos. Por outro lado, o Método do Desconto Limitado é mais audacioso, pois caso as propriedades não sejam corretamente degradadas pode-se julgar que o ponto material tenha uma resistência maior do que a verdadeira. Tal fato, exige um balanço muito criterioso entre os dois métodos a fim de que se possa obter resultados fisicamente consistentes. Sendo assim, além da escolha do Critério de Danificação/Falha, o Procedimento de Análise de Danificação/Falha Progressiva exige a especificação de uma Lei de Evolução de Dano/Falha.

Finalmente, após a escolha do modelo que irá representar os fenômenos intra e interlaminares pode-se realizar a análise estrutural do laminado. Tal análise segue de uma maneira geral, o fluxograma mostrado na FIGURA 2.2-10. Nota-se que inicialmente deve-se estabelecer as propriedades elásticas e os valores de resistência mecânica associados a uma lâmina ortotrópica. Tanto as propriedades como os valores de resistência podem ser obtidos através de ensaios experimentais, através da literatura ou com base na formulação da Regra das Misturas (TSAI; HAHN, 1980) (VINSON; SIERAKOWSKI, 1987). No entanto, vários pesquisadores aconselham a realização de ensaios experimentais, pois cada compósito possui características específicas devido ao tipo de reforço utilizado, ou devido ao tipo de resina polimérica ou então devido às condições de fabricação. 


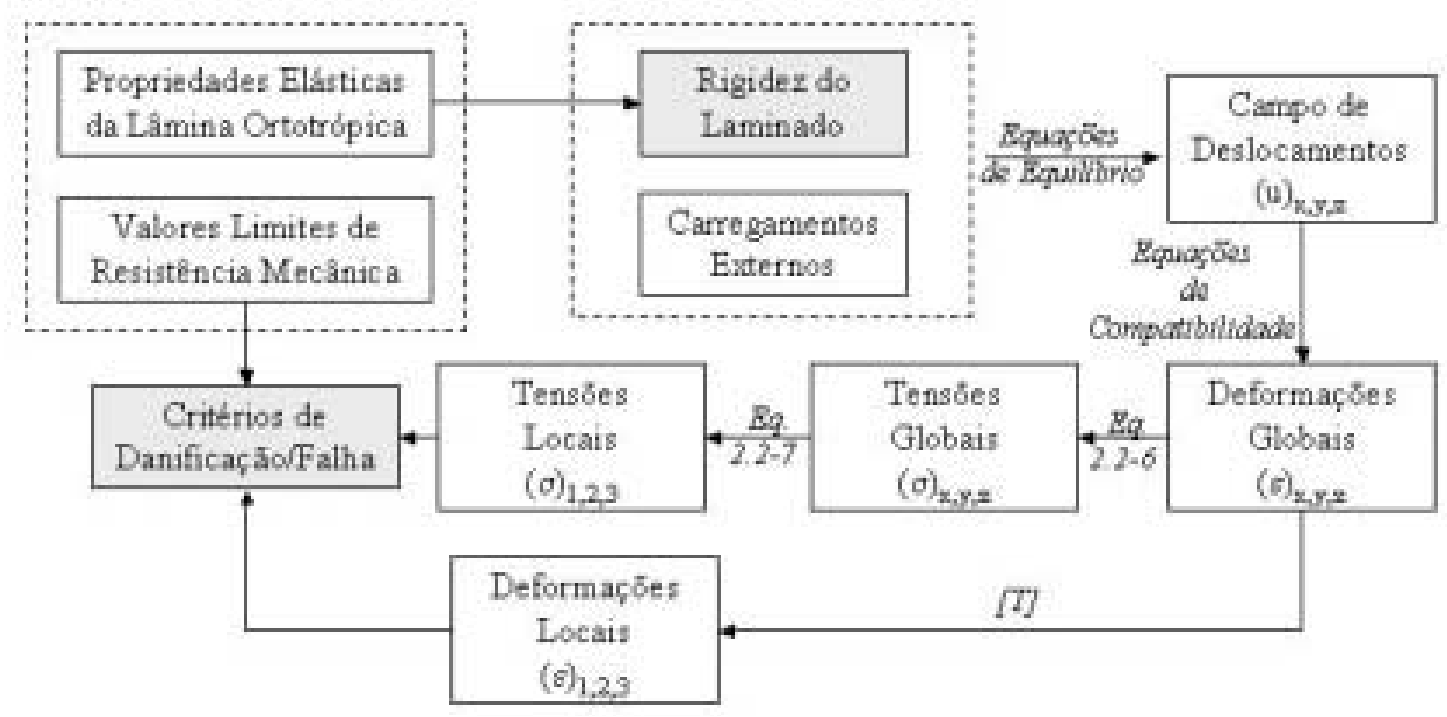

FIGURA 2.2-10 - Fluxograma de análise de uma estrutura laminada

Com base nas propriedades elásticas, determina-se a rigidez de uma lâmina ortotrópica como demonstra a equação (2.2-2), podendo assim, em seguida, calcular a Rigidez do Laminado. Sob posse dessa rigidez global e dos carregamentos externos atuantes na estrutura, pode-se calcular o campo de deslocamentos de um dado ponto material em relação ao sistema global de coordenadas utilizando as Equações de Equilíbrio do sistema. Ao determinar os deslocamentos, torna-se possível obter as deformações para o sistema global de coordenadas aplicando as Equações de Compatibilidade. Essas deformações ao serem substituídas nas Relações Constitutivas (equação 2.2-6) fornecem as componentes de tensão do ponto material em relação ao sistema de coordenadas global. No entanto, a grande maioria dos critérios para materiais compósitos poliméricos reforçados é estabelecido para analisar o dano ou a falha de uma lâmina. Sendo assim, utiliza-se a equação 2.2-7 para obter as componentes de tensão do ponto material em relação ao sistema de coordenadas local. Além disso, há muitos critérios escritos em função das deformações. Neste caso, deve-se aplicar diretamente a transformação [T] ao vetor das deformações escrito em função das coordenadas globais. Por fim, concluí-se que há dois pontos cruciais na análise estrutural de um laminado. O primeiro consiste na escolha de um Modelo de Material que seja adequado para representar todos os mecanismos de danificação intralaminar e falha interlaminar. O segundo consiste em determinar a Rigidez do Laminado que depende do tipo de abordagem (analítica ou numérica) utilizada para prever o comportamento da estrutura. 


\subsubsection{Abordagem Analítica}

As soluções analíticas quase-estáticas são capazes de demonstrar o comportamento global da estrutura e estão baseadas nas teorias de vigas, placas e cascas descritas a partir dos fundamentos da Teoria da Elasticidade (ABRATE, 1998). No entanto, para solucionar o problema de materiais compósitos recorre-se geralmente à Teoria Clássica de Laminados. Neste caso, a viga ou a placa em análise é tratada como uma estrutura laminada com espessura de camada dada por $\mathrm{h}_{\mathrm{K}}-\mathrm{h}_{\mathrm{K}-1}$ (FIGURA 2.2.1$1(\mathrm{a}))$.

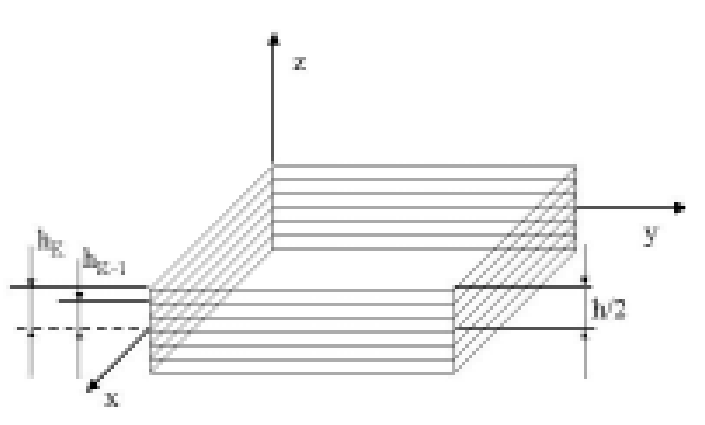

(a)

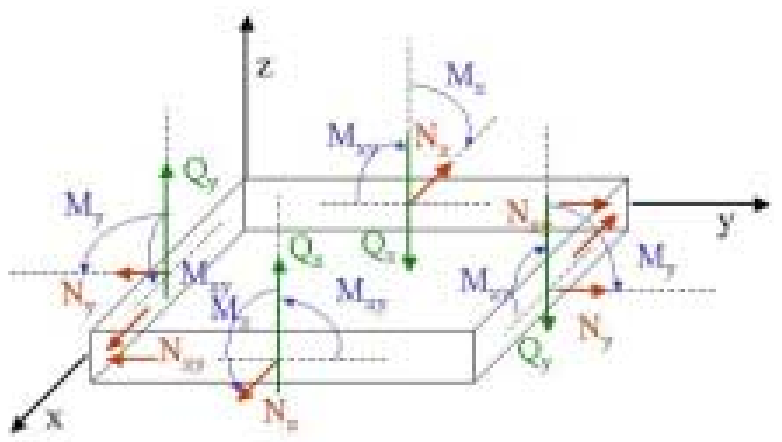

(b)

FIGURA 2.2.1-1 - (a) Estrutura laminada; (b) Esforços atuantes

Em se tratando de uma estrutura tipo placa (FIGURA 2.2.1-1(b)), tem-se que os esforços no plano x-y $(\mathrm{N})$, os esforços de cisalhamento transversal (Q) e os momentos (M) atuantes são obtidos da seguinte forma:

$$
\left[\begin{array}{c}
\mathrm{N}_{\mathrm{x}} \\
\mathrm{N}_{\mathrm{y}} \\
\mathrm{N}_{\mathrm{xy}} \\
\mathrm{Q}_{\mathrm{x}} \\
\mathrm{Q}_{\mathrm{y}}
\end{array}\right]=\int_{-\mathrm{h} / 2}^{\mathrm{h} / 2}\left[\begin{array}{c}
\sigma_{\mathrm{x}} \\
\sigma_{\mathrm{y}} \\
\sigma_{\mathrm{xy}} \\
\sigma_{\mathrm{xz}} \\
\sigma_{\mathrm{yz}}
\end{array}\right] \mathrm{dz} \quad(2.2 .1-1) \quad\left[\begin{array}{c}
\mathrm{M}_{\mathrm{x}} \\
\mathrm{M}_{\mathrm{y}} \\
\mathrm{M}_{\mathrm{xy}}
\end{array}\right]=\int_{-\mathrm{h} / 2}^{\mathrm{h} / 2}\left[\begin{array}{c}
\sigma_{\mathrm{x}} \\
\sigma_{\mathrm{y}} \\
\sigma_{\mathrm{xy}}
\end{array}\right] \mathrm{zdz}
$$

Caso sejam consideradas as relações cinemáticas estabelecidas por Kirchhoff temse que as deformações $\varepsilon_{\mathrm{xz}}$, $\varepsilon_{\mathrm{yz}}$ e $\varepsilon_{\mathrm{z}}$ serão nulas (FIGURA 2.2.1-2). 


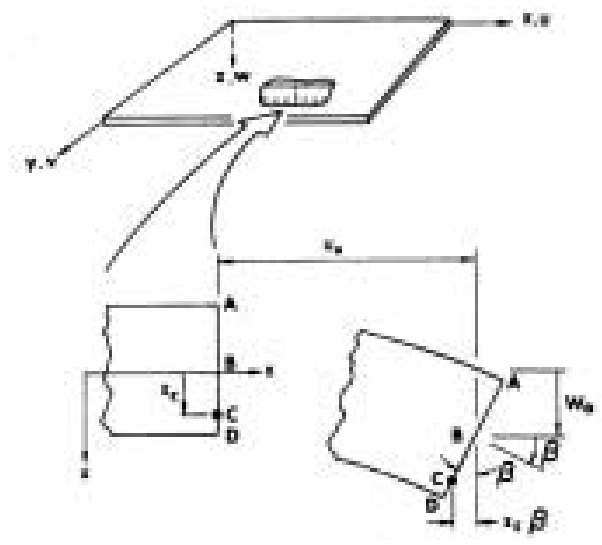

FIGURA 2.2.1-2 - Aproximações cinemáticas de Kirchhoff

$\mathrm{O}$ estado de tensão de uma lâmina $\mathrm{k}$ poderá ser calculado com base nas deformações no plano que divide o laminado ao meio (plano médio do laminado) bem como na curvatura do laminado que é medida em relação ao plano médio.

$$
\left[\begin{array}{c}
\sigma_{\mathrm{x}} \\
\sigma_{\mathrm{y}} \\
\sigma_{\mathrm{xy}}
\end{array}\right]_{\mathrm{k}}=\left[\begin{array}{lll}
\overline{\mathrm{Q}}_{11} & \overline{\mathrm{Q}}_{12} & \overline{\mathrm{Q}}_{16} \\
\overline{\mathrm{Q}}_{12} & \overline{\mathrm{Q}}_{22} & \overline{\mathrm{Q}}_{26} \\
\overline{\mathrm{Q}}_{16} & \overline{\mathrm{Q}}_{26} & \overline{\mathrm{Q}}_{66}
\end{array}\right]_{\mathrm{k}}\left[\left[\begin{array}{c}
\varepsilon_{\mathrm{x} 0} \\
\varepsilon_{\mathrm{y} 0} \\
\varepsilon_{\mathrm{xy} 0}
\end{array}\right]+\mathrm{z}\left[\begin{array}{c}
\mathrm{K}_{\mathrm{x}} \\
\mathrm{K}_{\mathrm{y}} \\
\mathrm{K}_{\mathrm{xy}}
\end{array}\right]\right]
$$

onde:

$[\overline{\mathrm{Q}}]_{\mathrm{K}}=$ matriz de rigidez da lâmina $\mathrm{k}$

$\left[\varepsilon_{\mathrm{o}}\right]=$ deformações no plano médio

$\mathrm{z}=$ distância da lâmina até o plano médio

$[\mathrm{K}]=$ curvatura medida em relação ao plano médio

Substituindo a equação (2.2.1-3) na equação (2.2.1-1) pode-se calcular os esforços (N) no plano x-y:

$$
\begin{gathered}
{\left[\begin{array}{c}
\mathrm{N}_{\mathrm{X}} \\
\mathrm{N}_{\mathrm{Y}} \\
\mathrm{N}_{\mathrm{XY}}
\end{array}\right]=\sum_{\mathrm{K}=1}^{\mathrm{n}}\left\{\int_{\mathrm{h}_{\mathrm{K}-1}}^{\mathrm{h}_{\mathrm{K}}}[\overline{\mathrm{Q}}]_{\mathrm{K}}\left[\begin{array}{c}
\varepsilon_{\mathrm{x} 0} \\
\varepsilon_{\mathrm{y} 0} \\
\varepsilon_{\mathrm{xy} 0}
\end{array}\right] \mathrm{dz}+\int_{\mathrm{h}_{\mathrm{K}-1}}^{\mathrm{h}_{\mathrm{K}}}[\overline{\mathrm{Q}}]_{\mathrm{K}}\left[\begin{array}{c}
\mathrm{K}_{\mathrm{x}} \\
\mathrm{K}_{\mathrm{y}} \\
\mathrm{K}_{\mathrm{xy}}
\end{array}\right] \mathrm{zdz}\right\}} \\
\text { ou }[\mathrm{N}]=[\mathrm{A}]\left[\varepsilon_{0}\right]+[\mathrm{B}][\mathrm{K}]
\end{gathered}
$$


onde:

$$
[\mathrm{A}]=\int_{\mathrm{h}_{\mathrm{K}-1}}^{\mathrm{h}_{\mathrm{K}}}[\overline{\mathrm{Q}}]_{\mathrm{K}} \mathrm{dz} \text { e }[\mathrm{B}]=\int_{\mathrm{h}_{\mathrm{K}-1}}^{\mathrm{h}_{\mathrm{K}}}[\overline{\mathrm{Q}}]_{\mathrm{K}} \mathrm{zdz}
$$

Substituindo a equação (2.2.1-3) na equação (2.2.1-2) pode-se calcular os momentos (M):

$$
\begin{aligned}
& {\left[\begin{array}{c}
\mathrm{M}_{\mathrm{X}} \\
\mathrm{M}_{\mathrm{Y}} \\
\mathrm{M}_{\mathrm{XY}}
\end{array}\right]=\sum_{\mathrm{K}=1}^{\mathrm{n}}\left\{\int_{\mathrm{h}_{\mathrm{K}-1}}^{\mathrm{h}_{\mathrm{K}}}[\overline{\mathrm{Q}}]_{\mathrm{K}}\left[\begin{array}{c}
\varepsilon_{\mathrm{x} 0} \\
\varepsilon_{\mathrm{y} 0} \\
\varepsilon_{\mathrm{xy} 0}
\end{array}\right] \mathrm{zdz}+\int_{\mathrm{h}_{\mathrm{K}-1}}^{\mathrm{h}_{\mathrm{K}}}[\overline{\mathrm{Q}}]_{\mathrm{K}}\left[\begin{array}{c}
\mathrm{K}_{\mathrm{x}} \\
\mathrm{K}_{\mathrm{y}} \\
\mathrm{K}_{\mathrm{xy}}
\end{array}\right] \mathrm{z}^{2} \mathrm{dz}\right\}} \\
& \text { ou }[M]=[B]\left[\varepsilon_{0}\right]+[D][K]
\end{aligned}
$$

onde:

$$
[D]=\int_{h_{K-1}}^{h_{K}}[\bar{Q}]_{K} z^{2} d z
$$

Em suma tem-se:

$$
\left[\begin{array}{l}
{[\mathrm{N}]} \\
{[\mathrm{M}]}
\end{array}\right]=\left[\begin{array}{ll}
{[\mathrm{A}]} & {[\mathrm{B}]} \\
{[\mathrm{B}]} & {[\mathrm{D}]}
\end{array}\right]\left[\begin{array}{l}
{\left[\varepsilon_{\mathrm{o}}\right]} \\
{[\mathrm{K}]}
\end{array}\right]
$$

É importante destacar que as relações cinemáticas de Kirchhoff não contabilizam a influência das tensões de cisalhamento transversal, ou seja, as seções transversais ao plano médio que eram normais mesmo antes da aplicação do carregamento, permanecem normais após a estrutura ser solicitada. Entretanto, essas tensões são de extrema importância para análise de delaminações. Além disso, se a estrutura for relativamente espessa tem-se que a resposta poderá ser prejudicada caso as contribuições das tensões de cisalhamento transversal não forem calculadas. Esse mesmo problema pode ocorrer se modos de vibrar de alta freqüência forem excitados durante uma análise de impacto, de tal forma que os mesmos governem a resposta dinâmica da estrutura (ABRATE, 1998). Sendo assim, torna-se necessário utilizar relações cinemáticas mais completas tal como as relações estabelecidas por MidlinReissner, ou estabelecidas por Reddy ou então especificadas por teorias de ordem superior (“Higher-order Shear deformation Theory - HST”) (ABRATE, 1998). 
Vinson e Sierakowski (1987) consideram que a deformação causada pelo cisalhamento transversal será definida por uma função parabólica em cada lâmina, porém esta função será descontínua na interface. Esta hipótese faz com que os esforços de cisalhamento $(\mathrm{Q})$ possam ser calculados da seguinte maneira:

$$
\begin{aligned}
& \mathrm{Q}_{\mathrm{x}}=2\left(\mathrm{~A}_{55} \varepsilon_{\mathrm{xz}}+\mathrm{A}_{45} \varepsilon_{\mathrm{yz}}\right) \\
& \mathrm{Q}_{\mathrm{y}}=2\left(\mathrm{~A}_{45} \varepsilon_{\mathrm{xz}}+\mathrm{A}_{44} \varepsilon_{\mathrm{yz}}\right)
\end{aligned}
$$

onde:

$$
\mathrm{A}_{\mathrm{ij}}=\frac{5}{4} \sum_{\mathrm{k}=1}^{\mathrm{N}}\left(\overline{\mathrm{Q}}_{\mathrm{ij}}\right)_{\mathrm{k}}\left[\mathrm{h}_{\mathrm{k}}-\mathrm{h}_{\mathrm{k}-1}-\frac{4}{3}\left(\mathrm{~h}_{\mathrm{k}}^{3}-\mathrm{h}_{\mathrm{k}-1}^{3}\right) \frac{1}{\mathrm{~h}^{2}}\right]
$$

Conseqüentemente sob posse dos esforços solicitantes e das propriedades elásticas das lâminas, pode-se obter as deformações no laminado e com isso calcular as tensões e verificar assim, a ocorrência de falhas. Nos trabalhos desenvolvidos por Tsai (1986) e Hyer (1998) é possível notar a ampla aplicação da Teoria Clássica de Laminados (TCL). Com relação ao trabalho de Tsai (1986), tem-se que o autor desenvolveu um programa, implementando toda essa teoria. Por outro lado, Hyer (1998) aplicou a TCL para avaliar o comportamento mecânico de várias estruturas sob várias situações de carregamentos, incluindo tubos com diferentes seqüências de empilhamento. Porém, nota-se que as soluções quase-estáticas analíticas são simples e podem fornecer bons resultados apenas para alguns casos específicos como vigas, tubos e placas. Além disso, muitas vezes, a TCL é somente aplicada para prever a danificação ou falha da primeira lâmina ("first ply failure"), não sendo assim empregada numa análise progressiva de danificação/falha.

\subsubsection{Abordagem Numérica}

Estruturas laminadas com uma geometria mais complexa ou possuindo um estado triplo de tensões podem ser solucionadas através de técnicas numéricas. É o caso da análise das tensões na borda de um laminado, que devido ao chamado efeito de borda ("end effects") requerem uma solução que considere as tensões normais ao plano da lâmina e as tensões de cisalhamento transversal, pois as mesmas promovem a falha por delaminação. 


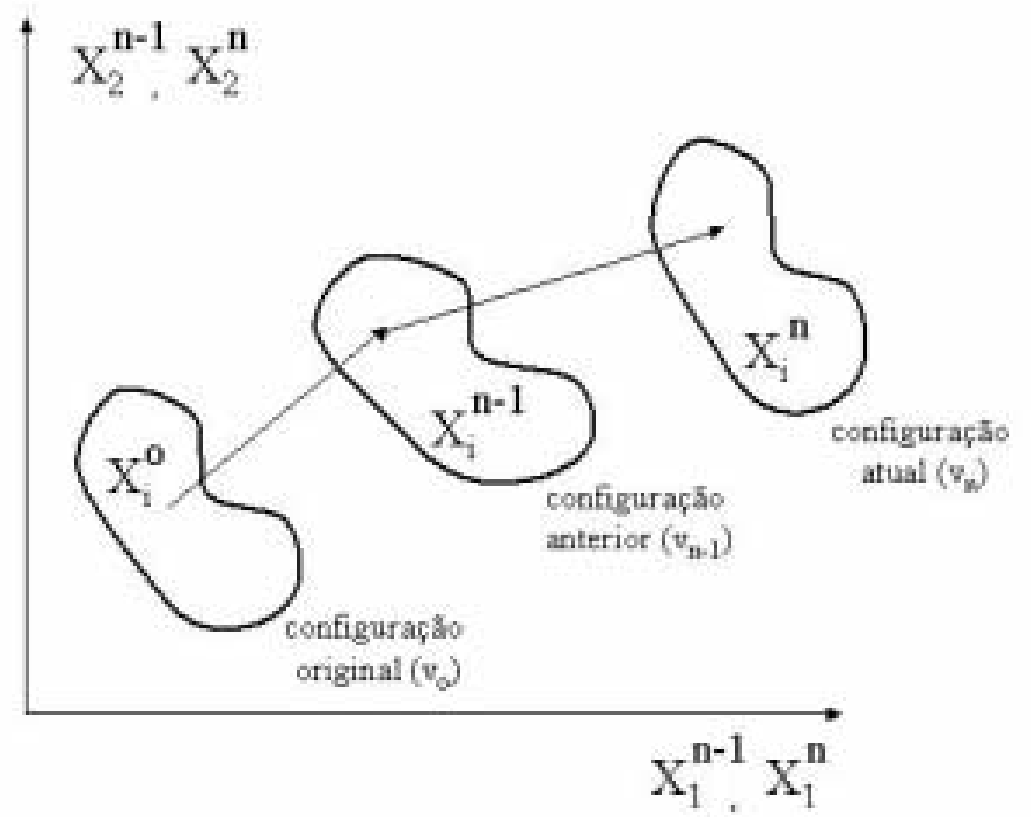

FIGURA 2.2.2-1 - Deformação de um corpo elástico num sistema cartesiano de coordenadas

Dentre os vários métodos numéricos existentes para solucionar problemas do contínuo, destaca-se o Método dos Elementos Finitos (MEF) por ser um dos mais utilizados. Sendo assim, considere um corpo elástico com uma configuração original $\mathrm{v}_{\mathrm{o}}$ que se deforma até a configuração atual $\mathrm{v}_{\mathrm{n}}$ a partir de uma configuração anterior $\mathrm{v}_{\mathrm{n}-1}$ (FIGURA 2.2.2-1). A equação de equilíbrio na forma variacional escrita para o passo atual $\left(\mathrm{P}=\mathrm{P}^{\mathrm{n}}\right)$ em termos da configuração anterior $\mathrm{V}_{\mathrm{n}-1}$ é dada por:

$$
\int_{v_{n-1}} S_{i j}^{n} \Delta E_{i j} d v-\int_{S_{\sigma}} \bar{T}_{i}^{n} \Delta u_{i} d a-\int_{S_{u}} S_{i j}^{n} n_{j} \Delta \bar{u}_{i} d a=0 \quad i, j=1,2
$$

onde:

$\mathrm{S}_{\mathrm{ij}}^{\mathrm{n}}=$ tensões de Piola-Kirchhoff no passo atual

$\Delta \mathrm{E}_{\mathrm{ij}}=$ incrementos de deformação de Green no passo atual

$\overline{\mathrm{T}}_{\mathrm{i}}^{\mathrm{n}}=$ tensões que atuam na superfície $\mathrm{S}_{\sigma}$ correspondente a $\mathrm{P}^{\mathrm{n}}$

$\Delta \mathrm{u}_{\mathrm{i}}=$ incremento de deslocamento

$\Delta \overline{\mathrm{u}}_{\mathrm{i}}=$ deslocamento prescrito na superfície $\mathrm{S}_{\mathrm{u}}$ na configuração $\mathrm{v}_{\mathrm{n}-1}$

$\mathrm{n}_{\mathrm{j}}=$ versor normal à superfície do corpo

As tensões podem ser expressas da seguinte forma: 


$$
\mathrm{S}_{\mathrm{ij}}^{\mathrm{n}}=\sigma_{\mathrm{ij}}^{\mathrm{n}-1}+\Delta \mathrm{S}_{\mathrm{ij}}
$$

Onde $\sigma_{\mathrm{ij}}^{\mathrm{n}-1}$ correspondem às tensões de Cauchy na configuração deformada $\mathrm{v}_{\mathrm{n}-1} \mathrm{e}$ $\Delta \mathrm{S}_{\mathrm{ij}}^{\mathrm{n}}$ são os incrementos de tensão de Kirchhoff da configuração $\mathrm{V}_{\mathrm{n}-1}$ para configuração $\mathrm{V}_{\mathrm{n}}$ em termos da configuração $\mathrm{v}_{\mathrm{n}-1}$.

Substituindo a equação (2.2.2-2) na equação (2.2.2-1) tem-se:

$$
\int_{v_{n-1}} \Delta S_{i j} \Delta E_{i j} d v=\int_{S_{\sigma}} \bar{T}_{i}^{n} \Delta u_{i} d a+\int_{S_{u}}\left(\sigma_{i j}^{n-1}+\Delta S_{i j}\right) \Delta \bar{u}_{i} d a-\int_{v_{n-1}} \sigma_{i j}^{n-1} \Delta E_{i j} d v
$$

Por outro lado, os incrementos de deformação de Green podem ser escritos da seguinte forma:

$$
\Delta \mathrm{E}_{\mathrm{ij}}=\Delta \mathrm{e}_{\mathrm{ij}}+\Delta \eta_{\mathrm{ij}}
$$

onde:

$$
\begin{aligned}
& \Delta \mathrm{e}_{\mathrm{ij}}=\frac{1}{2}\left(\Delta \mathrm{u}_{\mathrm{i}, \mathrm{j}}+\Delta \mathrm{u}_{\mathrm{j}, \mathrm{i}}\right) \\
& \Delta \eta_{\mathrm{ij}}=\frac{1}{2}\left(\Delta \mathrm{u}_{\mathrm{k}, \mathrm{i}} \Delta \mathrm{u}_{\mathrm{k}, \mathrm{j}}\right) \quad(\mathrm{i}, \mathrm{j}, \mathrm{k}=1,2)
\end{aligned}
$$

Onde $\mathrm{e}_{\mathrm{ij}}$ corresponde às tensões associadas às pequenas deformações ao passo que $\eta_{\mathrm{ij}}$ corresponde ao tensor das rotações associado às grandes deformações.

Combinando a equação (2.2.2-3) com (2.2.2-4), tem-se a chamada formulação Lagrangeana Atualizada para um dado problema:

$$
\begin{aligned}
& \int_{v_{n-1}} \Delta S_{i j} \Delta E_{i j} d v+\int_{v_{n-1}} \sigma_{i j}^{n-1} \Delta \eta_{i j} d v=\int_{S_{\sigma}} \bar{T}_{i}^{n} \Delta u_{i} d a+\int_{S_{u}}\left(\sigma_{i j}^{n-1}+\Delta S_{i j}\right) \Delta \bar{u}_{i} d a \\
& -\int_{v_{n-1}} \sigma_{i j}^{n-1} \Delta e_{i j} d v
\end{aligned}
$$

Para solucionar a equação acima, é necessário aplicar as relações constitutivas (relações tensão-deformação). Para tal, adota-se que o incremento de carga $\Delta \mathrm{P}$ deva ser pequeno o suficiente para que as relações tensão-deformação sejam tratadas como sendo 
lineares entre o passo de carga (n-1) e (n). Então a relação tensão-deformação incremental pode ser expressa como:

$$
\Delta \mathrm{S}_{\mathrm{ij}}=\mathrm{C}_{\mathrm{ijkl}}^{\mathrm{n}-1} \Delta \mathrm{E}_{\mathrm{kl}} \cong \mathrm{C}_{\mathrm{ijkl}}^{\mathrm{n}-1} \Delta \mathrm{e}_{\mathrm{kl}}
$$

Onde $\mathrm{C}_{\mathrm{j} j \mathrm{kl}}^{\mathrm{n}-1}$ é o tensor constitutivo que é função da matriz $[\overline{\mathrm{Q}}]^{\mathrm{n}-1}$ dada pela equação (2.2-5). Para representação da não-linearidade de material associada a ação das tensões de cisalhamento pode ser utilizada a relação estabelecida por Hahn e Tsai (1973):

$$
\gamma_{12}=\left(\frac{1}{G_{12}}\right) \sigma_{12}+\alpha \sigma_{12}^{3}
$$

$\mathrm{G}_{12}$ é o módulo de cisalhamento da lâmina e $\alpha$ é uma constante que pode ser determinada experimentalmente.

Finalmente, substituindo as relações constitutivas na equação (2.2.2-5), tem-se:

$$
\begin{aligned}
& \int_{v_{n-1}} \Delta \mathrm{e}_{\mathrm{kl}} \mathrm{C}_{\mathrm{ijkl}}^{\mathrm{n}-1} \Delta \mathrm{e}_{\mathrm{ij}} \mathrm{dv}+\int_{\mathrm{v}_{\mathrm{n}-1}} \sigma_{\mathrm{ij}}^{\mathrm{n}-1} \Delta \eta_{\mathrm{ij}} \mathrm{dv}=\int_{\mathrm{S}_{\sigma}} \overline{\mathrm{T}}_{\mathrm{i}}^{\mathrm{n}} \Delta \mathrm{u}_{\mathrm{i}} \mathrm{da}+\int_{\mathrm{S}_{\mathrm{u}}}\left(\sigma_{\mathrm{ij}}^{\mathrm{n}-1}+\Delta \mathrm{S}_{\mathrm{ij}}\right) \Delta \overline{\mathrm{u}}_{\mathrm{i}} \mathrm{da} \\
& -\int_{\mathrm{v}_{\mathrm{n}-1}} \sigma_{\mathrm{ij}}^{\mathrm{n}-1} \Delta \mathrm{e}_{\mathrm{ij}} \mathrm{dv}
\end{aligned}
$$

Com o incremento do carregamento $\mathrm{P}$, o material pode sofrer danificação, ao qual resulta em degradação das propriedades. Conseqüentemente as componentes da matriz $[\overline{\mathrm{Q}}]^{\mathrm{n}-1}$ são reduzidas de acordo com o tipo de dano ocorrido. Neste momento, um algoritmo de danificação/falha progressiva deve ser utilizado a fim de prever quando o dano ou a falha ocorre e o quanto deverá ser degradado. Uma vez ocorrido o dano, as tensões e deformações no laminado serão redistribuídas devido à redução das propriedades mecânicas, principalmente na vizinhança da região danificada. Sendo assim, após o processo de degradação das propriedades devido a um incremento de carga, a estrutura deverá restabelecer o equilíbrio com uma nova rigidez. Para tal, devese utilizar a equação de equilíbrio (2.2.2-8) com as propriedades de material atualizadas (degradadas). Porém, o alto grau de não-linearidade do problema faz com que a sua 
solução seja difícil. Neste momento, aplica-se uma estratégia numérica baseada no Método dos Elementos Finitos, onde a matriz de propriedades de material $\mathrm{C}_{\mathrm{ijkl}}^{\mathrm{n}-1}$ depende do estado de tensões e de deformações do passo em análise, tratando-se assim de um problema não-linear.

Em primeiro lugar, deve-se ressaltar que para solucionar problemas quaseestáticos não-lineares, recorre-se frequentemente a um método iterativo baseado em Newton-Raphson. Portanto, ao ser utilizado um elemento isoparamétrico de 8 nós, os incrementos de deslocamento $\Delta \mathrm{u}_{\mathrm{i}}$ e deformações $\Delta \mathrm{u}_{\mathrm{i}, \mathrm{j}}$ podem ser expressos da seguinte forma:

$$
\begin{array}{ll}
\Delta \mathrm{u}_{\mathrm{i}}=\mathrm{N}_{\alpha} \Delta \mathrm{q}_{\mathrm{i} \alpha} & (\alpha=1,8 \text { e } \mathrm{i}=1,2) \\
\Delta \mathrm{u}_{\mathrm{i}, \mathrm{j}}=\mathrm{N}_{\alpha, \mathrm{j}} \Delta \mathrm{q}_{\mathrm{i} \alpha} & (\alpha=1,8 \text { e } \mathrm{i}=1,2)
\end{array}
$$

Onde $\mathrm{N}_{\alpha}$ são as funções de forma do elemento finito escolhido e $\Delta \mathrm{q}_{\mathrm{i \alpha}}$ são os incrementos nodais de deslocamento. Substituindo as equações (2.2.2-9) e (2.2.2-10) em (2.2.2-8), obtém-se:

$$
\left[\mathrm{K}_{\mathrm{i} \beta \mathrm{k} \alpha}^{\mathrm{n}-1}\right] \Delta \mathrm{q}_{\mathrm{k} \alpha}=\mathrm{R}_{\mathrm{i} \beta}^{\mathrm{n}}-\mathrm{F}_{\mathrm{i} \beta}^{\mathrm{n}-1}
$$

onde:

$$
\begin{gathered}
{\left[\mathrm{K}_{\mathrm{i} \beta \mathrm{k} \alpha}^{\mathrm{n}-1}\right]=\int_{\mathrm{v}_{\mathrm{n}-1}} \mathrm{~N}_{\alpha, 1} \mathrm{C}_{\mathrm{ijkl}}^{\mathrm{n}-1} \mathrm{~N}_{\beta, j} \mathrm{dv}=\text { matriz de rigidez na configuração anterior (n-1) }} \\
\mathrm{R}_{\mathrm{i} \beta}^{\mathrm{n}}=\int_{\mathrm{S} \sigma} \bar{T}_{\mathrm{i}}^{\mathrm{n}} \mathrm{N}_{\beta} \mathrm{da}=\text { vetor de forças externas na configuração atual (n) } \\
\mathrm{F}_{\mathrm{i} \beta}^{\mathrm{n}-1}=\int_{v_{\mathrm{n}-1}} \sigma_{\mathrm{ij}}^{\mathrm{n}-1} \mathrm{~N}_{\beta, j} \mathrm{dv}=\text { vetor de forças internas nodais equivalente na } \\
\text { configuração anterior (n-1) }
\end{gathered}
$$

Desde que as propriedades de material $\mathrm{C}_{\mathrm{ijkl}}$ dependam das tensões e deformações na configuração atual, a equação (2.2.2-11) pode ser solucionada por um processo de iteração numérica:

$$
{ }^{(\mathrm{m}-1)}\left[\mathrm{K}_{\mathrm{i} \beta \mathrm{k} \alpha}\right] \Delta \mathrm{r}_{\mathrm{k} \alpha}=\mathrm{R}_{\mathrm{i} \beta}^{\mathrm{n}}-^{(\mathrm{m})} \mathrm{F}_{\mathrm{i} \beta}^{\mathrm{n}}
$$


Onde $\Delta \mathrm{r}_{\mathrm{k} \alpha}$ são pequenos incrementos nodais na m-ésima iteração que possuem a seguinte relação com $\Delta \mathrm{q}_{\mathrm{k} \alpha}$ :

$$
{ }^{(\mathrm{m})} \Delta \mathrm{q}_{\mathrm{k} \alpha}={ }^{(\mathrm{m}-1)} \Delta \mathrm{q}_{\mathrm{k} \alpha}+\Delta \mathrm{r}_{\mathrm{k} \alpha}
$$

Além disso, tem-se que:

$$
{ }^{(m)} F_{i \beta}^{n}=\int_{v_{n-1}}{ }^{(m)} \sigma_{i j}^{n} N_{\beta, j} d v
$$

Deve-se ressaltar que a iteração $(\mathrm{m})$ em cada incremento $(\mathrm{n})$ irá se repetir até que seja satisfeita a seguinte condição:

$$
\frac{\left|{ }^{(\mathrm{m}-1)} \Delta \mathrm{q}_{\mathrm{k} \alpha}\right|}{{ }^{(\mathrm{m})} \Delta \mathrm{q}_{\mathrm{k} \alpha}}<<\text { Tolerância }
$$

Assim, uma vez que o dano seja previsto por um determinado critério, as propriedades do material $\mathrm{C}_{\mathrm{ijkl}}$ devem ser reduzidas de acordo com um modelo de degradação das propriedades. Essa degradação das propriedades afetará a distribuição de tensões principalmente na vizinhança da região danificada. Essas tensões podem ser atualizadas utilizando novamente a iteração por Newton-Raphson desde que a matriz de propriedades de material seja novamente corrigida. Com isso, o procedimento será repetido até que nenhum dano adicional seja provocado por um dado nível de carregamento.

Conclui-se assim que uma análise estrutural, analítica ou numérica, capaz de prever de forma razoável o comportamento mecânico de um CPR, depende não somente da escolha de um Critério de Danificação/Falha e de uma Lei de Evolução de Dano/Falha, mas também da determinação precisa das propriedades elásticas bem como dos valores limites de resistência de uma lâmina ortotrópica. Sendo assim, no próximo capítulo serão apresentados e discutidos maiores detalhes sobre a fabricação e a realização de ensaios experimentais em compósitos poliméricos laminados. Os resultados experimentais obtidos serão utilizados pelo Modelo de Material proposto que deverá ser aplicado a uma simulação computacional de um teste de flexão 3-pontos. 
Comparando os resultados numéricos com os resultados experimentais, poder-se-á avaliar a capacidade do Modelo de Material proposto em representar de forma coerente os fenômenos físicos envolvidos, como mostra a FIGURA 2.2.2-2. Além disso, os resultados experimentais irão fornecer informações relevantes sobre o comportamento mecânico da amostra em material compósito polimérico frente a um dado tipo de solicitação.

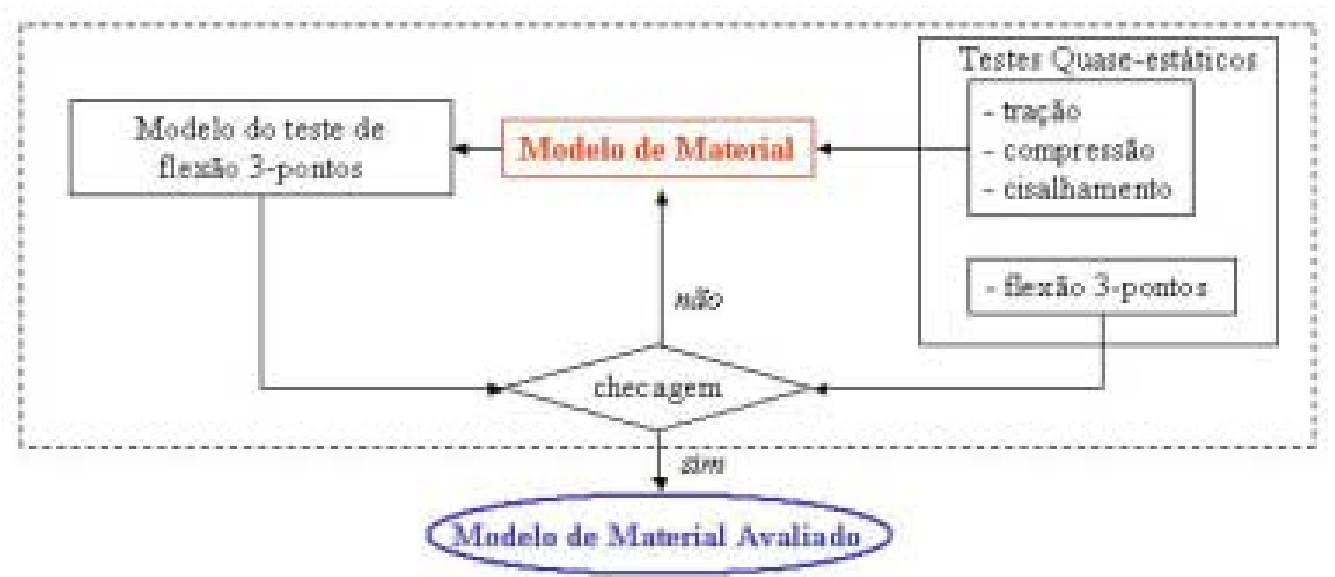

FIGURA 2.2.2-2 - Procedimento de avaliação do Modelo de Material

Deve-se destacar ainda que o Modelo de Material proposto deverá ser avaliado de forma análoga, utilizando um teste de endentação bem como um teste de impacto. 


\section{Capítulo 3}

\section{MATERIAIS E MÉTODOS}

\subsection{MATERIAIS COMPÓSITOS POLIMÉRICOS}

O material empregado para fabricação dos corpos-de-prova utilizados neste trabalho, consiste de fibras unidirecionais pré-impregnadas com resina ("pregreg") e comumente é encontrado em bobinas (FIGURA 3.1-1(a)). Optou-se por fibra de carbono impregnada com resina epóxi (resina termofixa) devido à ampla aplicação deste tipo de material na indústria aeronáutica. Vale ressaltar que o reforço unidirecional possibilita o empilhamento de lâminas formando assim um laminado com reforços multi-direcionais (FIGURA 3.1-1(b)). Posteriormente, neste mesmo capítulo, serão descritos todos os procedimentos experimentais necessários para a obtenção dos principais parâmetros associados a uma lâmina unidirecional do material.

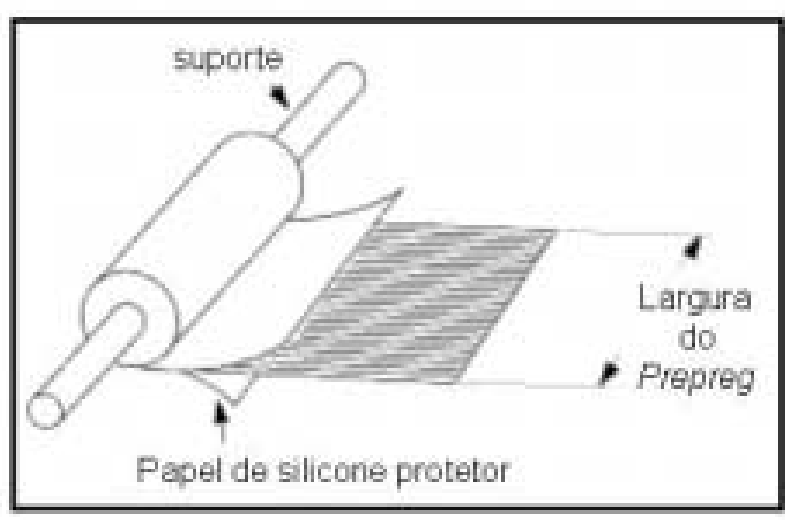

(a)

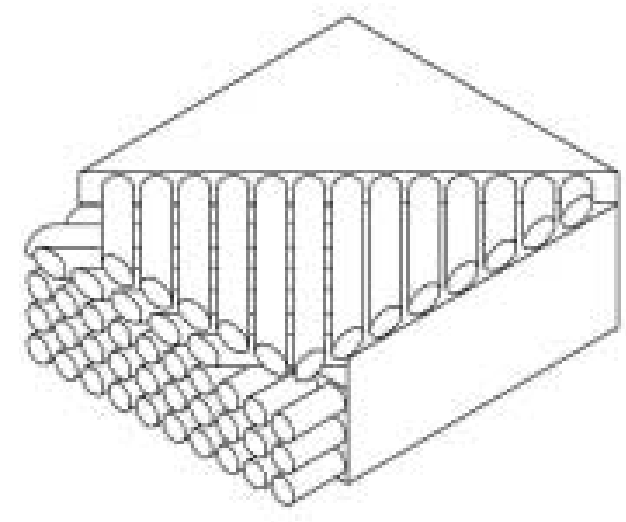

(b)

FIGURA 3.1-1 - Tecido pré-impregnado (“prepreg”):

(a) Bobina de "prepreg"; (b) Empilhamento de lâminas unidirecionais 
A escolha do "prepreg" baseou-se na busca de um material que pudesse gerar, juntamente com o processo de fabricação, corpos-de-prova capazes de fornecer resultados experimentais consistentes com o intuito de avaliar o modelo de material proposto. Segundo a literatura e de acordo com informações de muitos fabricantes de material compósito (Hexcel ${ }^{\circledR}$ e SP-Systems ${ }^{\circledR}$ ), os “prepregs" são considerados excelentes materiais, fornecendo propriedades atrativas não somente para a indústria aeronáutica mas também para o setor aeroespacial.

Para o presente trabalho, utilizou-se um "prepreg" fabricado pela empresa Hexcel $^{\circledR}$, sendo o mesmo conhecido como M9/M10 www.hexcel.com. Tal material possui alta versatilidade quanto à fabricação, pois pode ser moldado sob baixa pressão, entre 0,3 bar $(0,03 \mathrm{MPa})$ e 5 bar $(0,5 \mathrm{MPa})$, e com temperaturas que variam de $85{ }^{\circ} \mathrm{C}$ a $150{ }^{\circ} \mathrm{C}$. Segundo seu fabricante, o material M10 foi desenvolvido para componentes industriais de grande porte que venham ser submetidos a severas condições ambientais, tal como pás de turbinas. Além disso, o M10 possui alta resistência à fadiga e bom acabamento superficial. No entanto, deve-se ressaltar que como todo "prepreg", o fabricante aconselha armazená-lo a $-18{ }^{\circ} \mathrm{C}$, por um prazo máximo de 12 meses.

\subsection{FABRICAÇÃO DAS AMOSTRAS}

Foram utilizadas normas técnicas desenvolvidas pela American Society for Testing and Materials (ASTM) tanto para a fabricação dos corpos-de-prova como para todos os ensaios experimentais. Sendo assim, optou-se por fabricar os corpos-de-prova e realizar os ensaios num centro de pesquisa que possuísse equipamentos adequados e uma certa experiência em avaliar o comportamento mecânico de compósitos poliméricos reforçados. Para tal, foi escolhido o Leuven Composites Processing Centre (LCPC) constituído por professores e pesquisadores dos Departamentos de Engenharia Mecânica e de Materiais da Katholieke Universiteit Leuven (KU Leuven).

O processo de fabricação dos "prepregs" M10 está intimamente associado com o ciclo de cura da resina epóxi. Segundo a Hexcel $^{\circledR}$, o ciclo de cura ideal para o M10 é atingido quando o material é processado a $120^{\circ} \mathrm{C}$, sob uma pressão que varia entre $0,3 \mathrm{e}$ 5 bar durante 60 minutos. A TABELA 3.2-1 mostra algumas informações relacionadas à resina epóxi, após o ciclo de cura ideal ter sido realizado. 
TABELA 3.2-1 - Propriedades, valores de resistência e de deformação da resina epóxi do M10 para o ciclo de cura ideal $\left(\right.$ Hexcel $\left.^{\circledR}\right)$

\begin{tabular}{cc}
\hline Informação sobre a Resina Epóxi do M10 & Valor \\
\hline Resistência à tração & $85 \mathrm{MPa}$ \\
Módulo de elasticidade à tração & $3,2 \mathrm{GPa}$ \\
Limite máximo de deformação & $3,75 \%$ \\
Resistência à flexão & $136 \mathrm{MPa}$ \\
Módulo de elasticidade à flexão & $3,16 \mathrm{GPa}$ \\
Densidade da resina curada & $1,2 \mathrm{~g} / \mathrm{cm}^{3}$ \\
\hline
\end{tabular}

De acordo com a Hexcel ${ }^{\circledR}$, outros ciclos de cura podem ser empregados sem que haja alteração do desempenho da estrutura que será obtida. Caso a pressão seja mantida entre 0,3 e 5 bar pode-se utilizar os valores de temperatura e tempo da TABELA 3.2-2.

TABELA 3.2-2 - Alternativas de ciclo de cura para o M10 (Hexcel ${ }^{\circledR}$ )

\begin{tabular}{cc}
\hline Temperatura $\left[{ }^{\mathbf{0}} \mathbf{C}\right]$ & Tempo \\
\hline 85 & 12 a 16 horas \\
95 & 6 horas \\
110 & 4 horas \\
130 & 45 minutos \\
140 & 30 minutos \\
150 & 10 minutos \\
\hline
\end{tabular}

Dessa forma, optou-se por seguir as recomendações do fabricante a fim de obter corpos-de-prova que viessem fornecer resultados experimentais consistentes com o intuito final de avaliar o modelo de material proposto. No entanto, antes da aplicação do ciclo de cura pré-estabelecido pelo fabricante do material, há toda uma fase de preparação, que vai desde o corte do tecido pré-impregnado até a vedação completa do sistema para garantir a eficiência da ação do vácuo. Todas essas etapas fazem parte da Fase de Laminação e estão descritas a seguir:

1) Limpar a superfície do molde com acetona e posteriormente aplicar um agente desmoldante; 
2) Aplicar uma camada de tecido de nylon ("peel ply") sobre o molde. Atentar-se para manter o tecido completamente esticado;

3) Empilhar as camadas de "prepreg" de acordo com o que foi especificado;

4) Aplicar uma camada de tecido de nylon ("peel ply") sobre as lâminas empilhadas;

5) Aplicar um filme desmoldante de teflon;

6) Colocar um tecido absorvente ("breather") sobre o filme desmoldante de teflon a fim de que o mesmo venha reter o excesso de resina durante a moldagem;

7) Aplicar novamente um filme desmoldante de teflon para garantir que a resina não irá aderir à bolsa de vácuo;

8) Colocar novamente um tecido absorvente ("breather") sobre o filme desmoldante de teflon, garantindo assim a absorção da resina;

9) Montar uma bolsa de vácuo, envolvendo todos os itens descritos acima. Tal bolsa deve possuir um pequeno furo onde será ajustado um bico que conectará uma mangueira a uma bomba de vácuo;

10) Vedar as bordas da bolsa de vácuo a fim de garantir a eficiência da ação do mesmo.

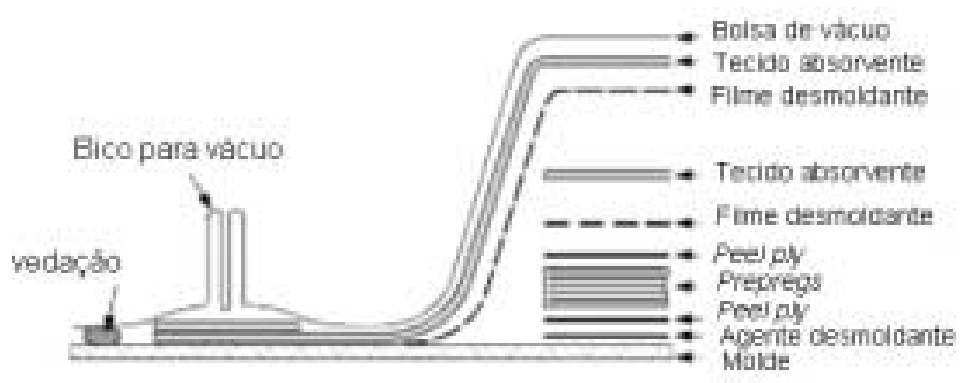

FIGURA 3.2-1 - Fase de preparação para efetuar moldagem do prepreg

A FIGURA 3.2-1 apresenta todo o sistema montado, ou seja, o conjunto preparado para ser levado para a auto-clave. No entanto, vale destacar que antes do fechamento da auto-clave, aplica-se cerca de -0,8 bar (-0,08 MPa) com auxílio da bomba de vácuo.

Após a Fase de Laminação (preparação) e com o sistema sob vácuo, segue-se para a Fase de Moldagem (cura), aplicando pressão e temperatura de acordo com as especificações fornecidas pelo fabricante do material. O LCPC da KU Leuven dispõe de uma auto-clave controlada computacionalmente que permite fazer rampas de aquecimento a uma taxa de $3^{\circ} \mathrm{C} / \mathrm{min}$ e rampas de resfriamento a uma taxa de $2^{\circ} \mathrm{C} / \mathrm{min}$, 
podendo atingir uma temperatura máxima de $180^{\circ} \mathrm{C}$. Por outro lado, quanto aos limites de pressão e vácuo tem-se respectivamente 8 bar (0,8 MPa) e -0,8 bar (-0,08 MPa).

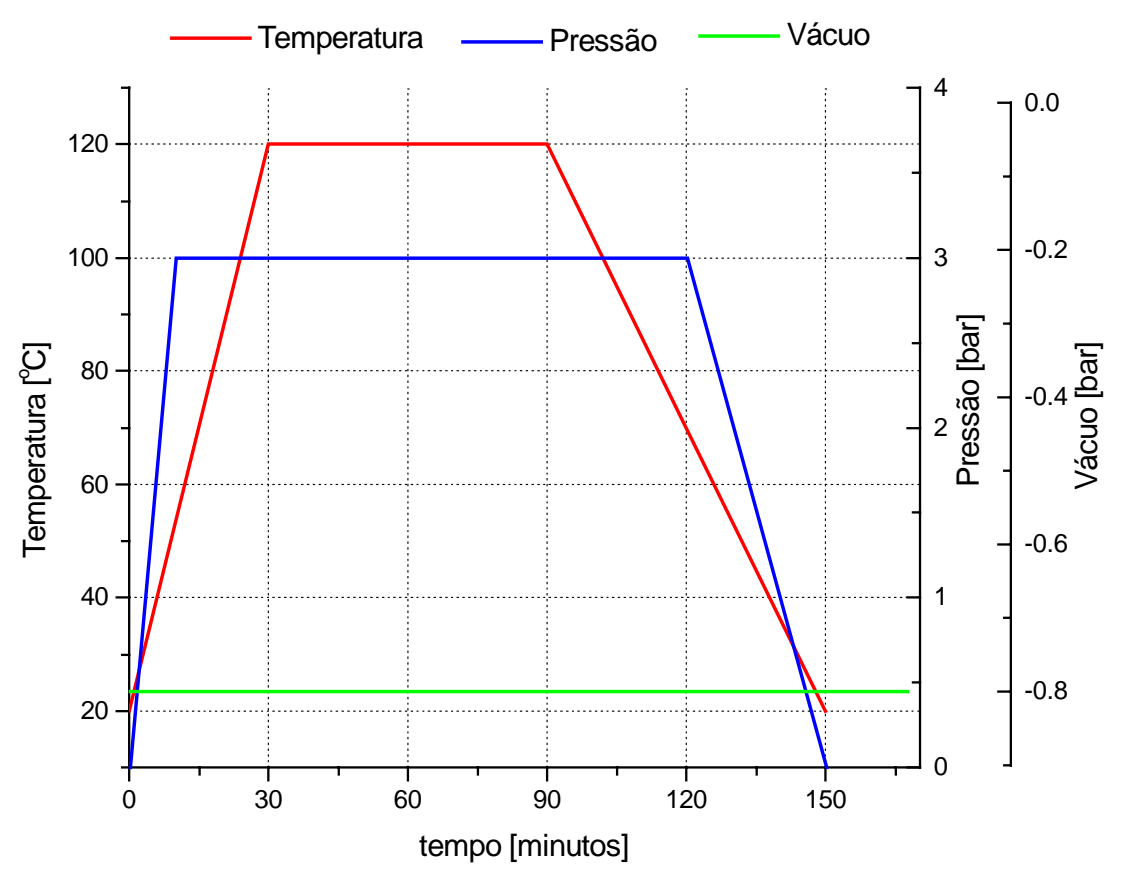

FIGURA 3.2-2 - Ciclo de cura ideal para o M10 $\left(\right.$ Hexcel $\left.^{\circledR}\right)$

Considerando que a temperatura ambiente esteja por volta dos $20{ }^{\circ} \mathrm{C}$, demora-se cerca de 30 minutos para que se atinja os $120^{\circ} \mathrm{C}$ desejados. Neste instante, a viscosidade da resina é mínima, mas por outro lado, as reações químicas de intercruzamento já iniciaram durante a fase de aquecimento. Dessa forma, é de fundamental importância manter por 60 minutos a resina sob o patamar dos $120^{\circ} \mathrm{C}$ a fim de que não haja degradação do material por exotermia (CARLSSON; PIPES, 1987). Durante esses 60 minutos, aplica-se uma pressão de 3 bar (0,3 MPa), visando assim, expulsar o excesso de resina e compactar o laminado (FIGURA 3.2-2). Vale ressaltar que antes de ligar a auto-clave, colocou-se o sistema sob a ação de $-0,8$ bar (-0,08 $\mathrm{MPa})$ de vácuo para eliminar possíveis bolhas que viessem a se formar com o aquecimento da resina. Devese destacar também que a pressão é mantida durante a fase de resfriamento do equipamento para garantir a forma do laminado compactado. Somente após o resfriamento do equipamento é que a pressão pode ser reduzida, e então o molde pode ser retirado da auto-clave. Finalmente, após 150 minutos, pode-se remover as placas curadas da auto-clave (FIGURA 3.2-2). 
TABELA 3.2-3 - Corpos-de-prova obtidos utilizando o “prepreg” M10 (Hexcel ${ }^{\circledR}$ ) ( $\mathrm{L}=$ comprimento; $\mathrm{W}=$ largura; $\mathrm{H}=$ espessura)

\begin{tabular}{|c|c|c|c|c|}
\hline Norma & $\begin{array}{c}\text { Sequência de } \\
\text { Empilhamento }\end{array}$ & $\begin{array}{c}\mathbf{L} \\
{[\mathrm{mm}]}\end{array}$ & $\begin{array}{c}\mathrm{W} \\
{[\mathrm{mm}]}\end{array}$ & $\begin{array}{c}\mathbf{H} \\
{[\mathrm{mm}]}\end{array}$ \\
\hline \multicolumn{5}{|c|}{ Amostras para Ensaios Quase-Estáticos } \\
\hline \multirow{2}{*}{ D3039 } & {$[0]_{5}$} & 250 & 15 & 0,9 \\
\hline & {$[90]_{5}$} & 175 & 25 & 0,9 \\
\hline \multirow{2}{*}{ D3410 } & {$[0]_{15}$} & 150 & 10 & 2,4 \\
\hline & {$[90]_{15}$} & 150 & 25 & 2,3 \\
\hline D3518 & {$[+45 /-45]_{4 \mathrm{~s}}$} & 250 & 25 & 2,7 \\
\hline \multirow{4}{*}{$\begin{array}{c}\mathrm{D} 790 \\
\left(\operatorname{span}^{(*)} / \mathrm{H}=32\right)\end{array}$} & {$[0]_{10}$} & 80 & 25 & 1,8 \\
\hline & {$[90]_{10}$} & 80 & 25 & 1,8 \\
\hline & {$[0 / 90 / 0 / 90 / 0]_{\mathrm{s}}$} & 80 & 25 & 1,8 \\
\hline & {$[+45 /-45 /+45 / 0 / 90]_{\mathrm{s}}$} & 80 & 25 & 1,8 \\
\hline \multirow{4}{*}{$\begin{array}{c}\mathrm{D} 2344 \\
\left(\operatorname{span}^{(*)} / \mathrm{H}=4\right)\end{array}$} & {$[0]_{14}$} & 14 & 12,5 & 2,4 \\
\hline & {$[90]_{14}$} & 14 & 12,5 & 2,3 \\
\hline & {$[0 / 90 / 0 / 90 / 0 / 90 / 0]_{\mathrm{s}}$} & 14 & 12,5 & 2,4 \\
\hline & {$\left[+45 /-45 /+45 / 0_{2} / 90_{2}\right]_{\mathrm{s}}$} & 14 & 12,5 & 2,3 \\
\hline \multirow{3}{*}{$\begin{array}{l}\text { Endentação } \\
\text { (Método FD) }\end{array}$} & {$[0]_{10}$} & 120 & 120 & 1,8 \\
\hline & {$[0 / 90 / 0 / 90 / 0]_{\mathrm{s}}$} & 120 & 120 & 1,8 \\
\hline & {$[+45 /-45 /+45 / 0 / 90]_{\mathrm{s}}$} & 120 & 120 & 1,8 \\
\hline \multicolumn{5}{|c|}{ Amostras para Ensaios Dinâmicos } \\
\hline \multirow{3}{*}{$\begin{array}{c}\text { D5628 } \\
\text { (Método FD) }\end{array}$} & {$[0]_{10}$} & 120 & 120 & 1,8 \\
\hline & {$[0 / 90 / 0 / 90 / 0]_{\mathrm{s}}$} & 120 & 120 & 1,8 \\
\hline & {$[+45 /-45 /+45 / 0 / 90]_{\mathrm{s}}$} & 120 & 120 & 1,8 \\
\hline
\end{tabular}

(*) O span é definido como sendo a distância entre os apoios do teste de flexão

A última etapa consiste em cortar as amostras de acordo com as dimensões especificadas pelas normas descritas pela American Society for Testing and Materials (ASTM). Para tal etapa, utiliza-se uma ferramenta adiamantada ("diamond saw") a fim de garantir a precisão do corte, atingindo assim, as tolerâncias especificadas pelas normas. Vale ressaltar que foram fabricados em média dez corpos-de-prova para cada tipo de ensaio com uma dada sequiência de empilhamento. 
$\mathrm{Na}$ TABELA 3.2-3 é possível verificar as dimensões e seqüências de empilhamento de todos os corpos-de-prova que foram fabricados através da tecnologia descrita anteriormente.

\subsection{ENSAIOS QUASE-ESTÁTICOS}

Os primeiros ensaios quase-estáticos (tração, compressão, cisalhamento e flexão) seguiram as normas da American Society for Testing and Materials (ASTM) e foram importantes para a determinação das propriedades elásticas e dos valores de resistência do "prepreg" M10.

Segundo Carvalho (1996), há algumas particularidades relacionadas aos ensaios mecânicos em compósitos, tais como:

1. Os ensaios mecânicos que são realizados para a determinação de propriedades mecânicas dos materiais bem como para determinação dos valores de resistência mecânica estão fundamentados em conceitos básicos de mecânica. Tais conceitos são aplicados satisfatoriamente para materiais elásticos, homogêneos e isótropos. Entretanto, os materiais compósitos poliméricos reforçados (CPR) possuem heterogeneidade, anisotropia e muitas vezes comportamento inelástico, dificultando assim, a aplicação de tais conceitos;

2. Surgem grandes dificuldades na execução dos ensaios tais como:

$\checkmark$ influência de efeitos de borda ("end-effects") que geram regiões de concentração de tensão próximas às arestas da amostra;

$\checkmark$ aplicação de níveis de carregamento adequados sem causar falhas prematuras ao material;

$\checkmark$ utilização de dimensões apropriadas (em particular espessura) em relação à escala de heterogeneidade do material;

3. A anisotropia também propicia alguns problemas, tais como:

$\checkmark$ agrava os efeitos de borda ("end-effects"), que dependem da geometria da amostra e do grau de anisotropia;

$\checkmark$ promove falhas prematuras em regiões do corpo de prova que estão próximas às fixações;

$\checkmark$ promove delaminações prematuras em arestas vivas ("free edges"), gerando assim a formação de outros mecanismos de falha; 
4. Os testes em compósitos são de alto custo, pois:

$\checkmark$ geralmente os materiais compósitos são caros;

$\checkmark$ a fabricação de amostras demanda atenção meticulosa a detalhes;

5. Em determinados casos, as normas tradicionais (ASTM, ISO, DIN, etc.) podem ser bastante adequadas; enquanto que em outros, podem ser totalmente impróprias.

$\mathrm{Na}$ literatura é possível encontrar mais uma gama de comentários com relação à execução de ensaios mecânicos em compósitos. Muitas vezes, pequenos detalhes durante a fabricação ou durante os testes podem levar a resultados totalmente inconsistentes.

Inicialmente, deve-se destacar que antes da realização dos ensaios experimentais, determinou-se a fração volumétrica de fibra dos "prepregs" fabricados $\left(\mathrm{V}_{\mathrm{f}}\right)$ que pode ser obtida através da Massa Regional do mesmo, dada por:

$$
\mathrm{W}_{\text {regional }}=\frac{\mathrm{M}_{\mathrm{fs}}}{\mathrm{W}_{\mathrm{f}}}
$$

onde:

$\mathrm{M}_{\mathrm{fs}}=$ massa de fibra a seco (“dry fiber weight”) por unidade de área

$\mathrm{W}_{\mathrm{f}}=$ fração mássica de fibra

No entanto, a Massa Regional também pode ser calculada através da espessura de cada camada multiplicada pela densidade do compósito:

$$
\mathrm{W}_{\text {regional }}=\mathrm{t}_{\mathrm{c}} \rho_{\mathrm{c}}
$$

onde:

$$
\begin{aligned}
& t_{c}=\text { espessura da camada } \\
& \rho_{c}=\text { densidade do compósito }
\end{aligned}
$$

Além disso, tem-se que a fração volumétrica de fibra é dada por:

$$
\mathrm{V}_{\mathrm{f}}=\frac{\rho_{\mathrm{c}}}{\rho_{\mathrm{f}}} \mathrm{W}_{\mathrm{f}}
$$


onde:

$$
\rho_{\mathrm{f}}=\text { densidade da fibra }
$$

Igualando (3.3-1) com (3.3-2), isolando $\mathrm{W}_{\mathrm{f}}$ e substituindo em (3.3-3) tem-se:

$$
\mathrm{V}_{\mathrm{f}}=\frac{\mathrm{M}_{\mathrm{fs}}}{\rho_{\mathrm{f}} \mathrm{t}_{\mathrm{c}}}
$$

Aplicando a equação (3.3-4) para vários tipos de corpos-de-prova, chega-se em alguns valores de fração volumétrica que são apresentados na TABELA 3.3-1. Vale ressaltar que o valor de massa de fibra a seco (“dry fiber weight") por unidade de área $\left(\mathrm{M}_{\mathrm{fs}}\right)$ é igual a $200 \mathrm{~g} / \mathrm{m}^{2}$ e foi fornecido pela Hexcel ${ }^{\circledR}$. Além disso, o valor de densidade da fibra foi obtido da literatura, sendo considerado igual a $1,8 \mathrm{~g} / \mathrm{m}^{3}$.

TABELA 3.3-1 - Valores de fração volumétrica de fibra para alguns corpos-de-prova (“prepreg" M10 - Hexcel ${ }^{\circledR}$ )

\begin{tabular}{cccc}
\hline \multirow{2}{*}{ Teste } & $\begin{array}{c}\text { Sequência de } \\
\text { Empilhamento }\end{array}$ & $\begin{array}{c}\text { Espessura da Camada } \\
{[\mathbf{m m}]}\end{array}$ & $\mathbf{V}_{\mathbf{f}}[\boldsymbol{\%}]$ \\
\hline Tração & {$[0]_{5}$} & 0,18 & 62 \\
\hline Compressão & {$[0]_{15}$} & 0,17 & 65 \\
\hline Cisalhamento & {$[+45 /-45]_{4 \mathrm{~s}}$} & 0,17 & 65 \\
\hline \multirow{2}{*}{ Flexão 3-Pontos } & {$[0]_{10}$} & 0,17 & 65 \\
& {$[0 / 90 / 0 / 90 / 0]_{\mathrm{s}}$} & 0,18 & 62 \\
& {$[0]_{14}$} & 0,17 & 65 \\
& {$[0 / 90 / 0 / 90 / 0 / 90 / 0]_{\mathrm{s}}$} & 0,17 & 65 \\
\hline Impacto & {$[0]_{10}$} & 0,17 & 65 \\
& {$[0 / 90 / 0 / 90 / 0]_{\mathrm{s}}$} & 0,18 & 62 \\
& {$[+45 /-45 /+45 / 0 / 90]_{\mathrm{s}}$} & 0,18 & 62 \\
\hline
\end{tabular}

Diante dos resultados encontrados, optou-se assim, por escolher um valor médio de $63 \%$ que aplicado à Regra das Misturas forneceu um valor de $1,58 \mathrm{~g} / \mathrm{cm}^{3}$ para a densidade do compósito fabricado. Também através deste valor de fração volumétrica, pôde-se buscar na literatura informações sobre compósitos de resina epóxi reforçados 
com fibra de carbono unidirecional (TABELA 3.3-2). Tais informações foram extremamente importantes, pois auxiliaram na previsão dos resultados experimentais bem como na verificação da consistência dos mesmos.

TABELA 3.3-2 - Propriedades elásticas e valores de resistência mecânica para compósitos em resina epóxi reforçados com fibra de carbono unidirecional.

\begin{tabular}{|c|c|c|c|c|}
\hline \multirow{2}{*}{$\begin{array}{c}\text { Propriedades Elásticas } \\
\text { e } \\
\text { Valores de Resistência }\end{array}$} & \multirow{2}{*}{ Unidade } & \multicolumn{3}{|c|}{ Unidirecional } \\
\hline & & Valor ${ }^{(i)}$ & Valor $^{(i i)}$ & Valor $^{\text {(iii) }}$ \\
\hline \multicolumn{5}{|l|}{ Propriedades Elásticas } \\
\hline \multicolumn{5}{|l|}{ Módulo de elasticidade } \\
\hline paralelo à fibra ( $\left.\mathrm{E}_{11}\right)$ & $\mathrm{GPa}$ & 105,71 & 132 & 148 \\
\hline perpendicular à fibra $\left(E_{22}=E_{33}\right)$ & $\mathrm{GPa}$ & 8,57 & 10,3 & 9,65 \\
\hline Densidade $\left(\rho_{\mathrm{c}}\right)$ & $10^{3} \mathrm{~kg} / \mathrm{m}^{3}$ & - & 1,47 & - \\
\hline \multicolumn{5}{|l|}{ Módulo de Cisalhamento } \\
\hline para o plano $1-2\left(\mathrm{G}_{12}=\mathrm{G}_{13}\right)$ & $\mathrm{GPa}$ & 4,39 & 6,5 & 4,55 \\
\hline para o plano $2-3\left(\mathrm{G}_{23}\right)$ & $\mathrm{GPa}$ & 3,05 & - & - \\
\hline \multicolumn{5}{|l|}{ Coeficientes de Poisson } \\
\hline$v_{12}=v_{13}$ & - & 0,327 & 0,25 & 0,3 \\
\hline$v_{23}$ & - & 0,306 & - & - \\
\hline \multicolumn{5}{|l|}{ Valores de Resistência } \\
\hline \multicolumn{5}{|l|}{ Resistência paralela à fibra } \\
\hline sob tração $\left(X_{T}\right)$ & $\mathrm{MPa}$ & 2096 & 1240 & 1314 \\
\hline sob compressão $\left(\mathrm{X}_{\mathrm{C}}\right)$ & $\mathrm{MPa}$ & 1179 & 830 & 1220 \\
\hline \multicolumn{5}{|l|}{ Resistência perpendicular à fibra } \\
\hline sob tração $\left(\mathrm{Y}_{\mathrm{T}}\right)$ & $\mathrm{MPa}$ & 31 & 45 & 43 \\
\hline sob compressão $\left(\mathrm{Y}_{\mathrm{C}}\right)$ & $\mathrm{MPa}$ & - & 140 & 168 \\
\hline \multicolumn{5}{|l|}{ Resistência ao cisalhamento } \\
\hline no plano 1-2 $\left(\mathrm{S}_{12}=\mathrm{S}_{13}\right)$ & $\mathrm{MPa}$ & - & 62 & 48 \\
\hline no plano $2-3\left(\mathrm{~S}_{23}\right)$ & $\mathrm{MPa}$ & 89 & - & - \\
\hline Fração Volumétrica em Fibra $\left(\mathrm{V}_{\mathrm{f}}\right)$ & $\%$ & 60 & 60 & 60 \\
\hline
\end{tabular}

(i) Hexcel $^{\circledR}$ (prepreg M40J); (ii) (ENGINEERED MATERIALS HANDBOOK, 1987);

(iii) (TSAI, 1986) 


\subsubsection{Ensaios de Tração e Compressão}

\section{Ensaios de Traç̃o}

Esses ensaios foram realizados com a finalidade de obter os módulos de elasticidade e os valores limites de resistência e de deformação associados ao carregamento de tração. Os ensaios de tração seguiram algumas especificações da norma ASTM D3039/D3039M-95a. Os corpos-de-prova para as lâminas empilhadas a $0^{\circ}$ possuem largura igual a $15 \mathrm{~mm}$, comprimento igual a $250 \mathrm{~mm}$ e espessura igual a 0,9 mm (FIGURA 3.3.1-1(a)). Por outro lado, os corpos-de-prova com lâminas empilhadas a $90^{\circ}$, possuem largura igual a $25 \mathrm{~mm}$, comprimento igual a $175 \mathrm{~mm}$ e espessura igual a 0,9 mm (FIGURA 3.3.1-1(b)). Por fim, a velocidade para todos os testes foi igual a 1,0 $\mathrm{mm} / \mathrm{min}$.

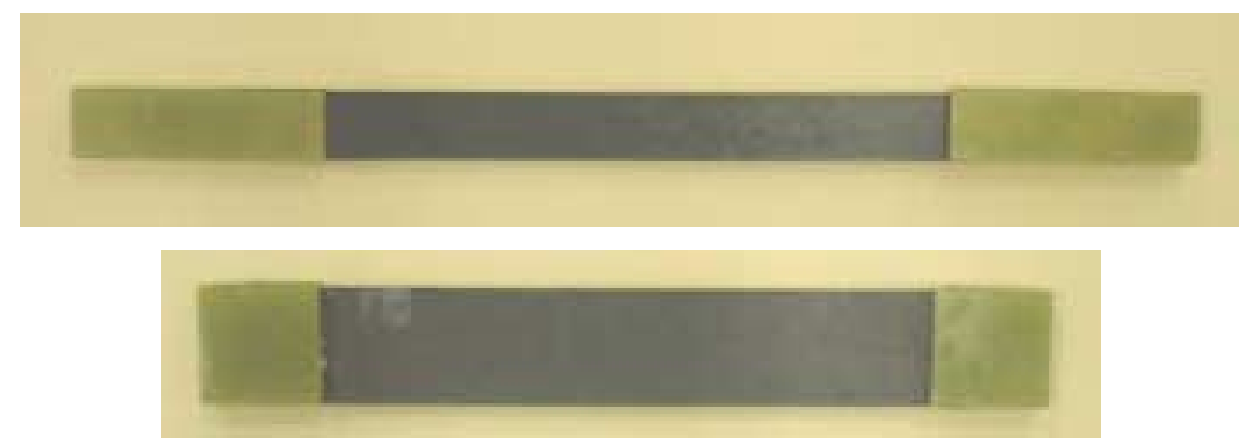

FIGURA 3.3.1-1 - Amostras para ensaios de tração:

(a) lâminas empilhadas a $0^{\circ}$; (b) lâminas empilhadas a $90^{\circ}$

Para o módulo de elasticidade paralelo à fibra $\left(\mathrm{E}_{11}\right)$ foi encontrado um valor igual a $127 \mathrm{GPa}$ através de amostras com as lâminas orientadas a $0^{\circ}$ e com o auxílio de um extensômetro. Nota-se no gráfico de tensão-deformação apresentado pela FIGURA 3.3.1-2(a) que próximo da tensão igual a $700 \mathrm{MPa}$ há uma certa perda de rigidez por parte do laminado que está sendo tracionado. Na verdade, isto indica o momento em que o extensômetro foi removido da amostra a fim de evitar a sua danificação. Por outro lado, a FIGURA 3.3.1-2(b) apresenta o gráfico tensão-deformação obtido através do deslocamento das garras (deslocamento do "cross head" da máquina). Nota-se que neste caso não há aquela falsa perda de rigidez identificada na FIGURA 3.3.1-2(a). Entretanto, o valor do módulo de elasticidade encontrado é menor (100 GPa), pois esta medida possui a influência da flexibilidade da máquina. 
Para a resistência à tração paralela à fibra $\left(\mathrm{X}_{\mathrm{T}}\right)$ foram especificados dois valores importantes (FIGURA 3.3.1-2(b)). O primeiro está relacionado com o valor último de resistência do laminado que chega a atingir $1940 \mathrm{MPa}$ após a falha completa do mesmo. O segundo valor demonstra que a curva tensão-deformação apresenta uma certa perda de linearidade devido a algumas falhas iniciais que ocorreram no laminado. Para maioria das amostras tem-se que este valor está próximo de 1400MPa.

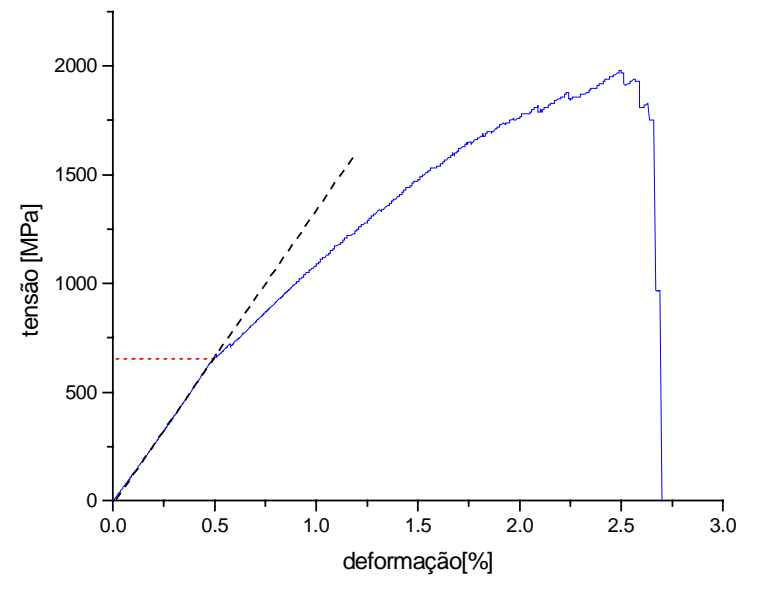

(a)

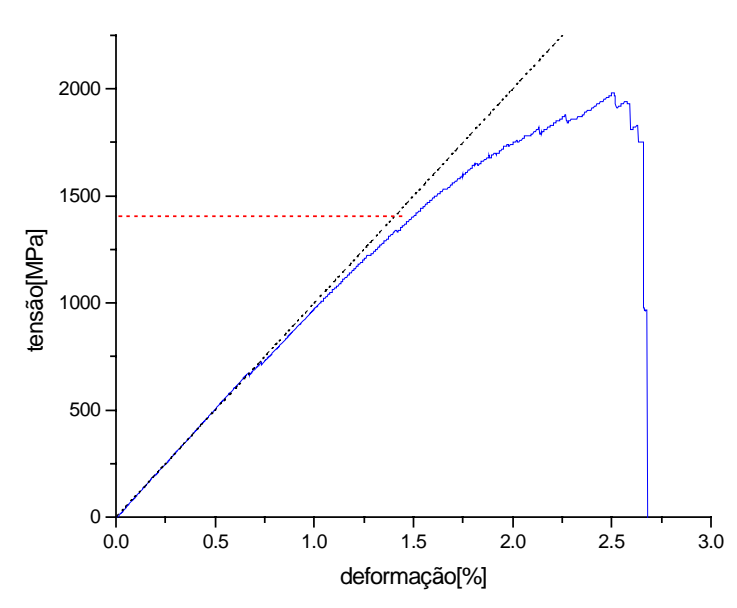

(b)

FIGURA 3.3.1-2 - Curvas tensão-deformação dos corpos-de-prova a $0^{\circ}$ sob teste de tração: (a) Gráfico obtido pelo extensômetro;

(b) Gráfico obtido pelo cross head da máquina

Para o módulo de elasticidade perpendicular à fibra $\left(E_{22}\right)$ foi encontrado um valor igual a 8,1 GPa através de amostras com as lâminas orientadas a $90^{\circ}$ e com o auxílio do “cross head" da máquina. Não foi possível utilizar extensômetros, pois as amostras rompiam rapidamente, impossibilitando assim a remoção do mesmo em tempo hábil. Sendo assim, é muito provável que o valor correto do módulo de elasticidade perpendicular à fibra seja maior. Além disso, nota-se no gráfico de tensão-deformação apresentado pelas FIGURAS 3.3.1-3(a) e 3.3.1-3(b) que as amostras falharam sob um nível de tensão muito baixo (entre $12 \mathrm{MPa}$ e $15 \mathrm{MPa}$ ). Entretanto, de acordo com a TABELA 3.3-2, as amostras deveriam falhar para um valor que fosse cerca de três a quatro vezes superior ao obtido. É importante destacar que a maioria das amostras fraturaram em regiões próximas do ponto de aplicação de carga (próximo das garras). Isto pode ser explicado através do Princípio de Saint-Venants associado ao efeito de 
borda ("end effects") que domina a resposta, provocando a ruptura da amostra. Sendo assim, a espessura utilizada não foi suficiente para evitar a falha prematura das mesmas.

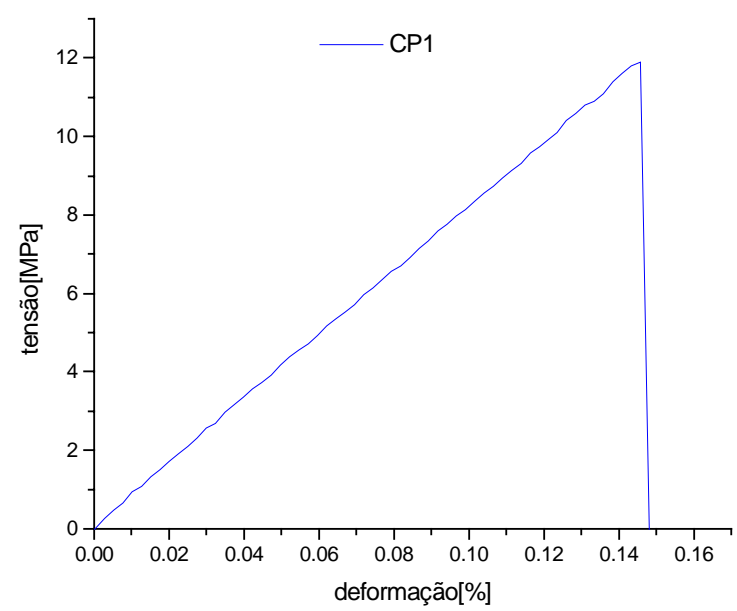

(a)

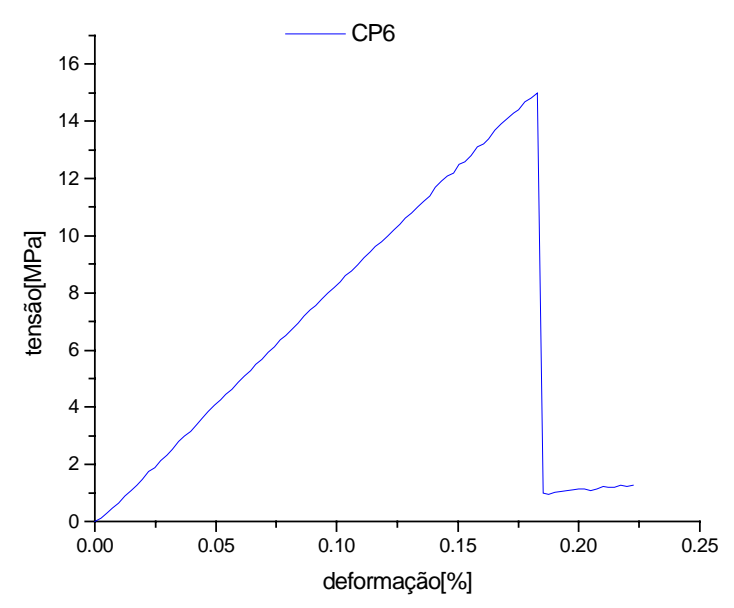

(b)

FIGURA 3.3.1-3 - Curvas tensão-deformação dos corpos-de-prova a $90^{\circ}$ sob teste de tração:(a) Corpo de prova número 1; (b) Corpo de prova número 6

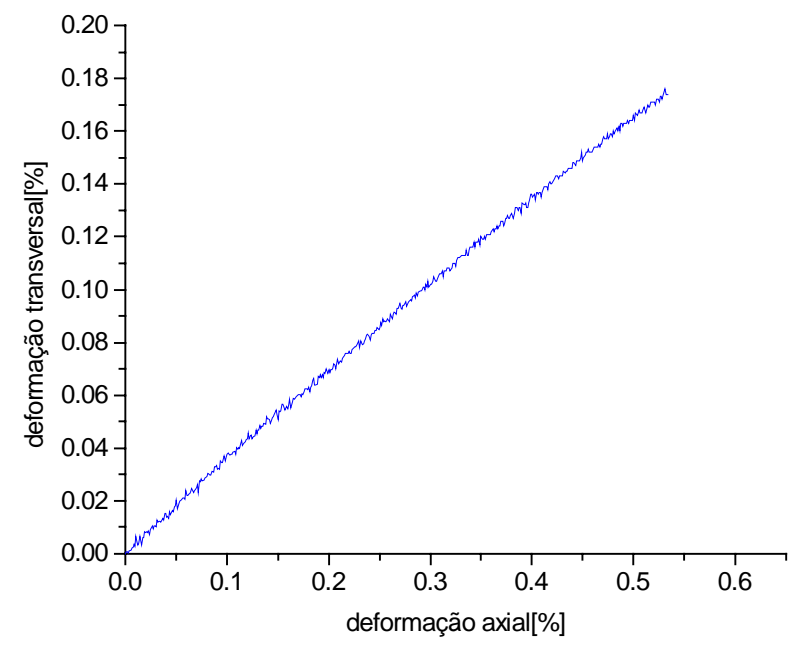

FIGURA 3.3.1-4 - Gráfico da deformação transversal em função da deformação axial

Para o coeficiente de Poisson $v_{12}$ foi encontrado um valor igual a 0,34 através de amostras com as lâminas orientadas a $0^{\circ}$ e com o auxílio de extensômetros colocados na direção axial e transversal ao carregamento aplicado (FIGURA 3.3.1-4). 


\section{Ensaios de Compressão}

Segundo Carlsson e Pipes (1987), quando os CPR são carregados sob compressão na direção da fibra, o modo de falha dominante é a flambagem local da fibra em uma pequena região da amostra que está sendo testada. Sendo assim, essa instabilidade das fibras acarreta a formação de uma zona de flambagem bem como a ocorrência de eventuais fraturamentos de algumas fibras (FIGURA 3.3.1-5(a)). Por outro lado, o carregamento de compressão na direção transversal às fibras produzirá falha por cisalhamento (FIGURA 3.3.1-5(b)).

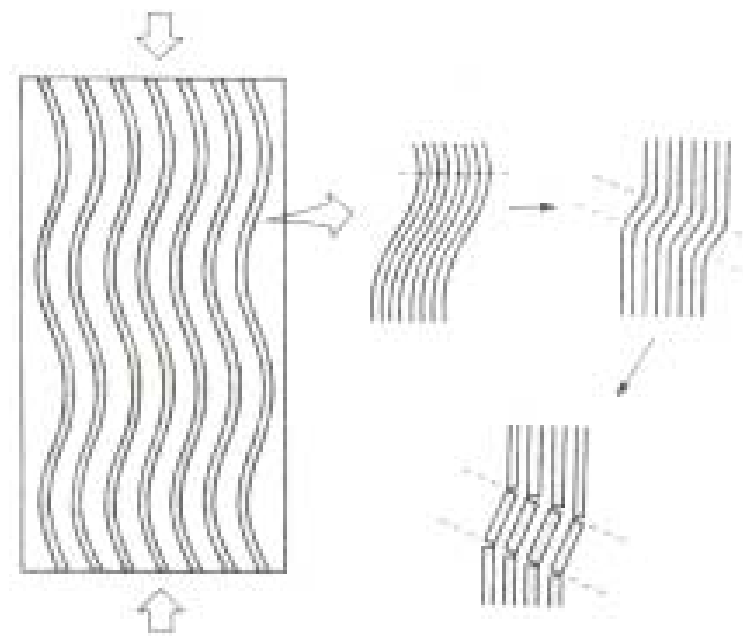

(a)

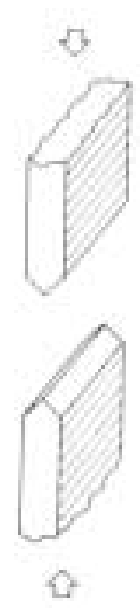

(b)

FIGURA 3.3.1-5 - Modos de falha de CPR a compressão:

(a) Flambagem local das fibras; (b) Falha por cisalhamento

(CARLSSON; PIPES, 1987)

Dessa forma, para que se possa determinar com precisão o comportamento mecânico sob compressão de um CPR, deve-se seguir as seguintes recomendações:

- Produzir amostras sem bolhas e com uma certa homogeneidade a fim de evitar a redução da resistência devido à concentrações de tensão;

- Garantir as tolerâncias de fabricação especificadas pela norma ASTM D3410/D3410M-95 a fim de evitar falhas causadas pela instabilidade global da amostra;

- Inibir as instabilidades localizadas por parte das fibras, ao qual constitui um fenômeno intrínseco ao material. 


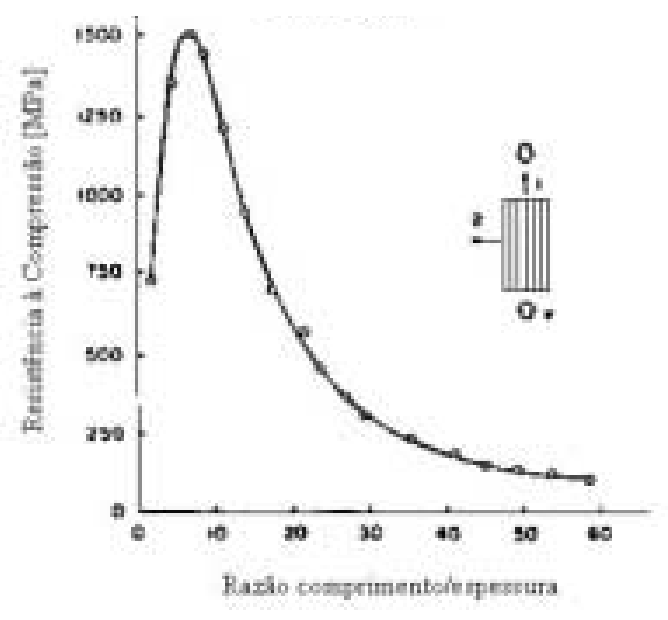

FIGURA 3.3.1-6 - Resistência à compressão em função da razão comprimento de flambagem pela espessura da amostra

(CARLSSON; PIPES, 1987)

Entretanto, atender todas essas recomendações simultaneamente, torna a determinação da resistência à compressão de um CPR uma tarefa muito difícil. Pequenos erros cometidos durante a fabricação das amostras, ou uma montagem inadequada da mesma no dispositivo de testes podem gerar carregamentos com um certo grau de excentricidade em relação ao eixo de simetria da amostra. Dessa forma, momentos fletores passam a atuar na estrutura, criando uma situação propícia para a ocorrência da instabilidade geométrica ao longo do comprimento (modo de flambagem mais favorável). Uma alternativa seria a utilização de amostras curtas, no entanto devese ter muito cuidado para evitar os efeitos provocados pela concentração de tensão devido à proximidade do engastamento em relação à região de interesse da amostra (região central). Nota-se pela FIGURA 3.3.1-6 que para valores elevados da razão comprimento de flambagem pela espessura da amostra tem-se uma falha das amostras sob uma tensão muito baixa devido à flambagem. Por outro lado, para valores menores dessa razão pode-se chegar a tensões de falha maiores. Entretanto, caso essa razão seja muito reduzida, a proximidade do engastamento passa ser importante. Este fenômeno da distância do engastamento é explicado pelo Princípio de Saint Venant, que demonstra a ocorrência de falha prematura da amostra devido às concentrações de tensão (CARLSSON; PIPES, 1987). 


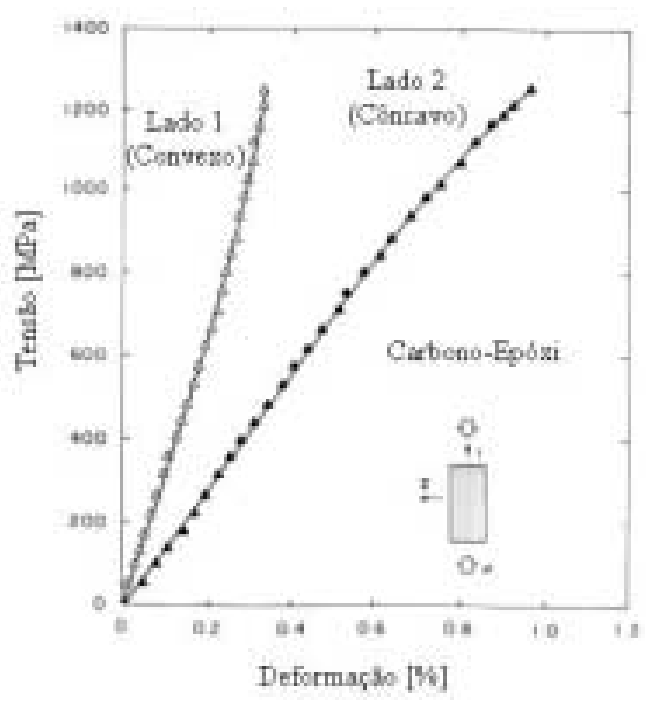

(a)

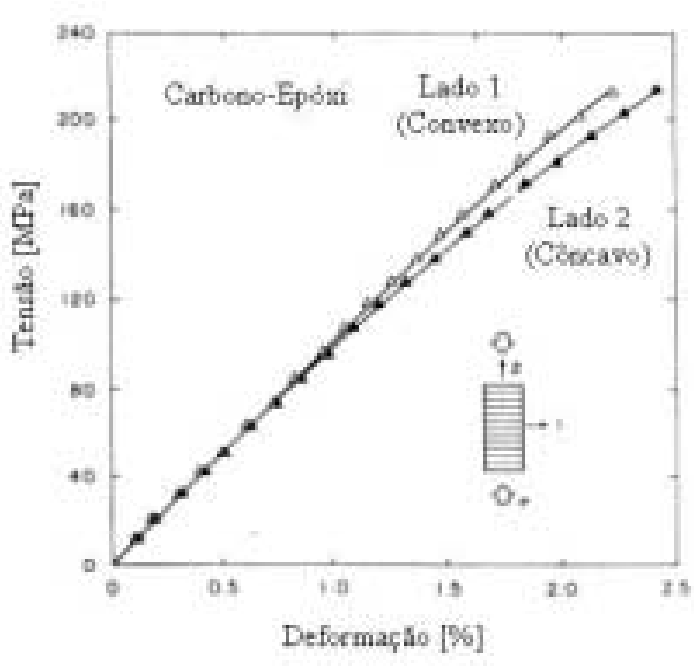

(b)

FIGURA 3.3.1-7 - Ensaios utilizando "strain gauges back-to-back": (a)Amostra carregada excentricamente; (b) Amostra carregada uniformemente (adaptado de Carlsson e Pipes (1987))

Dessa forma, para que os efeitos de excentricidade sejam detectados, torna-se necessária a colocação de "strain gauges back-to-back", ou seja, nos dois lados da amostra. A FIGURA 3.3.1-7(a) mostra a curva de tensão de compressão em função da deformação para uma amostra carregada excentricamente.Verifica-se que esse tipo de solicitação produz um carregamento combinado que é dado por uma compressão axial associada a uma flexão. Sendo assim, há uma superposição de efeitos que pode levar a uma falha sob uma tensão mais baixa ou mais alta, dependendo do lado da amostra que está sendo avaliado. Porém, a FIGURA 3.3.1-7(b) mostra a curva de tensão de compressão em função da deformação para uma amostra carregada uniformemente. Nota-se que as curvas medidas em ambos os lados pelos "strain gauges" são muito similares.

Diante do problema da excentricidade do carregamento nos testes de compressão, um grande número de dispositivos de fixação bem como de geometrias de amostras foram e ainda são desenvolvidos. Vários exemplos desses dispositivos podem ser encontrados na literatura (WHITNEY; DANIEL; PIPES, 1984). Dentre esses, um dos mais conhecidos é o teste de compressão IITRI desenvolvido pelo Illinois Institute of Technology Research Institute, onde as garras do dispositivo minimizam o problema de excentricidade dos carregamentos (FIGURA 3.3.1-8). No entanto, deve-se ressaltar que 
as variações na espessura da amostra não podem exceder $\pm 1 \%$. Além disso, deve-se garantir o paralelismo das arestas da amostra e principalmente o paralelismo dos "strain gauges" ao serem fixados.

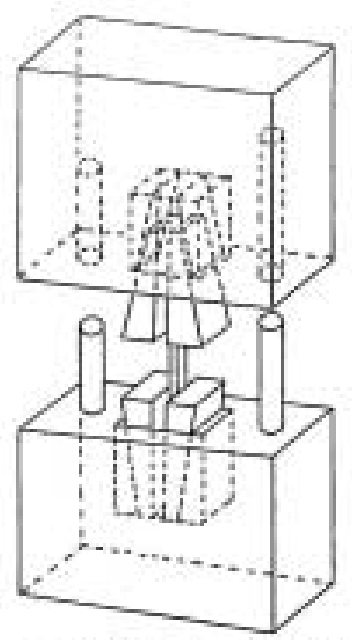

FIGURA 3.3.1-8 - Dispositivo IITRI para ensaio de compressão

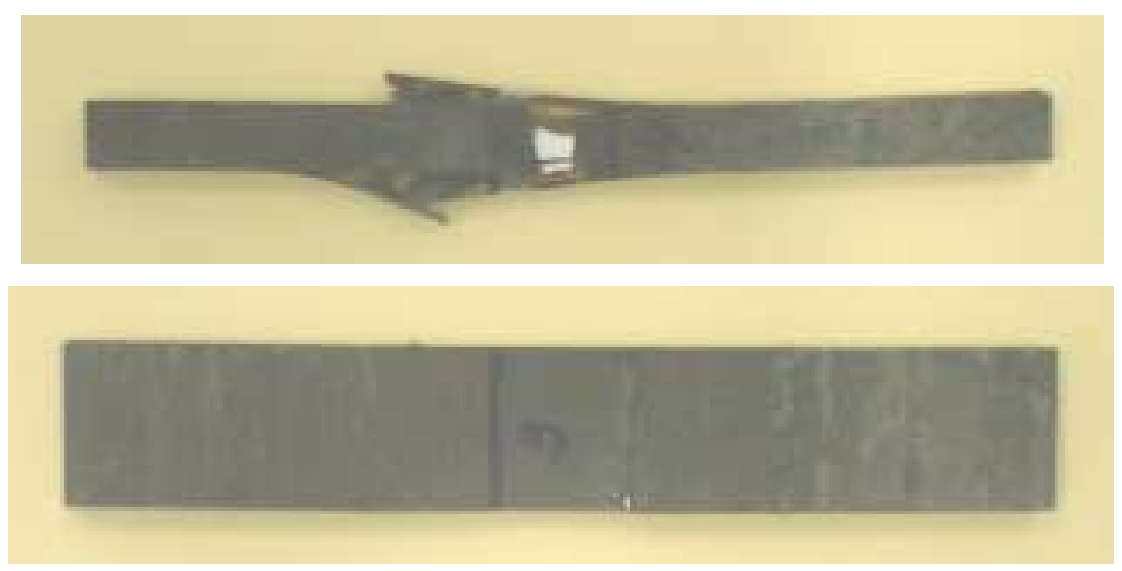

FIGURA 3.3.1-9 - Amostras para ensaios de compressão:

(a) lâminas empilhadas a $0^{\circ}$ (amostra fraturada com "strain-gauge");

(b) lâminas empilhadas a $90^{\circ}$

Neste ensaio, a velocidade de aplicação da carga deve ser igual a $1,5 \mathrm{~mm} / \mathrm{min}$ e os corpos-de-prova com lâminas empilhadas a $0^{\circ}$ possuem largura igual a $10 \mathrm{~mm}$, comprimento igual a $150 \mathrm{~mm}$ e espessura igual a 2,4 $\mathrm{mm}$. Por outro lado, os corpos-deprova com lâminas empilhadas a $90^{\circ}$ possuem largura igual a $25 \mathrm{~mm}$, comprimento igual a $150 \mathrm{~mm}$ e espessura igual a $2,3 \mathrm{~mm}$. 
Para o módulo de elasticidade paralelo à fibra sob compressão $\left(\mathrm{E}_{11 \mathrm{c}}\right)$ foi encontrado, entre as amostras com as lâminas orientadas a $0^{\circ}$, um valor máximo de 154,36 GPa e um valor mínimo de 111,24 GPa.

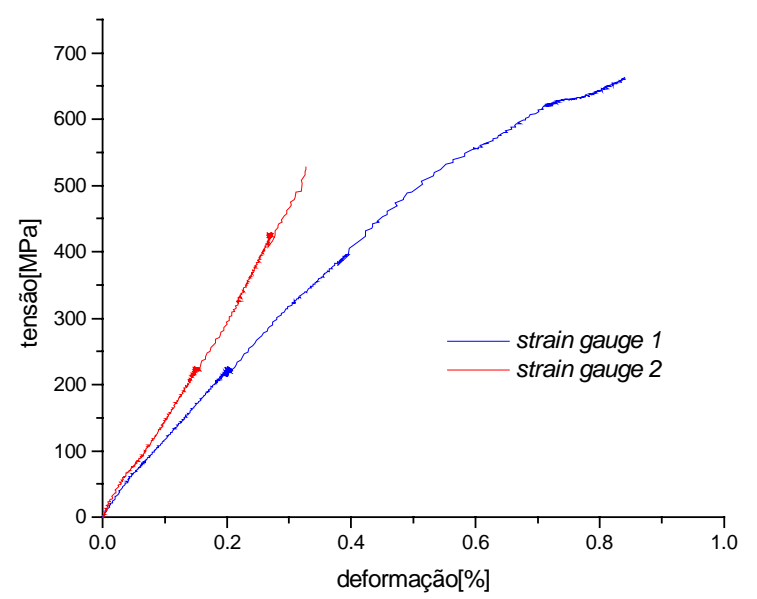

(a)

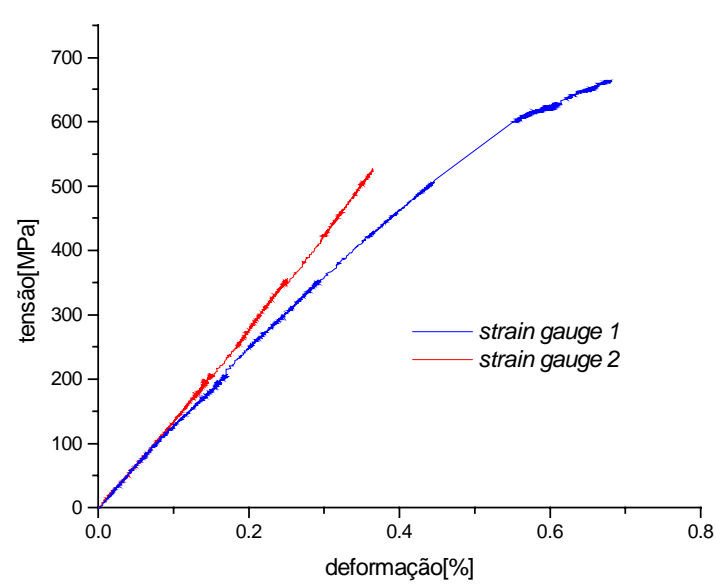

(b)

FIGURA 3.3.1-10 - Curvas tensão-deformação dos corpos-de-prova a $0^{\circ}$ sob teste de compressão: (a) carregamentos combinados (b) carregamento uniforme

Além disso, com o auxílio de "strain gauges back-to-back", verificou-se o quanto a ocorrência de carregamentos combinados influenciaram no processo de falha. Nota-se no gráfico de tensão-deformação apresentado pela FIGURA 3.3.1-10(a) que há presença de carregamentos combinados pois as curvas de ambos "strain gauges" divergem. Por outro lado, a FIGURA 3.3.1-10(b) evidencia que a amostra foi carregada quase uniformemente e as curvas dos "strain gauges" praticamente convergiram. Vale ressaltar que o módulo de elasticidade paralelo à fibra sob compressão para esses testes oscilou entre $120 \mathrm{GPa}$ e $140 \mathrm{GPa}$, mostrando assim que o módulo de elasticidade à compressão está muito próximo do módulo de elasticidade à tração (127 GPa). Para o módulo de elasticidade perpendicular à fibra sob compressão $\left(\mathrm{E}_{22 \mathrm{c}}\right)$ foi encontrado, entre as amostras com as lâminas orientadas a $90^{\circ}$, um valor máximo de $10,86 \mathrm{GPa}$ e um valor mínimo de 9,16 GPa. Além disso, através dos "strain gauges back-to-back", verificou-se o quanto a ocorrência de carregamentos combinados influenciaram no processo de falha. Nota-se no gráfico de tensão-deformação apresentado pela FIGURA 3.3.1-11(a) que há presença de carregamentos combinados pois as curvas de ambos "strain gauges" divergem. Por outro lado, a FIGURA 3.3.1-11(b) demonstra que a amostra foi carregada uniformemente e as curvas dos "strain gauges" convergiram. Vale ressaltar que o módulo de elasticidade perpendicular à fibra sob compressão para 
esses testes esteve em torno dos $10 \mathrm{GPa}$, demonstrando assim que o módulo de elasticidade à compressão está muito próximo do módulo de elasticidade à tração $(8,1$ GPa). Além disso, deve-se lembrar que os resultados de compressão foram obtidos utilizando "strain gauges" ao passo que os resultados de tração foram obtidos utilizando o deslocamento do "cross head" da máquina. Portanto, os resultados de compressão são mais precisos do que os resultados de tração que já indicavam uma sub-estimativa do módulo de elasticidade devido à influência da flexibilidade da máquina.

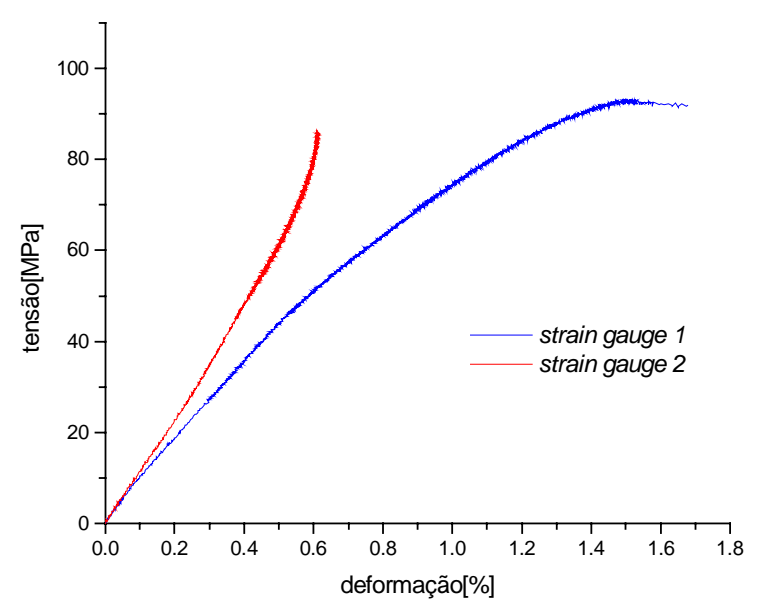

(a)

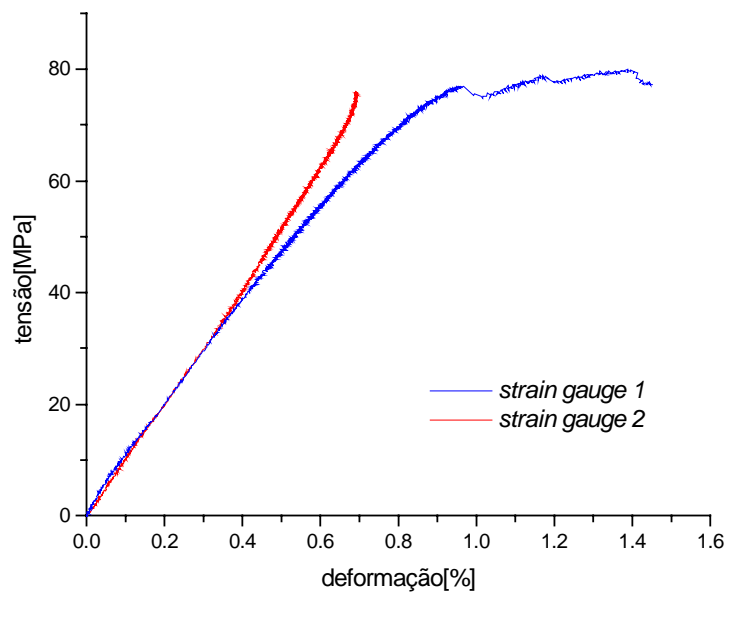

(b)

FIGURA 3.3.1-11 - Curvas tensão-deformação dos corpos-de-prova a $90^{\circ}$ sob teste de compressão: (a) carregamentos combinados (b) carregamento uniforme

Para a resistência à compressão paralela à fibra $\left(\mathrm{X}_{\mathrm{C}}\right)$ foi encontrado um valor máximo igual a $930 \mathrm{MPa}$. No entanto, deve-se destacar que mesmo para os casos em que as curvas de ambos "strain gauges" convergiram, verificou-se uma pequena presença de carregamentos combinados a partir de 0,15\% de deformação (FIGURA 3.3.1-10(b)). Por outro lado, para a resistência à compressão perpendicular à fibra $\left(\mathrm{Y}_{\mathrm{C}}\right)$ foi encontrado um valor máximo igual a $130 \mathrm{MPa}$. No entanto, deve-se destacar novamente que mesmo para os casos em que as curvas de ambos "strain gauges" convergiram, verificou-se uma pequena presença de carregamentos combinados a partir de 0,5\% de deformação (FIGURA 3.3.1-11(b)). Portanto, os valores de resistência à compressão obtidos experimentalmente podem estar abaixo do valor real. Segundo a literatura pode-se chegar a $1220 \mathrm{MPa}$ para a resistência paralela à fibra e a $168 \mathrm{MPa}$ para a resistência perpendicular à fibra (TABELA 3.3-2). 


\subsubsection{Ensaios de Cisalhamento}

O estudo do comportamento de CPR frente a carregamentos de cisalhamento pode ser realizado seguindo a norma ASTM D3518/3518M-94, possibilitando assim, constatar o comportamento não-linear descrito no trabalho de Hahn e Tsai (1973) (FIGURA 3.3.2-1 (a)). Nesta norma, tem-se que através de um teste de tração em amostras com as lâminas empilhadas a $+/-45^{\circ}$ pode-se produzir um campo de tensões de cisalhamento como mostra a FIGURA 3.3.2-1(b).

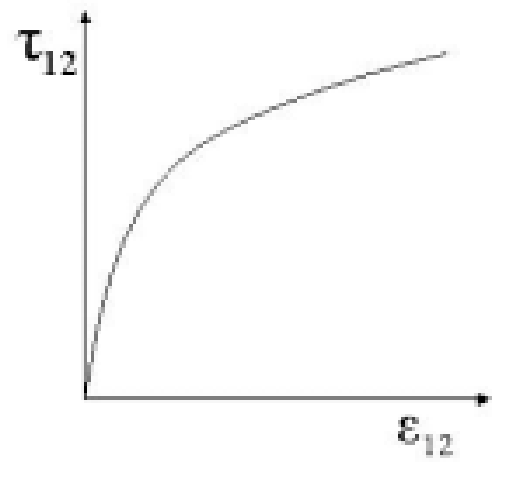

(a)

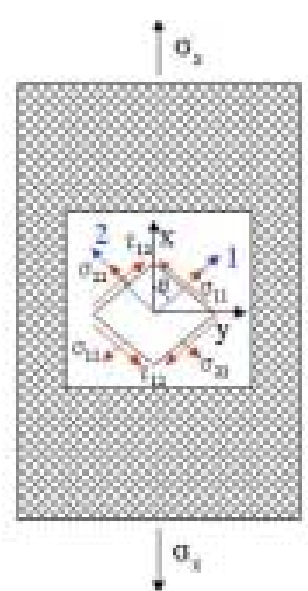

(b)

FIGURA 3.3.2-1 - Teste de Cisalhamento:

(a) Curva de tensão de cisalhamento em função das distorções angulares

(b) Campo de tensões no corpo de prova para cisalhamento

Sendo assim, tem-se que:

$$
\tau_{12}= \pm \sigma_{\mathrm{x}} / 2
$$

onde:

$$
\sigma_{\mathrm{x}}=\text { tensão aplicada durante o teste de tração }
$$

Quanto às deformações, tem-se que:

$$
\begin{aligned}
& \varepsilon_{11}=\left(\varepsilon_{\mathrm{x}}+\varepsilon_{\mathrm{y}}\right) / 2 \\
& \varepsilon_{22}=\left(\varepsilon_{\mathrm{x}}+\varepsilon_{\mathrm{y}}\right) / 2
\end{aligned}
$$




$$
\varepsilon_{12}=\left(\varepsilon_{\mathrm{x}}-\varepsilon_{\mathrm{y}}\right) / 2 \text { ou } \gamma_{12}=\left(\varepsilon_{\mathrm{x}}-\varepsilon_{\mathrm{y}}\right)
$$

Pela relação constitutiva pode-se obter uma expressão para calcular o módulo de cisalhamento no plano $1-2\left(\mathrm{G}_{12}\right)$, pois:

$$
\tau_{12}=\mathrm{G}_{12} \gamma_{12}
$$

onde:

$$
G_{12}=\frac{\sigma_{x} / 2}{\left(\varepsilon_{x}-\varepsilon_{y}\right)}
$$

Os corpos-de-prova que seguem a norma ASTM D3518/D3518-94a são constituídos por lâminas empilhadas a $+/-45^{\circ}$ de maneira simétrica, possuindo largura igual a $25 \mathrm{~mm}$, comprimento igual a $250 \mathrm{~mm}$ e espessura igual a $2,7 \mathrm{~mm}$. Por fim, devese ressaltar que a velocidade para todos os testes foi igual a $2,0 \mathrm{~mm} / \mathrm{min}$.

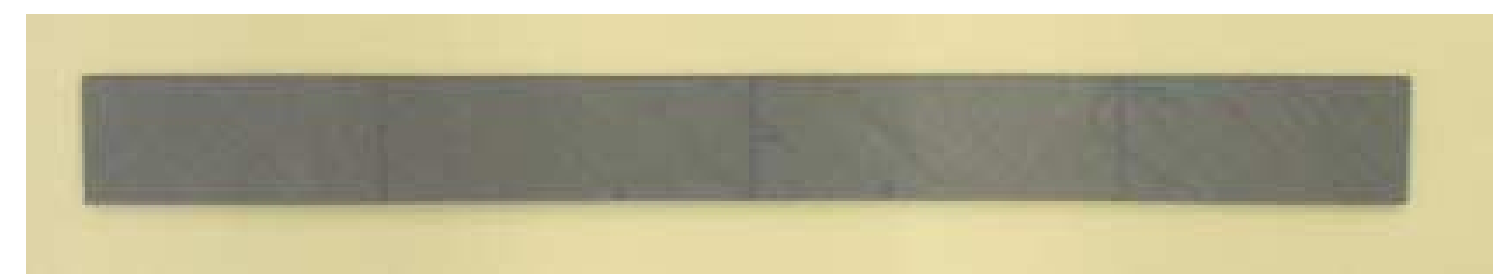

FIGURA 3.3.2-2 - Amostras para ensaios de cisalhamento

Para o módulo de cisalhamento no plano 1-2 $\left(\mathrm{G}_{12}\right)$ foi encontrado um valor igual a 5,4 GPa com o auxílio de dois extensômetros colocados respectivamente na direção axial e transversal em relação ao carregamento aplicado. Além disso, mediu-se $53 \mathrm{MPa}$ para o valor da resistência ao cisalhamento no plano 1-2 ( $\left.\mathrm{S}_{12}\right)$ (FIGURA 3.3.2-3(a)). Vale ressaltar que tomando também como referência o gráfico das tensões de cisalhamento em função das distorções angulares, pode-se calcular o valor do parâmetro de não-linearidade $\alpha$, pois a curva pode ser descrita por:

$$
\gamma_{12}=\mathrm{S}_{66} \tau_{12}+\mathrm{S}_{6666} \tau_{12}^{3}
$$


onde:

$$
\begin{aligned}
\gamma_{12}= & \mathrm{e}_{6}=\text { deformação por cisalhamento (distorção angular) } \\
\tau_{12}= & \sigma_{6}=\text { tensões de cisalhamento } \\
\mathrm{S}_{66}= & \text { flexibilidade associada ao cisalhamento }=1 / \mathrm{G}_{12} \\
\mathrm{~S}_{6666}= & \text { componente do tensor de } 4^{\mathrm{a}} \text { ordem } \\
& \text { (parâmetro de não-linearidade } \alpha \text { ) }
\end{aligned}
$$

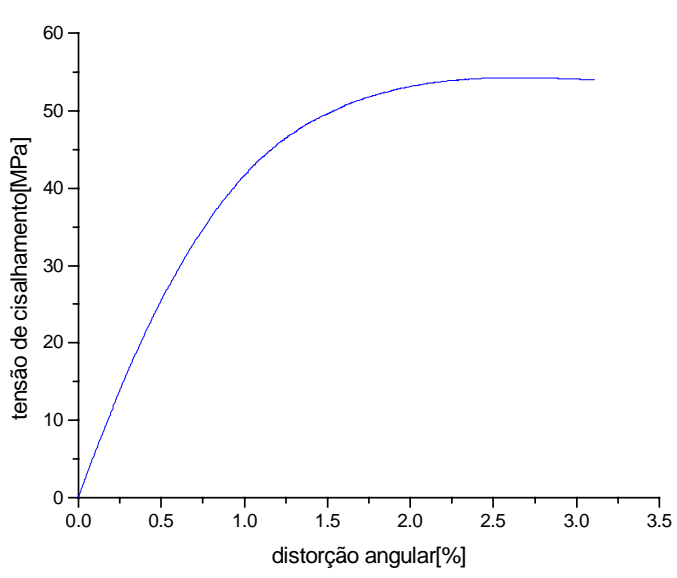

(a)

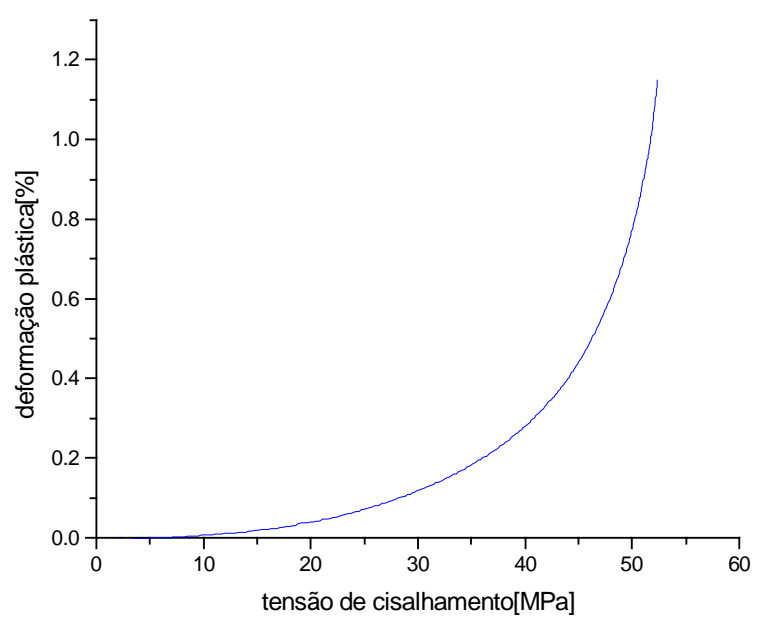

(b)

FIGURA 3.3.2-3 - Curvas dos corpos-de-prova a +/ $-45^{\circ}$ sob tração:

(a) Tensão de cisalhamento-distorções angulares

(b) Deformações permanentes-tensão de cisalhamento

Além disso, tem-se que:

$$
\gamma_{12}^{\text {total }}=\gamma_{12}^{\text {elástico }}+\gamma_{12}^{\text {plástico }}
$$

Assim,

$$
\gamma_{12}^{\text {total }}-\gamma_{12}^{\text {elástico }}=\gamma_{12}^{\text {plástico }}
$$

Portanto,

$$
\left(\gamma_{12}-S_{66} \tau_{12}\right)=S_{6666} \tau_{12}^{3}
$$


Por fim, aplicando logaritmo na equação acima, tem-se:

$$
\log \left(\gamma_{12}-S_{66} \tau_{12}\right)=\log S_{6666}+3 \log \tau_{12}
$$

Ou seja:

$$
\log \left(\gamma_{12}-\mathrm{S}_{66} \tau_{12}\right)-3 \log \tau_{12}=\log \mathrm{S}_{6666}
$$

Como os pontos $\tau_{12}$ e $\gamma_{12}$ foram medidos experimentalmente tem-se que o valor do $\log \mathrm{S}_{6666}$ pode ser determinado.

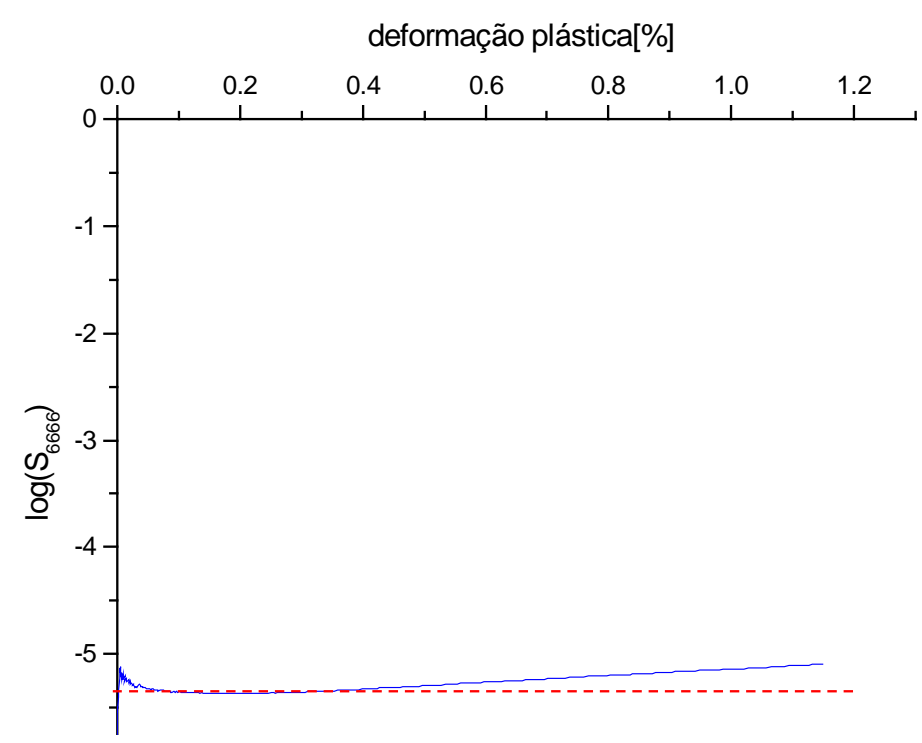

FIGURA 3.3.2-4 - Determinação do parâmetro de não-linearidade $\alpha$

A FIGURA 3.3.2-4 apresenta o gráfico do $\log \mathrm{S}_{6666}$ em função da $\gamma_{12}^{\text {plástico }}$. Note que o valor do logaritmo para o parâmetro de não-linearidade é cerca de $-5,4$. No entanto, tal parâmetro foi calculado com base em valores de tensão que estão em $\mathrm{MPa}^{3}$. Sendo assim, tem-se que o $\log \mathrm{S}_{6666}$ será igual a $-5,4(\mathrm{MPa})^{-3}$. Portanto, $\mathrm{S}_{6666}$ será igual a $3,98 \times 10^{-24}(\mathrm{~Pa})^{-3}$, demonstrando uma certa coerência com resultados similares obtidos por Hahn e Tsai (1973). 


\subsubsection{Ensaios de Flexão 3-Pontos}

Inicialmente, deve-se destacar que os testes de flexão foram realizados tanto com o intuito de avaliar o modelo de material proposto como também para obter mais informações sobre o comportamento mecânico do material que estava sendo utilizado, pois estes testes são de fácil execução, além de serem realizados em amostras com geometria simples. Sendo assim, o presente trabalho irá apresentar resultados provenientes de dois tipos de teste de flexão. O primeiro que segue a norma ASTM D790-96a e o segundo que segue a norma ASTM D2344-84 (Re-aprovada em 1995). Ambos realizados sob a aplicação do carregamento em três pontos (FIGURA 3.3.3-9).

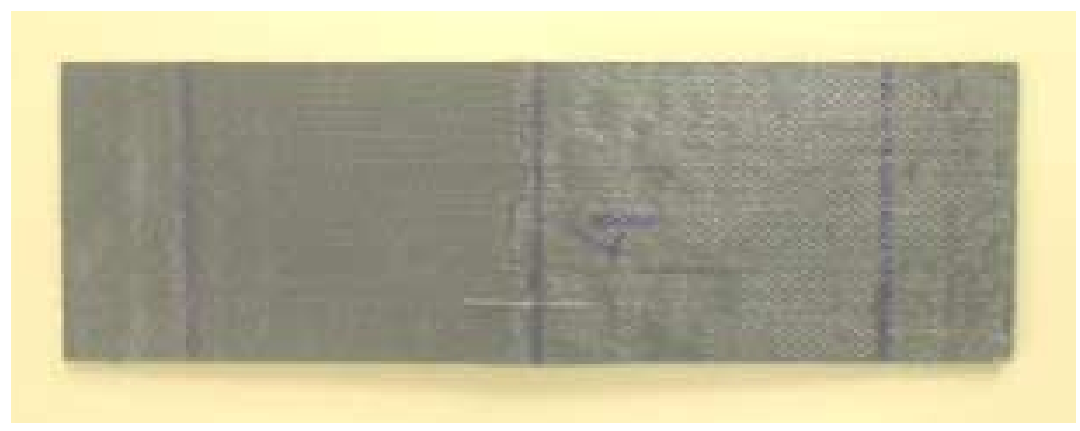

(a)

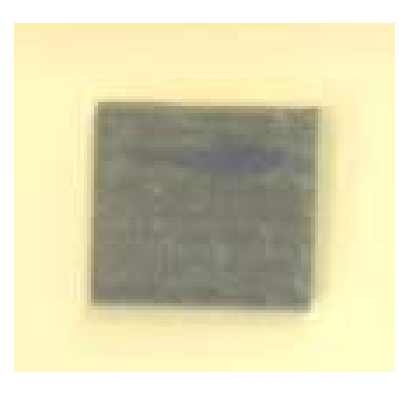

(b)

FIGURA 3.3.3-1 - Amostras para ensaios de flexão 3-pontos:

(a) norma ASTM D790-96a; (b) norma ASTM D2344-84

A TABELA 3.3.3-1 traz os valores de comprimento (L), largura (W), espessura (H) e velocidade do teste (V) de todos os corpos-de-prova que foram ensaiados ao longo do desenvolvimento do presente trabalho. É importante destacar que os corpos-de-prova que seguem a norma ASTM D790 e possuem seqüência de empilhamento de $[0]_{10}$ e de $[90]_{10}$ foram utilizados para verificar algumas propriedades obtidas nos ensaios anteriores (ensaios de tração e compressão). Por outro lado, todos os corpos-de-prova que seguem a norma ASTM D2344 foram utilizados para que houvesse um melhor entendimento do comportamento mecânico do material utilizado. Por fim, os corpos-deprova que seguem a norma ASTM D790 e possuem seqüência de empilhamento igual a $[0]_{10},[0 / 90 / 0 / 90 / 0]_{\mathrm{s}}$ e $[+45 /-45 /+45 / 0 / 90]_{\mathrm{s}}$ serão utilizados para avaliar o modelo de material proposto no Capítulo 4. 
TABELA 3.3.3-1 - Especificações para os testes de flexão três-pontos ( $\mathrm{L}=$ comprimento; $\mathrm{W}=$ largura; $\mathrm{H}=$ espessura)

\begin{tabular}{cccccc}
\hline \multirow{2}{*}{ Norma } & $\begin{array}{c}\text { Sequência de } \\
\text { Empilhamento }\end{array}$ & $\begin{array}{c}\mathbf{L} \\
{[\mathbf{m m}]}\end{array}$ & $\begin{array}{c}\mathbf{W} \\
{[\mathbf{m m}]}\end{array}$ & $\begin{array}{c}\mathbf{H} \\
{[\mathbf{m m}]}\end{array}$ & $\begin{array}{c}\mathbf{V} \\
{[\mathbf{m m} / \mathbf{m i n}]}\end{array}$ \\
\hline \multirow{2}{*}{$\begin{array}{c}\mathrm{D} 790 \\
\left(\operatorname{span}^{(*)} / \mathrm{H}=32\right)\end{array}$} & {$[0]_{10}$} & 80 & 25 & 1,8 & 2,8 \\
& {$[90]_{10}$} & 80 & 25 & 1,8 & 2,8 \\
& {$[+45 /-45 /+45 / 0 / 90]_{\mathrm{s}}$} & 80 & 25 & 1,8 & 2,8 \\
\hline \multirow{2}{*}{$\mathrm{D} 2344$} & {$[0]_{14}$} & 14 & 12,5 & 2,4 & 0,5 \\
$\left(\operatorname{span}^{(*)} / \mathrm{H}=4\right)$ & {$[0 / 90 / 0 / 90 / 0 / 90 / 0]_{\mathrm{s}}$} & 14 & 12,5 & 2,4 & 0,5 \\
& {$\left[+45 /-45 /+45 / 0_{2} / 90_{2}\right]_{\mathrm{s}}$} & 14 & 12,5 & 2,3 & 0,5 \\
\hline
\end{tabular}

(*) O span é definido como sendo a distância entre os apoios do teste de flexão

Com base nas condições aplicadas nos testes de flexão 3-pontos para amostras a $0^{\circ}$ e utilizando a seguinte equação da Teoria da Elasticidade (CARLSSON; PIPES, 1987):

$$
\mathrm{w}=0,02083 \frac{\mathrm{PS}^{3}}{\mathrm{E}_{11} \mathrm{I}}
$$

onde:

$$
\begin{aligned}
& \mathrm{P}=\text { carga concentrada no centro da viga } \\
& \mathrm{S}=\text { span } \\
& \mathrm{I}=\text { momento de inércia da viga }
\end{aligned}
$$

Tem-se para $\mathrm{E}_{11}$ igual a $100 \mathrm{GPa}$ (baseado nos resultados dos ensaios de tração e compressão) e carregamento igual a $0,92 \mathrm{kN}$, um valor de deslocamento igual a 3,65 mm. No gráfico de força-deflexão para amostras orientadas a $0^{\circ}$ (FIGURA 3.3.3-2(a)) é possível encontrar o valor de $3,43 \mathrm{~mm}$. A diferença de $0,22 \mathrm{~mm}$ pode ser explicada através da influência da compressão durante o teste de flexão 3-pontos bem como através da simplicidade do modelo adotado. 


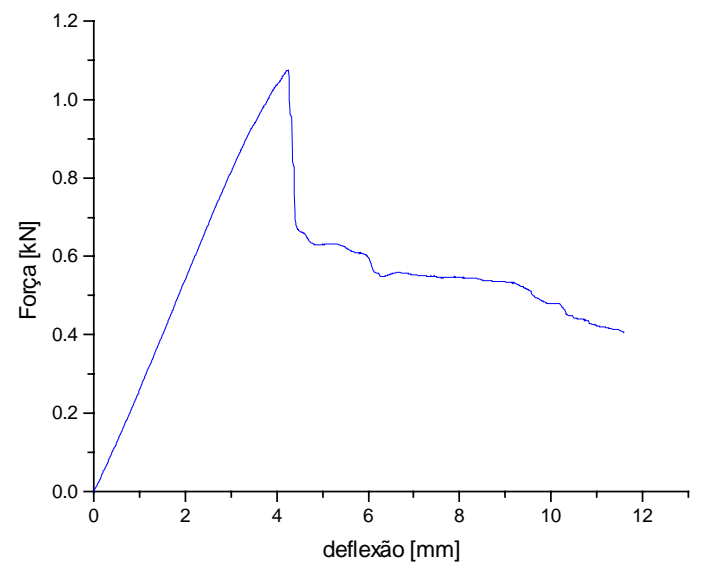

(a)

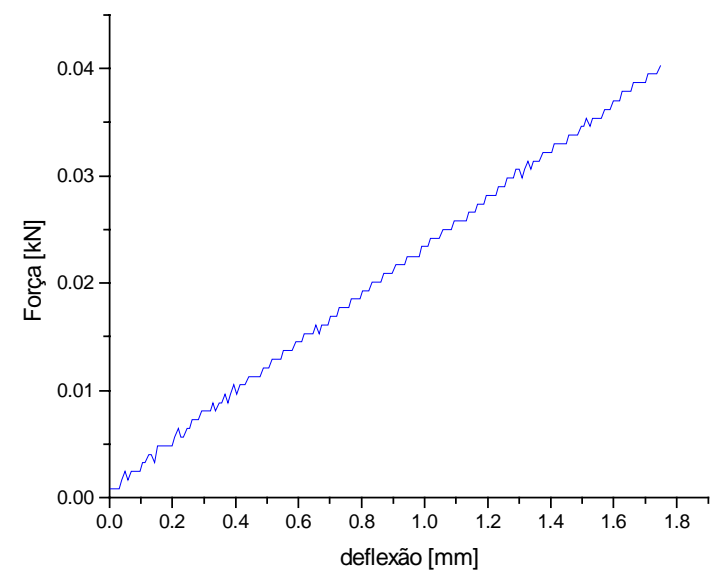

(b)

FIGURA 3.3.3-2 - Curvas força-deflexão obtidas do teste de flexão 3-pontos (ASTM D790-96a): (a) Amostra com lâminas a $0^{\circ}$; (b) Amostra com lâminas a $90^{\circ}$

Deve-se destacar que o mesmo raciocínio utilizado acima, pode ser aplicado para testes de flexão 3-pontos onde as amostras possuem as lâminas orientadas a $90^{\circ}$ :

$$
\mathrm{w}=0,02083 \frac{\mathrm{PS}^{3}}{\mathrm{E}_{22} \mathrm{I}}
$$

Dessa forma, utilizando a equação (3.3.3-2), tem-se para $E_{22}$ igual a $8 \mathrm{GPa}$ (baseado nos testes de tração e compressão) e um carregamento igual a 0,019 kN, um valor de deslocamento igual a $0,78 \mathrm{~mm}$. No gráfico de força-deflexão para amostras orientadas a $90^{\circ}$ (FIGURA 3.3.3-2(b)) é possível encontrar o valor de 0,81 mm. A diferença de $0,03 \mathrm{~mm}$ pode ser explicada novamente através da influência da compressão durante o teste de flexão 3-pontos bem como através da simplicidade do modelo adotado.

Além da influência da compressão durante os testes de flexão, deve-se ressaltar que as curvas de força-deflexão foram obtidas utilizando o deslocamento do "cross head" da máquina. Portanto, as medidas do teste de flexão foram também influenciadas pela flexibilidade da mesma, revelando assim, um valor menor para o módulo de elasticidade. Tudo isto, pode ser confirmado através do cálculo do módulo aparente de flexão ( $\left.E_{11}^{f}\right)$ que é dado por (CARLSSON; PIPES, 1987): 


$$
\mathrm{E}_{11}^{\mathrm{f}}=\frac{\mathrm{PS}^{3}}{4 \mathrm{bh}^{3} \mathrm{w}}
$$

onde:

$$
\begin{aligned}
& \mathrm{h}=\text { espessura da amostra } \\
& \mathrm{b}=\text { largura da amostra }
\end{aligned}
$$

Substituindo os valores associados ao teste de flexão 3-pontos para amostras a $0^{\circ}$ chega-se ao valor de $114 \mathrm{GPa}$ para o módulo aparente de flexão. O mesmo raciocínio descrito acima pode ser aplicado para a obtenção do módulo aparente de flexão perpendicular às fibras $\left(\mathrm{E}_{22}^{\mathrm{f}}\right)$ que será igual a 7,7 GPa, caso sejam utilizados nos cálculos, os parâmetros empregados no teste de flexão 3-pontos das amostras a $90^{\circ}$.

Deve-se ressaltar ainda que pela FIGURA 3.3.3-2(a), verifica-se a ocorrência de uma falha em $1,1 \mathrm{kN}$. Neste instante, varias fibras localizadas no topo do laminado falham por compressão e na base do laminado falham por tração. Há assim, uma perda acentuada da rigidez da estrutura. A partir de 4,0 mm de deflexão ocorrem outras falhas, como fratura da matriz e esmagamento das fibras que estão próximas do aplicador de carga. Por outro lado, para a FIGURA 3.3.3-2(b), tem-se o colapso completo da estrutura através da fratura da matriz caracterizada por uma fissura na base do laminado. Tal fissura está alinhada com as fibras dispostas transversalmente e ocorre quando o carregamento atinge $0,04 \mathrm{kN}$.

Novamente, recorrendo à Teoria da Elasticidade, é possível obter o valor das deformações no plano 1-2 (plano da lâmina) para um teste de flexão, utilizando a seguinte equação (CARLSSON; PIPES, 1987):

$$
\varepsilon_{11}^{\mathrm{f}}=\frac{\mathrm{PSh}}{8 \mathrm{E}_{11}^{\mathrm{f}} \mathrm{I}}
$$

Conseqüentemente, os valores de tensão normal podem ser obtidos por:

$$
\sigma_{11}^{\mathrm{f}}=\frac{3 \mathrm{PS}}{2 \mathrm{bh}^{2}}
$$

Portanto, para amostras a $0^{\circ}$ chega-se ao valor de resistência igual a $1350 \mathrm{MPa}$ (FIGURA 3.3.3-3(a)). Nota-se que este valor é muito próximo do valor de $1400 \mathrm{MPa}$ 
obtido no teste de tração. Além disso, as equações (3.3.3-4) e (3.3.3-5) podem ser também aplicadas para amostras a $90^{\circ}$. Neste caso, tem-se um valor de resistência igual a $47 \mathrm{MPa}$ (FIGURA 3.3.3-3(b)). Vale lembrar que este valor não pôde ser obtido através do teste de tração. No entanto, o resultado encontrado no teste de flexão é plenamente satisfatório, pois a TABELA 3.3-2 indica para esta resistência, o valor de 45 MPa.

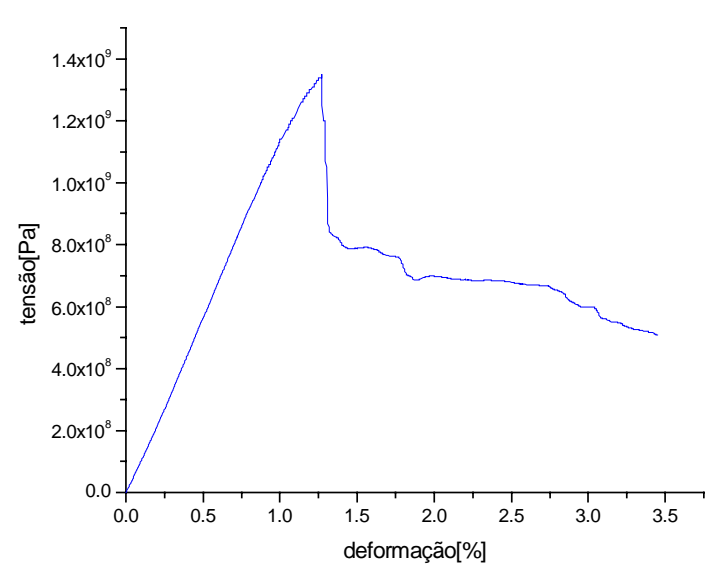

(a)

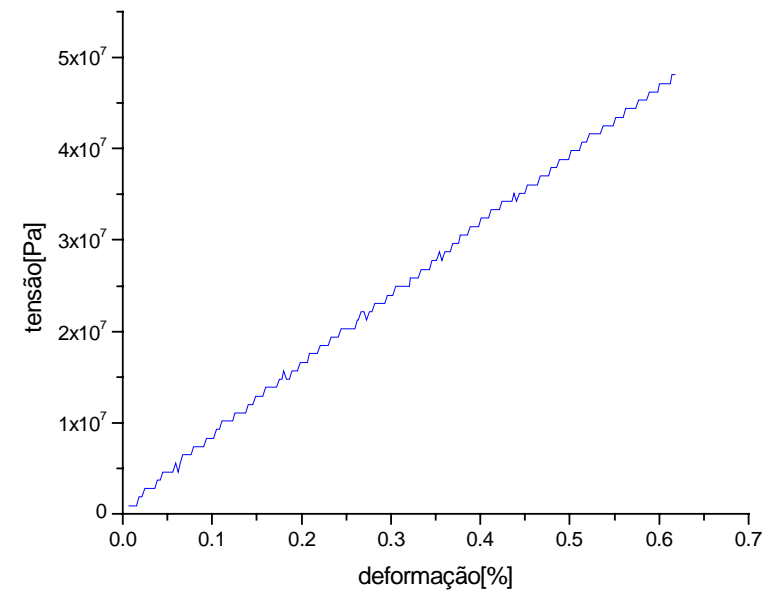

(b)

FIGURA 3.3.3-3 - Curvas tensão-deformação obtidas do teste de flexão 3-pontos (ASTM D790-96a): (a) Amostra com lâminas a 0; (b) Amostra com lâminas a 90

O fenômeno das delaminações pode ser avaliado em amostras com as fibras orientadas a $0^{\circ}$ sujeitas ao teste de flexão 3-pontos desde que a relação entre span/espessura seja pequena. Dessa forma, é possível induzir na estrutura altas tensões de cisalhamento e obter assim, o valor da resistência do laminado ao cisalhamento transversal. Segundo a norma ASTM D 2344, a relação span/espessura deve ser igual a 4, para compósitos poliméricos reforçados com fibra carbono, a fim de que o valor de resistência seja calculado através da seguinte equação:

$$
\tau_{\mathrm{m}}=\frac{3 \mathrm{P}}{4 \mathrm{~A}}
$$

onde:

$\mathrm{P}=$ carga de falha sob flexão 3 pontos

$\mathrm{A}=$ área da seção transversal da amostra 
No entanto, Whitney; Daniel e Pipes (1984) verificaram que as tensões de cisalhamento transversal não estão distribuídas parabolicamente para algumas secções de um laminado sob flexão 3-pontos. Portanto, o máximo valor da tensão de cisalhamento não está localizado no centro da viga, como mostra uma das curvas da FIGURA 3.3.3-4 (curva B).

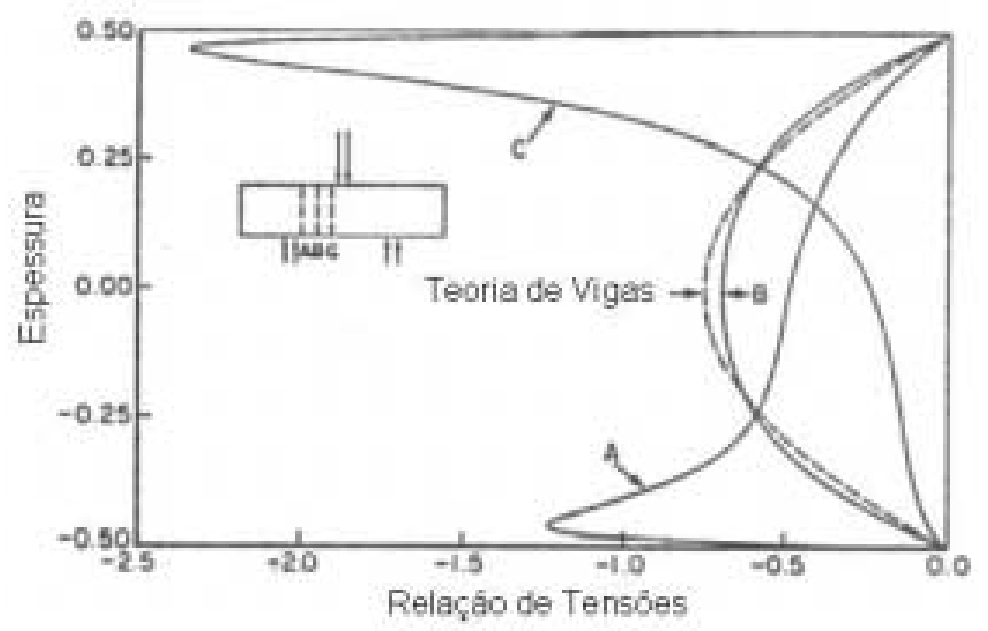

FIGURA 3.3.3-4 - Distribuição das tensões de cisalhamento transversal para uma viga de carbono grafite e resina epóxi (span/espessura $=4$ ) sob flexão 3-pontos (adaptado de WHITNEY; DANIEL; PIPES, 1984)

Note que pela Teoria de Vigas, a tensão de cisalhamento transversal pode ser prevista com precisão apenas para os pontos localizados na secção B, ou seja, para os pontos que não estão próximos dos apoios ou do ponto de aplicação da carga. Porém, para os pontos localizados próximos às bordas do laminado nas seções A (próximo dos apoios) ou C (próximos do ponto de aplicação da carga), pode-se chegar a um valor igual a 2,5 vezes maior do que o valor previsto no centro da estrutura pela Teoria de Vigas. Portanto, Whitney; Daniel e Pipes (1984) identificaram que devido a esses pontos concentradores de tensão, há ocorrência inicialmente de uma fratura vertical próxima do ponto de aplicação da carga, antes mesmo de surgir a primeira delaminação interlaminar. Sendo assim, o valor de resistência $\tau_{\mathrm{m}}$ determinado através da norma ASTM D 2344 é conhecido como valor de resistência aparente ao cisalhamento transversal.

Com base na FIGURA 3.3.3-5, pode-se chegar ao valor de 62,3 MPa para a resistência aparente ao cisalhamento transversal do prepreg M10. Além disso, através 
desse mesmo gráfico verifica-se que as primeiras falhas ocorreram em 2,6kN. Neste caso, o processo de falha inicia-se com trincas verticais próximas ao aplicador de carga. Posteriormente, surgem as primeiras delaminações próximas do topo do laminado e do ponto de aplicação da carga. Neste instante, nota-se uma queda do valor da carga, mantendo-se praticamente até $0,8 \mathrm{~mm}$ de deslocamento. A partir deste ponto surgem novas delaminações que fazem novamente o laminado perder rigidez. Verifica-se claramente que o avanço da delaminação não proporciona uma queda de rigidez tão acentuada como produz o surgimento de novas delaminações. Por fim, a partir de 1,0 mm de deflexão, verifica-se que a amostra passa sofrer um forte carregamento compressivo, evidenciando que o teste deve ser finalizado. Diante dessas observações, tem-se que o valor de $62,3 \mathrm{MPa}$ deve estar abaixo do valor real de resistência ao cisalhamento transversal. Isto pode ser confirmado, através da TABELA 3.3-1 que fornece um valor igual a $89 \mathrm{MPa}$ para o prepreg M40J.

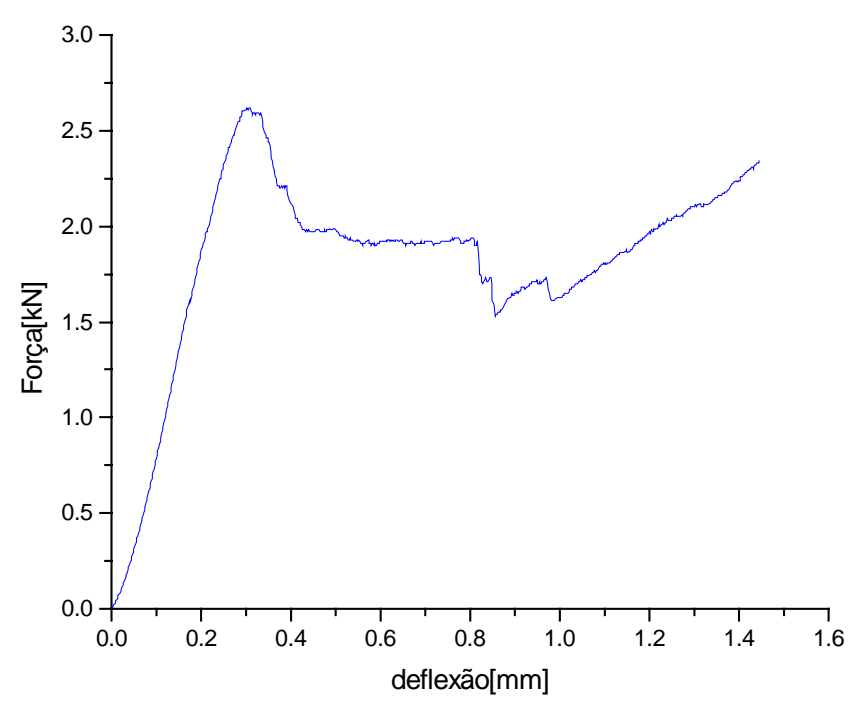

FIGURA 3.3.3-5 - Gráfico força-deflexão para amostras orientadas a $0^{\circ}$ (ASTM D2344)

Além das amostras com lâminas empilhadas somente a $0^{\circ}$ foram avaliadas amostras com seqüência de empilhamento igual a $[0 / 90 / 0 / 90 / 0 / 90 / 0]_{\mathrm{s}}$ bem como igual a [+45/-45/ $\left.+45 / 0_{2} / 90_{2}\right]_{\mathrm{s}}$. Sendo assim, nestes casos, buscou-se verificar o comportamento mecânico de estruturas com tendência a delaminar que estão sob altas tensões de cisalhamento transversal. 


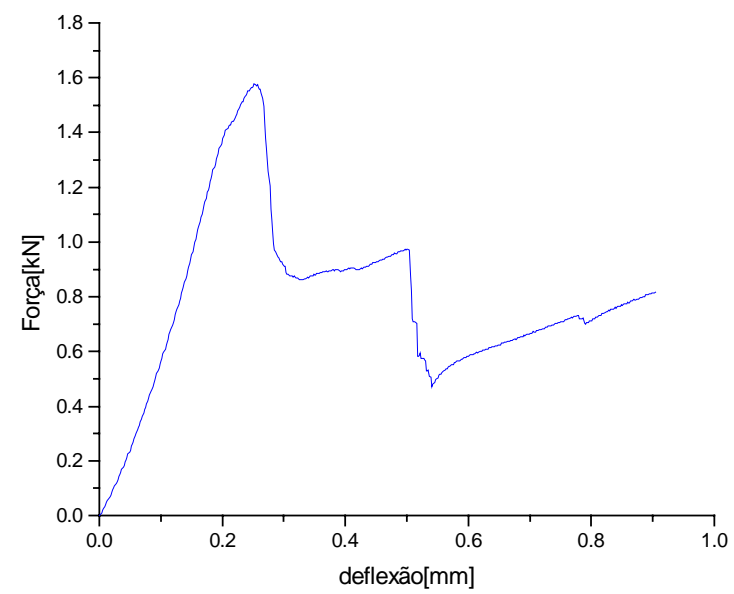

(a)

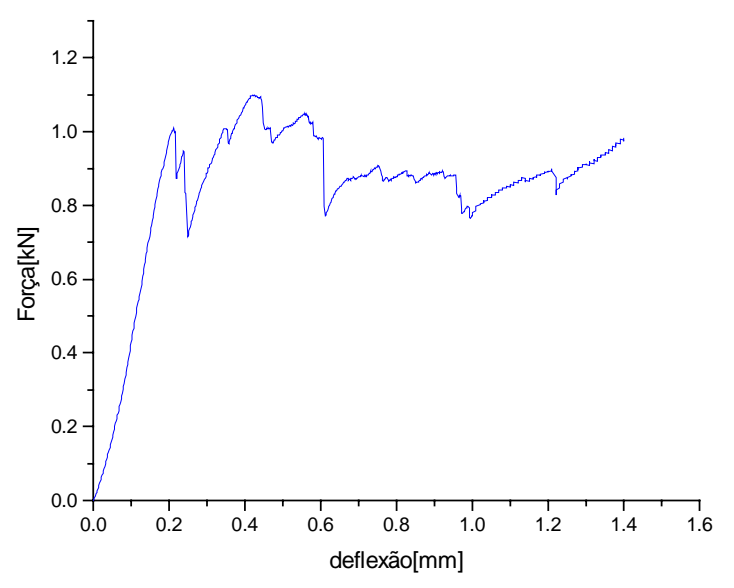

(b)

FIGURA 3.3.3-6 - Resultados dos testes de flexão 3-pontos (ASTM D2344):

(a) Lâminas orientadas a $[0 / 90 / 0 / 90 / 0 / 90 / 0]_{\mathrm{s}}$;

(b) Lâminas orientadas a $\left[+45 /-45 /+45 / 0_{2} / 90_{2}\right]_{\mathrm{s}}$

Na FIGURA 3.3.3-6(a) tem-se a ocorrência das primeiras falhas em 1,60 kN, surgindo as primeiras delaminações entre a interface das lâminas $0^{\circ} / 90^{\circ}$ que estão mais próximas do topo e do aplicador de carga. Verifica-se que há uma queda acentuada no valor da força, mantendo-se praticamente constante até $0,5 \mathrm{~mm}$. Neste instante ocorrem novas delaminações que ocasionam novamente uma forte perda de rigidez da estrutura. Tais constatações experimentais confirmam que a evolução das delaminações não reduz tanto a rigidez da estrutura como o surgimento de novas delaminações. Por outro lado, a FIGURA 3.3.3-6(b) apresenta um gráfico com um sinal contendo várias oscilações devido a sequência de empilhamento do laminado. Sendo assim, na verdade, há a ocorrência de uma série de fenômenos quase que simultaneamente. Durante os ensaios, pode-se observar que surgiram inicialmente trincas verticais localizadas nas camadas a $90^{\circ}$ bem como delaminações entre as lâminas $0^{\circ} / 90^{\circ}$ que estavam próximas do topo e do aplicador de carga, proporcionando assim a primeira redução de rigidez. Posteriormente, tem-se as primeiras delaminações entre as camadas $0^{\circ} / 45^{\circ}$. Além disso, devido às camadas $\mathrm{a}+/-45^{\circ}$, tem-se o comportamento não-linear devido às tensões de cisalhamento no plano da lâmina. Tudo isso, faz com que seja difícil a interpretação das oscilações do gráfico força-deflexão para essas amostras.

Finalmente, diante de todos esses resultados tem-se a seguir a apresentação de uma síntese dos mesmos comparando com valores da literatura. 


\subsubsection{Síntese dos Resultados dos Ensaios Quase-Estáticos}

Na TABELA 3.3.4-1 os resultados obtidos nos testes quase-estáticos e os resultados apresentados pela literatura são comparados. Deve-se lembrar que muitos desses valores serão empregados nos modelos para realização das simulações computacionais. Nota-se que praticamente todos os valores foram obtidos experimentalmente, exceto $G_{23}, v_{23}$ e $S_{23}$. Em primeiro lugar, deve-se ressaltar que o coeficiente de Poisson $v_{23}$ é muito difícil de ser obtido experimentalmente. Em segundo lugar, os valores de $G_{23}$ e $S_{23}$ poderiam ser determinados utilizando a norma ASTM D5379/D5379M-93, porém para a sua execução necessita-se de equipamentos complexos e ultraprecisos a fim de evitar carregamentos indesejáveis, simulando assim, quase um estado de carregamento próximo ao cisalhamento puro. Somado a isso, tem-se que a geometria dos corpos-de-prova apesar de simples, requisita tolerâncias de fabricação apertadas, acarretando assim num custo muito alto. Portanto, optou-se por utilizar valores de um material similar fabricado pela própria Hexcel ${ }^{\circledR}$ (prepreg M40J). No entanto, deve-se salientar que os compósitos fabricados são únicos pois possuem um tipo específico de resina epóxi, um tipo específico de fibra de carbono e foram moldados sob condições também específicas. Dessa forma, os valores obtidos experimentalmente podem algumas vezes se aproximar muito de valores da literatura como também podem ser completamente diferentes.

Por fim, é muito importante destacar que os valores obtidos experimentalmente possuem uma boa consistência física, como foi evidenciado através dos testes de flexão 3-pontos. Além disso, durante cada ensaio experimental, verificou-se que as curvas de resposta das amostras para cada tipo de teste não apresentaram problemas de divergência entre si, demonstrando a qualidade do material e do processo de fabricação empregado. 
TABELA 3.3.4-1 - Comparação dos resultados experimentais do prepreg M10 com valores da literatura

\begin{tabular}{|c|c|c|c|}
\hline \multirow{2}{*}{$\begin{array}{c}\text { Propriedades Elásticas } \\
\text { e } \\
\text { Valores de Resistência }\end{array}$} & \multirow{2}{*}{ Unidade } & \multicolumn{2}{|c|}{ Unidirecional } \\
\hline & & Valor $^{(\mathbf{i})}$ & Valor \\
\hline \multicolumn{4}{|l|}{ Propriedades Elásticas } \\
\hline \multicolumn{4}{|l|}{ Módulo de elasticidade } \\
\hline paralelo à fibra $\left(\mathrm{E}_{11}\right)$ & $\mathrm{GPa}$ & 127 & $132^{(\mathrm{iii})}$ \\
\hline perpendicular à fibra $\left(E_{22}=E_{33}\right)$ & $\mathrm{GPa}$ & 10 & $10,3^{(\mathrm{iii})}$ \\
\hline Densidade $\left(\rho_{\mathrm{c}}\right)$ & $10^{3} \mathrm{~kg} / \mathrm{m}^{3}$ & 1,58 & $1,47^{(\mathrm{iii})}$ \\
\hline \multicolumn{4}{|l|}{ Módulo de Cisalhamento } \\
\hline para o plano $1-2\left(\mathrm{G}_{12}=\mathrm{G}_{13}\right)$ & $\mathrm{GPa}$ & 5,4 & $4,55^{(\mathrm{iv})}$ \\
\hline para o plano $2-3\left(\mathrm{G}_{23}\right)$ & $\mathrm{GPa}$ & $3,05^{(\mathrm{ii})}$ & $3,05^{(\mathrm{ii})}$ \\
\hline \multicolumn{4}{|l|}{ Coeficientes de Poisson } \\
\hline$v_{12}=v_{13}$ & - & 0,34 & $0,327^{(\mathrm{ii})}$ \\
\hline$v_{23}$ & - & $0,306^{(\mathrm{ii})}$ & $0,306^{(\mathrm{ii})}$ \\
\hline \multicolumn{4}{|l|}{ Valores de Resistência } \\
\hline \multicolumn{4}{|l|}{ Resistência paralela à fibra } \\
\hline sob tração $\left(\mathrm{X}_{\mathrm{T}}\right)$ & $\mathrm{MPa}$ & 1400 & $1314^{(\mathrm{iv})}$ \\
\hline sob compressão $\left(\mathrm{X}_{\mathrm{C}}\right)$ & $\mathrm{MPa}$ & 930 & $1179^{(i i)}$ \\
\hline \multicolumn{4}{|l|}{ Resistência perpendicular à fibra } \\
\hline sob tração $\left(\mathrm{Y}_{\mathrm{T}}\right)$ & $\mathrm{MPa}$ & 47 & $45^{(\mathrm{iii})}$ \\
\hline sob compressão $\left(\mathrm{Y}_{\mathrm{C}}\right)$ & $\mathrm{MPa}$ & 130 & $140^{(\mathrm{iii})}$ \\
\hline \multicolumn{4}{|l|}{ Resistência ao cisalhamento } \\
\hline para o plano $1-2\left(\mathrm{~S}_{12}=\mathrm{S}_{13}\right)$ & $\mathrm{MPa}$ & 53 & $48^{(\mathrm{iv})}$ \\
\hline para o plano $2-3\left(\mathrm{~S}_{23}\right)$ & $\mathrm{MPa}$ & $89^{(\mathrm{ii})}$ & $89^{(\mathrm{ii})}$ \\
\hline Fração Volumétrica em Fibra $\left(\mathrm{V}_{\mathrm{f}}\right)$ & $\%$ & 63 & 60 \\
\hline
\end{tabular}

(i) presente trabalho; (ii) Hexcel ${ }^{(B)}$ (prepreg M40J);

(iii) (ENGINEERED MATERIALS HANDBOOK, 1987);(iv) (TSAI, 1986) 


\section{Capítulo 4}

\section{MODELO DE MATERIAL PROPOSTO}

\subsection{ANÁLISE PROGRESSIVA DE DANIFICAÇÃO E FALHA}

A escolha do modelo de material é uma das fases determinantes para uma avaliação coerente do processo de danificação e falha de um CPR. Dessa forma, somente através de um modelo adequado é que a simulação computacional será capaz de prever com uma certa precisão o comportamento mecânico de um dado componente fabricado em CPR sob um determinado tipo de carregamento.

$\mathrm{Na}$ literatura avaliada é comum encontrar o termo "Failure Criteria" para especificar o início do processo de danificação intralaminar ou falha interlaminar e o termo "Property Degradation Model" para especificar como o dano ou a falha irá evoluir após o mesmo ser detectado. No presente trabalho, serão adotados os termos Critério de Danificação Intralaminar e Lei de Evolução de Dano Intralaminar para que se possa avaliar os danos ocorridos na fibra ou na matriz e a evolução destes. Por outro lado, para que se possa avaliar as falhas interlaminares (delaminações) será adotado um Critério de Falha Interlaminar e uma Lei de Evolução de Falha Interlaminar. Portanto, o Critério deverá indicar quando o dano ou a falha ocorre, em qual lâmina bem como o modo dominante. Associado a isto, a Lei de Evolução deverá degradar as propriedades mecânicas da lâmina em função do modo detectado.

Deve-se destacar que para uma análise via Método dos Elementos Finitos, o Critério será aplicado a um dado ponto de Gauss associado a uma certa lâmina em cada passo de carga $\mathrm{P}^{\mathrm{n}}$ (FIGURA 4.1-1). Sendo assim, o valor do critério calculado para este ponto de integração indicará se uma dada lâmina danificou. Caso a lâmina não tenha danificado, deve-se incrementar um novo passo de carga. Caso contrário, deve-se 
degradar as suas propriedades elásticas tomando como referência a Lei de Evolução. Este procedimento deverá ser aplicado a todos os pontos de integração que danificaram de modo que se possa quantificar o novo valor da rigidez da estrutura para um dado incremento de carga. Somente após o cálculo dessa nova rigidez, busca-se restabelecer o equilíbrio da estrutura para o carregamento $\mathrm{P}^{\mathrm{n}}$. Este novo estado de equilíbrio levará a um processo de redistribuição das tensões no laminado, promovendo assim a danificação de novos Pontos de Gauss ou a ocorrência de falhas interlaminares que influenciarão outra vez na rigidez global. Portanto, o processo será incremental e iterativo, devendo ser finalizado quando a rigidez global da estrutura estiver muito comprometida.

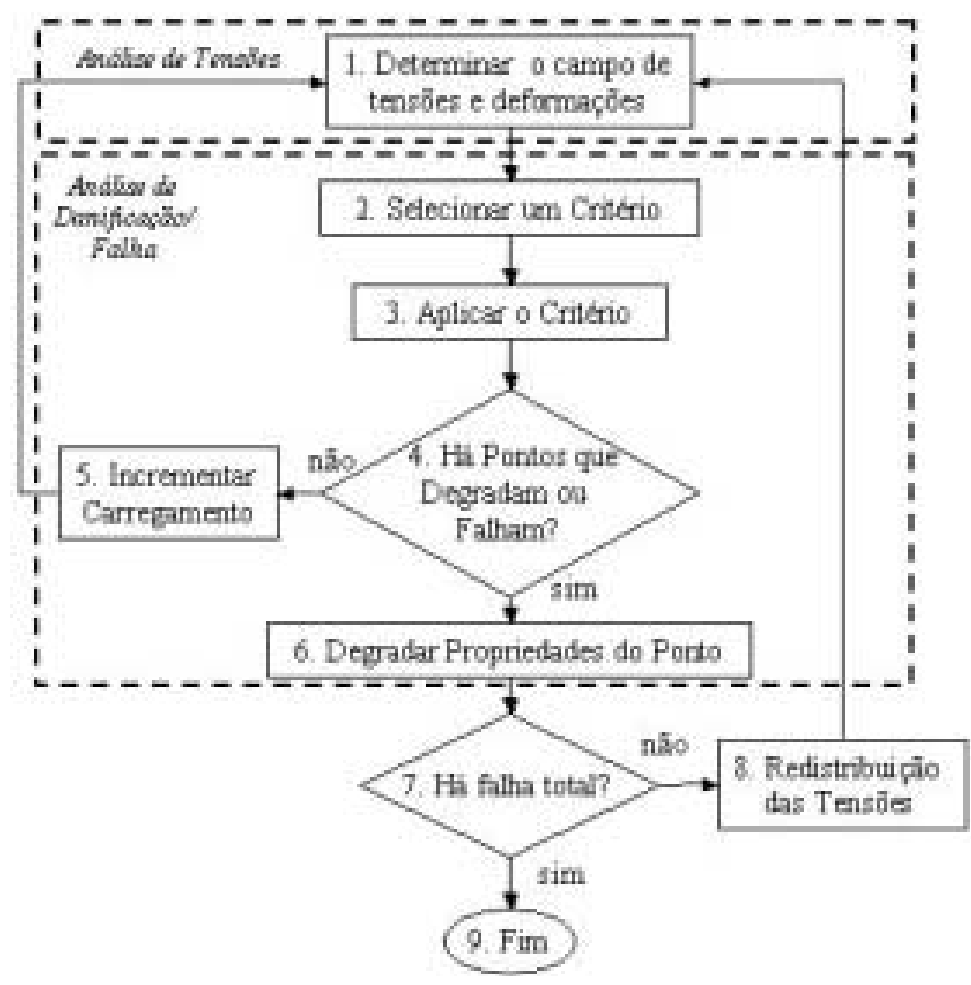

FIGURA 4.1-1 - Fluxograma de análise progressiva de danificação e falha em laminados

Nota-se assim que a análise progressiva de danificação e falha de um laminado consiste de duas etapas: Análise de Tensões e Análise de Danificação/Falha. Apesar dos danos intralaminares para laminados finos serem provocados principalmente pelas tensões que atuam no plano da lâmina, tem-se que as falhas interlaminares são geralmente provocadas pelo aumento das tensões que atuam na direção normal ao plano da lâmina bem como pelas tensões de cisalhamento transversal. Isto faz com que seja 
necessário, em muitos casos, considerar um estado triplo de tensões para a análise de falha de um laminado. Conseqüentemente, tem-se para cada Ponto de Gauss associado a uma certa lâmina a seguinte relação constitutiva:

$$
\sigma_{\text {Local }}=\left[\begin{array}{c}
\sigma_{1} \\
\sigma_{2} \\
\sigma_{3} \\
\sigma_{12} \\
\sigma_{13} \\
\sigma_{23}
\end{array}\right]=\left[\begin{array}{cccccc}
\mathrm{Q}_{11} & \mathrm{Q}_{12} & \mathrm{Q}_{13} & 0 & 0 & 0 \\
\mathrm{Q}_{21} & \mathrm{Q}_{22} & \mathrm{Q}_{23} & 0 & 0 & 0 \\
\mathrm{Q}_{31} & \mathrm{Q}_{32} & \mathrm{Q}_{33} & 0 & 0 & 0 \\
0 & 0 & 0 & 2 \mathrm{Q}_{44} & 0 & 0 \\
0 & 0 & 0 & 0 & 2 \mathrm{Q}_{55} & 0 \\
0 & 0 & 0 & 0 & 0 & 2 \mathrm{Q}_{66}
\end{array}\right]\left[\begin{array}{c}
\varepsilon_{1} \\
\varepsilon_{2} \\
\varepsilon_{3} \\
\varepsilon_{12} \\
\varepsilon_{13} \\
\varepsilon_{23}
\end{array}\right]
$$

onde:

$$
\begin{array}{ll}
\mathrm{Q}_{11}=\frac{\mathrm{E}_{11}\left(1-v_{23} v_{32}\right)}{\Delta} & \mathrm{Q}_{12}=\frac{\mathrm{E}_{11}\left(v_{21}+v_{31} v_{23}\right)}{\Delta}=\frac{\mathrm{E}_{22}\left(v_{12}+v_{32} v_{13}\right)}{\Delta} \\
\mathrm{Q}_{22}=\frac{\mathrm{E}_{22}\left(1-v_{31} v_{13}\right)}{\Delta} & \mathrm{Q}_{13}=\frac{\mathrm{E}_{11}\left(v_{31}+v_{21} v_{32}\right)}{\Delta}=\frac{\mathrm{E}_{22}\left(v_{13}+v_{12} v_{23}\right)}{\Delta} \\
\mathrm{Q}_{33}=\frac{\mathrm{E}_{33}\left(1-v_{12} v_{21}\right)}{\Delta} & \mathrm{Q}_{23}=\frac{\mathrm{E}_{22}\left(v_{32}+v_{12} v_{31}\right)}{\Delta}=\frac{\mathrm{E}_{33}\left(v_{23}+v_{21} v_{13}\right)}{\Delta} \\
\mathrm{Q}_{44}=\bar{G}_{12} & \Delta=1-v_{12} v_{21}-v_{23} v_{32}-v_{31} v_{13}-2 v_{21} v_{32} v_{13} \\
\mathrm{Q}_{55}=\mathrm{G}_{13} & \\
\mathrm{Q}_{66}=\mathrm{G}_{23} &
\end{array}
$$

Além disso, deve-se considerar o comportamento não-linear devido às tensões de cisalhamento atuantes no plano da lâmina (plano 1-2). Sendo assim, $\overline{\mathrm{G}}_{12}$ deverá corresponder ao módulo de cisalhamento "atualizado", pois será calculado através do valor numérico da tangente da curva de tensão de cisalhamento em função da distorção angular:

$$
\bar{G}_{12}=\frac{\partial f\left(\gamma_{12}\right)}{\partial \gamma_{12}}=\frac{1}{\frac{1}{G_{12}}+3 \alpha \sigma_{12}^{2}}
$$

Onde $\alpha$ representa o valor dado pelo componente do tensor de $4^{\text {a }}$ ordem demonstrado por Hahn e Tsai (1973) e obtido através dos ensaios experimentais quaseestáticos de cisalhamento. Posteriormente, Hahn e Tsai (1974) apresentaram uma discussão preliminar de como deveria evoluir a degradação das propriedades de uma estrutura fabricada em material compósito polimérico reforçado (FIGURA 4.1-2). 


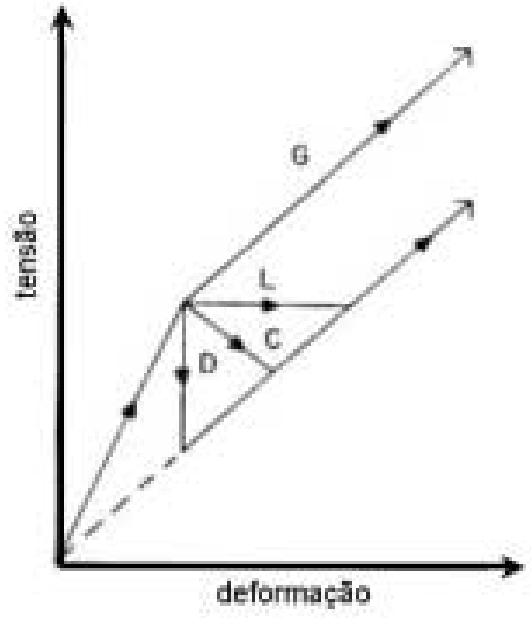

(a)

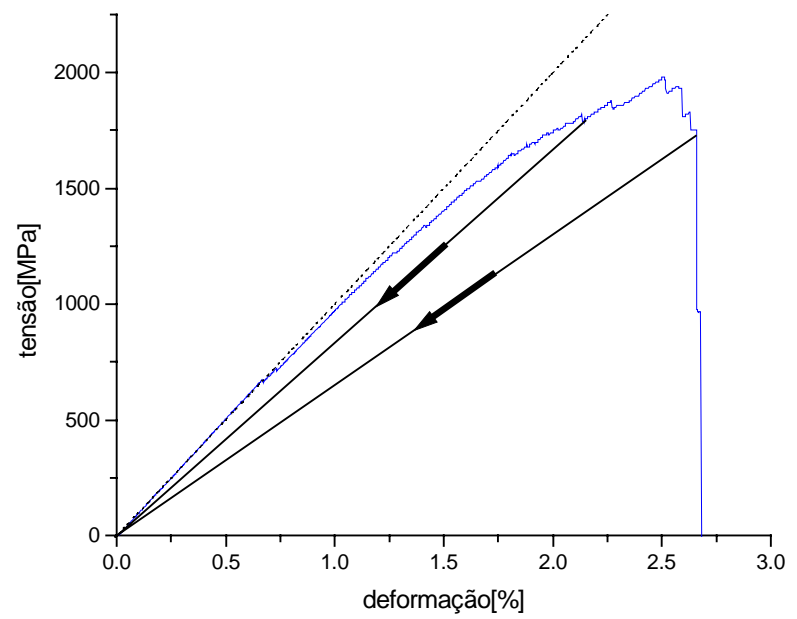

(b)

FIGURA 4.1-2 - Processo de degradação das propriedades de um CPR:

(a) Proposto por Hahn e Tsai (HAHN; TSAI, 1974); (b) Proposto no presente trabalho.

De acordo com a FIGURA 4.1-2(a), tem-se que os compósitos com as lâminas orientadas a $90^{\circ}$ possuem uma resposta segundo o caminho $\mathrm{D}$, ou seja, apresentam uma degradação abrupta das propriedades. Para os compósitos híbridos, que são resinas reforçadas por tipos diferentes de fibra, a falha segue o caminho C ou L. Por fim, para os compósitos convencionais (fibra de vidro e epóxi; carbono e epóxi; boro e epóxi) do tipo "cross-ply" a resposta tende a seguir o caminho G, demonstrando assim um processo de degradação gradual. No presente trabalho também será utilizado um processo de degradação gradual que será posteriormente melhor detalhado. Além disso, a FIGURA 4.1-2(b) mostra que caso haja descarregamento, a resposta não seguirá mais a curva do material ao ultrapassar as tensões limites especificadas. Nota-se que a reta de descarregamento possui inclinação diferente da elástica (reta tracejada), retornando assim a zero se todo carregamento for removido. Dessa forma, o modelo de material proposto não contempla a existência de deformações residuais (deformações permanentes). Essa hipótese pode ser considerada aceitável para o presente trabalho, pois os compósitos poliméricos utilizados são constituídos por resina epóxi e fibra de carbono que são na sua grande maioria materiais frágeis.

Sendo assim, a consistência das Análises de Danificação/Falha depende dos Critérios e das Leis de Evolução adotados. Segue portanto, a descrição e principalmente as justificativas pela qual alguns critérios e leis foram escolhidos para a realização do presente trabalho. 


\subsection{ANÁLISE DE DANIFICAÇÃO INTRALAMINAR}

A identificação de um dano intralaminar, seja da fibra ou da matriz, sob tração ou sob compressão, será efetuada pelo Critério de Danificação Intralaminar. Sendo assim, o Critério adotado deverá ser capaz de quantificar quatro modos distintos de danificação intralaminar:

1. Danificação da fibra sob compressão;

2. Danificação da fibra sob tração;

3. Danificação da matriz sob compressão;

4. Danificação da matriz sob tração.

Com base no modo de degradação identificado é que se deve aplicar a Lei de Evolução de Dano para que as propriedades do ponto material afetado possam ser devidamente degradadas.

\subsubsection{Critérios de Danificação Intralaminar}

Hashin (1980) propôs um critério capaz de identificar os modos de danificação intralaminares sob estado triplo e sob estado plano de tensões. Chang e Chang (1987a e 1987b) acrescentaram ao Critério de Hashin, descrito para o estado plano de tensões, bem como ao Critério de Yamada-Sun (YAMADA; SUN,1978), os efeitos de nãolinearidade devido às tensões de cisalhamento atuantes no plano da lâmina tal como fora demonstrado por Hahn e Tsai (1973). O êxito obtido nos trabalhos publicados posteriormente por Chang; Liu e Chang (1991), Chang e Lessard (1991), Lessard e Shokrieh (1995) e Perugini; Riccio e Scaramuzzino (2001) demonstraram as potencialidades do Critério de Chang-Chang. Além disso, recentemente, Paris (2001) mencionou em seu relatório que o Critério de Hashin é um dos mais adequados para análise de materiais compósitos poliméricos reforçados. Diante disso, optou-se numa primeira fase do presente projeto, empregar o Critério de Hashin para o estado plano de tensões acrescentando ao mesmo os efeitos de não-linearidade devido às tensões de cisalhamento atuantes no plano da lâmina. Sendo assim, o critério utilizado consiste de quatro sub-critérios capazes de identificar os respectivos modos de danificação intralaminar: 
Modo da Fibra sob Compressão $\left(\sigma_{1}<0\right)$ :

$$
\left(\frac{\sigma_{1}}{\mathrm{X}_{\mathrm{C}}}\right)^{2}=\mathrm{e}_{\mathrm{F}}^{2}\left\{\begin{array}{c}
\text { se } \mathrm{e}_{\mathrm{F}}>1 \rightarrow \text { danificou } \\
\text { se } \mathrm{e}_{\mathrm{F}} \leq 1 \rightarrow \text { não danificou }
\end{array}\right.
$$

Onde $\mathrm{X}_{\mathrm{C}}$ corresponde à resistência sob compressão longitudinal (direção 1 paralela às fibras).

Modo da Fibra sob Tração (fratura da fibra) $\left(\sigma_{1} \geq 0\right)$ :

$$
\left(\frac{\sigma_{1}}{X_{T}}\right)^{2}+\frac{\int_{0}^{\gamma_{12}} \sigma_{12} \mathrm{~d} \gamma_{12}}{\int_{0}^{\gamma_{12}^{u}} \sigma_{12} \mathrm{~d} \gamma_{12}}=\mathrm{e}_{\mathrm{F}}^{2}
$$

Sendo $\gamma_{12}^{\mathrm{u}}$ a deformação última por cisalhamento tem-se que:

$$
\begin{aligned}
& \left(\frac{\sigma_{1}}{\mathrm{X}_{\mathrm{T}}}\right)^{2}+\frac{\left(2 \sigma_{12}^{2} / \mathrm{G}_{12}\right)+\left(3 \alpha \sigma_{12}^{4}\right)}{\left(2 \mathrm{~S}_{12}^{2} / \mathrm{G}_{12}\right)+\left(3 \alpha \mathrm{S}_{12}^{4}\right)}=\mathrm{e}_{\mathrm{F}}^{2}, \text { ou seja, } \\
& \left(\frac{\sigma_{1}}{\mathrm{X}_{\mathrm{T}}}\right)^{2}+\frac{\mathrm{F}_{1}}{\mathrm{~F}_{2}}=\mathrm{e}_{\mathrm{F}}^{2}\left\{\begin{array}{c}
\text { se } \mathrm{e}_{\mathrm{F}}>1 \rightarrow \text { danificou } \\
\text { se } \mathrm{e}_{\mathrm{F}} \leq 1 \rightarrow \text { não danificou }
\end{array}\right.
\end{aligned}
$$

Onde $\mathrm{X}_{\mathrm{T}}$ corresponde à resistência sob tração longitudinal (direção 1 - paralela às fibras) e $\mathrm{S}_{12}$ corresponde a resistência ao cisalhamento. Vale ressaltar que se $\alpha$ for igual zero, recai-se no critério proposto por Hashin (1980).

Modo da Matriz sob Compressão (esmagamento da matriz) $\left(\sigma_{2}<0\right)$ :

$$
\left(\frac{\sigma_{2}}{2 S_{23}}\right)^{2}+\left[\left(\frac{Y_{C}}{2 S_{23}}\right)^{2}-1\right] \frac{\sigma_{2}}{Y_{C}}+\frac{F_{1}}{F_{2}}=e_{M}^{2}\left\{\begin{array}{c}
\text { se } e_{M}>1 \rightarrow \text { danificou } \\
\text { se } e_{M} \leq 1 \rightarrow \text { não danificou }
\end{array}\right.
$$

Onde $\mathrm{Y}_{\mathrm{C}}$ corresponde à resistência sob compressão transversal (direção 2 normal às fibras). 
Modo da Matriz sob Tração (fratura da matriz) $\left(\sigma_{2} \geq 0\right)$ :

$$
\left(\frac{\sigma_{2}}{\mathrm{Y}_{\mathrm{T}}}\right)^{2}+\frac{\mathrm{F}_{1}}{\mathrm{~F}_{2}}=\mathrm{e}_{\mathrm{M}}^{2}\left\{\begin{array}{c}
\text { se } \mathrm{e}_{\mathrm{M}}>1 \rightarrow \text { danificou } \\
\text { se } \mathrm{e}_{\mathrm{M}} \leq 1 \rightarrow \text { não danificou }
\end{array}\right.
$$

Onde $\mathrm{Y}_{\mathrm{T}}$ corresponde à resistência sob tração transversal (direção 2 - normal às fibras).

Numa segunda fase do projeto formulou-se e empregou-se o Critério de Hashin para o estado triplo de tensões também acrescentando os efeitos de não-linearidade devido às tensões de cisalhamento atuantes no plano da lâmina. Com isso pode-se obter as seguintes equações:

Modo da Fibra sob Compressão $\left(\sigma_{1}<0\right)$ :

$$
\left(\frac{\sigma_{1}}{\mathrm{X}_{\mathrm{C}}}\right)^{2}=\mathrm{e}_{\mathrm{F}}^{2}\left\{\begin{array}{c}
\text { se } \mathrm{e}_{\mathrm{F}}>1 \rightarrow \text { danificou } \\
\text { se } \mathrm{e}_{\mathrm{F}} \leq 1 \rightarrow \text { não danificou }
\end{array}\right.
$$

Modo da Fibra sob Tração (fratura da fibra) $\left(\sigma_{1} \geq 0\right)$ :

$$
\left(\frac{\sigma_{1}}{\mathrm{X}_{\mathrm{T}}}\right)^{2}+\left(\frac{\sigma_{13}}{\mathrm{~S}_{12}}\right)^{2}+\frac{\mathrm{F}_{1}}{\mathrm{~F}_{2}}=\mathrm{e}_{\mathrm{F}}^{2}\left\{\begin{array}{c}
\text { se } \mathrm{e}_{\mathrm{F}}>1 \rightarrow \text { danificou } \\
\text { se } \mathrm{e}_{\mathrm{F}} \leq 1 \rightarrow \text { não danificou }
\end{array}\right.
$$

Modo da Matriz sob Compressão (esmagamento da matriz) $\left(\sigma_{2}+\sigma_{3}<0\right)$ :

$$
\begin{aligned}
& \frac{1}{4 \mathrm{~S}_{23}^{2}}\left(\sigma_{2}+\sigma_{3}\right)^{2}+\left[\left(\frac{\mathrm{Y}_{\mathrm{C}}}{2 \mathrm{~S}_{23}}\right)^{2}-1\right] \frac{\left(\sigma_{2}+\sigma_{3}\right)}{\mathrm{Y}_{\mathrm{C}}}+\frac{1}{\mathrm{~S}_{23}^{2}}\left(\sigma_{23}^{2}-\sigma_{2} \sigma_{3}\right) \\
& +\left(\frac{\sigma_{13}}{\mathrm{~S}_{12}}\right)^{2}+\frac{\mathrm{F}_{1}}{\mathrm{~F}_{2}}=\mathrm{e}_{\mathrm{M}}^{2}\left\{\begin{array}{c}
\text { se } \mathrm{e}_{\mathrm{M}}>1 \rightarrow \text { danificou } \\
\text { se } \mathrm{e}_{\mathrm{M}} \leq 1 \rightarrow \text { não danificou }
\end{array}\right.
\end{aligned}
$$

Onde $\mathrm{S}_{23}$ corresponde a resistência ao cisalhamento no plano 2-3. 
Modo da Matriz sob Tração (fratura da matriz) $\left(\sigma_{2}+\sigma_{3} \geq 0\right)$ :

$$
\begin{aligned}
& \frac{1}{\mathrm{Y}_{\mathrm{T}}^{2}}\left(\sigma_{2}+\sigma_{3}\right)^{2}+\frac{1}{\mathrm{~S}_{23}^{2}}\left(\sigma_{23}^{2}-\sigma_{2} \sigma_{3}\right)+\left(\frac{\sigma_{13}}{\mathrm{~S}_{12}}\right)^{2} \\
& +\frac{\mathrm{F}_{1}}{\mathrm{~F}_{2}}=\mathrm{e}_{\mathrm{M}}^{2}\left\{\begin{array}{c}
\text { se } \mathrm{e}_{\mathrm{M}}>1 \rightarrow \text { danificou } \\
\text { se } \mathrm{e}_{\mathrm{M}} \leq 1 \rightarrow \text { não danificou }
\end{array}\right.
\end{aligned}
$$

Por fim, ambos os Critérios descritos acima foram implementados em linguagem FORTRAN e posteriormente compilados juntamente com o pacote de elementos finitos ABAQUS $^{\circledR}$. Deve-se ressaltar que mais detalhes sobre a implementação do modelo proposto serão apresentados neste mesmo capítulo no item 4.4 .

\subsubsection{Leis de Evolução de Dano Intralaminar}

A Lei de Evolução de Dano depende do modo de danificação predominante e está dividida em dois grupos, ou seja, há uma lei de degradação das propriedades caso ocorra um dano na fibra e uma lei de degradação das propriedades caso ocorra um dano na matriz. É importante ressaltar que essas leis são formuladas em função de parâmetros que podem ser obtidos da literatura, de ensaios experimentais em corpos-de-prova ou então a partir de modelos matemáticos que possuem solução analítica ou somente solução numérica. No entanto, há alguns pesquisadores (BOLZON; GHILOTTI; MAIER, 2002) que preferem recorrer a uma Análise Inversa para determinar tais parâmetros. Neste caso, utiliza-se o próprio ensaio experimental da estrutura que está sendo analisada para determinar parâmetros associados ao material. A Análise Inversa pode ser aplicada não somente para este tipo de problema, mas também para uma gama de outros problemas, compreendendo assim um vasto campo de estudo (TARANTOLA, 1987). No presente trabalho optou-se pela calibração dos parâmetros de material utilizando Análise Inversa bem como informações provenientes da literatura. As fontes utilizadas para obter determinados parâmetros serão descritas neste mesmo capítulo, mas o procedimento de calibração dos parâmetros utilizando Análise Inversa será detalhado no capítulo seguinte.

Por fim, deve-se destacar que será adotada a hipótese de que toda falha intralaminar não irá alterar as propriedades que não estão associadas ao plano da lâmina $1-2\left(E_{33} ; G_{13} ; G_{23} ; v_{23}\right.$ e $\left.v_{13}\right)$. 


\section{Danificacão da Matriz}

Em se tratando da danificação da matriz, a lei de degradação foi baseada no conceito de densidade de fissuramento ("crack density"). Tal conceito vem sendo utilizado com muito êxito por vários pesquisadores como pode ser evidenciado nos trabalhos de Nuismer e Tan (1988), Tan e Nuismer (1989), Tan (1991) e Varna (2002). O conceito de "crack density" determina que os fatores de degradação das propriedades de material são variáveis internas de estado que dependem da densidade de fissuramento da matriz polimérica (TAN, 1991). Vários trabalhos como de Chang; Liu e Chang (1991), Chang e Lessard (1991), Lessard e Shokrieh (1995) e Perugini; Riccio e Scaramuzzino (2001) demonstraram que após a primeira incidência de dano na matriz polimérica tem-se que os valores do módulo de elasticidade $E_{22}$ e o coeficiente de Poisson $v_{12}$ são fortemente afetados, não ocorrendo o mesmo para $\mathrm{o}$ módulo de elasticidade $\mathrm{E}_{11}$. Sendo assim, caso haja danificação da matriz (resina polimérica) sob tração ou sob compressão, as propriedades associadas a um dado ponto material devem ser ajustadas segundo a TABELA 4.2.2-1.

TABELA 4.2.2-1 - Ajuste das propriedades do ponto material devido à danificação da matriz

\begin{tabular}{cc}
\hline Propriedades Elásticas & Propriedades Degradadas \\
\hline $\mathrm{E}_{11}$ & $\mathrm{E}_{11}^{\mathrm{dm}}=\mathrm{E}_{11}$ \\
$\mathrm{E}_{22}$ & $\mathrm{E}_{22}^{\mathrm{dm}}=0$ \\
$\mathrm{v}_{12}$ & $\mathrm{v}_{12}^{\mathrm{dm}}=0$ \\
\hline
\end{tabular}

Além disso, deve-se considerar o comportamento não-linear devido às tensões de cisalhamento atuantes no plano da lâmina (plano 1-2). Dessa forma, $\overline{\mathrm{G}}_{12}^{\mathrm{dm}}$ deverá corresponder ao módulo de cisalhamento "atualizado" degradado:

$$
\bar{G}_{12}^{\mathrm{dm}}=\frac{\partial \mathrm{f}\left(\gamma_{12}\right)}{\partial \gamma_{12}}=\frac{1}{\frac{1}{\mathrm{G}_{12}}+3 \alpha \sigma_{12}^{2}}
$$

Finalmente, de acordo com a relação expressa na equação (4.1-1) tem-se um novo tensor constitutivo devido à danificação da matriz que será dado por: 


$$
\left[\mathrm{Q}_{\mathrm{M}}^{\mathrm{d}}\right]=\left[\begin{array}{cccccc}
\mathrm{Q}_{11}^{\mathrm{dm}} & \mathrm{Q}_{12}^{\mathrm{dm}} & \mathrm{Q}_{13}^{\mathrm{dm}} & 0 & 0 & 0 \\
\mathrm{Q}_{21}^{\mathrm{dm}} & \mathrm{Q}_{22}^{\mathrm{dm}} & \mathrm{Q}_{23}^{\mathrm{d}} & 0 & 0 & 0 \\
\mathrm{Q}_{31}^{\mathrm{dm}} & \mathrm{Q}_{32}^{\mathrm{dm}} & \mathrm{Q}_{33}^{\mathrm{dm}} & 0 & 0 & 0 \\
0 & 0 & 0 & 2 \mathrm{Q}_{44}^{\mathrm{dm}} & 0 & 0 \\
0 & 0 & 0 & 0 & 2 \mathrm{Q}_{55} & 0 \\
0 & 0 & 0 & 0 & 0 & 2 \mathrm{Q}_{66}
\end{array}\right]
$$

onde:

$$
\begin{aligned}
& \mathrm{Q}_{11}^{\mathrm{dm}}=\frac{\mathrm{E}_{11}\left(1-v_{23} v_{32}\right)}{\Delta^{\mathrm{dm}}} \quad \mathrm{Q}_{12}^{\mathrm{dm}}=\frac{\mathrm{E}_{11}\left(v_{21}^{\mathrm{dm}}+v_{31} v_{23}\right)}{\Delta^{\mathrm{dm}}} \\
& \mathrm{Q}_{22}^{\mathrm{dm}}=\frac{\mathrm{E}_{22}^{\mathrm{dm}}\left(1-\mathrm{v}_{31} \mathrm{v}_{13}\right)}{\Delta^{\mathrm{dm}}} \quad \mathrm{Q}_{13}^{\mathrm{dm}}=\frac{\mathrm{E}_{11}\left(\mathrm{v}_{31}+\mathrm{v}_{21}^{\mathrm{dm}} \mathrm{v}_{32}\right)}{\Delta^{\mathrm{dm}}} \\
& \mathrm{Q}_{33}^{\mathrm{dm}}=\frac{\mathrm{E}_{33}\left(1-v_{21}^{\mathrm{dm}} v_{12}^{\mathrm{dm}}\right)}{\Delta^{\mathrm{dm}}} \quad \mathrm{Q}_{23}^{\mathrm{dm}}=\frac{\mathrm{E}_{22}^{\mathrm{dm}}\left(v_{32}+v_{12}^{\mathrm{dm}} v_{31}\right)}{\Delta^{\mathrm{dm}}} \\
& \mathrm{Q}_{44}^{\mathrm{dm}}=\overline{\mathrm{G}}_{12}^{\mathrm{dm}} \\
& \Delta^{\mathrm{dm}}=1-v_{12}^{\mathrm{dm}} v_{21}^{\mathrm{dm}}-v_{23} v_{32}-v_{31} v_{13}-2 v_{21}^{\mathrm{dm}} v_{32} v_{13}
\end{aligned}
$$

\section{$\underline{\text { Danificacão da Fibra }}$}

Em se tratando da danificação da fibra, deve-se ressaltar inicialmente que todas as propriedades elásticas associadas ao plano da lâmina 1-2 serão afetadas (CHANG; CHANG, 1987a) (CHANG; CHANG, 1987b). Com base na literatura e em resultados experimentais, $\mathrm{o}$ módulo de elasticidade $E_{22}$ e o coeficiente de Poisson $v_{12}$ são degradados totalmente ou quase que totalmente. De acordo com o trabalho de Feih e Schercliff (2000), a degradação dessas propriedades pode ser de até 99\% para compósitos poliméricos reforçados com fibra de carbono. Há ainda pesquisadores que obtiveram resultados satisfatórios ao reduzir a zero o valor dessas propriedades após a ocorrência do primeiro dano da fibra (CHANG; LIU; CHANG, 1991) (CHANG; LESSARD, 1991).

Por outro lado o módulo de Elasticidade $E_{11}$ e o módulo de cisalhamento $G_{12}$ devem ser degradados parcialmente. Essa degradação parcial pode ser efetuada de duas formas:

Através de um fator constante de degradação;

$\checkmark$ Através de uma função de degradação.

Vários trabalhos presentes na literatura optaram pela degradação baseada em um fator constante (TAN, 1991) (LESSARD; SHOKRIEH, 1995) (KERMANIDIS et al, 2000) (FEIH; SCHERCLIFF, 2000). Sendo assim, tem-se que: 


$$
\begin{aligned}
& \mathrm{E}_{11}^{\mathrm{df}}=\mathrm{d}_{11}^{\mathrm{F}} \mathrm{E}_{11} \\
& \mathrm{G}_{12}^{\mathrm{df}}=\mathrm{d}_{12}^{\mathrm{F}} \mathrm{G}_{12}
\end{aligned}
$$

onde:

$$
\begin{aligned}
& \mathrm{d}_{11}^{\mathrm{F}}=\text { fator de degradação para o módulo de elasticidade } \mathrm{E}_{11} \\
& \mathrm{~d}_{12}^{\mathrm{F}}=\text { fator de degradação para o módulo } \mathrm{G}_{12}
\end{aligned}
$$

Yamada e Sun (1978) baseando-se na Teoria de Falha de Feixes de Fibra expressaram uma lei de degradação na forma de uma função exponencial. Segundo a Teoria de Falha de Feixes de Fibra, a tensão de tração média requisitada para fraturar uma simples fibra é muito maior do que a resistência média de uma fibra num feixe. Portanto, a tensão requisitada para romper uma só fibra dentro de uma lâmina unidirecional é muito maior do que a tensão que será requisitada para fraturar uma fibra num laminado. Isto faz com que a danificação da fibra seja fortemente influenciada pelas dimensões da área que está sendo solicitada, ou seja, a resistência da lâmina depende claramente da área danificada. Diante desse fato, Yamada e Sun (1978) propuseram que tanto o valor de resistência à tração longitudinal como o valor de resistência ao cisalhamento no plano 1-2, deveriam ser calculados considerando uma certa natureza estatística de falha dos laminados. Dessa forma, esses valores de resistência deveriam ser escritos em função de uma distribuição estatística de Weibull que seria ajustada com base em resultados experimentais:

$$
\mathrm{F}(\mathrm{x})=1-\exp \left[-\left(\frac{\mathrm{x}}{\mathrm{m}}\right)^{\mathrm{a}}\right]
$$

onde:

a e m são parâmetros associados à distribuição de Weibull

Posteriormente, Chang e Chang (1987a e 1987b) postularam que o módulo de elasticidade à tração na direção longitudinal $E_{11}$ e o módulo de cisalhamento no plano da lâmina $G_{12}$ deveriam ser degradados da seguinte forma:

$$
\mathrm{E}_{11}^{\mathrm{df}}=\mathrm{E}_{11} \exp \left[-\left(\frac{\mathrm{A}}{\mathrm{A}_{\mathrm{o}}}\right)^{\beta}\right]
$$




$$
\mathrm{G}_{12}^{\mathrm{df}}=\mathrm{G}_{12} \exp \left[-\left(\frac{\mathrm{A}}{\mathrm{A}_{\mathrm{o}}}\right)^{\beta}\right]
$$

onde:

$\mathrm{A}=$ zona danificada prevista pelo critério de danificação

$\mathrm{A}_{\mathrm{o}}=$ zona de interação de falha da fibra associada com a medida de resistência a tração da mesma

$\beta=$ parâmetro de forma da distribuição de Weibull

A zona de interação de falha $\left(\mathrm{A}_{\mathrm{o}}\right)$ é função do comprimento crítico de falha $(\delta)$ de tal forma que $\mathrm{A}_{\mathrm{o}}$ é igual a $\delta^{2}$. O valor do comprimento crítico pode ser calculado utilizando conceitos de Mecânica da Fratura. Sendo assim, determina-se um modelo matemático que possui solução analítica ao qual permite definir a zona de interação existente uma fibra danificada que sofreu "pull-out" e a região da matriz atingida. Tal parâmetro está associado diretamente ao tipo de fibra e resina que são empregados. Com isso, para compósitos que fraturam mais gradativamente, os valores de $\delta$ são menores ao passo que para compósitos que fraturam de forma mais abrupta, os valores de $\delta$ são maiores. Shahid e Chang (1995) demonstraram que o valor de $\delta$ para compósitos de resina epóxi reforçada com fibra de carbono varia entre 0,025 e 0,06 polegadas.

No presente trabalho optou-se por utilizar tanto a degradação baseada em um fator constante como numa lei exponencial. No entanto, decidiu-se mudar a lei de danificação proposta por Chang e Chang (1987a e 1987b) (eq. 4.2.2-6 e eq. 4.2.2-7) a fim de gerar uma redução menos acentuada das propriedades. Porém, a degradação da mesma passou a ser influenciada pelo segundo invariante da parte desviadora do tensor de deformações:

$$
\begin{aligned}
& E_{11}^{d f}=E_{11} \exp \left[-\left(\frac{A}{A_{o}}\right) H\right]-B \bar{\varepsilon} \\
& G_{12}^{d f}=G_{12} \exp \left[-\left(\frac{A}{A_{o}}\right) H\right]-B \bar{\varepsilon}
\end{aligned}
$$

onde:

$H=$ parâmetro que controla o grau de degradação da propriedade

$\mathrm{B}=$ parâmetro de ajuste da função de degradação

$\bar{\varepsilon}=$ Segundo invariante das deformações desviadoras 
Conseqüentemente tanto $\mathrm{H}$ como $\mathrm{B}$ são parâmetros que deverão ser calibrados, utilizando o procedimento de Análise Inversa. Dessa forma, com base em resultados experimentais bem como resultados provenientes das análises computacionais, tais parâmetros serão devidamente ajustados. Além disso, para o presente trabalho, o valor da zona danificada prevista pelo Critério de Danificação (A) será adotado igual a 1/4 do valor da área do elemento finito que possui 4 pontos de Gauss e que contenha falha em um desses pontos de integração. Vale ressaltar que o valor da propriedade será degradado somente quando o critério de danificação da fibra for verificado. Sendo assim, até a não verificação do critério, o valor da propriedade se manterá constante, dentro do regime elástico. Somente quando uma área danificada for identificada é que a propriedade deverá ser degradada em função do valor desta área e do estado de deformações presente no meio.

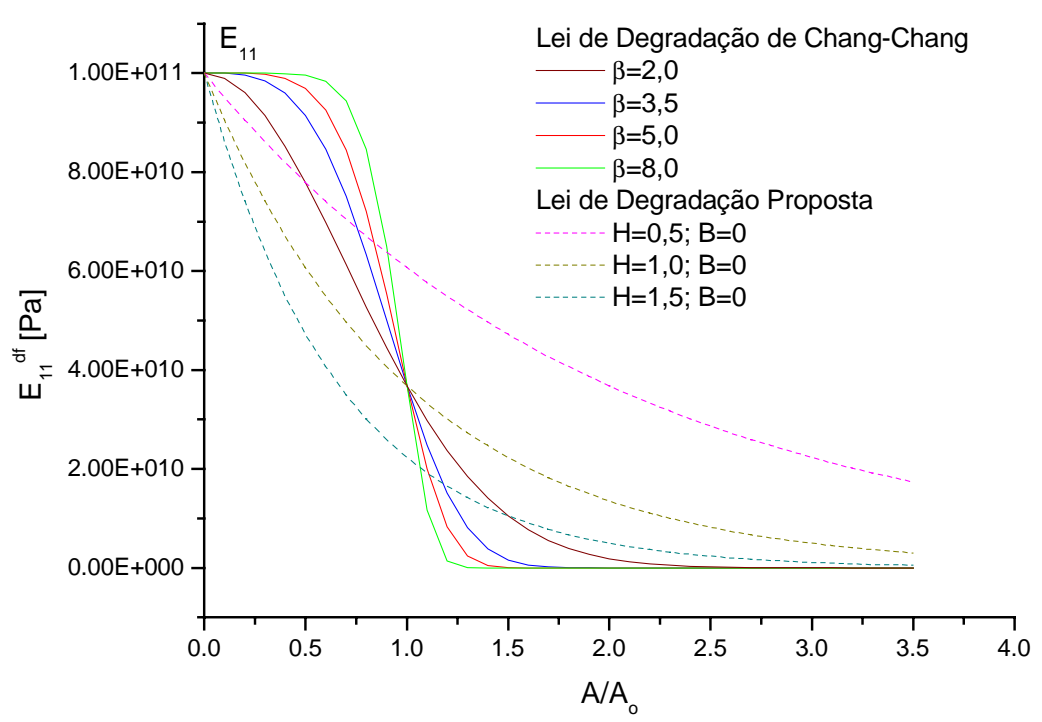

FIGURA 4.2.2-1 - Degradação do módulo de Young E 11

Nota-se pela FIGURA 4.2.2-1 que a degradação do módulo de Young $\mathrm{E}_{11}$ é mais acentuada quando se utiliza a lei proposta por Chang-Chang. No presente trabalho, o parâmetro $\mathrm{H}$ apenas multiplica a relação $\mathrm{A} / \mathrm{A}_{0}$, fazendo com que a degradação seja mais suave. No entanto, é importante ressaltar que caso esta degradação seja muito lenta, deve-se acionar o parâmetro B de tal forma que ao ocorrer acréscimo de deformações essa degradação deverá acelerar-se automaticamente. Em suma, caso haja danificação da fibra sob tração ou sob compressão, as propriedades associadas a um dado ponto material devem ser ajustadas segundo a TABELA 4.2.2-2. 
TABELA 4.2.2-2 - Ajuste das propriedades do ponto material devido à danificação da fibra

\begin{tabular}{ccc}
\hline $\begin{array}{c}\text { Propriedades } \\
\text { Elásticas }\end{array}$ & \multicolumn{2}{c}{ Propriedades Degradadas } \\
\cline { 2 - 3 } $\mathrm{E}_{11}$ & Fator Constante & Função Exponencial \\
\hline $\mathrm{E}_{12}^{\mathrm{df}}=\mathrm{d}_{11}^{\mathrm{F}} \mathrm{E}_{11}$ & $\mathrm{E}_{11}^{\mathrm{df}}=\mathrm{E}_{11} \exp \left[-\left(\frac{\mathrm{A}}{\mathrm{A}_{\mathrm{o}}}\right) \mathrm{H}\right]-\mathrm{B} \bar{\varepsilon}$ \\
$\mathrm{E}_{22}$ & $\mathrm{G}_{12}^{\mathrm{df}}=\mathrm{d}_{12}^{\mathrm{F}} \mathrm{G}_{12}$ & $\mathrm{G}_{12}^{\mathrm{df}}=\mathrm{G}_{12} \exp \left[-\left(\frac{\mathrm{A}}{\mathrm{A}_{\mathrm{o}}}\right) \mathrm{H}\right]-\mathrm{B} \bar{\varepsilon}$ \\
$\mathrm{v}_{12}$ & $\mathrm{E}_{22}^{\mathrm{df}}=0$ & $\mathrm{E}_{22}^{\mathrm{df}}=0$ \\
$\mathrm{v}_{12}^{\mathrm{df}}=0$ & $\mathrm{v}_{12}^{\mathrm{df}}=0$
\end{tabular}

Finalmente, de acordo com a relação expressa na equação (4.1-1) tem-se um novo tensor constitutivo devido à danificação da fibra que será dado por:

$$
\left[\mathrm{Q}_{\mathrm{F}}^{\mathrm{d}}\right]=\left[\begin{array}{cccccc}
\mathrm{Q}_{11}^{\mathrm{df}} & \mathrm{Q}_{12}^{\mathrm{df}} & \mathrm{Q}_{13}^{\mathrm{df}} & 0 & 0 & 0 \\
\mathrm{Q}_{21}^{\mathrm{df}} & \mathrm{Q}_{22}^{\mathrm{df}} & \mathrm{Q}_{23}^{\mathrm{df}} & 0 & 0 & 0 \\
\mathrm{Q}_{31}^{\mathrm{df}} & \mathrm{Q}_{32}^{\mathrm{df}} & \mathrm{Q}_{33}^{\mathrm{df}} & 0 & 0 & 0 \\
0 & 0 & 0 & 2 \mathrm{Q}_{44}^{\mathrm{df}} & 0 & 0 \\
0 & 0 & 0 & 0 & 2 \mathrm{Q}_{55} & 0 \\
0 & 0 & 0 & 0 & 0 & 2 \mathrm{Q}_{66}
\end{array}\right]
$$

onde:

$$
\begin{array}{ll}
\mathrm{Q}_{11}^{\mathrm{df}}=\frac{E_{11}^{\mathrm{df}}\left(1-v_{23} v_{32}\right)}{\Delta^{\mathrm{df}}} & \mathrm{Q}_{12}^{\mathrm{df}}=\frac{\mathrm{E}_{11}^{\mathrm{df}}\left(v_{21}^{\mathrm{df}}+v_{31} v_{23}\right)}{\Delta^{\mathrm{df}}} \\
\mathrm{Q}_{22}^{\mathrm{df}}=\frac{E_{22}^{\mathrm{df}}\left(1-v_{31} v_{13}\right)}{\Delta^{\mathrm{df}}} & \mathrm{Q}_{13}^{\mathrm{df}}=\frac{\mathrm{E}_{11}^{\mathrm{df}}\left(v_{31}+v_{21}^{\mathrm{df}} v_{32}\right)}{\Delta^{\mathrm{df}}} \\
\mathrm{Q}_{33}^{\mathrm{df}}=\frac{E_{33}\left(1-v_{21}^{\mathrm{df}} v_{12}^{\mathrm{df}}\right)}{\Delta^{\mathrm{df}}} & \mathrm{Q}_{23}^{\mathrm{df}}=\frac{E_{22}^{\mathrm{df}}\left(v_{32}+v_{12}^{\mathrm{df}} v_{31}\right)}{\Delta^{\mathrm{df}}} \\
\mathrm{Q}_{44}^{\mathrm{df}}=\overline{\mathrm{G}}_{12}^{\mathrm{df}} & \Delta^{\mathrm{df}}=1-v_{12}^{\mathrm{df}} v_{21}^{\mathrm{df}}-v_{23} v_{32}-v_{31} v_{13}-2 v_{21}^{\mathrm{df}} v_{32} v_{13}
\end{array}
$$

Além disso, deve-se considerar o comportamento não-linear devido às tensões de cisalhamento atuantes no plano da lâmina (plano 1-2). Dessa forma, $\overline{\mathrm{G}}_{12}^{\mathrm{df}}$ deverá corresponder ao módulo de cisalhamento "atualizado" degradado: 


$$
\overline{\mathrm{G}}_{12}^{\mathrm{df}}=\frac{1}{\frac{1}{\mathrm{G}_{12}^{\mathrm{df}}}+3 \alpha \sigma_{12}^{2}}
$$

Onde o parâmetro $\mathrm{G}_{12}^{\mathrm{df}}$ será obtido através da equação (4.2.2-9) que considera a degradação da propriedade em função da danificação da fibra

Por fim, todas as Leis de Evolução de Dano descritas acima foram implementadas em linguagem FORTRAN e posteriormente compiladas juntamente com o pacote de elementos finitos ABAQUS ${ }^{\circledR}$. Deve-se ressaltar novamente que mais detalhes sobre a implementação dessas leis serão apresentados neste mesmo capítulo no item 4.4.

\subsection{ANÁLISE DE FALHA INTERLAMINAR}

A identificação de uma falha interlaminar (delaminação) será realizada pelo Critério de Falha Interlaminar. Após a identificação da delaminação, aplica-se a Lei de Evolução de Falha para que as propriedades do ponto material afetado possam ser devidamente enfraquecidas.

\subsubsection{Critério de Falha Interlaminar}

O Critério de Falha Interlaminar adotado no presente trabalho foi escolhido com base nos critérios utilizados por vários pesquisadores: Liu; Kutlu e Chang (1993), Kermanidis et al (2000), Dávila e Camanho (2001), Dávila; Camanho e Moura (2001) e Kostopoulos et al. (2002).

Como as delaminações são causadas principalmente pelas tensões que atuam fora do plano da lâmina, adota-se o seguinte critério:

Falha por Delaminação sob Tração $\left(\sigma_{3} \geq 0\right)$ :

$$
\left(\frac{\sigma_{3}}{Z_{\mathrm{T}}}\right)^{2}+\left(\frac{\sigma_{13}}{\mathrm{~S}_{13}}\right)^{2}+\left(\frac{\sigma_{23}}{\mathrm{~S}_{23}}\right)^{2}=\mathrm{e}_{\text {dela }}^{2}\left\{\begin{array}{c}
\text { se } \mathrm{e}_{\text {dela }}>1 \rightarrow \text { falhou } \\
\mathrm{se} \mathrm{e}_{\text {dela }} \leq 1 \rightarrow \text { não falhou }
\end{array}\right.
$$

Onde $\mathrm{Z}_{\mathrm{T}}$ corresponde à resistência à tração transversal (direção 3 - normal plano da lâmina). 
Deve-se ressaltar que a equação (4.3.1-1) identifica somente o início da delaminação. De acordo com Jang (1994), pode-se ainda modelar a propagação da delaminação calculando a taxa de energia de deformação liberada ("strain energy release rate") com base em conceitos da Mecânica da Fratura, como foi demonstrado por Dávila e Camanho (2001) e Dávila; Camanho e Moura (2001). Além disso, após a delaminação, há a ocorrência de mecanismos de atrito e contato entre as lâminas que se separaram. No entanto, o presente trabalho irá se limitar em prever apenas o início do processo de delaminação e avaliará as conseqüências que este fenômeno irá produzir no laminado que falhou.

\subsubsection{Lei de Evolução de Falha Interlaminar}

Devido à separação das lâminas adjacentes, deve-se considerar que a falha por delaminação afetará as propriedades do ponto material que estão associadas à direção normal ao plano da lâmina $\left(E_{33}, G_{23}, G_{13}, v_{23}\right.$ e $\left.v_{13}\right)$. Portanto, quando a falha por delaminação ocorre, considera-se que região delaminada não é capaz de suportar carregamentos na direção normal ao plano da lâmina (tensões normais e tensões de cisalhamento transversais). Neste caso, tanto os módulos $E_{33}, G_{23}$ e $G_{13}$ como os coeficientes de Poisson $v_{23}$ e $v_{13}$ sofrerão uma degradação parcial através da aplicação de um fator constante de degradação:

$$
\begin{aligned}
& \mathrm{E}_{33}^{\text {dela }}=\mathrm{d}_{1}^{\text {dela }} \mathrm{E}_{33} \\
& \mathrm{G}_{23}^{\text {dela }}=\mathrm{d}_{2}^{\text {dela }} \mathrm{G}_{23} \\
& \mathrm{G}_{13}^{\text {dela }}=\mathrm{d}_{3}^{\text {dela }} \mathrm{G}_{13} \\
& \mathrm{v}_{23}^{\text {dela }}=\mathrm{d}_{4}^{\text {dela }} \mathrm{v}_{23} \\
& \mathrm{v}_{13}^{\text {dela }}=\mathrm{d}_{5}^{\text {dela }} \mathrm{v}_{13}
\end{aligned}
$$

onde:

$\mathrm{d}_{1}^{\text {dela }}=$ fator de degradação do módulo de elasticidade $\mathrm{E}_{33}$

$\mathrm{d}_{2}^{\text {dela }}=$ fator de degradação do módulo de cisalhamento $\mathrm{G}_{23}$

$\mathrm{d}_{3}^{\text {dela }}=$ fator de degradação do módulo de cisalhamento $\mathrm{G}_{13}$

$\mathrm{d}_{4}^{\text {dela }}=$ fator de degradação do coeficiente de Poisson $v_{23}$

$\mathrm{d}_{5}^{\text {dela }}=$ fator de degradação do coeficiente de Poisson $v_{13}$ 
Segundo Kermanidis et al. (2000) todos os fatores de degradação descritos acima podem ser iguais a zero. Entretanto, a fim de evitar problemas numéricos devido ao mau condicionamento da matriz de rigidez, optou-se por torna-los iguais a 0,01 . Sendo assim, tal parâmetro fará com que as propriedades elásticas sejam reduzidas em $99 \%$ do valor inicial.

Apesar das delaminações não afetarem o módulo de cisalhamento no plano da lâmina 1-2, deve-se considerar o comportamento não-linear devido às tensões de cisalhamento atuantes neste plano. Dessa forma, $\overline{\mathrm{G}}_{12}^{\text {dela }}$ deverá corresponder ao módulo de cisalhamento "atualizado" degradado:

$$
\bar{G}_{12}^{\text {dela }}=\frac{\partial f\left(\gamma_{12}\right)}{\partial \gamma_{12}}=\frac{1}{\frac{1}{G_{12}}+3 \alpha \sigma_{12}^{2}}
$$

Finalmente, de acordo com a relação expressa na equação (4.1-1) tem-se um novo tensor constitutivo devido à falha interlaminar que será dado por:

$$
\left[\mathrm{Q}_{\text {dela }}^{\text {d }}\right]=\left[\begin{array}{cccccc}
\mathrm{Q}_{11}^{\text {dela }} & \mathrm{Q}_{12}^{\text {dela }} & \mathrm{Q}_{13}^{\text {dela }} & 0 & 0 & 0 \\
\mathrm{Q}_{21}^{\text {dela }} & \mathrm{Q}_{22}^{\text {dela }} & \mathrm{Q}_{23}^{\text {dela }} & 0 & 0 & 0 \\
\mathrm{Q}_{31}^{\text {dela }} & \mathrm{Q}_{32}^{\text {dela }} & \mathrm{Q}_{33}^{\text {dela }} & 0 & 0 & 0 \\
0 & 0 & 0 & 2 \mathrm{Q}_{44}^{\text {dela }} & 0 & 0 \\
0 & 0 & 0 & 0 & 2 \mathrm{Q}_{55}^{\text {dela }} & 0 \\
0 & 0 & 0 & 0 & 0 & 2 \mathrm{Q}_{66}^{\text {dela }}
\end{array}\right]
$$

onde:

$$
\begin{array}{rlrl}
\mathrm{Q}_{11}^{\text {dela }} & =\frac{\mathrm{E}_{11}\left(1-v_{23}^{\text {dela }} v_{32}^{\text {dela }}\right)}{\Delta^{\text {dela }}} & & \\
\mathrm{Q}_{22}^{\text {dela }} & =\frac{\mathrm{E}_{22}\left(1-v_{31}^{\text {dela }} v_{13}^{\text {dela }}\right)}{\Delta^{\text {dela }}} & \mathrm{Q}_{12}^{\text {dela }}=\frac{E_{11}\left(v_{21}+v_{31}^{\text {dela }} v_{23}^{\text {dela }}\right)}{\Delta^{\text {dela }}} \\
\mathrm{Q}_{33}^{\text {dela }} & =\frac{E_{33}^{\text {dela }}\left(1-v_{21} v_{12}\right)}{\Delta^{\text {dela }}} & \mathrm{Q}_{13}^{\text {dela }}=\frac{E_{11}\left(v_{31}^{\text {dela }}+v_{21} v_{32}^{\text {dela }}\right)}{\Delta^{\text {dela }}} \\
\mathrm{Q}_{44}^{\text {dela }} & =\bar{G}_{12}^{\text {dela }} & \mathrm{Q}_{23}^{\text {dela }}=\frac{E_{22}\left(v_{32}^{\text {dela }}+v_{12} v_{31}^{\text {dela }}\right)}{\Delta^{\text {dela }}} \\
\mathrm{Q}_{55}^{\text {dela }} & =\mathrm{G}_{13}^{\text {dela }} & \Delta^{\text {dela }}=1-v_{12} v_{21}-v_{23}^{\text {dela }} v_{32}^{\text {dela }}-v_{31}^{\text {dela }} v_{13}^{\text {dela }}-2 v_{21} v_{32}^{\text {dela }} v_{13}^{\text {dela }} \\
\mathrm{Q}_{66}^{\text {dela }}=G_{23}^{\text {dela }} & &
\end{array}
$$




\subsection{IMPLEMENTAÇÃO DO MODELO PROPOSTO}

Todos os Critérios e Leis de Evolução de Danos e Falhas descritos acima foram implementados em linguagem FORTRAN e posteriormente compilados juntamente com o pacote de elementos finitos ABAQUS ${ }^{\circledR}$. Vale ressaltar que o ABAQUS ${ }^{\circledR}$ permite aos seus usuários a criação de sub-rotinas próprias ("user subroutines") a fim de que as mesmas possam ser compiladas em FORTRAN juntamente com o programa. Para implementação de sub-rotinas de material existem duas alternativas: USDFLD e UMAT. As sub-rotinas USDFLD permitem que determinadas variáveis de estado previamente escolhidas pelo usuário possam ser atualizadas em toda iteração. Porém o tensor constitutivo deverá ser atualizado somente uma única vez. Por outro lado, as subrotinas UMAT permitem que tanto as variáveis de estado como o tensor constitutivo possam ser atualizados em todas iterações (ABAQUS, 2002).

As implementações das sub-rotinas de material seguiram uma seqüência gradativa de complexidade a fim de que os parâmetros associados aos modelos pudessem ser analisados de maneira mais criteriosa. Dessa forma, tem-se a seguinte ordem de implementação:

1) Implementação dos Critérios de Danificação e das Leis de Evolução de Dano para estado plano de tensões utilizando sub-rotinas USDFLD;

2) Implementação dos Critérios de Danificação e das Leis de Evolução de Dano para estado plano de tensões utilizando sub-rotinas UMAT;

3) Implementação dos Critérios de Danificação e das Leis de Evolução de Dano para estado triplo de tensões utilizando sub-rotinas UMAT;

4) Implementação dos Critérios de Danificação e das Leis de Evolução de Dano para estado triplo de tensões bem como dos Critérios de Falha e das Leis de Evolução de Falha utilizando sub-rotinas UMAT.

Todas as sub-rotinas FORTRAN foram devidamente documentadas e podem ser consultadas no Apêndice A. Na FIGURA 4.4-1 tem-se um algoritmo geral da sub-rotina USDFLD bem como da sua interação com o programa ABAQUS ${ }^{\circledR}$. 


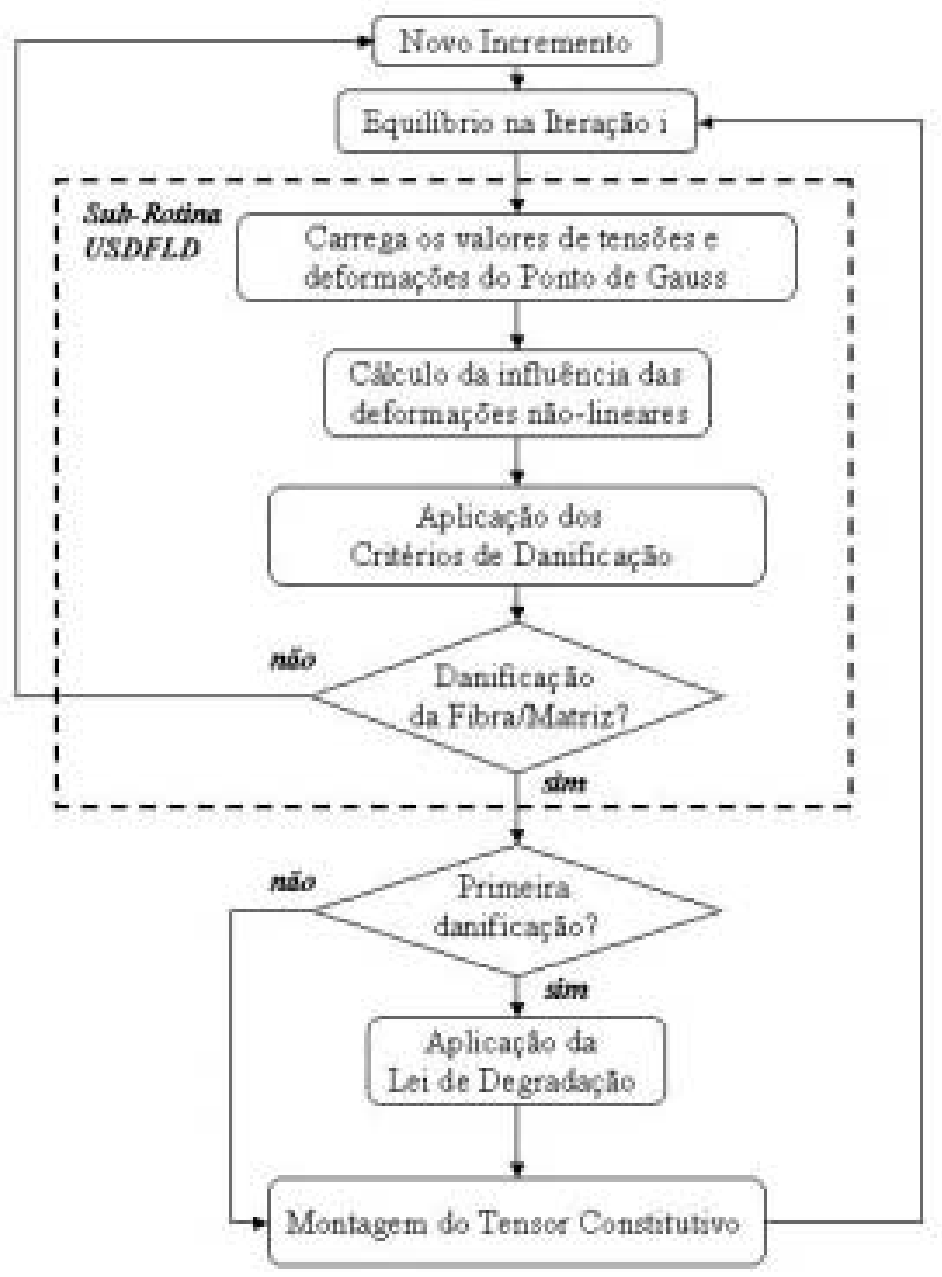

FIGURA 4.4-1 - Fluxograma do algoritmo da sub-rotina USDFLD

Nota-se pelo fluxograma do algoritmo que inicialmente a sub-rotina USDFLD carrega os valores de tensão calculados pelo programa ABAQUS ${ }^{\circledR}$. Posteriormente, calcula-se a influência das deformações não-lineares causadas pela ação do cisalhamento no plano da lâmina. Vale ressaltar que essa influência será utilizada no processo de degradação do ponto material. Em seguida, aplica-se os valores de tensão aos sub-critérios de danificação a fim de se verificar algum dano na fibra ou na matriz. Caso nenhum dano seja detectado, acrescenta-se um incremento de carga. Caso contrário, aplica-se a Lei de Degradação em função do dano ocorrido desde que seja a primeira incidência de tal tipo de dano no ponto de integração avaliado. Essa degradação é dada em função de um fator constante de degradação. Dessa forma, o usuário poderá escolher este fator, mas será o programa $\mathrm{ABAQUS}{ }^{\circledR}$ que irá degradar as propriedades e assim então, montar o novo tensor constitutivo para o respectivo ponto de integração. Deve-se destacar que se o ponto de integração é reincidente num 
determinado tipo de ocorrência de dano, o programa ABAQUS ${ }^{\circledR}$ não aplicará novamente o fator de degradação, fazendo com que as propriedades do ponto material na iteração atual sejam iguais às propriedades na iteração anterior. Ao final da montagem de todos os respectivos tensores constitutivos, o programa irá montar a rigidez de cada elemento laminado e por conseguinte a rigidez global de toda estrutura para que se possa assim, verificar o equilíbrio na iteração desejada.

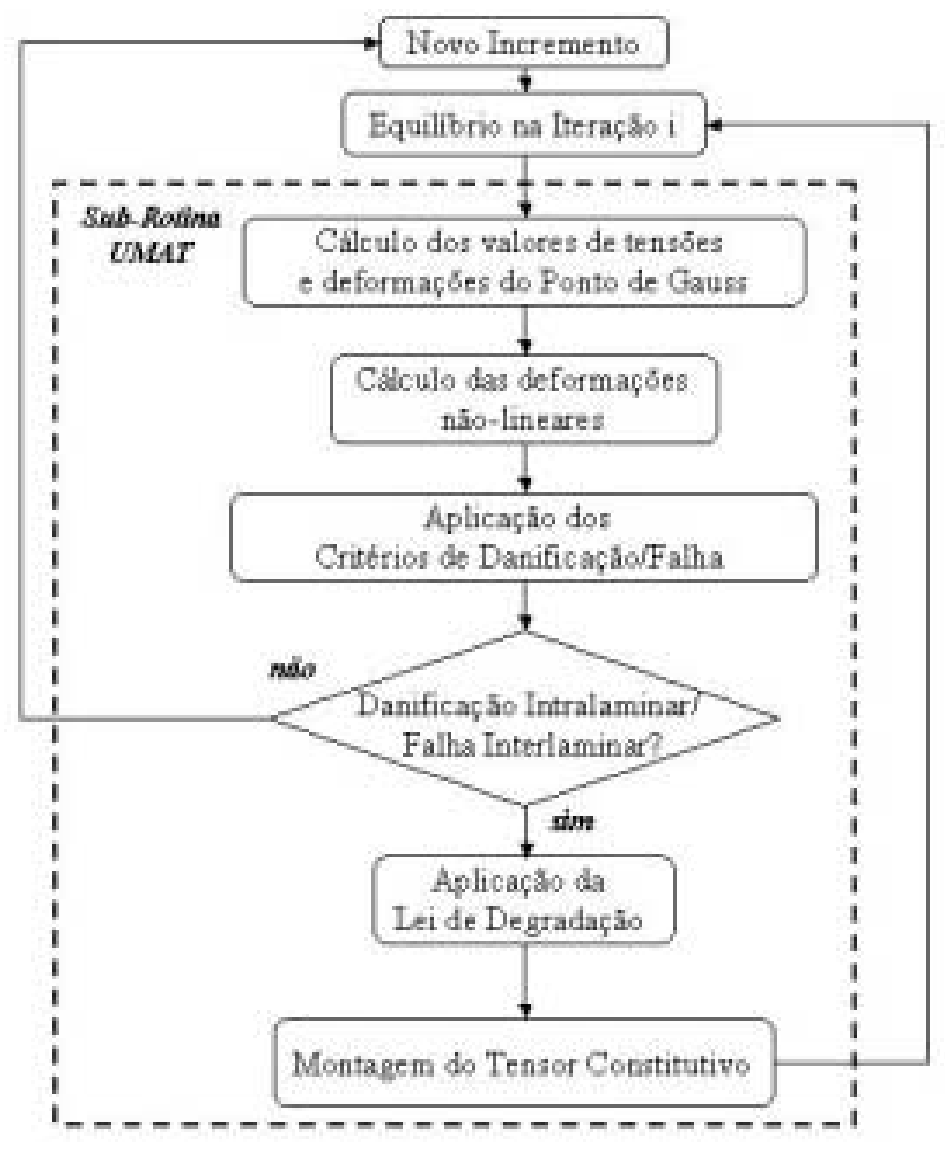

FIGURA 4.4-2 - Fluxograma do algoritmo das sub-rotinas UMAT

Na FIGURA 4.4-2 tem-se um fluxograma do algoritmo das sub-rotinas UMAT bem como da sua interação com o programa ABAQUS ${ }^{\circledR}$. Em princípio nota-se uma certa diferença desse fluxograma para o apresentado anteriormente, pois a sub-rotina UMAT computa os valores de tensão. Posteriormente, calcula-se as deformações nãolineares causadas pela ação do cisalhamento no plano da lâmina. Em seguida aplica-se os valores de tensão aos sub-critérios de danificação intralaminar e de falha interlaminar a fim de se verificar algum dano na fibra ou na matriz ou alguma delaminação. Caso nenhum dano ou falha seja detectado, acrescenta-se um incremento de carga. Caso 
contrário, aplica-se a Lei de Degradação em função do dano ou falha ocorrida. Neste caso, a degradação poderá ser função de um fator constante de degradação ou então da lei de degradação escolhida pelo próprio usuário. Dessa forma, a UMAT será responsável pela montagem do novo tensor constitutivo para o respectivo ponto de integração. Deve-se destacar que se o ponto de integração é reincidente num determinado tipo de ocorrência de dano ou falha, a UMAT aplicará novamente o fator ou lei de degradação, fazendo com que as propriedades do ponto material na iteração atual sejam diferente das propriedades na iteração anterior. Ao final da montagem de todos os respectivos tensores constitutivos, o programa irá montar a rigidez de cada elemento laminado e por conseguinte a rigidez global de toda estrutura para que se possa assim, verificar o equilíbrio na iteração desejada.

\subsection{ANÁLISE DE TESTES DE TRAÇÃO E COMPRESSÃO}

É importante ressaltar que os critérios e leis de degradação foram implementados com o intuito de avaliar as potencialidades e limitações dos modelos de material bem como calibrar os parâmetros de material associados a tais modelos. Sendo assim, neste item serão apresentados resultados e discussões das análises computacionais dos ensaios de tração e compressão.

Para o ensaio de tração foi desenvolvido um modelo constituído por elementos do tipo casca, designado Elemento S8R que contém 8 nós e 4 pontos de integração (ABAQUS, 2002) a fim de avaliar o laminado sob estado plano de tensões. Neste modelo, as vinculações e os carregamentos foram impostos de tal forma que os nós localizados numa extremidade estão vinculados simulando a garra fixa e aos nós da outra extremidade aplica-se um dado deslocamento simulando a garra móvel (FIGURA 4.5-1(a)). Um modelo similar foi desenvolvido para os ensaios de compressão (FIGURA 4.5-1(b)), onde numa extremidade tem-se a aplicação de vinculações simulando o travamento da amostra no dispositivo empregado ao passo que na outra, tem-se a aplicação de um dado deslocamento simulando o deslocamento da parte superior do dispositivo IITRI projetado pelo Illinois Institute of Technology Research Institute e descrito no capítulo anterior (FIGURA 3.3.1-8). 


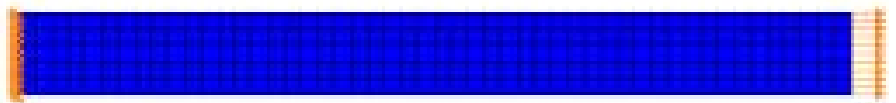

(a)

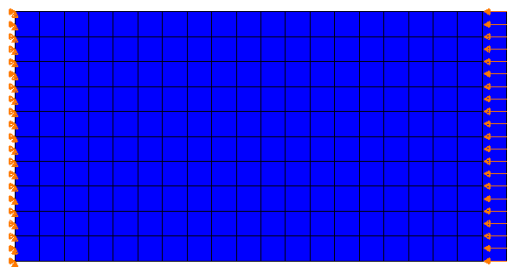

(b)

FIGURA 4.5-1 - Modelos do ensaio de tração (a) e do ensaio de compressão (b)

Tanto para o modelo de tração como para o modelo de compressão utilizou-se Critérios de Danificação e Leis de Evolução de Dano para estado plano de tensões através da compilação de sub-rotinas UMAT (descrita no Apêndice A). Dessa forma, pode-se calibrar os parâmetros B e H que estão associados ao modelo de material proposto. Vale ressaltar que as propriedades elásticas e os valores de resistência mecânica utilizados nas simulações foram obtidos da TABELA 3.3.4-1 apresentada no capítulo anterior.

Os parâmetros da função de degradação da fibra $(\delta, H$ e B) são calibrados em função do resultado experimental. $O$ valor de $\delta$ para compósitos de resina epóxi reforçada com fibra de carbono varia entre 0,025 e 0,06 polegadas (SHAHID; CHANG, 1995). Sendo assim, verifica-se após algumas simulações que um valor razoável para $\delta$ é 0,05 ao passo que para $H$ é um valor próximo de 0,035. A FIGURA 4.5-2 mostra que caso o valor do parâmetro B seja igual a zero, os resultados numéricos convergem para os resultados experimentais até um deslocamento próximo a 3,7 mm. No entanto, como a lei de degradação é muito branda, tem-se que a curva teórica demonstra que o modelo ainda possuí uma determinada rigidez após $3,7 \mathrm{~mm}$ de deslocamento, ao passo que o ensaio experimental evidencia uma queda acentuada de rigidez. Dessa forma, optou-se por ajustar o parâmetro $\mathrm{B}$, chegando ao valor $8 \times 10^{8}$. Nota-se na FIGURA 4.5-2 que a curva simulada acompanha a curva experimental até o deslocamento atingir 3,0 $\mathrm{mm}$. Porém, após este nível de deslocamento, verifica-se uma perda acentuada da rigidez da estrutura, fazendo com que um novo valor para o parâmetro B fosse ajustado. Porém, após várias simulações observou-se que os modelos são extremamente sensíveis a variações no parâmetro B. Sendo assim, para valores de B ligeiramente menores que $8 \times 10^{8}$, a resposta é similar aos modelos que possuem B igual a zero. Por outro lado, para modelos com B ligeiramente maiores que $8 \times 10^{8}$, tem-se uma perda repentina de rigidez por parte da estrutura. 


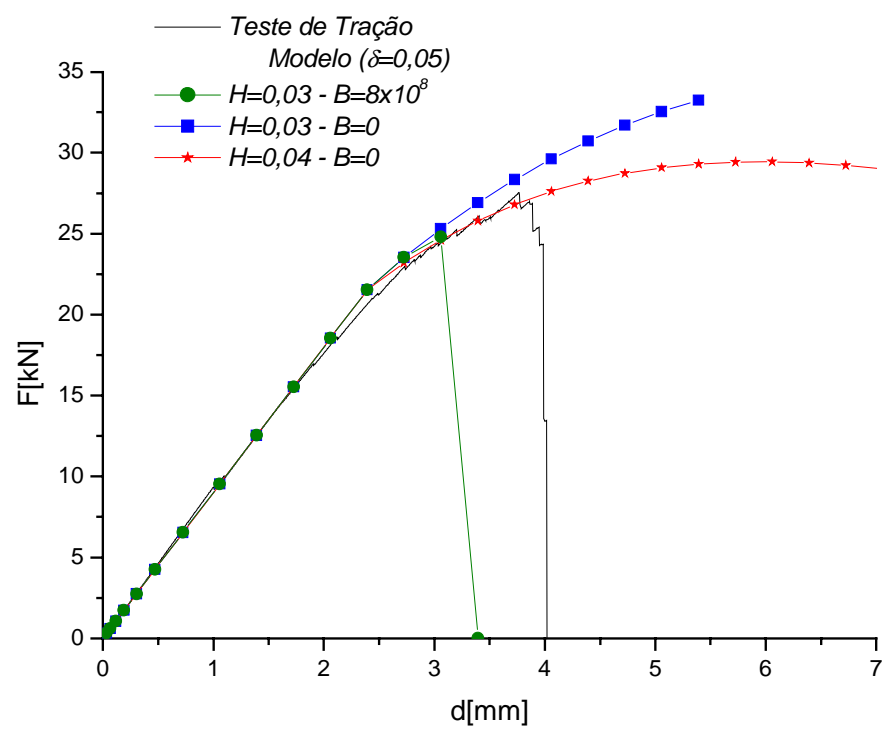

FIGURA 4.5-2 - Calibração dos parâmetros H e B para o modelo do ensaio de tração $[0]_{5}$

Com base nestes primeiros resultados, verifica-se que a fase conhecida como "pós-falha" não é facilmente representada por um modelo, necessitando assim ser investigada com maior profundidade. Essa investigação inclui um estudo que seja capaz de identificar se o modelo computacional depende do tamanho do incremento de carga e da densidade da malha de elementos finitos.

Quanto ao tamanho do incremento, Feih e Schercliff (2000) declararam que os algoritmos de danificação/falha podem apresentar uma sequência bem como uma quantidade diferente de elementos que danificam em função do número de incrementos. A FIGURA 4.5-3 confirma que a solução depende do tamanho do incremento, pois foram utilizados os mesmos parâmetros de malha e material e foram obtidos resultados diferentes. Dessa forma, caso o passo de carga seja diferente, haverá uma ocorrência maior ou menor de pontos de integração danificados. Portanto, os parâmetros $\mathrm{H} \mathrm{e} \mathrm{B}$ necessitam ser re-calibrados, quando o número de incrementos é alterado. Feih e Schercliff (2000) apresentaram alguns procedimentos numéricos que podem ser realizados para evitar tal problema. Uma das alternativas consiste em garantir que somente um ponto de integração se danifique em cada incremento. Para tal, torna-se necessário reinicializar sempre a análise, reduzindo o incremento caso mais de um ponto venha a apresentar danificação na primeira iteração. Mesmo assim, o crescimento estável de dano não é garantido para as iterações subseqüentes, pois o procedimento é aplicado somente para a primeira iteração. Uma outra alternativa consiste em varrer 
todos os pontos de integração e calcular para cada um, o valor do critério de danificação. Somente o ponto de integração que possuir o maior valor será degradado, os demais permaneceram intactos. Este procedimento deve ser executado em todas as iterações até que a estrutura atinja o equilíbrio para um dado incremento. Tal método é conhecido como "One-by-One" e pode garantir um crescimento mais estável de dano.

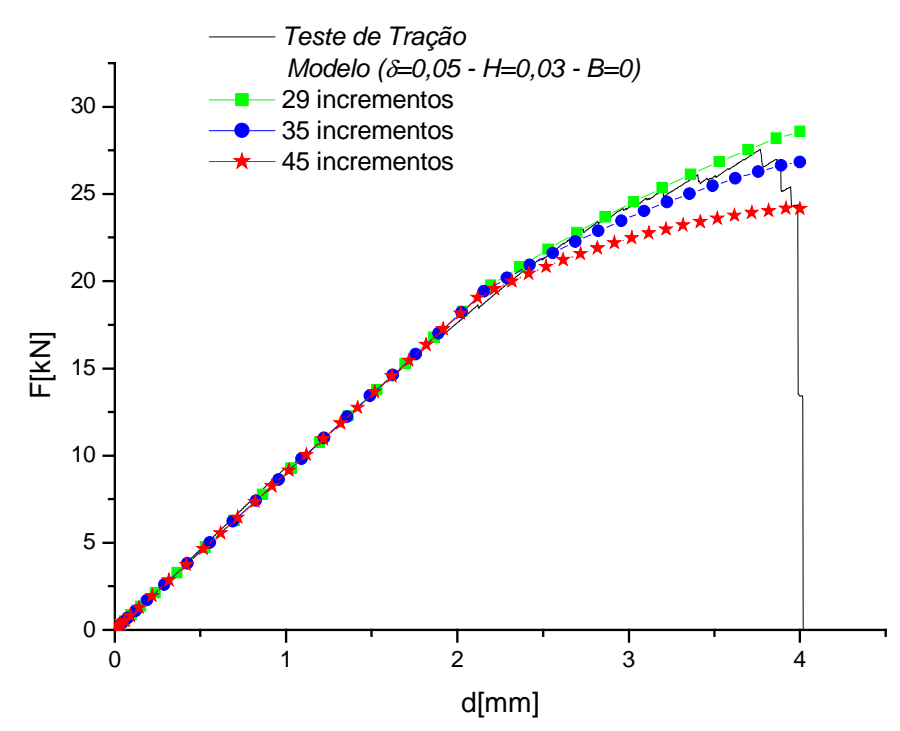

FIGURA 4.5-3 - Influência do número de incrementos na solução do modelo do ensaio de tração $[0]_{5}$

Quanto à densidade da malha, verifica-se através da FIGURA 4.5-4 que a solução apresentada pelo modelo implementado também depende do grau de refinamento de malha que está sendo empregado. Para uma malha mais grosseira $(5 \times 50=250$ elementos) tem-se uma queda mais acentuada da rigidez, ao passo que para uma malha mais refinada tem-se uma queda mais suave $(8 \times 80=640$ elementos $)$. Isto ocorre, pois os pontos de Gauss para uma malha mais grosseira estão mais "espalhados" tendo assim que cobrir uma área maior do domínio investigado. Dessa forma, a falha dos mesmos promove uma perda maior de rigidez do que numa malha mais refinada. 


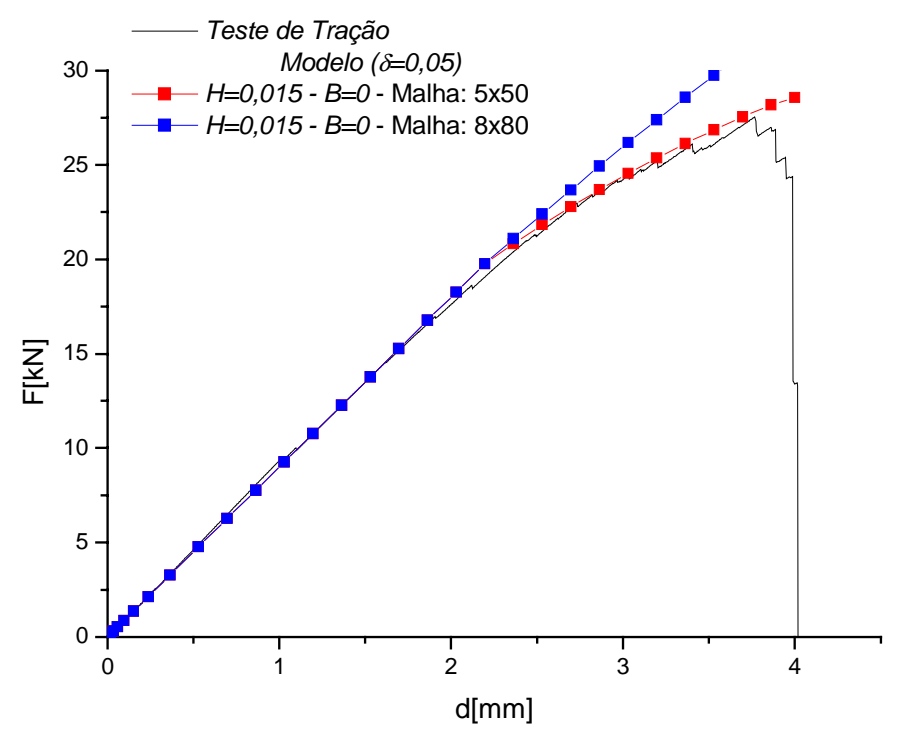

FIGURA 4.5-4 - Influência da densidade de malha na solução do modelo do ensaio de tração $[0]_{5}$

Verifica-se inicialmente que os resultados obtidos dos testes de compressão tanto $[0]_{15}$ como [90 $]_{15}$ não permitiram a calibração dos parâmetros $\delta, \mathrm{H}$ e B. Isto ocorreu, pois devido à complexidade desses testes pôde-se obter apenas o registro da resposta linear elástica dada pelos "strain-gauges back-to-back”. No entanto, foi possível avaliar se o modelo elástico de material implementado via UMAT poderia fornecer resultados coerentes para carregamentos de compressão. Para tal, variou-se os valores do módulo de Young a fim de verificar a sensibilidade do modelo frente a este parâmetro de material. Para as amostras a $[0]_{15}$ (FIGURA 4.5-5(a)), nota-se que a resposta numérica que mais se aproximou da experimental foi para um módulo de Young igual a $130 \mathrm{GPa}$, ao passo que para as amostras a $[90]_{15}$ foi para um módulo igual a 11 GPa (FIGURA 4.5-5(b)). Isto demonstra que a parte linear elástica do modelo implementado produzirá respostas consistentes quando a estrutura estiver solicitada sob compressão. 


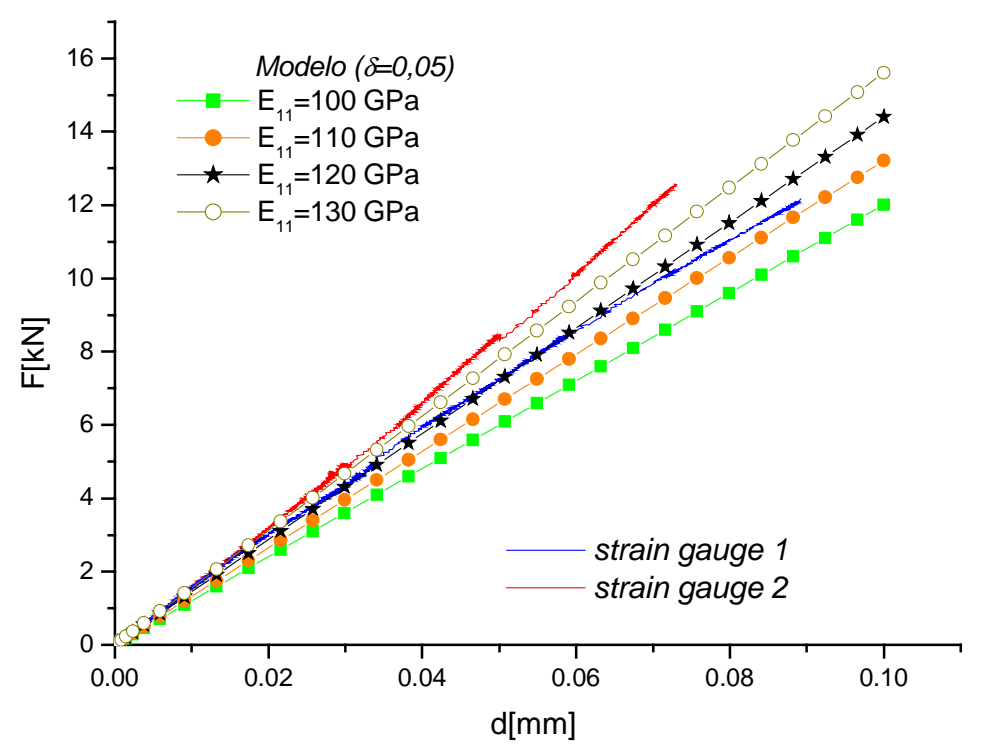

(a)

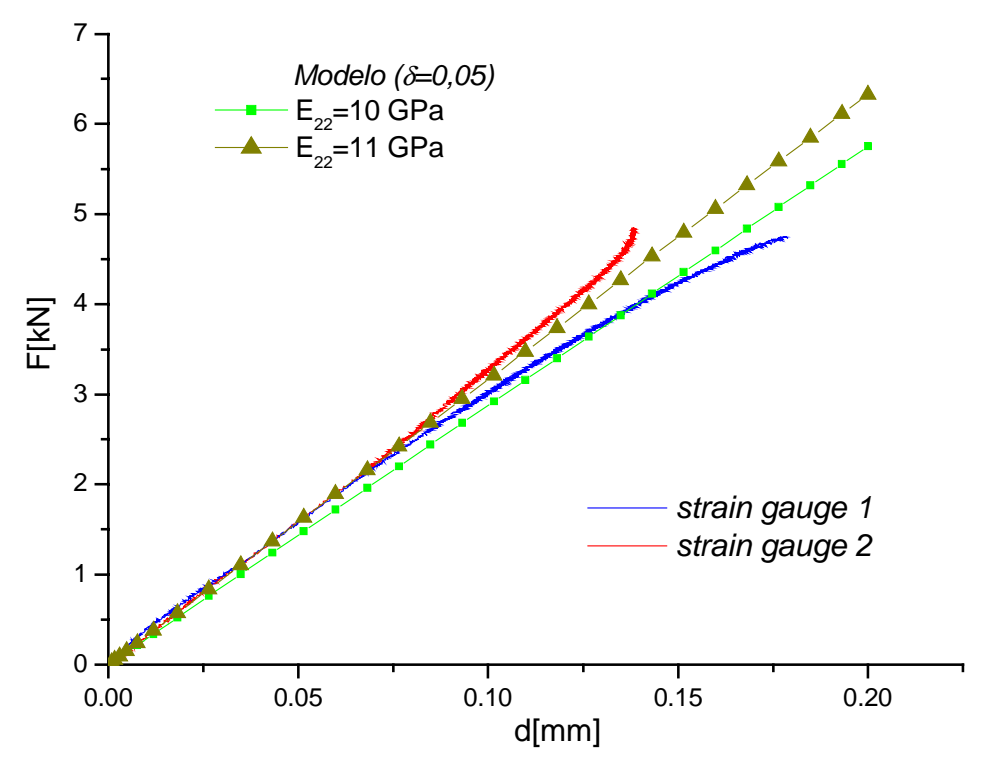

(b)

FIGURA 4.5-5 - Avaliação da sensibilidade da resposta ao módulo de Young para modelos dos ensaios de compressão: (a) amostras a a $[0]_{15}$; (b) amostras a $[90]_{15}$

A fim de continuar o processo de investigação das potencialidades e limitações dos modelos de material implementados, segue-se no próximo capítulo a aplicação desses modelos para outros tipos de testes. Além disso, com o intuito de empregar Análise Inversa, os parâmetros $\delta, \mathrm{H}$ e B calibrados através do modelo do ensaio de tração serão tomados como valores de partida para algumas das próximas calibrações. 


\section{Capítulo 5}

\section{APLICAÇÃO DO MODELO DE MATERIAL}

\subsection{APRESENTAÇÃO DOS ESTUDOS DE CASOS}

Os critérios e leis de degradação implementados serão novamente avaliados e discutidos neste capítulo. Para tal utilizou-se três diferentes estudos de caso bem como uma estratégia de análise, envolvendo ensaios experimentais e simulações computacionais.

O primeiro estudo consiste de uma viga sob flexão 3-pontos. Neste caso foram avaliados todos os modelos implementados e foram calibrados os seus respectivos parâmetros. Tais análises e calibrações realizadas seguiram uma dada seqüência baseada no incremento de complexidade do modelo:

1) Critérios de Danificação e Leis de Evolução de Dano para estado plano de tensões (sub-rotinas USDFLD);

2) Critérios de Danificação e Leis de Evolução de Dano para estado plano de tensões (sub-rotinas UMAT);

3) Critérios de Danificação e Leis de Evolução de Dano para estado triplo de tensões (sub-rotinas UMAT);

4) Critérios de Danificação e Leis de Evolução de Dano para estado triplo de tensões bem como Critérios de Falha e Leis de Evolução de Falha (subrotinas UMAT).

Após a calibração desses parâmetros partiu-se para o segundo estudo que consiste de uma placa circular totalmente engastada nas bordas sendo solicitada no centro por um carregamento quase-estático, ou seja, tal estudo trata-se de um Teste de Endentação 
(“Indentation Test"). O terceiro e último estudo de caso consiste também de uma placa circular totalmente engastada nas bordas, porém solicitada no centro por um carregamento dinâmico de impacto, ou seja, tal estudo trata-se de um Teste de Impacto (“Drop-test").

\subsection{ENSAIOS DE FLEXÃO 3-PONTOS}

Como foi descrito anteriormente no Capítulo 3, os testes de flexão foram realizados tanto com o intuito de avaliar o modelo de material proposto como também para obter mais informações sobre o comportamento mecânico do material utilizado. No entanto, para o propósito de avaliar o modelo de material foram utilizadas apenas amostras que seguem a norma ASTM D790 e possuem seqüência de empilhamento igual a $[0]_{10},[0 / 90 / 0 / 90 / 0]_{\mathrm{s}}$ e $[+45 /-45 /+45 / 0 / 90]_{\mathrm{s}}$ (TABELA 5.2-1).

TABELA 5.2-1 - Especificações para os testes de flexão três-pontos

( $\mathrm{L}=$ comprimento; $\mathrm{W}=$ largura; $\mathrm{H}=$ espessura)

\begin{tabular}{cccccc}
\hline \multirow{2}{*}{ Norma } & $\begin{array}{c}\text { Sequência de } \\
\text { Empilhamento }\end{array}$ & $\begin{array}{c}\mathbf{L} \\
{[\mathbf{m m}]}\end{array}$ & $\begin{array}{c}\mathbf{W} \\
{[\mathbf{m m}]}\end{array}$ & $\begin{array}{c}\mathbf{H} \\
{[\mathbf{m m}]}\end{array}$ & $\begin{array}{c}\mathbf{V} \\
{[\mathbf{m m} / \mathbf{m i n}]}\end{array}$ \\
\hline \multirow{2}{*}{$\mathrm{D} 790$} & {$[0]_{10}$} & 80 & 25 & 1,8 & 2,8 \\
$\left(\operatorname{span}^{(*)} / \mathrm{H}=32\right)$ & {$[0 / 90 / 0 / 90 / 0]_{\mathrm{s}}$} & 80 & 25 & 1,8 & 2,8 \\
& {$[+45 /-45 /+45 / 0 / 90]_{\mathrm{s}}$} & 80 & 25 & 1,8 & 2,8 \\
\hline
\end{tabular}

(*) O span é definido como sendo a distância entre os apoios do teste de flexão

\subsubsection{Resultados Experimentais}

Na FIGURA 5.2.1-1 verifica-se a ocorrência de uma falha em 1,1 kN. Neste instante, varias fibras localizadas no topo do laminado falham por compressão e na base do laminado falham por tração. Há assim, uma perda acentuada da rigidez da estrutura. A partir de 4,0 mm de deflexão ocorrem outras falhas, como fratura da matriz e esmagamento das fibras que estão próximas do aplicador de carga.

Para as amostras com seqüência de empilhamento igual a $[0 / 90 / 0 / 90 / 0]_{\mathrm{s}}$ bem como igual a $[+45 /-45 /+45 / 0 / 90]_{s}$, os resultados experimentais apresentaram algumas delaminações, o que caracteriza uma diferença de comportamento frente às estruturas que possuem lâminas empilhadas somente em uma direção. Tal fenômeno pode ser explicado devido à diferença de rigidez de duas lâminas adjacentes com orientações de 
fibra diferentes. Portanto, a probabilidade da ocorrência desse fenômeno é diretamente proporcional ao número de lâminas adjacentes com orientação diferente e principalmente com orientações bem distintas tal como $0^{\circ} / 90^{\circ}$ (ABRATE, 1998). Essa diferença de rigidez caracteriza uma diferença de resposta por parte de cada lâmina que tende a se deslocar de forma diferente. Tudo isto é evitado pelas tensões desenvolvidas na interface que fazem com que todas as lâminas do laminado se desloquem juntas e na mesma direção. No entanto, quando essas tensões superam a resistência interlaminar, tem-se a ocorrência das delaminações.

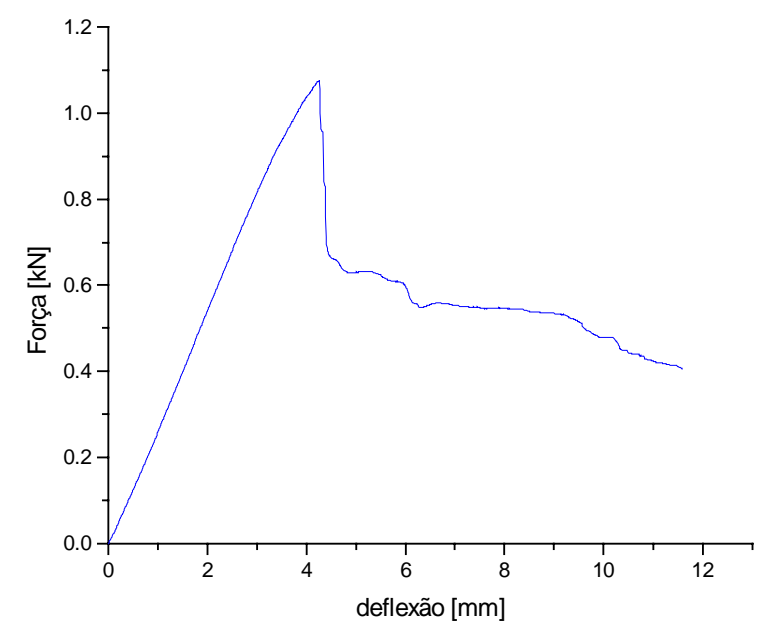

FIGURA 5.2.1-1 - Gráfico força-deflexão para amostras orientadas a $0^{\circ}$

Na FIGURA 5.2.1-2 pode-se verificar as primeiras falhas (ruptura da matriz) a partir de $0,75 \mathrm{kN}$ para um deslocamento de 4,00 $\mathrm{mm}$ que vão evoluindo até um carregamento igual a $0,85 \mathrm{kN}$. Neste instante, surgem as primeiras delaminações entre a interface das lâminas $0^{\circ} / 90^{\circ}$ que estão mais próximas do topo e do aplicador de carga, ou seja, para as lâminas que estão sob compressão acima da linha neutra. Verifica-se que há uma queda no valor da força, mantendo-se esta praticamente constante de 5,4 $\mathrm{mm}$ até 6,6 mm, caracterizando apenas um avanço das delaminações. Em 6,6 mm ocorre o fraturamento das fibras que estão localizadas na base do laminado, promovendo assim, uma queda acentuada da força bem como perda de rigidez. Em 7,7 mm são visualizadas novas falhas/danificações (delaminações e fratura de fibra) que determinam uma perda de rigidez mais acentuada da estrutura que suporta os carregamentos até $10 \mathrm{~mm}$, quando há uma falha completa da mesma.

Na FIGURA 5.2.1-3 verifica-se nitidamente o comportamento não-linear causado pelas tensões de cisalhamento que atuam no plano 1-2 (plano da lâmina) devido às 
camadas a $+/-45^{\circ}$. A partir de $8,5 \mathrm{~mm}$, nota-se um incremento considerável de rigidez devido possivelmente a uma combinação de fenômenos, tais como: endentação localizada nos apoios, atrito entre a amostra e os apoios, anisotropia do material e uma provável tendência de alinhamento com a direção (1) de ortotropia das fibras a $+/-45^{\circ}$ que estão localizadas nas lâminas mais externas devido à ação de carregamentos de tração. Finalmente, quando se atinge o valor de $0,61 \mathrm{kN}$ tem-se a ocorrência das delaminações entre as lâminas $0^{\circ} / 90^{\circ}$, proporcionando assim uma acentuada redução de carga. Logo em seguida, possivelmente devido às delaminações entre as lâminas $45^{\circ} / 0^{\circ}$ e à ruptura de algumas fibras há assim a falha completa da estrutura.

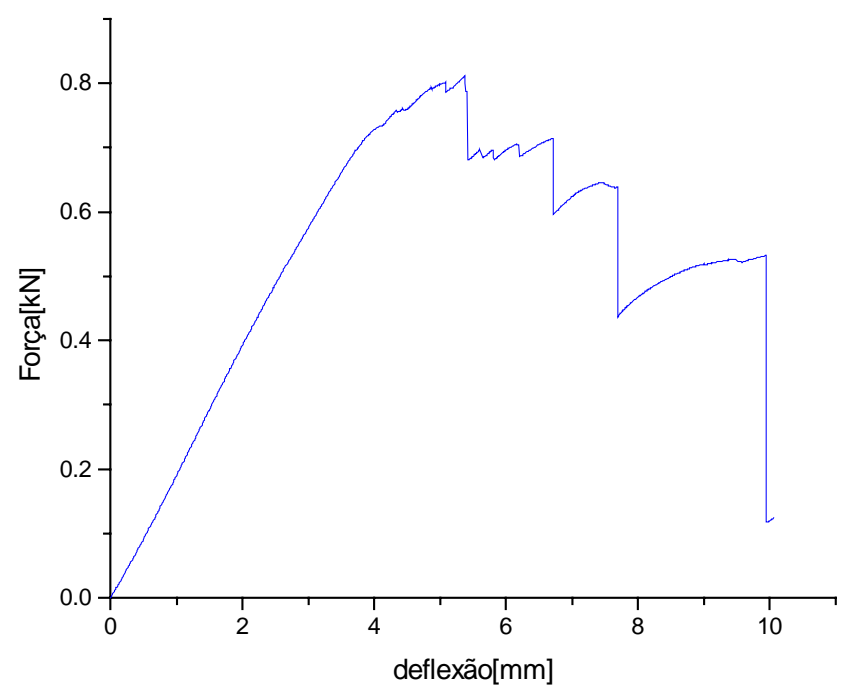

FIGURA 5.2.1-2 - Gráfico força-deflexão para amostras orientadas a [0/90/0/90/0]

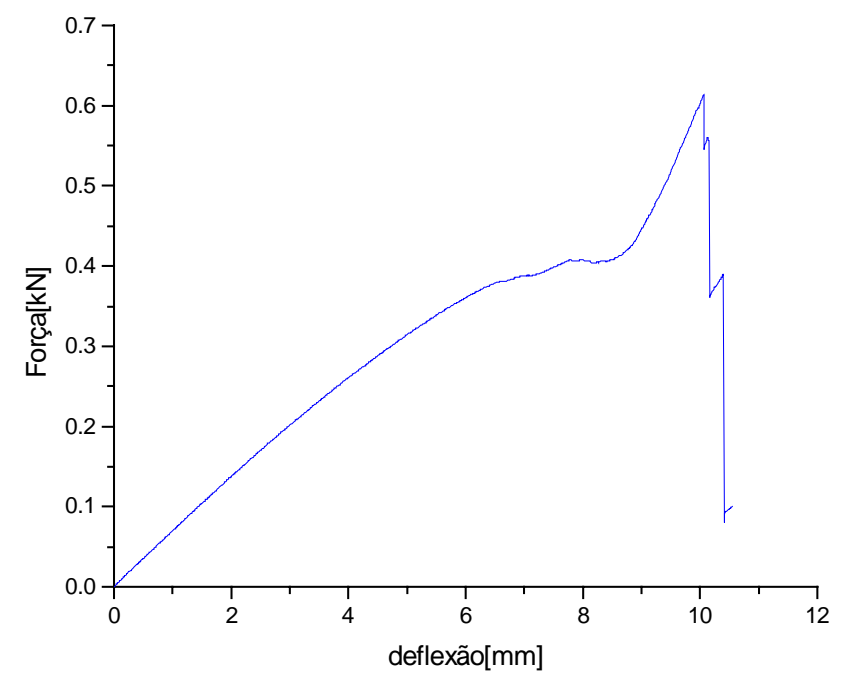

FIGURA 5.2.1-3 - Gráfico força-deflexão para amostras orientadas a $[+45 /-45 /+45 / 0 / 90]_{\text {s }}$ 


\subsubsection{Modelos computacionais}

Para o primeiro estudo de caso, tem-se que todos os modelos foram desenvolvidos no ABAQUS ${ }^{\circledR}$. É importante destacar que toda estratégia numérica necessária para solucionar tais modelos está descrita no Capítulo 2 (item 2.2.2 - Abordagem Numérica).

\section{Geometria do Modelo}

A geometria do modelo segue basicamente as dimensões da viga especificadas na TABELA 5.2-1. Vale ressaltar que tanto o aplicador de carga como os apoios utilizados nos testes de flexão 3-pontos não foram modelados. Sendo assim, tais peças foram substituídas por condições de contorno adequadas.

\section{Malha de elementos finitos com condições de contorno}

Para este primeiro estudo de caso, foram desenvolvidos dois tipos diferentes de modelos. Inicialmente, criou-se um modelo constituído por elementos do tipo casca, designado Elemento S8R que contém 8 nós e 4 pontos de integração (ABAQUS, 2002) a fim de avaliar o laminado sob estado plano de tensões. Neste modelo, as vinculações e os carregamentos foram simulados de tal forma que alguns nós próximos às bordas estão vinculados de modo a representar uma viga bi-apoiada, ao passo que os nós localizados no centro da viga representam o carregamento aplicado através da imposição de um deslocamento controlado (FIGURA 5.2.2-1(a)). Posteriormente, criouse um modelo constituído por elementos do tipo sólido, designado Elemento C3D8 que contém 8 nós e 4 pontos de integração (ABAQUS, 2002) a fim de avaliar o laminado sob estado triplo de tensões. A FIGURA 5.2.2-1(b) mostra que na espessura o sólido está dividido em 3 camadas, de tal forma que as duas camadas externas contém 3 lâminas (cada uma) ao passo que a camada interna possuí 4 lâminas. Sendo assim, para o laminado $[0 / 90 / 0 / 90 / 0]_{\mathrm{s}}$, as camadas externas possuem as lâminas $0^{\circ} / 90^{\circ} / 0^{\circ}$ e a interna contém as lâminas $90^{\circ} / 0^{\circ} / 0^{\circ} / 90^{\circ}$. Para o laminado [45/-45/45/0/90]s, as camadas externas possuem as lâminas $45^{\circ} / 45^{\circ} / 45^{\circ}$ ao passo que a camada interna possui as lâminas $0^{\circ} / 90^{\circ} / 90^{\circ} / 0^{\circ}$. Além disso, as vinculações e os carregamentos foram simulados de tal forma que alguns nós próximos às bordas localizados na base do laminado estão vinculados de modo a representar uma viga bi-apoiada, ao passo que o carregamento aplicado é representado através da imposição de um deslocamento controlado nos nós do centro da viga localizados no topo do modelo (FIGURA 5.2.2-1(b)). 

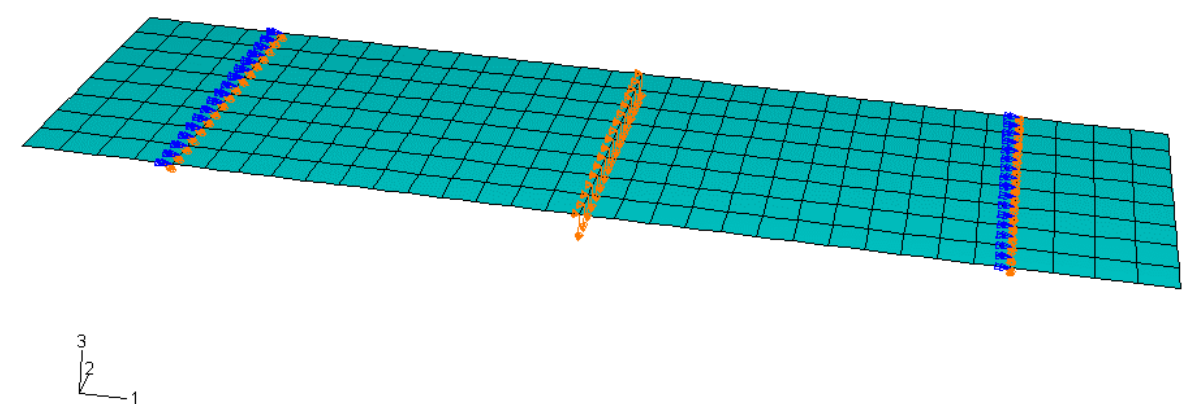

(a)

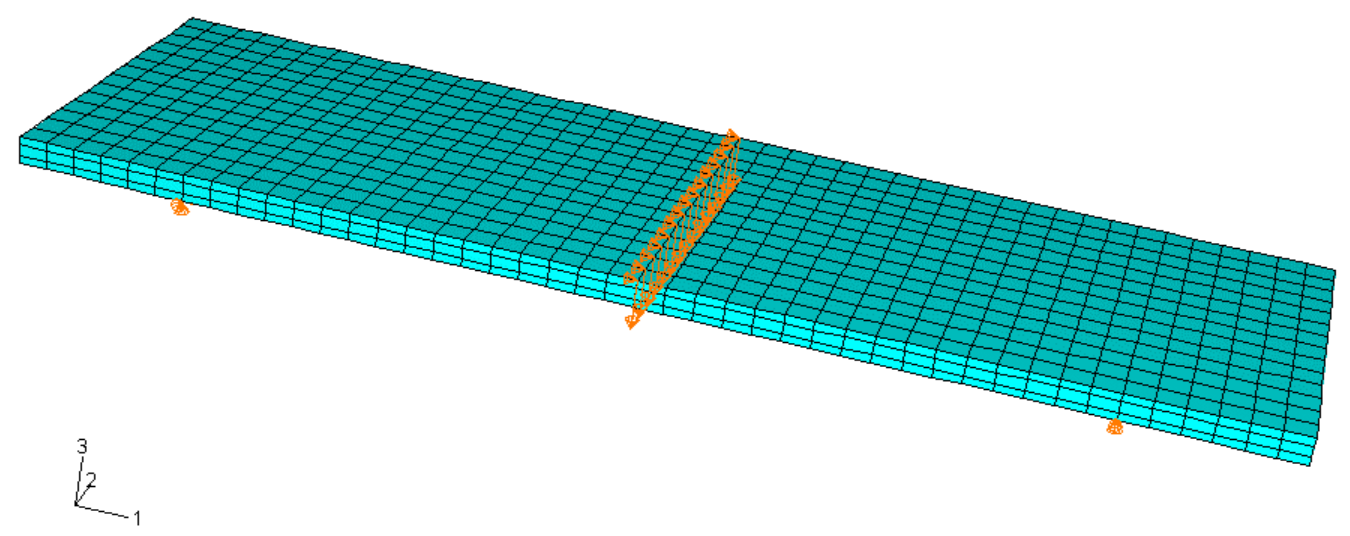

(b)

FIGURA 5.2.2-1 - Modelos do teste de flexão 3-pontos:

(a) Modelo em Casca (Elemento S8R); (b) Modelo Sólido (Elemento C3D8R)

\section{Modelos de Material}

Os modelos de material utilizados nas análises de flexão 3-pontos tiveram muitos de seus parâmetros alimentados através de informações provenientes de ensaios experimentais em corpos-de-prova ou da literatura descritos no Capítulo3. A TABELA 5.2.2-1 apresenta assim os valores empregados nas simulações computacionais. Nota-se que foi utilizado para $\mathrm{E}_{11}$ o valor de $100 \mathrm{GPa}$ ao invés de $127 \mathrm{GPa}$ que tinha sido determinado através do ensaio de tração com auxílio de extensômetros, eliminando assim os efeitos de flexibilidade da máquina. No entanto, os ensaios de flexão 3-pontos foram realizados medindo-se a deflexão da amostra através do deslocamento do "cross head" da máquina. Isto fez com que fosse necessário o emprego de um módulo de elasticidade menor, pois a flexibilidade da máquina não foi desconsiderada. Tal fato pôde ser confirmado no Capítulo 3 quando aplicou-se a equação (3.3.3-3) para o cálculo do módulo aparente de flexão $\left(E_{11}^{\mathrm{f}}\right)$. 
TABELA 5.2.2-1 - Propriedades elásticas e valores de resistência empregados nas simulações computacionais

\begin{tabular}{|c|c|c|c|}
\hline \multirow{2}{*}{$\begin{array}{l}\text { Propriedades Elásticas } \\
\text { e } \\
\text { Valores de Resistência }\end{array}$} & \multirow{2}{*}{ Unidade } & \multicolumn{2}{|c|}{ Unidirecional } \\
\hline & & Valor ${ }^{(i)}$ & Valor \\
\hline \multicolumn{4}{|l|}{ Propriedades Elásticas } \\
\hline \multicolumn{4}{|l|}{ Módulo de elasticidade } \\
\hline paralelo à fibra $\left(\mathrm{E}_{11}\right)$ & $\mathrm{GPa}$ & 100 & $127^{(\mathrm{ii})}$ \\
\hline perpendicular à fibra $\left(\mathrm{E}_{22}=\mathrm{E}_{33}\right)$ & $\mathrm{GPa}$ & 10 & $10^{(\mathrm{ii})}$ \\
\hline Densidade $\left(\rho_{\mathrm{c}}\right)$ & $10^{3} \mathrm{~kg} / \mathrm{m}^{3}$ & 1,58 & $1,58^{(\mathrm{ii})}$ \\
\hline \multicolumn{4}{|l|}{ Módulo de Cisalhamento } \\
\hline para o plano $1-2\left(\mathrm{G}_{12}=\mathrm{G}_{13}\right)$ & $\mathrm{GPa}$ & 5,4 & $5,4^{(\mathrm{ii})}$ \\
\hline para o plano $2-3\left(\mathrm{G}_{23}\right)$ & $\mathrm{GPa}$ & 3,05 & $3,05^{\text {(iii) }}$ \\
\hline \multicolumn{4}{|l|}{ Coeficientes de Poisson } \\
\hline$v_{12}=v_{13}$ & - & 0,34 & $0,34^{(\mathrm{ii})}$ \\
\hline$v_{23}$ & - & 0,306 & $0,306^{\text {(iii) }}$ \\
\hline \multicolumn{4}{|l|}{ Valores de Resistência } \\
\hline \multicolumn{4}{|l|}{ Resistência paralela à fibra } \\
\hline sob tração $\left(\mathrm{X}_{\mathrm{T}}\right)$ & $\mathrm{MPa}$ & 1400 & $1400^{(\mathrm{ii})}$ \\
\hline sob compressão $\left(\mathrm{X}_{\mathrm{C}}\right)$ & $\mathrm{MPa}$ & 930 & $930^{(\mathrm{ii})}$ \\
\hline \multicolumn{4}{|l|}{ Resistência perpendicular à fibra } \\
\hline sob tração $\left(\mathrm{Y}_{\mathrm{T}}\right)$ & MPa & 47 & $47^{(\mathrm{ii})}$ \\
\hline sob compressão $\left(\mathrm{Y}_{\mathrm{C}}\right)$ & $\mathrm{MPa}$ & 130 & $130^{\text {(ii) }}$ \\
\hline \multicolumn{4}{|l|}{ Resistência ao cisalhamento } \\
\hline para o plano $1-2\left(S_{12}=S_{13}\right)$ & $\mathrm{MPa}$ & 53 & $53^{(\mathrm{ii})}$ \\
\hline para o plano 2-3 $\left(\mathrm{S}_{23}\right)$ & $\mathrm{MPa}$ & 89 & $89^{(\mathrm{iii})}$ \\
\hline
\end{tabular}

(i) utilizado na simulação; (ii) determinado experimentalmente;

(iii) $\mathrm{Hexcel}^{\circledR}$ (prepreg M40J)

De acordo com o que foi comentado no item 5.1, tem-se para o estudo de caso de flexão 3-pontos, a avaliação e a calibração de quatro tipos de modelos diferentes (TABELA 5.2.2-2). 
TABELA 5.2.2-2 - Tipos modelos avaliados e calibrados

\begin{tabular}{|c|c|c|c|}
\hline Modelo & Critério & Lei & Sub-rotina \\
\hline $\mathrm{I}$ & Danificação Intralaminar 2D $\mathrm{D}^{(\mathrm{i})}$ & $\begin{array}{c}\text { Evolução de Dano } \\
\text { Constante }^{(\mathrm{iv})}\end{array}$ & USDFLD \\
\hline II & Danificação Intralaminar 2D ${ }^{(\mathrm{i})}$ & Evolução de Dano $^{(\mathrm{v})}$ & UMAT \\
\hline III & Danificação Intralaminar 3D ${ }^{\text {(ii) }}$ & Evolução de Dano $^{(v)}$ & UMAT \\
\hline IV & $\begin{array}{l}\text { Danificação Intralaminar 3D }{ }^{(i i)} \mathrm{e} \\
\text { Critério de Falha Interlaminar }\end{array}$ & $\begin{array}{l}\text { Evolução de Dano }^{(\mathrm{v})} \mathrm{e} \\
\text { Evolução de Falha }^{(\mathrm{vi})}\end{array}$ & UMAT \\
\hline
\end{tabular}

(i) Critério de Hashin com influência das tensões de cisalhamento para estado plano de tensões (equações (4.2.1-1), (4.2.1-3), (4.2.1-4) e (4.2.1-5));

(ii) Critério de Hashin com influência das tensões de cisalhamento para estado triplo de tensões (equações (4.2.1-6), (4.2.1-7), (4.2.1-8) e (4.2.1-9));

(iii) Critério de Falha Interlaminar considerando as tensões de cisalhamento transversal e tensões normais ao plano da lâmina (equação (4.3.1-1));

(iv) Lei de Evolução de Dano baseada em parâmetro constante de degradação tanto para danificação da fibra como para danificação da matriz (TABELAS 4.2.2-1 e 4.2.2-2);

(v) Lei de Evolução de Dano baseada em parâmetro constante de degradação para danificação da matriz e numa função de degradação para danificação da fibra (TABELAS 4.2.2-1 e 4.2.2-2);

(vi) Lei de Evolução de falha baseada em parâmetro constante de degradação (equações (4.3.2$1),(4.3 .2-2),(4.3 .2-3),(4.3 .2-4)$ e (4.3.2-5)).

\subsubsection{Resultados Numéricos}

Os resultados computacionais para este estudo de caso serão apresentados em função da seqüência de empilhamento dos laminados, a fim de que se possa avaliar os problemas numéricos de cada situação de empilhamento.

\section{Seqüência de Empilhamento $\mathrm{CO}_{10}$}

A FIGURA 5.2.3-1 compara as curvas de força-deflexão da simulação e do teste de flexão 3-pontos para lâminas orientadas a $[0]_{10}$, ao empregar o Modelo I descrito na TABELA 5.2.2-2. 


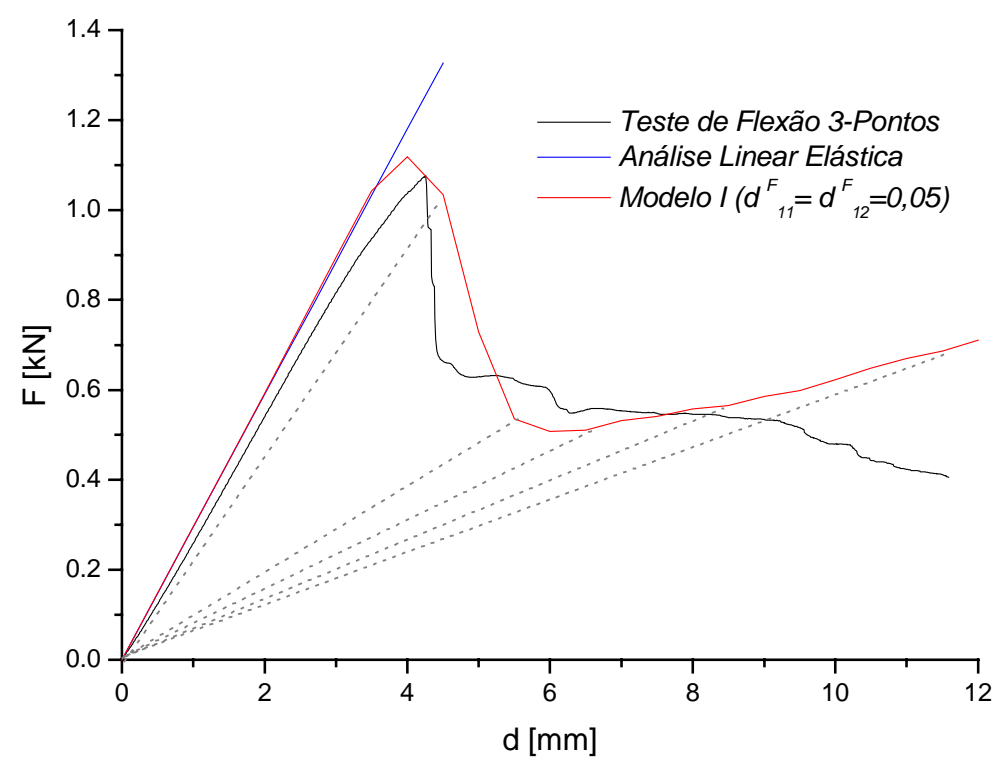

FIGURA 5.2.3-1 - Curvas força-deflexão para lâminas orientadas a [0] $]_{10}$ : Modelo I (sub-rotina USDFLD)

Nota-se que o Critério de Danificação empregado consegue identificar de forma bem satisfatória, os primeiros danos quando há uma deflexão de $3,5 \mathrm{~mm}$. Pois o pico de força experimental quase coincide com o pico de força teórico. Após 3,5 mm de deflexão aplica-se uma Lei de Evolução de Dano baseado num parâmetro constante de degradação que é igual a 0,05 para danificação da fibra $\left(\mathrm{d}_{11}^{\mathrm{F}}\right.$ e $\left.\mathrm{d}_{12}^{\mathrm{F}}\right)$ e zero para danificação da matriz. Dessa forma, quando o ponto de integração danifica devido ao rompimento da fibra tem-se que as suas propriedades $E_{11}$ e $G_{12}$ são degradadas em $95 \%$ e as propriedades $E_{22}$ e $v_{12}$ são reduzidas a zero. As próximas danificações ainda brandas são identificadas pelo modelo quando há uma deflexão igual a 4,0 mm. Porém, quando a deflexão atinge $4,5 \mathrm{~mm}$, o modelo constata uma danificação mais drástica e degrada bruscamente as propriedades do laminado. Essa redução da rigidez da estrutura pode ser observada através da linha cinza tracejada. Isto pode ser verificado no teste experimental e se caracteriza pelo rompimento abrupto das fibras. No entanto, no teste, tal fenômeno ocorreu com uma deflexão menor $(4,2 \mathrm{~mm})$. Por fim, verifica-se nos experimentos que a rigidez da estrutura continua reduzindo gradativamente com o incremento de deflexão, gerando assim uma curva descendente. $\mathrm{O}$ mesmo não é observado nas simulações, que apesar de demonstrar uma certa redução da rigidez, constata-se que essa redução tende a parar com o incremento de deflexão, gerando assim uma curva ascendente. Isto ocorre, pois os pontos de Gauss degradados não 
sofreram mais nenhuma degradação, como demonstrado na FIGURA 4.4-1 (Fluxograma do algoritmo da sub-rotina USDFLD).

Segundo Feih e Schercliff (2000), o crescimento do dano fisicamente tende a localizar-se na menor porção possível de volume e nenhum trabalho é necessário para que haja a evolução do mesmo. No entanto, a aplicação de um fator constante de degradação resulta numa espécie de "re-encruamento" do material ("rehardening effect"), levando assim a existência de um trabalho para que o dano possa evoluir. A fim de evitar tal problema aplicou-se a Lei de Evolução de Dano baseada em um parâmetro constante de degradação para danificação da matriz e numa função de degradação para danificação da fibra (TABELA 4.2.2-2). A FIGURA 5.2.3-2 compara as curvas de força-deflexão das simulações e do teste de flexão 3-pontos para lâminas orientadas a $[0]_{10}$, ao empregar o Modelo II descrito na TABELA 5.2.2-2.

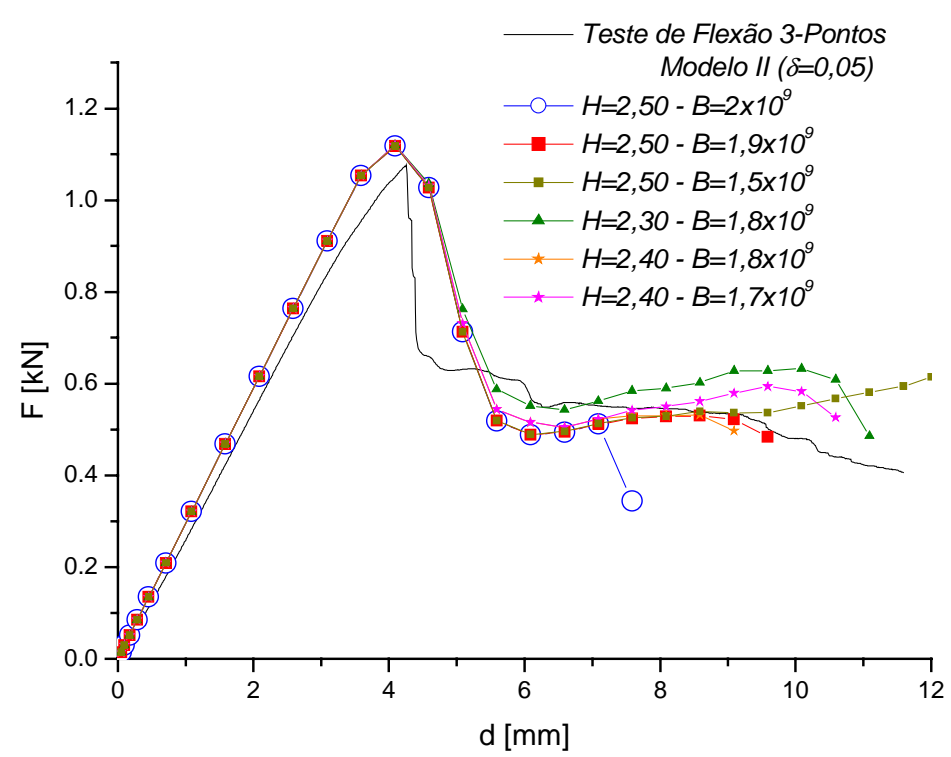

FIGURA 5.2.3-2 - Curvas força-deflexão para lâminas orientadas a [0] $]_{10}$ : Modelo II (sub-rotina UMAT)

De uma maneira geral, as curvas simuladas com base no Modelo II são um pouco similares a curva simulada com base no Modelo I até a estrutura atingir $7 \mathrm{~mm}$ de deflexão. A partir deste ponto a Lei de Evolução de Dano, baseada num parâmetro constante de degradação (igual a zero para danificação da matriz) e numa função de degradação para danificação da fibra, começa a produzir respostas diferentes. 
Os parâmetros da função de degradação da fibra $(\delta, \mathrm{H}$ e B) são calibrados em função dos resultados experimentais. Para tal, adotou-se preliminarmente os valores calibrados através do teste de tração (FIGURA 4.5-2). Porém, após algumas simulações, verifica-se que um valor razoável para $\delta$ é 0,05 ao passo que para $\mathrm{H}$ é um valor próximo de 2,5. Isto demonstra que provavelmente devido à anisotropia, os parâmetros calibrados através dos modelos dos ensaios de tração não poderão ser empregados diretamente para simular outros tipos de testes. Além disso, verificou-se que o valor do parâmetro B dependerá de $\mathrm{H}$, pois caso $\mathrm{H}$ seja maior o parâmetro B deverá ser menor e vice-versa. Para a análise dessa seqüência de empilhamento, o parâmetro B é de extrema importância, devendo assim controlar a perda de rigidez do laminado com o incremento de deflexão. Dessa forma, este parâmetro poderá evitar o fenômeno de "reencruamento" do material. No entanto, caso o valor de B fique acima de $2 \times 10^{9}$ (FIGURA 5.2.3-2), a degradação das propriedades se torna muito acentuada, acarretando numa perda rápida de rigidez. Essa degradação acentuada das propriedades torna a matriz de rigidez mal condicionada fazendo com que o algoritmo de solução por Newton-Raphson não encontre mais o equilíbrio numa dada iteração devido à perda de convergência numérica. Por outro lado, se o valor de B for menor ou igual a $1,5 \times 10^{9}$ (FIGURA 5.2.3-2), a degradação das propriedades se torna muito branda, acarretando numa perda muito pequena de rigidez. Dessa forma, foi necessário realizar um trabalho investigativo para se chegar num valor razoável de B $\left(1,9 \times 10^{9}\right)$ quando H é igual a 2,5.

Apesar de se ter obtido uma melhor representação do fenômeno de danificação, deve-se ressaltar novamente que estes resultados podem ser melhorados caso haja uma investigação mais detalhada dos erros numéricos que ocorrem na fase conhecida como "pós-falha". Como foi comentado no capítulo anterior, dentre os inúmeros problemas numéricos existentes destacam-se: a dependência dos resultados devido ao tamanho do incremento, à densidade de malha utilizada e ao tipo de elemento finito empregado.

Quanto ao tamanho do incremento, Feih e Schercliff (2000) declararam que os algoritmos de danificação/falha podem apresentar uma sequência bem como uma quantidade diferente de elementos que danificam em função do número de incrementos. Sendo assim, os elementos representados na FIGURA 5.2.3-3 poderiam ser outros, caso fosse utilizado um número de incrementos diferente na solução. 


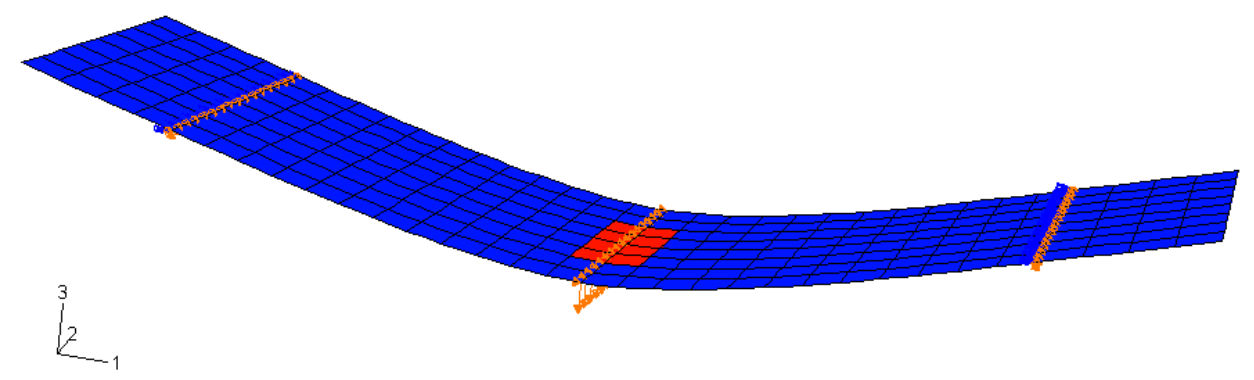

FIGURA 5.2.3-3 - Representação dos primeiros elementos que danificam para um total de 29 incrementos (lâminas orientadas a [0] $]_{10}$ - Modelo II)

A FIGURA 5.2.3-4 confirma que a solução depende do tamanho do incremento, pois foram utilizados os mesmos parâmetros de malha e material e foram obtidos resultados diferentes como já havia sido demonstrado através do modelo do teste de tração (item 4.5 do Capítulo 4).

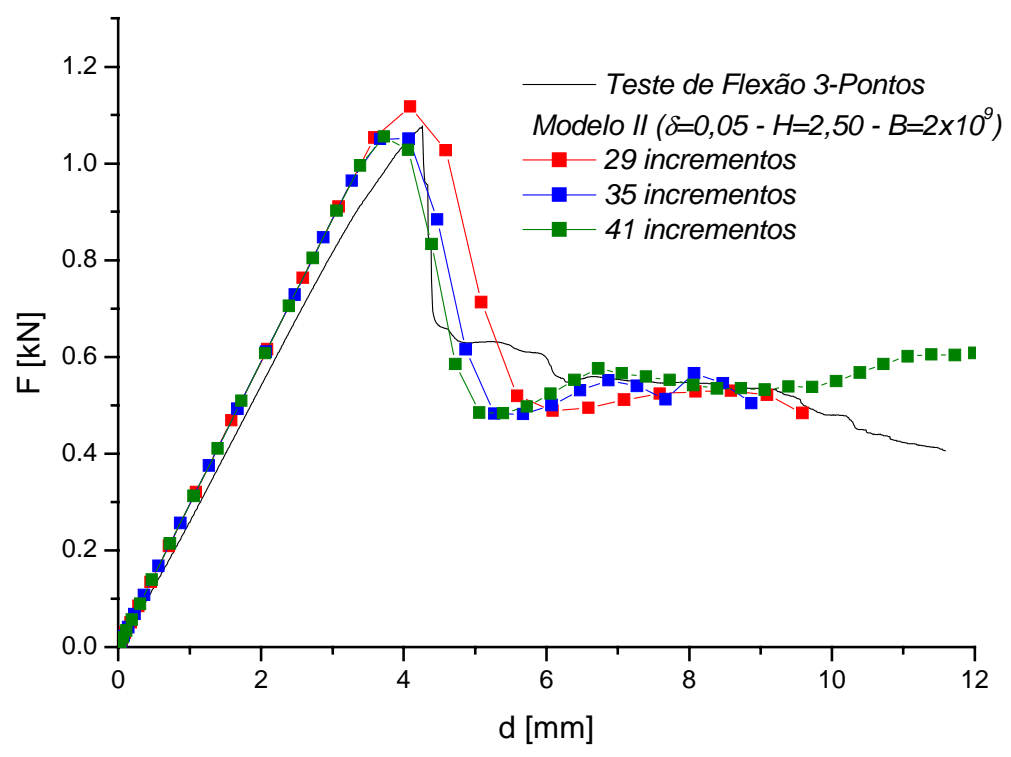

FIGURA 5.2.3-4 - Dependência do tamanho do incremento (lâminas orientadas a $[0]_{10}$ - Modelo II)

Quanto ao tipo de elemento finito empregado, tem-se na literatura uma gama de elementos e suas respectivas formulações. Para o presente estudo de caso, foram apresentadas até então, as soluções baseadas num elemento casca conhecido como Elemento S8R. No entanto, a FIGURA 5.2.3-5 apresenta as curvas de força-deflexão das simulações e do teste de flexão 3-pontos para lâminas orientadas a $[0]_{10}$, ao 
empregar elementos sólidos (Elemento C3D8R) e o Modelo III descrito na TABELA 5.2.2-2.

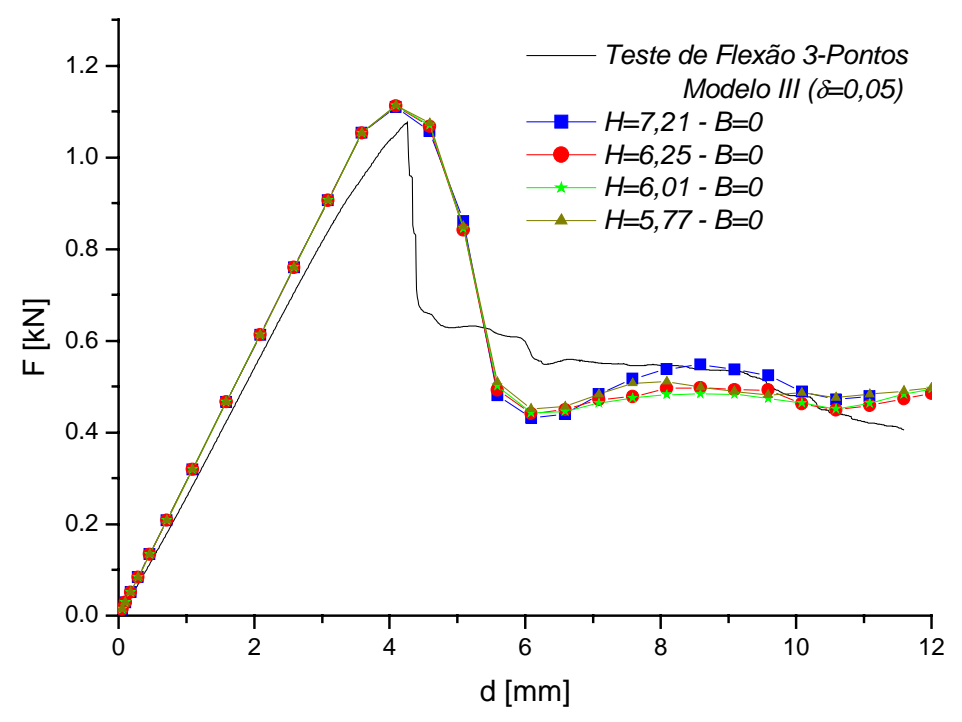

FIGURA 5.2.3-5 - Curvas força-deflexão para lâminas orientadas a [0] $]_{10}$ : Modelo III (sub-rotina UMAT)

De uma maneira geral, as curvas simuladas com base no Modelo III são um pouco distintas das curvas simuladas com base no Modelo II. Apesar da Lei de Evolução de Dano ser a mesma, os parâmetros da função de degradação da fibra $(\delta, \mathrm{H}$ e B) são diferentes dos valores calibrados anteriormente. Após algumas simulações, verifica-se que um valor razoável para $\delta$ é 0,05 ao passo que para $H$ é um valor que oscila entre 5,5 e 7,5. Por fim, o valor de B deve ser anulado, pois o modelo é altamente sensível a este parâmetro. Dessa forma, somente o parâmetro H poderá promover uma degradação das propriedades de forma mais branda ou mais acentuada.

A FIGURA 5.2.3-6 compara as curvas de força-deflexão das simulações ao empregar o modelo em casca com 256 elementos (8x32) e o modelo sólido com 1848 elementos $(14 \times 44 \times 3)$. Nota-se que até $9,5 \mathrm{~mm}$ de deflexão, o modelo em casca apresenta um resultado mais satisfatório do que o modelo sólido. Pois, enquanto o elemento casca possui os 6 graus de liberdade em cada nó (translação e giros em x, y e z), o elemento sólido possui apenas 3 graus de liberdade em cada nó (translação em x, y e z). No entanto, após 9,5 mm, tem-se que a solução numérica para o modelo em casca perde a convergência. Por outro lado, a solução numérica do modelo sólido segue até a deflexão atingir $11 \mathrm{~mm}$. Isto ocorre provavelmente porque o elemento casca baseia-se 
nas hipóteses de Kirchhoff apresentadas no Capítulo 2 e o modelo sólido não. Além disso, caso haja um refinamento maior da malha em elemento sólido, pode-se obter resultados melhores, porém o custo computacional aumenta razoavelmente.

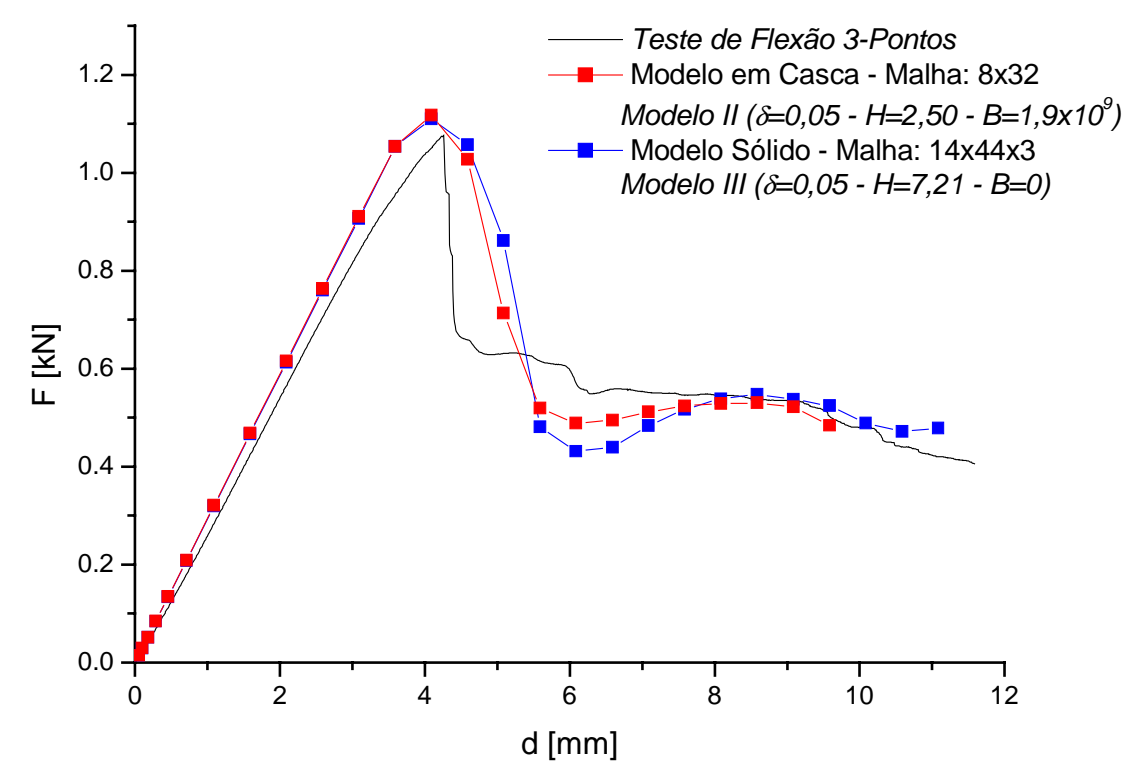

FIGURA 5.2.3-6 - Curvas força-deflexão para lâminas orientadas a [0] $]_{10}$ : Elemento S8R (Modelo II) x Elemento C3D8R (Modelo III)

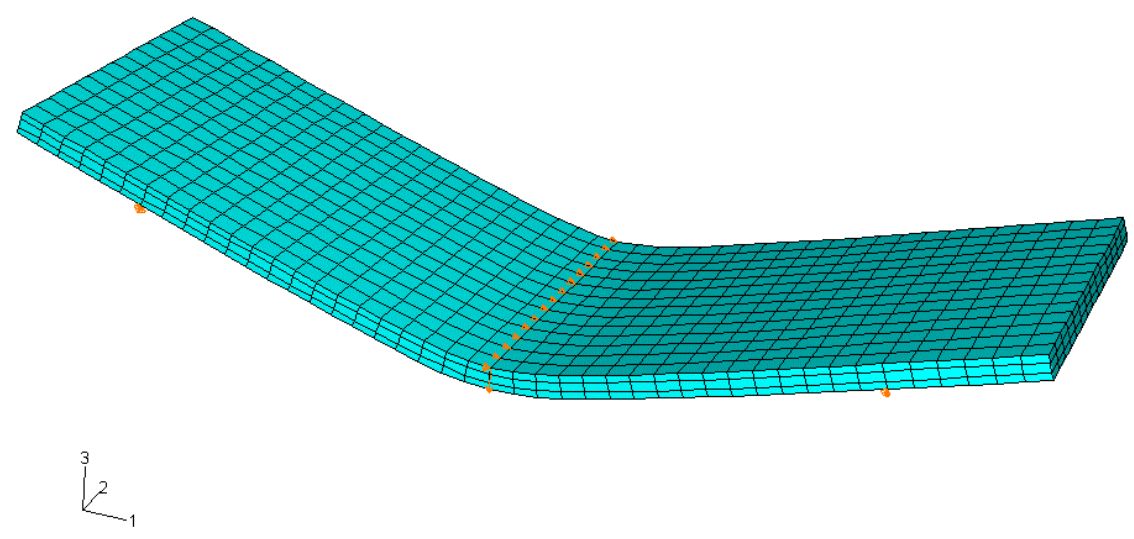

FIGURA 5.2.3-7 - Modelo sólido deformado

\section{Seqüência de Empilhamento [0/90/0/90/0ls}

A FIGURA 5.2.3-8 compara as curvas de força-deflexão da simulação e do teste de flexão 3-pontos para lâminas orientadas a [0/90/0/90/0 $]_{\text {s }}$, ao empregar o Modelo I descrito na TABELA 5.2.2-2. 


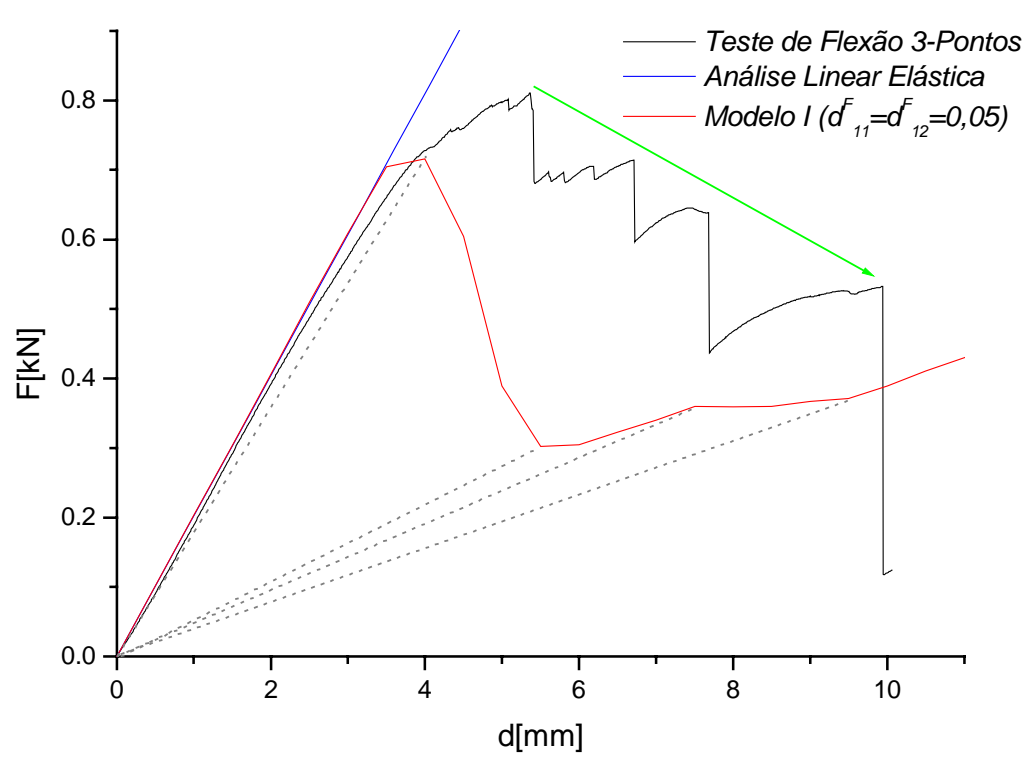

FIGURA 5.2.3-8 - Curvas força-deflexão para lâminas orientadas a [0/90/0/90/0]s: Modelo I (sub-rotina USDFLD)

Nota-se que o Critério de Danificação empregado consegue identificar os primeiros danos quando há uma deflexão de $3,5 \mathrm{~mm}$. Neste momento aplica-se uma Lei de Evolução de Dano baseado num parâmetro constante de degradação que é igual a 0,05 para danificação da fibra e zero para danificação da matriz. Dessa forma, quando o ponto de integração danifica devido à fibra tem-se que as suas propriedades $E_{11}$ e $G_{12}$ são degradadas em $95 \%$ e as propriedades $E_{22}$ e $v_{12}$ são reduzidas a zero. Essas primeiras danificações são brandas e provavelmente estão associadas às laminas orientadas a $90^{\circ}$. Porém, quando a deflexão atinge $4,0 \mathrm{~mm}$, a resposta do modelo apresenta uma danificação mais drástica e degrada provavelmente as propriedades das lâminas orientadas a $0^{\circ}$. Essa redução acentuada da rigidez da estrutura pode ser observada através da linha cinza tracejada. Isto não foi verificado no teste experimental, tendo ocorrido apenas uma perda de rigidez suave até $5,4 \mathrm{~mm}$ de deflexão. A partir deste ponto, verifica-se nos experimentos que a rigidez da estrutura continua reduzindo gradativamente com o incremento de deflexão, gerando assim uma curva descendente indicada pela seta verde da FIGURA 5.2.3-8. Associada a essa redução gradativa de rigidez nota-se algumas quedas abruptas da força devido às delaminações. No entanto, o mesmo resultado não é fornecido pelo modelo computacional, que após 5,5 mm tende a não mais reduzir a rigidez da estrutura com o incremento de deflexão, gerando assim uma curva ascendente. Isto ocorre, pois os pontos de Gauss degradados não sofreram mais nenhuma degradação, como demonstrado na FIGURA 4.4-1 (Fluxograma do 
algoritmo da sub-rotina USDFLD). Dessa forma, para novamente evitar o problema de "re-encruamento", aplicou-se uma Lei de Evolução de Dano diferente (TABELA 4.2.22).

A FIGURA 5.2.3-9 compara as curvas de força-deflexão das simulações e do teste de flexão 3-pontos para lâminas orientadas a [0/90/0/90/0 $]_{\mathrm{s}}$, ao empregar o Modelo II descrito na TABELA 5.2.2-2. Nota-se que as curvas simuladas com base no Modelo II são bem distintas da curva simulada com base no Modelo I, fornecendo assim resultados mais coerentes com os fenômenos observados nos ensaios experimentais. Isto ocorre, pois a Lei de Evolução de Dano, baseada num parâmetro constante de degradação que é igual a zero para danificação da matriz e numa função de degradação para danificação da fibra, produz uma degradação suave até $5,8 \mathrm{~mm}$. A partir deste ponto começa ocorrer uma degradação um pouco mais acentuada, porém gradativa, formando assim uma curva descendente como demonstrado pelo teste experimental.

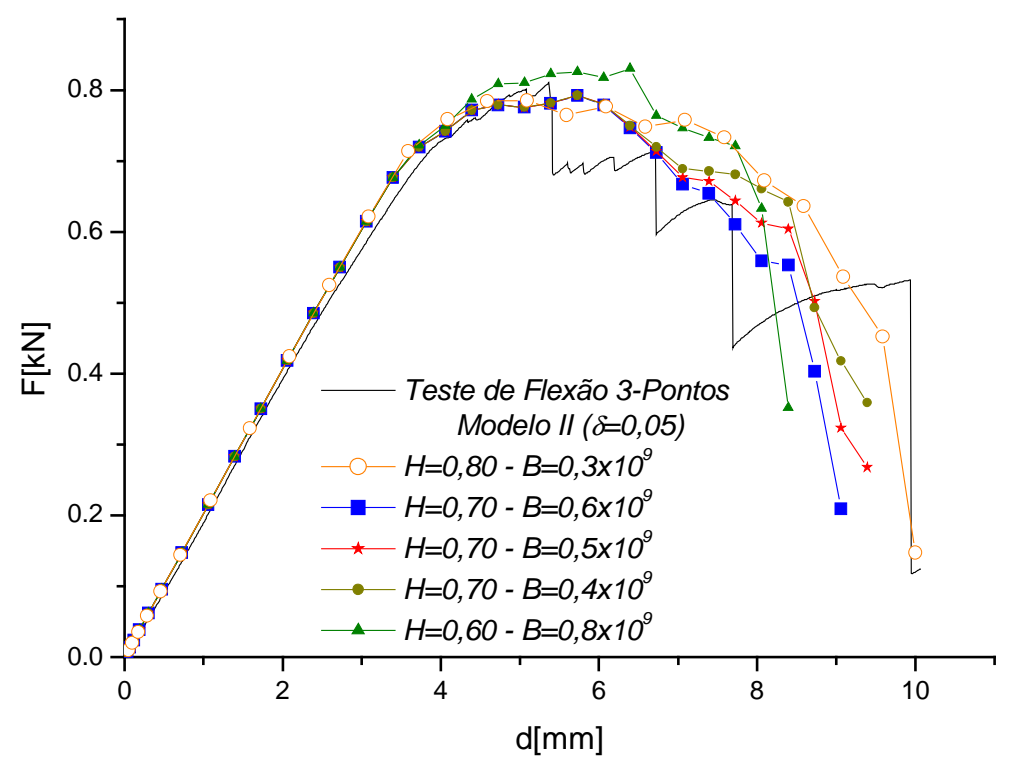

FIGURA 5.2.3-9 - Curvas força-deflexão para lâminas orientadas a [0/90/0/90/0]s:

Modelo II (sub-rotina UMAT)

Os parâmetros da função de degradação da fibra $(\delta, \mathrm{H}$ e B) são calibrados em função do resultado experimental, e após algumas simulações, verifica-se que um valor razoável para $\delta$ é 0,05 ao passo que para $H$ é um valor próximo a 0,7 . Novamente, o valor do parâmetro B dependerá de H, pois caso H seja maior, o parâmetro B deverá ser menor e vice-versa. Para a análise dessa seqüência de empilhamento, o valor do parâmetro B oscila entre $0,4 \times 10^{9}$ e $0,6 \times 10^{9}$ para H igual a 0,7 . No entanto, caso o valor 
de $\mathrm{B}$ aumente, a degradação das propriedades se torna muito acentuada, acarretando uma perda rápida de rigidez. Essa degradação acentuada das propriedades torna a matriz de rigidez mal condicionada fazendo com que o algoritmo de solução por NewtonRaphson não encontre mais o equilíbrio numa dada iteração devido à perda de convergência numérica. Por outro lado, se o valor de B reduzir, a degradação das propriedades se torna muito branda, acarretando numa perda muito pequena de rigidez, fazendo com que a curva teórica se afaste da experimental.

Para o presente estudo de caso, foram apresentadas também algumas soluções baseadas num elemento sólido conhecido como Elemento C3D8R. A FIGURA 5.2.3-10 apresenta as curvas de força-deflexão das simulações e do teste de flexão 3-pontos ao empregar o Modelo III descrito na TABELA 5.2.2-2.

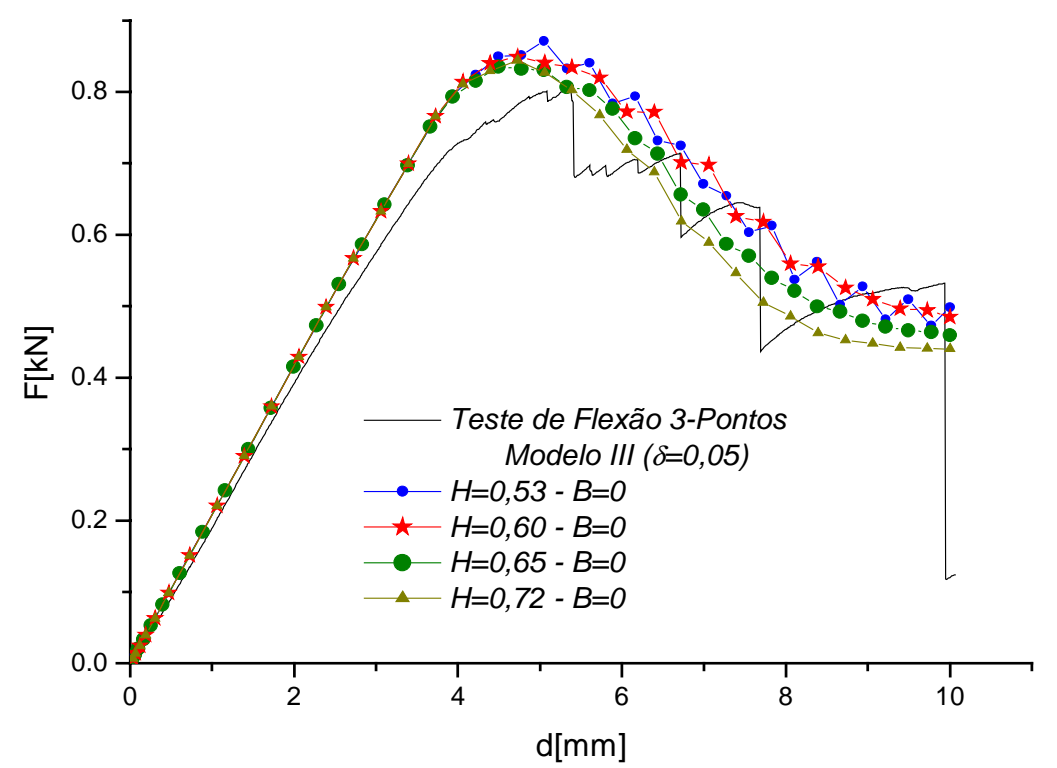

FIGURA 5.2.3-10 - Curvas força-deflexão para lâminas orientadas a [0/90/0/90/0]s:

Modelo III (sub-rotina UMAT)

As curvas simuladas com base no Modelo III são um pouco distintas das curvas simuladas com base no Modelo II. Apesar da Lei de Evolução de Dano ser a mesma, o parâmetro $\mathrm{H}$ da função de degradação da fibra é ligeiramente diferente do valor calibrado para o modelo em casca. Após algumas simulações, verifica-se que um valor razoável para $\delta$ é 0,05 ao passo que para $H$ é um valor que oscila entre 0,55 e 0,75 . Por fim, o valor de B deve ser igual a zero, pois o modelo é altamente sensível a este parâmetro. Dessa forma, somente o parâmetro H poderá promover uma degradação das propriedades de forma mais branda ou mais acentuada. 
A FIGURA 5.2.3-11 compara as curvas de força-deflexão das simulações ao empregar o modelo em casca com 256 elementos (8x32) e o modelo sólido com 1848 elementos $(14 \times 44 \times 3)$. Nota-se que até $7,7 \mathrm{~mm}$ de deflexão, o modelo em casca apresenta um resultado mais satisfatório do que o modelo sólido, pois enquanto o elemento casca possui os 6 graus de liberdade em cada nó (translação e giros em x, y e z), o elemento sólido possui apenas 3 graus de liberdade em cada nó (translação em x ,y e z). No entanto, após $8,0 \mathrm{~mm}$ de deflexão, tem-se que a solução numérica para o modelo em casca começa a demonstrar uma perda de rigidez muito acentuada. Por outro lado, a solução numérica do modelo sólido mantém uma degradação gradativa desde 5,4 $\mathrm{mm}$ até atingir $10 \mathrm{~mm}$ de deflexão. Isto ocorre provavelmente porque o elemento casca baseia-se nas hipóteses de Kirchhoff apresentadas no Capítulo 2.

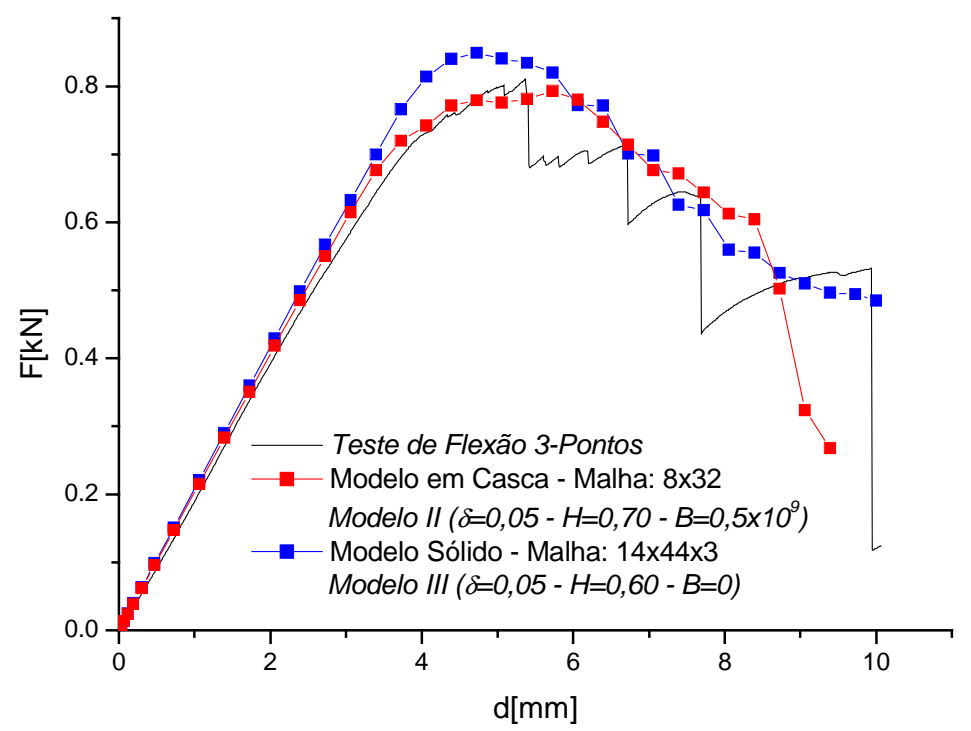

FIGURA 5.2.3-11 - Curvas força-deflexão para lâminas orientadas a [0/90/0/90/0]s: Elemento S8R (Modelo II) x Elemento C3D8R (Modelo III)

Além de se investigar a influência do tipo de elemento, buscou-se também analisar a influência da densidade de malha na simulação do teste de flexão 3-pontos ao empregar elementos sólidos. Verifica-se através da FIGURA 5.2.3-12 que o modelo de material implementado depende da densidade de malha utilizada, pois a fase linear elástica demonstra inicialmente que o modelo mais refinado com 1848 elementos $(14 \times 44 \times 3)$ produz uma resposta mais próxima do resultado experimental quando comparada à solução fornecida pelo modelo mais grosseiro com 720 elementos (8x30x3). Além disso, para simular a fase de "pós-falha", o parâmetro H teve que ser re- 
calibrado para 0,25 ao tornar a malha mais grosseira. Mesmo assim, após 7,5 mm de deflexão a resposta do modelo mais grosseiro se afasta muito mais do resultado experimental do que a resposta do modelo mais refinado.

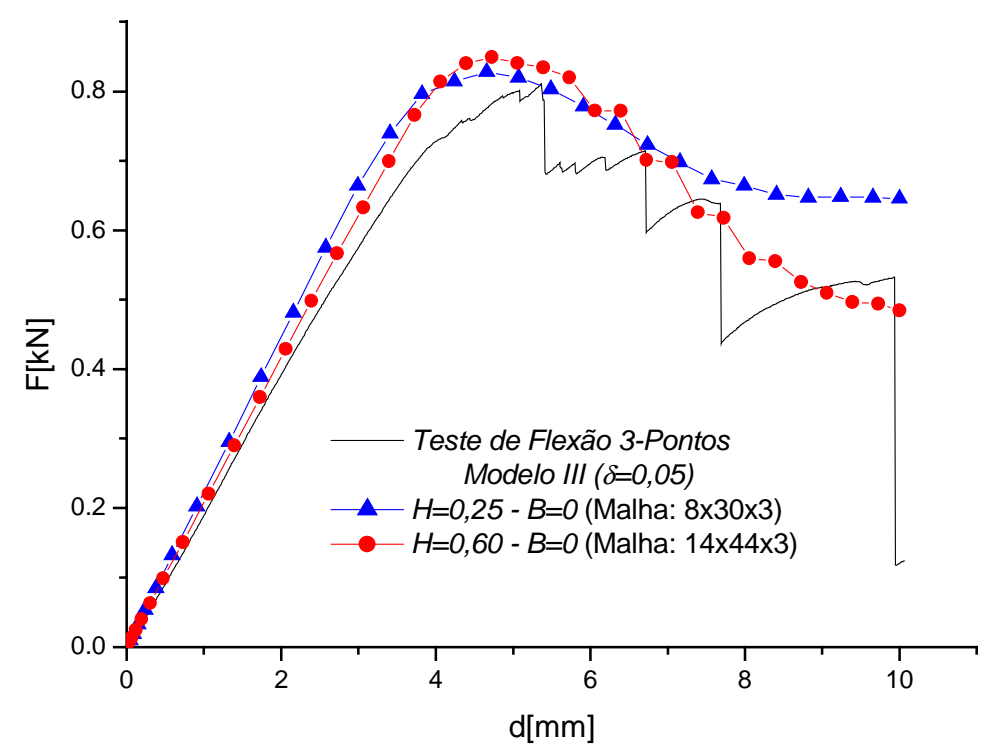

FIGURA 5.2.3-12 - Influência da densidade de malha na simulação do teste de flexão 3-pontos para lâminas orientadas a [0/90/0/90/0 $]_{s}$ : Modelo III (sub-rotina UMAT)

Por fim, para que o modelo computacional produza uma resposta mais coerente com os testes experimentais, torna-se necessário ainda simular as sucessivas delaminações. Sendo assim, houve a implementação do Modelo IV (TABELA 5.2.2-2) sob a forma de sub-rotina UMAT. Dessa forma, foi utilizada somente a geometria sólida discretizada pelo elemento C3D8R a fim de obter as tensões que promovem delaminações $\left(\sigma_{33}, \sigma_{13}\right.$ e $\left.\sigma_{23}\right)$. Além disso, foram empregados 3 pontos de integração ao longo da espessura, visando obter as tensões na base, no topo e no meio de cada lâmina. Porém, o critério de delaminação foi investigado apenas nos pontos de Gauss que estavam entre cada lâmina, ou seja, somente os pontos da base ou somente os pontos do topo. No entanto, a FIGURA 5.2.3-13 mostra que o Modelo IV não produziu nenhuma melhora significativa nos resultados numéricos. Sendo assim, não foi possível simular os degraus visualizados nos ensaios experimentais que caracterizam as delaminações. Para atingir tal qualidade na resposta numérica seria necessária uma análise mais rigorosa, empregando conceitos da Mecânica da Fratura a fim de simular não apenas a abertura da fissura, mas também a sua propagação. 


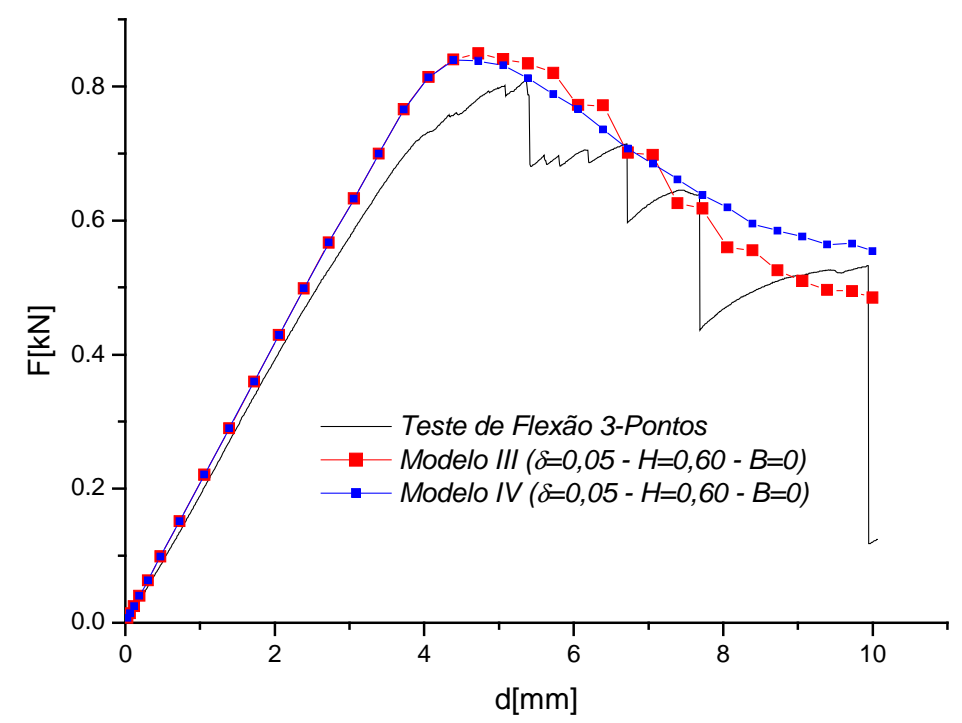

FIGURA 5.2.3-13 - Curvas força-deflexão para lâminas orientadas a [0/90/0/90/0]s:

Modelo III x Modelo IV

\section{Seqüência de Empilhamento $[+45 /-45 /+45 / 0 / 90]_{s}$}

A FIGURA 5.2.3-14 compara as curvas de força-deflexão da simulação e do teste de flexão 3-pontos para lâminas orientadas a $[+45 /-45 /+45 / 0 / 90]_{s}$, ao empregar o Modelo I descrito na TABELA 5.2.2-2.

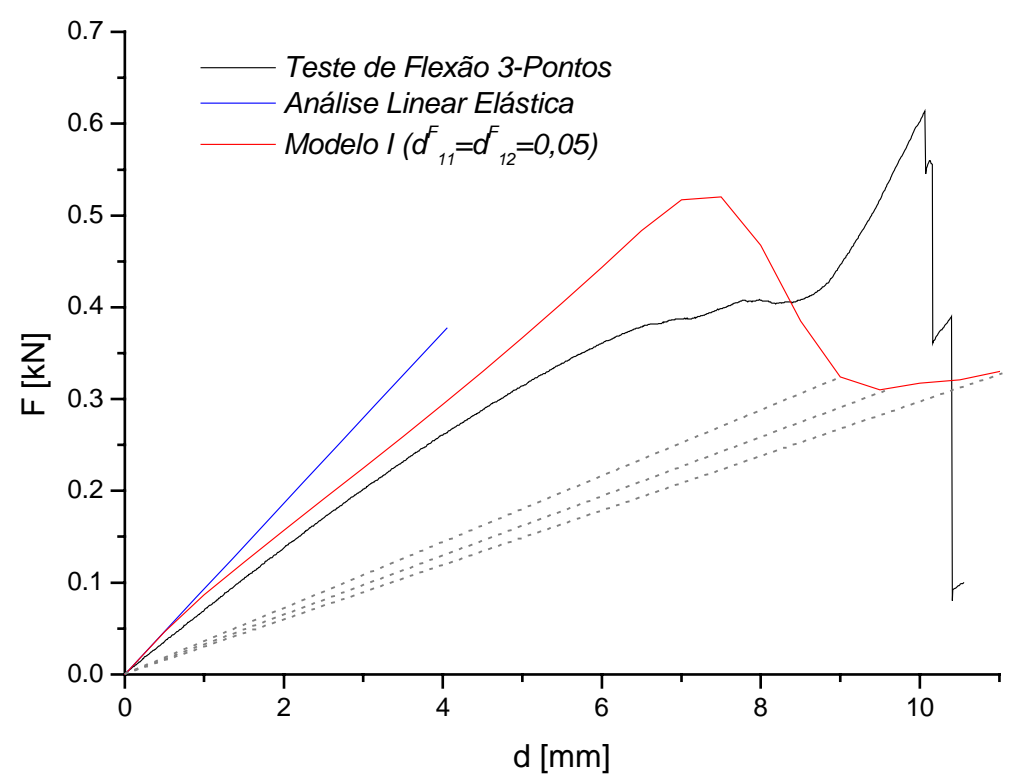

FIGURA 5.2.3-14 - Curvas força-deflexão para lâminas orientadas a [+45/-45/+45/0/90]s: Modelo I (sub-rotina USDFLD) 
Nota-se que o Critério de Danificação empregado consegue simular razoavelmente o teste até 4,0 $\mathrm{mm}$ de deflexão. Isto ocorre, pois o Modelo I de material é capaz de capturar os efeitos de não-linearidade causados pelas tensões de cisalhamento que atuam no plano da lâmina. Porém, a partir deste ponto a resposta do modelo computacional começa a divergir sensivelmente da resposta experimental. Além disso, quando o modelo atinge uma deflexão de $7,5 \mathrm{~mm}$, há uma perda de rigidez acentuada devido à Lei de Evolução de Dano que está baseada num parâmetro constante de degradação igual a 0,05 para danificação da fibra e igual a zero para danificação da matriz. Essa redução drástica da rigidez da estrutura pode ser observada através da linha cinza tracejada. No entanto, a partir deste ponto, verifica-se que o modelo computacional tende a não mais reduzir a rigidez da estrutura com o incremento de deflexão, gerando assim uma curva ascendente. Isto ocorre, pois os pontos de Gauss degradados não sofreram mais nenhuma degradação, como demonstrado na FIGURA 4.4-1 (Fluxograma do algoritmo da sub-rotina USDFLD). Dessa forma, conclui-se que o modelo computacional empregado não é adequado para simular uma grande parcela da curva experimental. Com isso, aplicou-se a Lei de Evolução de Dano baseada em um parâmetro constante de degradação para danificação da matriz e numa função de degradação para danificação da fibra (TABELA 4.2.2-2) a fim de melhorar os resultados obtidos numericamente.

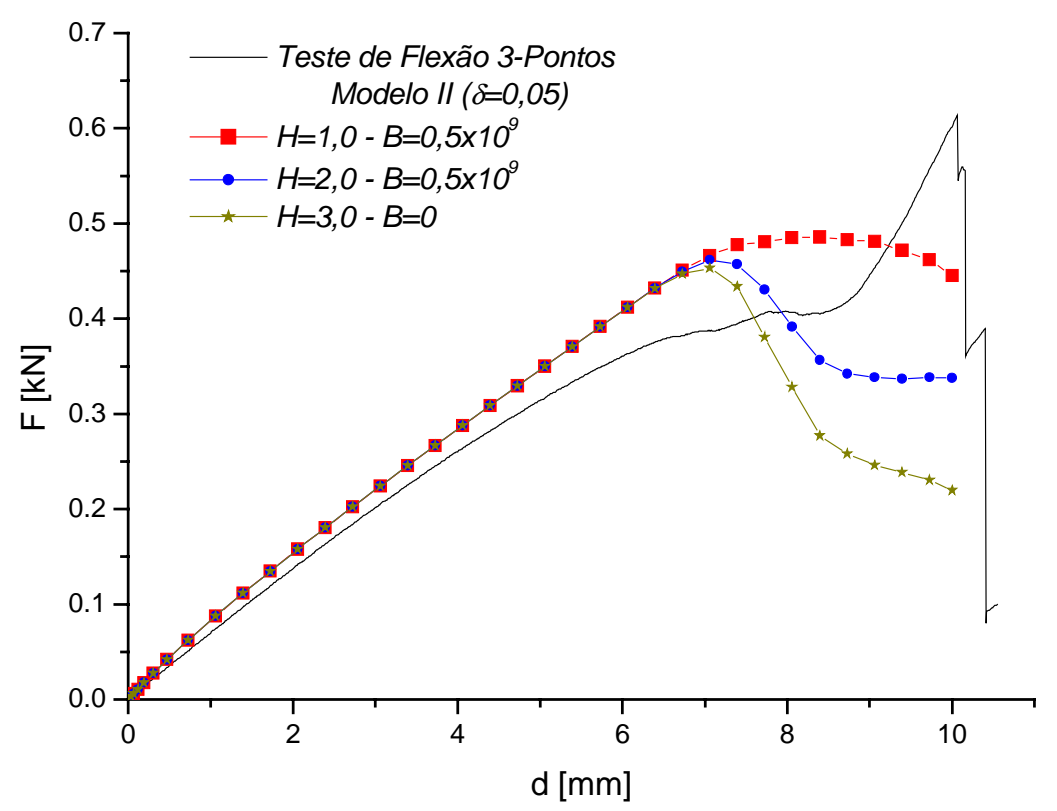

FIGURA 5.2.3-15 - Curvas força-deflexão para lâminas orientadas a 
A FIGURA 5.2.3-15 compara as curvas de força-deflexão das simulações e do teste de flexão 3-pontos para lâminas orientadas a $[+45 /-45 /+45 / 0 / 90]_{\mathrm{s}}$, ao empregar o Modelo II descrito na TABELA 5.2.2-2. Nota-se que as curvas simuladas com base no Modelo II conseguem representar razoavelmente o teste até 5,5 $\mathrm{mm}$ de deflexão. Isto ocorre, pois o Modelo II de material além de capturar os efeitos de não-linearidade causados pelas tensões de cisalhamento possui uma Lei de Evolução de Dano diferente, podendo produzir uma degradação mais branda.

Os parâmetros da função de degradação da fibra $(\delta, H$ e B) são calibrados em função do resultado experimental, e após algumas simulações, verifica-se que um valor razoável para $\delta$ é 0,05 , ao passo que para $H$ é um valor entre 1,0 e 3,0. Novamente, o valor do parâmetro $\mathrm{B}$ dependerá de $\mathrm{H}$, pois caso $\mathrm{H}$ seja maior, o parâmetro $\mathrm{B}$ deverá ser menor e vice-versa. Para a análise dessa seqüência de empilhamento, o valor do parâmetro B é igual a $0,5 \times 10^{9}$ para $\mathrm{H}$ igual a 1,0 ou igual a 2,0. No entanto, caso o valor de $\mathrm{H}$ aumente (cerca de 3,0), o valor de B necessita ser anulado, pois a degradação das propriedades se torna muito acentuada, acarretando numa perda rápida de rigidez. Entretanto, o resultado experimental demonstra que a rigidez da estrutura aumenta após a mesma ter atingido $8,5 \mathrm{~mm}$ de deflexão. Isto se deve provavelmente a uma combinação de efeitos tais como: endentação localizada nos apoios, atrito entre a amostra e os apoios, anisotropia do material e um provável alinhamento com a direção (1) de ortotropia das fibras a $+/-45^{\circ}$, que estão localizadas nas lâminas mais externas, devido à ação de carregamentos de tração. Porém, o modelo apenas contabiliza os efeitos causados pela anisotropia, o que faz com que a resposta produzida para um nível de deflexão superior a $8,5 \mathrm{~mm}$ não seja satisfatória.

É importante ressaltar que os resultados apresentados até então, são baseados em um modelo que utiliza elementos casca. Portanto, uma alternativa para melhorar os resultados numéricos foi criar um modelo empregando elementos sólidos (Elemento C3D8R) e o Modelo III de material descrito na TABELA 5.2.2-2. A FIGURA 5.2.3-16 apresenta as curvas de força-deflexão das simulações e do teste de flexão 3-pontos para lâminas orientadas a [+45/-45/+45/0/90]s. Verifica-se que as curvas simuladas com base no Modelo III se aproximam mais da resposta experimental na fase "pós-falha" do que as simuladas com base no Modelo II. Apesar da Lei de Evolução de Dano ser a mesma, os parâmetros da função de degradação da fibra $(\delta, \mathrm{H}$ e B) são um pouco diferentes dos valores calibrados anteriormente. Após algumas simulações, verifica-se que um valor 
razoável para $\delta$ é 0,05 ao passo que o valor de $\mathrm{H}$ oscila entre 1,2 e 1,8 e o valor de $\mathrm{B}$ deverá ser igual a $0,5 \times 10^{9}$.

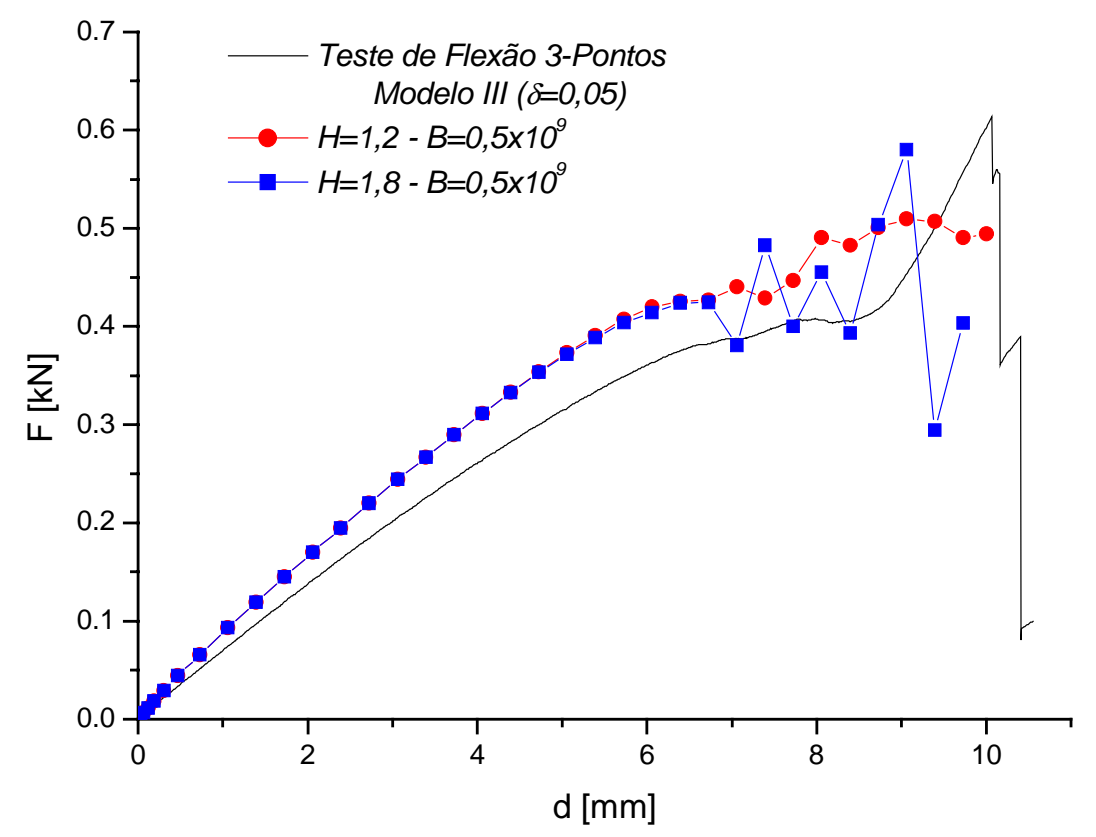

FIGURA 5.2.3-16 - Curvas força-deflexão para lâminas orientadas a [+45/-45/+45/0/90]s: Modelo III (sub-rotina UMAT)

A FIGURA 5.2.3-17 compara as curvas de força-deflexão das simulações ao empregar o modelo em casca e o modelo sólido. Nota-se que até 5,7 mm de deflexão, o modelo em casca apresenta um resultado mais satisfatório do que o modelo sólido. Pois, enquanto o elemento casca possui os 6 graus de liberdade em cada nó (translação e giros em x, y e z), o elemento sólido possui apenas 3 graus de liberdade em cada nó (translação em x, y e z). No entanto, após este valor, tem-se que a solução numérica para o modelo em casca começa a divergir do resultado experimental. Por outro lado, a solução numérica do modelo sólido passa a ter uma reposta mais coerente com os fenômenos físicos presentes no experimento. Isto ocorre provavelmente porque o elemento casca baseia-se nas hipóteses de Kirchhoff apresentadas no Capítulo 2.

Por fim, nota-se em todas as simulações que o modelo computacional aparenta ser um pouco mais rígido do que a estrutura real. Com isso, variou-se o valor do módulo de cisalhamento $\mathrm{G}_{12}$ a fim de verificar a sensibilidade do modelo frente a este parâmetro de material. 


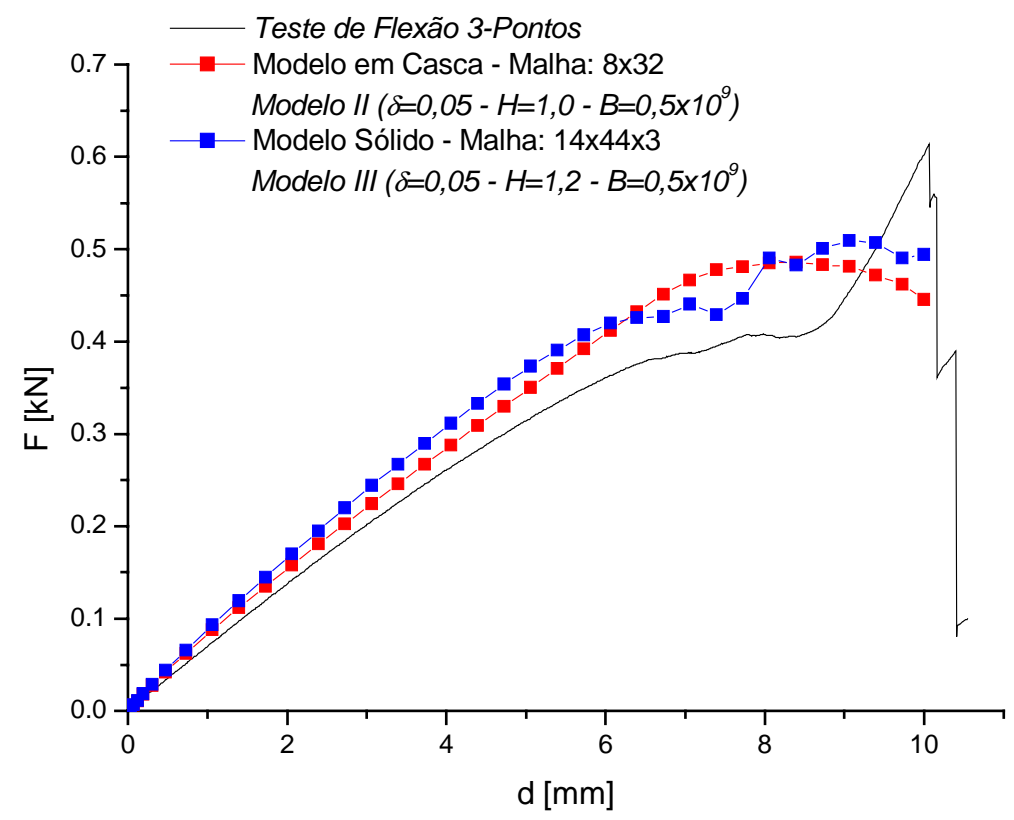

FIGURA 5.2.3-17 - Curvas força-deflexão para lâminas orientadas a [+45/-45/+45/0/90]s: Elemento S8R (Modelo II) x Elemento C3D8R (Modelo III)

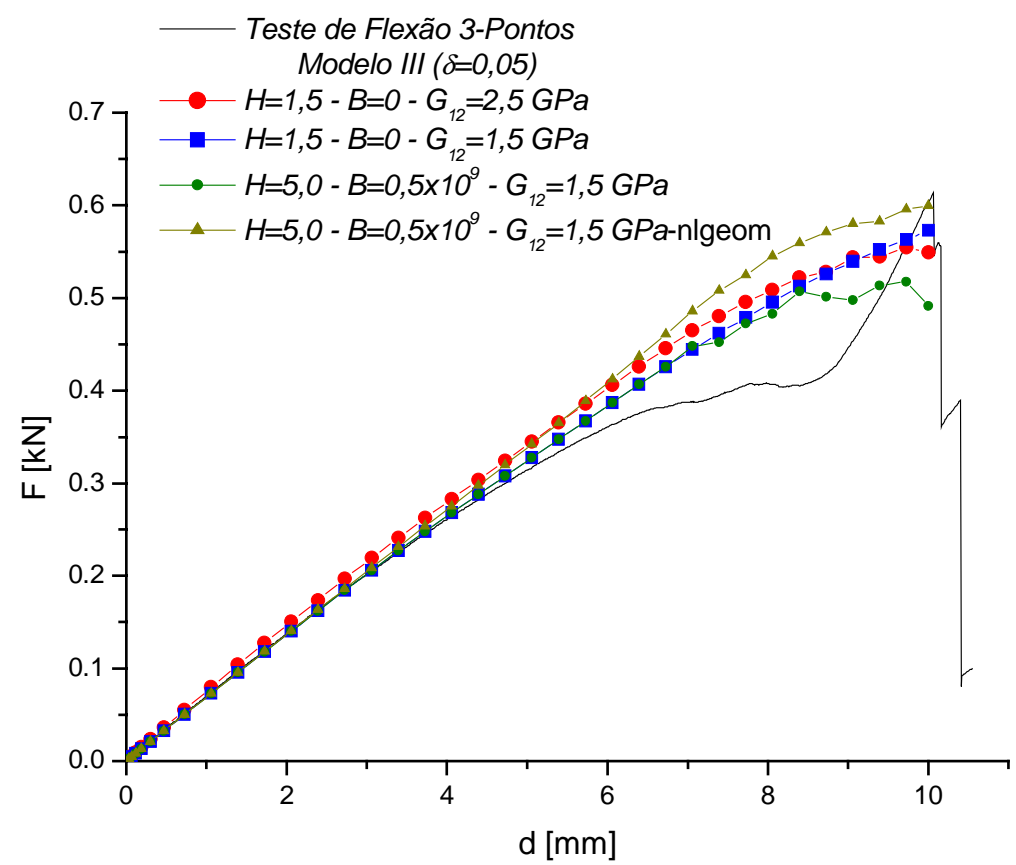

FIGURA 5.2.3-18 - Avaliação da sensibilidade da resposta ao módulo de cisalhamento $\mathrm{G}_{12}$ para lâminas orientadas a [+45/-45/+45/0/90]s (Modelo III)

Verifica-se na FIGURA 5.2.3-18 que caso o módulo de cisalhamento seja reduzido de 5,4 GPa para 2,5 $\mathrm{GPa}$ ou para 1,5 $\mathrm{GPa}$, há uma melhora sensível dos resultados até aproximadamente $6,0 \mathrm{~mm}$ de deflexão. Isto provavelmente ocorre, pois o ensaio para medir o módulo de cisalhamento foi realizado utilizando extensômetros de 
tal forma que não houve influência da rigidez da máquina nos experimentos. Porém, as deflexões obtidas dos testes de flexão 3-pontos foram capturadas à partir do deslocamento do "cross-head" da máquina. Conseqüentemente, esses ensaios têm a influência direta da rigidez da máquina e isto faz com que os resultados numéricos sejam melhores quando são utilizados módulos de cisalhamento menores. Nota-se também que apesar de realizar o equilíbrio do modelo na posição deslocada, através da opção "nlgeom” (“non-linearity geometric”) dada pelo programa ABAQUS ${ }^{\circledR}$, a resposta na fase "pós-falha" também não melhorou.

Finalmente, a questão da qualidade dos resultados numéricos de todos modelos pode ser também melhorada caso outro algoritmo de solução seja empregado. No entanto, devido à extensão do presente trabalho, nota-se que alguns aspectos numéricos foram investigados, porém não foram solucionados. Por outro lado, de acordo com a coerência dos resultados apresentados anteriormente, tem-se que os problemas numéricos abordados não invalidam a consistência física dos Modelos de Material II e III implementados sob a forma de sub-rotinas UMAT. 


\subsection{TESTES DE ENDENTAÇÃO E IMPACTO}

Os testes de endentação e impacto foram realizados também com o intuito de avaliar o modelo de material proposto e obter mais informações sobre o comportamento mecânico do material utilizado.

O teste de endentação ("indentation test") não segue nenhuma norma específica, na verdade, ele é realizado através da aplicação de um carregamento quase-estático em uma amostra com as mesmas dimensões e vinculações que serão utilizadas no teste de impacto ("drop-test"). Sendo assim, para o presente trabalho decidiu-se seguir algumas especificações da norma ASTM D5628-96 que determina condições de testes de impacto para compósitos poliméricos reforçados. De acordo com a norma ASTM D5628-96, o teste de impacto é classificado em função da geometria do impactador bem como em função da geometria da amostra. A FIGURA 5.3-1(a) mostra a geometria do impactador de alumínio com massa igual a 51,3 g que foi utilizado para endentar os corpos-de-prova. A FIGURA 5.3-1(b) apresenta como a amostra foi travada por dois discos de aço que são fixados por quatro parafusos sob um torque controlado de $27 \mathrm{Nm}$. Deve-se destacar que para essas condições, o teste realizado pode ser classificado como sendo do tipo Método FD (ASTM D5628-96).

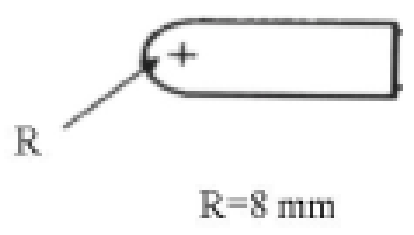

(a)

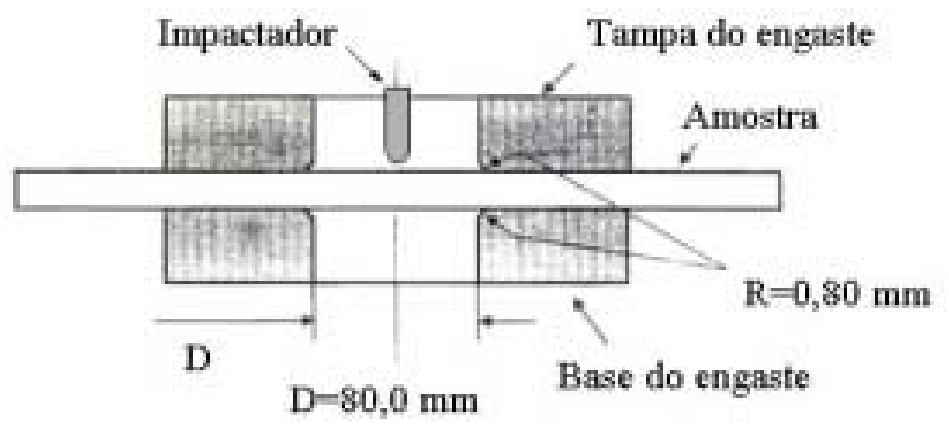

(b)

FIGURA 5.3-1 - Condições para o "indentation test"

(a) Geometria do impactador (endentador); (b) Engastamento das amostras

A TABELA 5.3-1 traz os valores de comprimento (L), largura (W), espessura (H) e velocidade (V) empregados durante os testes de endentação. Tal teste fornecerá o gráfico da força de contato em função do deslocamento do centro da amostra, considerando um carregamento quase-estático. 
TABELA 5.3-1 - Especificações para os testes de endentação ( $\mathrm{L}=$ comprimento; $\mathrm{W}=$ largura; $\mathrm{H}=$ espessura)

\begin{tabular}{ccccc}
\hline $\begin{array}{c}\text { Sequência de } \\
\text { Empilhamento }\end{array}$ & $\begin{array}{c}\mathbf{L} \\
{[\mathbf{m m}]}\end{array}$ & $\begin{array}{c}\mathbf{W} \\
{[\mathbf{m m}]}\end{array}$ & $\begin{array}{c}\mathbf{H} \\
{[\mathbf{m m}]}\end{array}$ & $\begin{array}{c}\mathbf{V} \\
{[\mathbf{m m} / \mathbf{m i n}]}\end{array}$ \\
\hline$[0]_{10}$ & 120 & 120 & 1,8 & 10 \\
\hline$[0 / 90 / 0 / 90 / 0]_{\mathrm{s}}$ & 120 & 120 & 1,8 & 10 \\
\hline$[+45 /-45 /+45 / 0 / 90]_{\mathrm{s}}$ & 120 & 120 & 1,8 & 10 \\
\hline
\end{tabular}

Os testes de impacto (“drop-tests”) são realizados com a finalidade de avaliar o modelo de material sob condições dinâmicas de carregamento. Como foi relatado anteriormente, os testes de impacto seguiram algumas especificações do Método FD descrito pela norma ASTM D5628-96. A TABELA 5.3-2 traz os valores de comprimento (L), largura (W), espessura $(\mathrm{H})$ das amostras bem como os valores de massa $\left(\mathrm{m}_{\mathrm{i}}\right)$, altura $\left(\mathrm{h}_{\mathrm{i}}\right)$, velocidade $\left(\mathrm{v}_{\mathrm{o}}\right)$ e energia de impacto $\left(\mathrm{E}_{\mathrm{i}}\right)$.

TABELA 5.3-2 - Especificações para os testes de impacto ( $\mathrm{L}=$ comprimento; $\mathrm{W}=$ largura; $\mathrm{H}=$ espessura $)$

\begin{tabular}{|c|c|c|c|c|c|c|c|}
\hline $\begin{array}{l}\text { Sequência de } \\
\text { Empilhamento }\end{array}$ & $\begin{array}{c}\mathbf{L} \\
{[\mathrm{mm}]}\end{array}$ & $\begin{array}{c}\mathbf{W} \\
{[\mathrm{mm}]}\end{array}$ & $\begin{array}{c}\mathbf{H} \\
{[\mathrm{mm}]}\end{array}$ & $\begin{array}{c}\mathbf{m}_{\mathbf{i}} \\
{[\mathrm{kg}]}\end{array}$ & $\begin{array}{c}\mathbf{h}_{\mathbf{i}} \\
{[\mathbf{m}]}\end{array}$ & $\begin{array}{c}\mathbf{v}_{\mathbf{o}} \\
{[\mathbf{m} / \mathbf{s}]}\end{array}$ & $\begin{array}{r}\mathbf{E}_{\mathbf{i}} \\
{[\mathbf{J}]}\end{array}$ \\
\hline \multirow{2}{*}[0]{$_{10}$} & 120 & 120 & 1,8 & 1,205 & 0,5 & 3,13 & 5,91 \\
\hline & 120 & 120 & 1,8 & 1,205 & 0,2 & 1,98 & 2,36 \\
\hline \multirow{3}{*}[0/90/0/90/0]{$_{\mathrm{s}}$} & 120 & 120 & 1,8 & 1,205 & 0,5 & 3,13 & 5,91 \\
\hline & 120 & 120 & 1,8 & 1,205 & 0,2 & 1,98 & 2,36 \\
\hline & 120 & 120 & 1,8 & 1,205 & 0,5 & 3,13 & 5,91 \\
\hline$[+45 /-45 /$ & 120 & 120 & 1,8 & 1,205 & 0,2 & 1,98 & 2,36 \\
\hline \multirow[t]{2}{*}{$+45 / 0 / 90]_{\mathrm{s}}$} & 120 & 120 & 1,8 & 2,205 & 0,5 & 3,13 & 10,82 \\
\hline & 120 & 120 & 1,8 & 2,205 & 0,2 & 1,98 & 4,33 \\
\hline
\end{tabular}

Deve-se ressaltar que apenas a massa do impactor é igual a 51,3 g que adicionada à massa do suporte e à massa da célula de carga, produz uma massa de impacto igual a 1,205 kg (FIGURA 5.3-2). Essa massa de impacto pode ser aumentada, adicionando alguns pesos padronizados ao suporte. Isto permitiu que houvesse um estudo da influência não somente da altura de impacto mas também da massa de impacto na 
resposta da estrutura. De acordo com a literatura, é sabido que a mudança do nível de energia de impacto pode levar a uma mudança dos mecanismos de falha da estrutura em CPR. Assim, para níveis de energia menor, espera-se a predominância de fissuras na matriz. Para níveis de energia maiores espera-se a ocorrência de delaminações e/ou fratura das fibras (ABRATE, 1998).
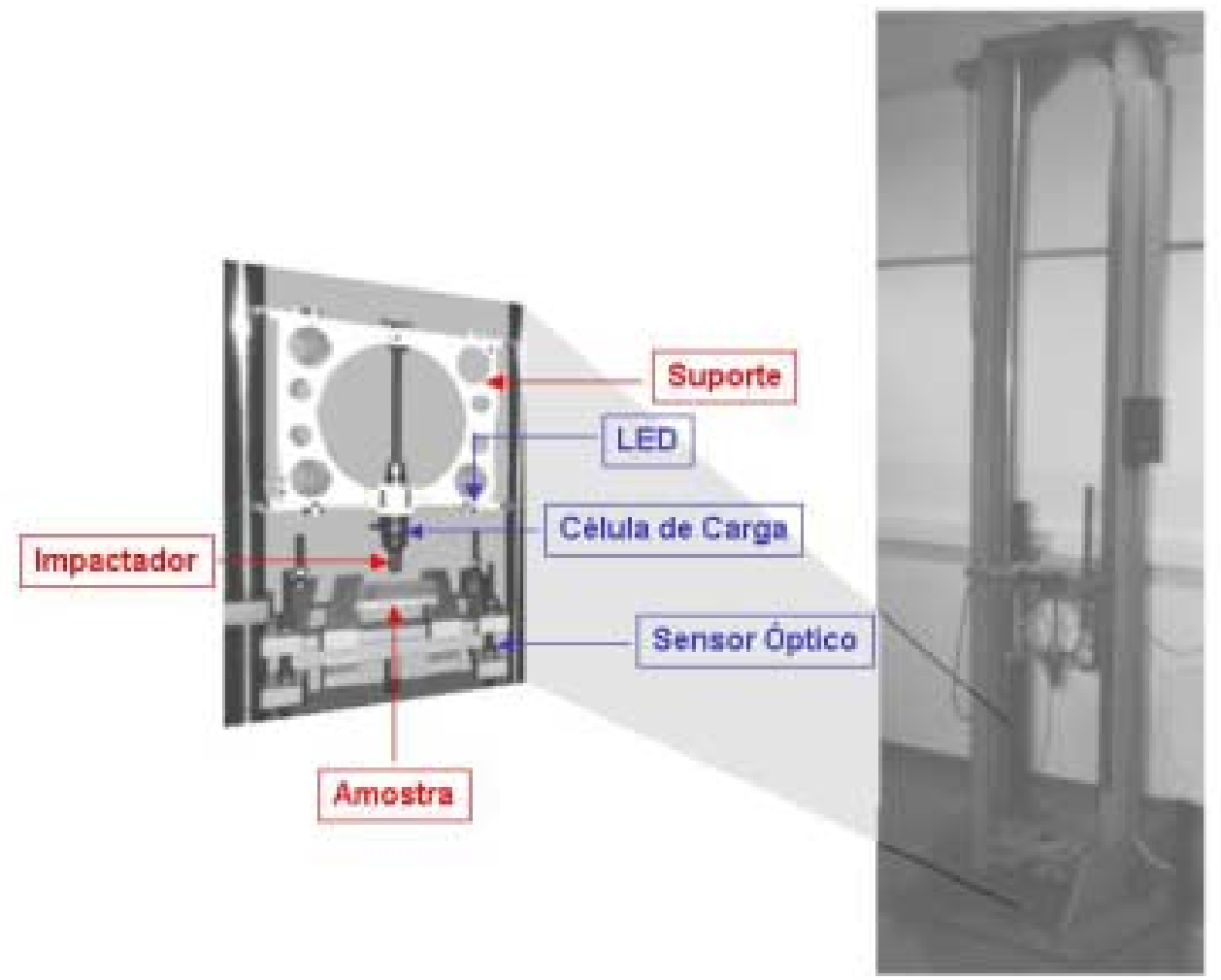

FIGURA 5.3-2 - Torre de impacto (“drop-tower") e dispositivos utilizados no teste

Outro aspecto importante que deve ser ressaltado é com relação às seqüências de empilhamento escolhidas. No caso, as estruturas com seqüência igual a $[0]_{10}$ deverão apresentar basicamente falhas na matriz e fratura de algumas fibras. Por outro lado, as estruturas com sequiência igual a $[0 / 90 / 0 / 90 / 0]_{\mathrm{s}}$ deverão apresentar falhas na matriz e muitas delaminações. Por fim, as estruturas com seqüência igual a [+45/-45/+45/0/90]s deverão apresentar falhas na matriz, delaminações e fraturamento das fibras. Esta última seqüência de empilhamento é muito interessante para análise, pois caracteriza um laminado conhecido como quase-isótropo. Na FIGURA 5.3-3 é possível verificar a geometria do corpo de prova utilizado tanto para "drop-test" como para o "indentation test" bem como a região que foi circundada pelos discos de travamento. 


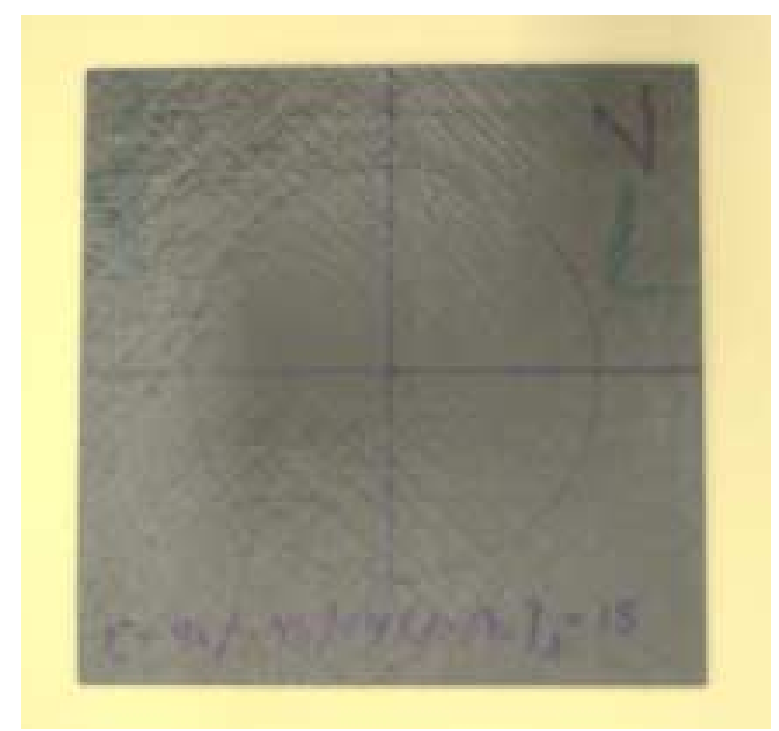

FIGURA 5.3-3 - Amostras utilizadas durante o "indentation test" e o "drop-test"

Por fim, tem-se que os testes permitiram obter resultados experimentais do tipo históricos de força, velocidade e deslocamento através de uma célula de carga, bem como através de um sistema constituído por um LED ("Ligth Emitting Diode") e por um sensor óptico. Vale ressaltar que a célula de carga está ligada a um amplificador Kistler $^{\circledR}$ (modelo 5007) que envia o sinal para um computador. Dentro do computador há uma placa de aquisição de dados de 11 bits, com entrada para até três canais, possuindo uma freqüência de amostragem ("sampling frequency") de $19 \mathrm{kHz}$ capaz de capturar um sinal que dure apenas alguns milisegundos.

Além dos testes de impacto e endentação, foram realizadas inspeções dos mecanismos de danificação e falha nas estruturas ensaiadas. Essas inspeções têm por objetivo detectar a extensão do dano e os principais fenômenos que ocorreram durante os testes de impacto e de endentação. Com isso, pode-se ter informações qualitativas sobre o comportamento da estrutura. Tais informações além de auxiliarem na calibração do modelo de material, fornecem imagens da extensão do dano que podem então ser comparadas às imagens obtidas no pós-processamento das análises numéricas.

Segundo Abrate (1998), as técnicas não destrutivas de avaliação de danificação e falha são suficientes para identificar os fenômenos predominantes que ocorreram durante o ensaio experimental. Por outro lado, as técnicas destrutivas de avaliação são utilizadas apenas com o intuito de verificar maiores detalhes nas amostras que danificaram. Além disso, de acordo com a literatura, as técnicas de inspeção são utilizadas em conjunto a fim de aumentar a qualidade das informações, principalmente 
para materiais novos que estão em fase de desenvolvimento. Sendo assim, quanto mais técnicas forem combinadas, mais preciso será o resultado da inspeção. No entanto, o custo operacional se eleva abruptamente. Dessa forma, geralmente, são utilizadas apenas uma ou duas técnicas não destrutivas de inspeção para avaliar as falhas sem que haja um alto custo operacional. No entanto, no presente trabalho, utilizou-se apenas a técnica de ultra-som C-Scan. Para tal, emitiu-se um sinal com uma frequência de $5 \mathrm{MHz}$ sobre uma região quadrada de $30 \mathrm{~mm}$ de lado onde houve o contato entre o impactador e a amostra. Além disso, manteve-se um incremento de varredura igual a 298,4 $\mu$ m para garantir uma certa qualidade na resolução das imagens capturadas.

Alguns equipamentos de ultra-som permitem a visualização da extensão do dano em uma determinada profundidade do material. Sendo assim, pode-se monitorar de forma precisa a localização e a extensão das delaminações entre as lâminas. No entanto, infelizmente, o equipamento de ultra-som do Leuven Composites Processing Centre (LCPC) da KU Leuven não dispõe deste recurso. Conseqüentemente, a imagem capturada é uma superposição das regiões danificadas em cada lâmina, ou seja, tem-se a projeção da falha de cada camada em um só plano. Por outro lado, deve-se salientar que através da imagem capturada pelo equipamento pôde-se identificar o tipo de danificação/falha predominante como será demonstrado posteriormente.

\subsubsection{Resultados Experimentais}

De acordo com a estratégia de análise determinada, o modelo de material será inicialmente avaliado e terá os seus parâmetros calibrados por um teste de endentação que consiste de um teste quase-estático realizado em uma estrutura com as mesmas dimensões e vinculações empregadas no teste de impacto. No entanto, é importante destacar que o valor último da força aplicado no teste de endentação deve ser baseado no pico de força encontrado no teste de impacto. Sendo assim, foi necessário realizar os testes de impacto antes dos testes de endentação.

\section{$\underline{\text { Resultados dos Testes de Impacto }}$}

A FIGURA 5.3.1-1 apresenta os históricos de força e de deslocamento do impactador quando este atinge amostras com lâminas orientadas a $[0]_{10}$. 


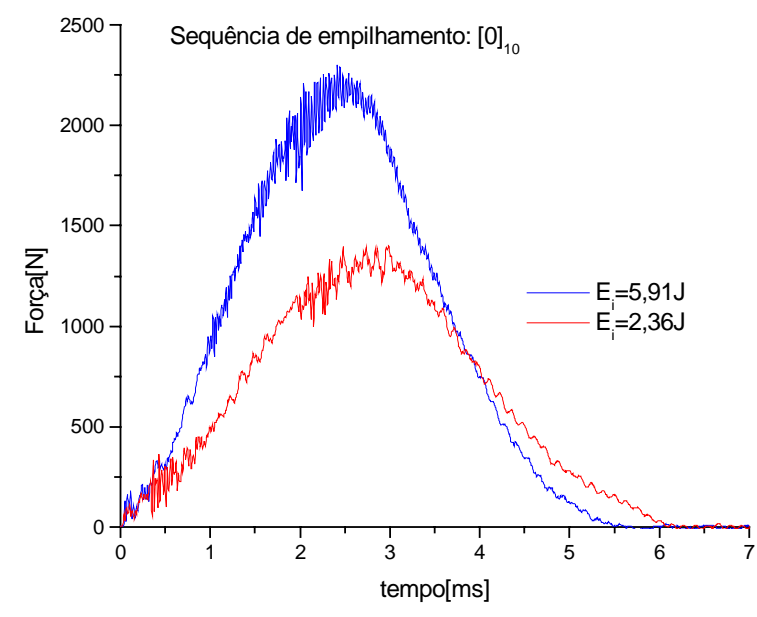

(a)

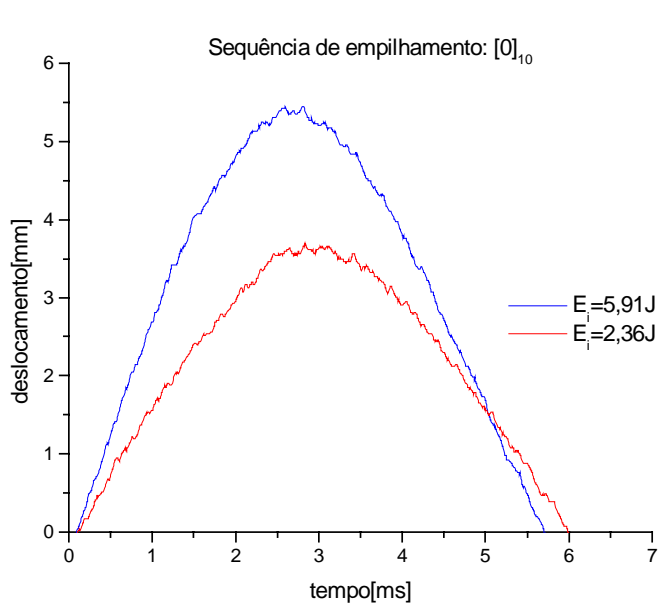

(b)

FIGURA 5.3.1-1 - Históricos para lâminas orientadas a $[0]_{10}$ :

(a) Históricos de força; (b) Históricos de deslocamento

Os históricos de força da FIGURA 5.3.1-1(a) apresentam inicialmente (até $1 \mathrm{~ms}$ ) uma região caracterizada por oscilações inerciais de alta frequiência devido ao contato inicial da amostra com o impactador. Posteriormente, a partir de $2 \mathrm{~ms}$, surgem algumas oscilações mais intensas que demonstram a ocorrência de danos, principalmente para as amostras sob $\mathrm{E}_{\mathrm{i}}$ igual a 5,91 $\mathrm{J}$ que atingiram um pico de força igual a $2.250 \mathrm{~N}$. Devido à seqüência de empilhamento, tem-se principalmente a ruptura da matriz, fazendo com que não haja assim, uma grande perda da rigidez global da estrutura. Portanto, não se verifica uma queda brusca do valor da força após o início do processo de danificação que chegou a atingir cerca de $1.300 \mathrm{~N}$ para as amostras sob $\mathrm{E}_{\mathrm{i}}$ igual a 2,36 J. Quanto ao tempo de contato, verifica-se que para as amostras impactadas sob um nível de energia maior, este tempo é cerca de 5,5 ms, ao passo que para as amostras impactadas sob um nível menor constata-se um tempo de contato maior $(6 \mathrm{~ms})$. Este tempo de contato será posteriormente avaliado com mais rigor, pois o mesmo determina a tendência da estrutura ter uma resposta dinâmica ou quase-estática. Além disso, nota-se pelo histórico de deslocamento (FIGURA 5.3.1-1(b)) que para $\mathrm{E}_{\mathrm{i}}$ igual a 5,91 J, o impactador penetrou na amostra cerca de 5,4 $\mathrm{mm}$ e em seguida retornou a uma altura menor do que a altura de lançamento. No entanto, para um nível de energia de impacto menor (2,36 J), registrou-se um valor de penetração menor, ou seja, igual a 3,6 mm. Portanto, a energia transferida $\left(E_{t}\right)$ para estrutura também foi inferior. Tudo isto pode ser confirmado através dos históricos de energia que são obtidos ao aplicar a seguinte expressão: 


$$
E_{t}(t)=\frac{m v_{o}^{2}}{2}-\frac{m\left(v_{t}(t)\right)^{2}}{2}
$$

onde:

$$
\mathrm{v}_{\mathrm{t}}(\mathrm{t})=\text { velocidade do impactador no tempo t para } \mathrm{t} \geq 0
$$

A velocidade do impactador é dada por:

$$
\mathrm{v}_{\mathrm{t}}(\mathrm{t})=\mathrm{v}_{\mathrm{o}}-\frac{1}{\mathrm{~m}} \int_{0}^{\mathrm{t}} \mathrm{F}_{\text {exp }} \mathrm{dt}
$$

onde:

$$
\begin{aligned}
& m=\text { massa do impactador } \\
& \mathrm{F}_{\text {exp }}=\text { força medida experimentalmente }
\end{aligned}
$$

A FIGURA 5.3.1-2 apresenta os históricos de energia para as amostras com lâminas orientadas a $[0]_{10}$, evidenciando que uma parcela da Energia de Impacto é armazenada pela estrutura sob forma de Energia Elástica, sendo assim devolvida ao impactador através de vibrações. Por outro lado, há uma outra parcela que é dissipada pelo laminado em forma de danificações e deformações permanentes, e poderia ser chamada de "Energia Dissipada". No entanto, a literatura geralmente expressa tal energia como sendo uma Energia Absorvida, pois de toda Energia de Impacto que foi transferida tem-se que essa parcela não foi devolvida em forma de vibrações elásticas.

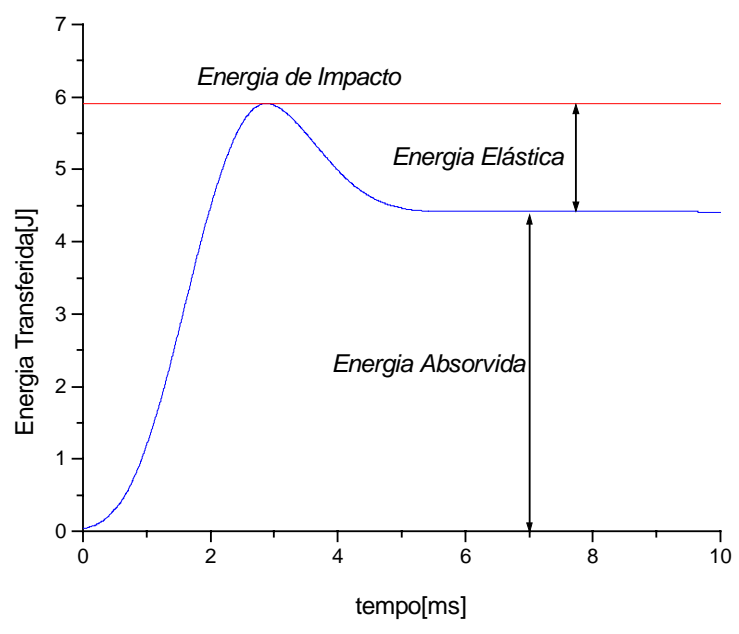

(a)

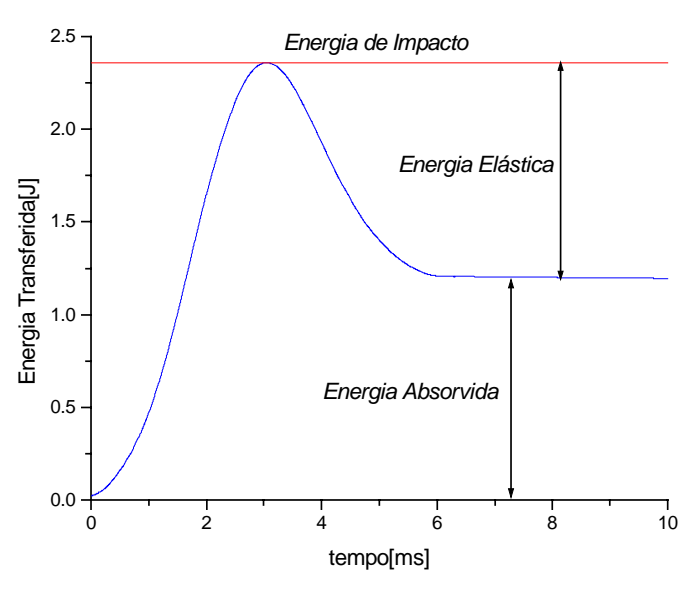

(b)

FIGURA 5.3.1-2 - Históricos de energia para lâminas orientadas a $[0]_{10}$ :

(a) Energia de impacto igual a 5,91 J; (b) Energia de impacto igual a 2,36 J 
Nota-se pela FIGURA 5.3.1-2(a) que as amostras impactadas a 5,91 J tiveram uma absorção de energia igual a 4,42 J, transferindo de volta para o impactador apenas $25 \%$ de toda a energia de impacto em forma de energia elástica de vibração. Em contra partida, as amostras impactadas a 2,36 J (FIGURA 5.3.1-2(b)), tiveram um nível de absorção de energia igual a 1,2 J, retornando assim 1,16 J para o impactador. Dessa forma, essas amostras devolveram praticamente $50 \%$ da energia de impacto em forma de vibrações elásticas. Isto indica que ocorreram poucas danificações, pois a estrutura não absorveu grande parte da energia de impacto que lhe foi transferida. Tal fato pode ser elucidado com o auxílio dos mapas de falha obtidos através da técnica de ultra-som C-Scan (FIGURA 5.3.1-3). As amostras impactadas a 5,91 J, apresentaram um dano mais concentrado ao redor do ponto de impacto. Por outro lado, as amostras impactadas a 2,36 J tiveram uma danificação mais distribuída, apresentando fissuras na matriz com preferência de propagação na direção paralela às fibras. Diante disso, pode-se considerar que essas amostras apresentaram apenas fratura da matriz, ao passo que as amostras impactadas sob um maior nível de energia tiveram fratura da matriz bem como ruptura de algumas fibras que estavam localizadas na face oposta do ponto de aplicação da força de impacto.
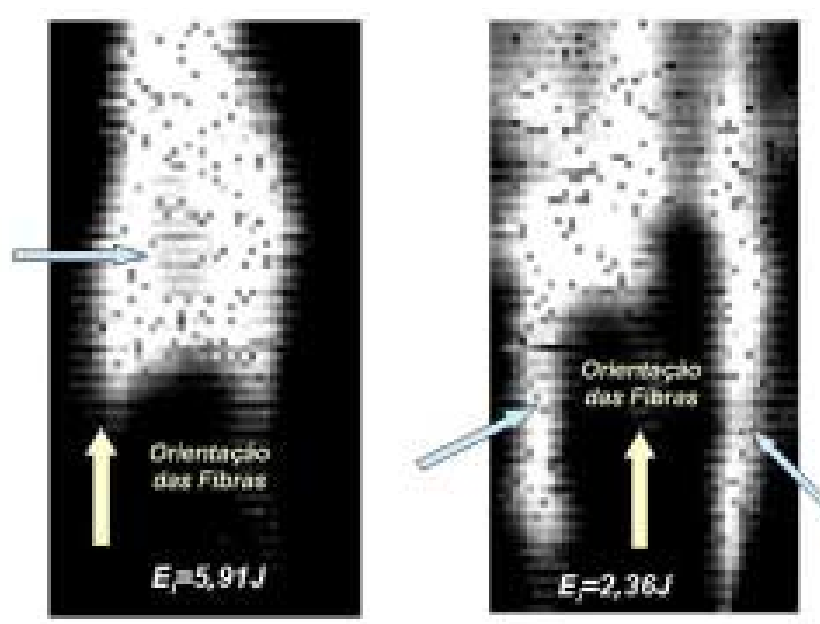

FIGURA 5.3.1-3 - Mapas de falha obtidos através da técnica de ultra-som C-Scan para lâminas orientadas a $[0]_{10}$

A FIGURA 5.3.1-4 apresenta os históricos de força e de deslocamento do impactador quando este atinge amostras com lâminas orientadas a [0/90/0/90/0 $]_{s}$. 


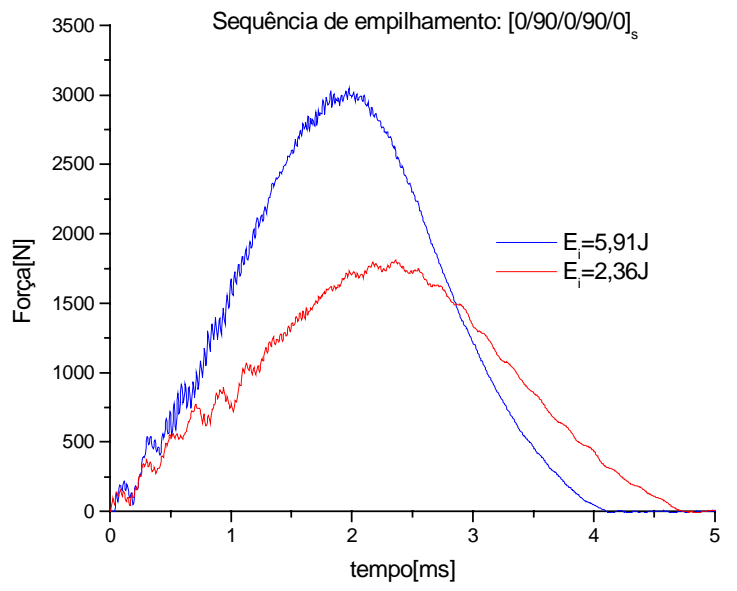

(a)

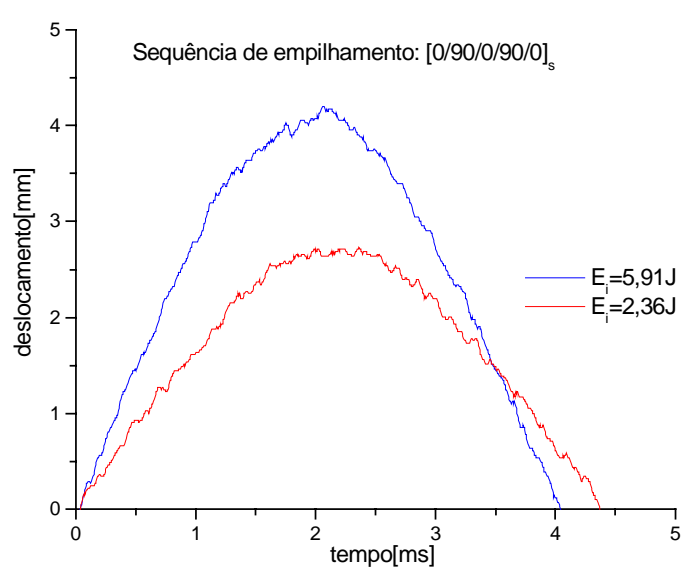

(b)

FIGURA 5.3.1-4 - Históricos para lâminas orientadas a [0/90/0/90/0]s:

(a) Históricos de força; (b) Históricos de deslocamento

Os históricos de força da FIGURA 5.3.1-4(a) apresentam inicialmente (até 1,2ms) uma região caracterizada por oscilações inerciais de alta freqüência devido ao contato inicial. Posteriormente, a partir de 1,8 ms, surgem algumas pequenas oscilações que demonstram a ocorrência de alguns mecanismos de falha. Devido à seqüência de empilhamento, pode-se ter ruptura da matriz bem como delaminações, porém, não são esperadas fraturas das fibras. Isto pode ser explicado através da ausência de uma queda brusca do valor da força após o início do processo de falha, demonstrando que não houve uma grande perda da rigidez global da estrutura. Quanto ao tempo de contato, verifica-se que para as amostras impactadas sob um nível de energia maior, este tempo é cerca de $4 \mathrm{~ms}$, ou seja, o contato termina $2 \mathrm{~ms}$ após a amostra ter atingido o seu pico de força em 3.000 N. Por outro lado, para as amostras impactadas sob um nível menor de energia, verifica-se um valor de pico de força menor $(1.750 \mathrm{~N})$, mas um tempo de contato maior (4,5 ms). Além disso, nota-se pelo histórico de deslocamento (FIGURA 5.3.1-4(b)) que para $E_{\mathrm{i}}$ igual a 5,91 J, o impactador penetrou na amostra cerca de 4,2 mm e em seguida retornou a uma altura menor do que a altura de lançamento. No entanto, para um nível de energia de impacto menor (2,36 J), registrou-se um valor de penetração menor, ou seja, igual a $2,7 \mathrm{~mm}$. Portanto, a energia transferida $\left(E_{t}\right)$ para estrutura também foi inferior. Tudo isto pode ser confirmado através da FIGURA 5.3.15.

Verifica-se pela FIGURA 5.3.1-5(a) que as amostras impactadas a 5,91 J tiveram uma absorção de energia igual a 3,96 J, transferindo de volta para o impactador cerca de 
$33 \%$ de toda a energia de impacto. Em contra partida, as amostras impactadas a 2,36 J (FIGURA 5.3.1-5(b)) tiveram um nível de absorção de energia igual a 0,58 J, retornando assim 1,78 J para o impactador. Dessa forma, essas amostras absorveram apenas $25 \%$ da energia de impacto em forma de danificações. Isto indica que ocorreram poucos mecanismos de danificação/falha, pois a estrutura apresentou uma resposta quase que totalmente elástica. Tal fato pode ser elucidado com o auxílio dos mapas de falha obtidos através da técnica de ultra-som C-Scan.

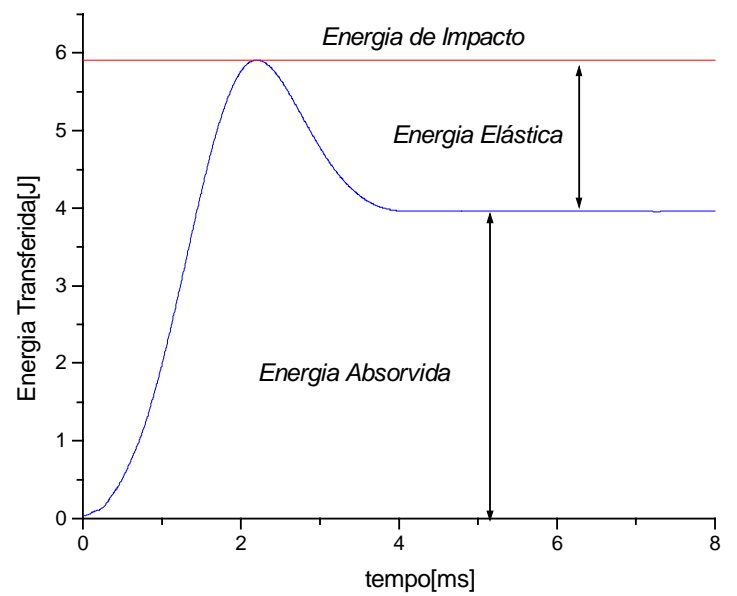

(a)

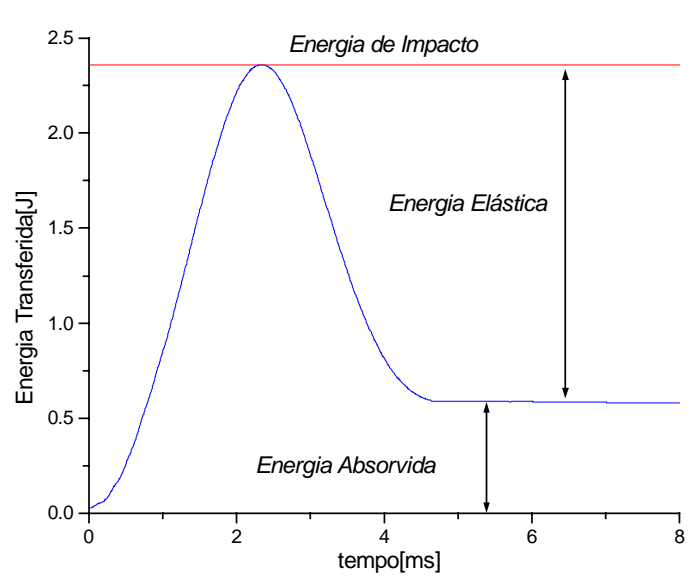

(b)

FIGURA 5.3.1-5 - Históricos de energia para lâminas orientadas a [0/90/0/90/0 $]_{s}$ :

(a) Energia de impacto igual a 5,91 J; (b) Energia de impacto igual a 2,36 J

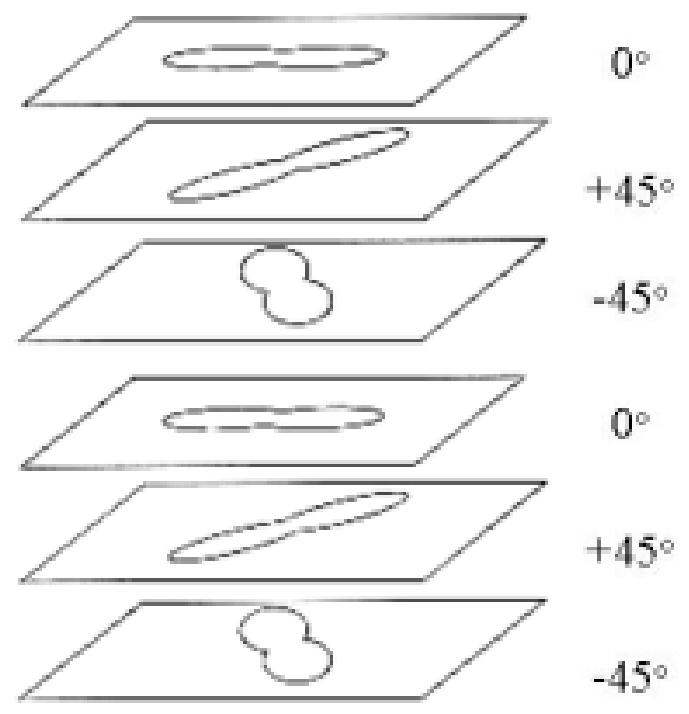

FIGURA 5.3.1-6 - Forma ("peanut shape") e orientação das delaminações (ABRATE, 1998) 
Segundo a literatura, as delaminações possuem uma forma específica ("peanut shape") com um certo grau de orientação em função das camadas que se delaminaram (FIGURA 5.3.1-6).

Na FIGURA 5.3.1-7 são apresentadas as formas de falha dos laminados provenientes da técnica $C$-Scan. É importante ressaltar que na verdade essas formas são constituídas pela superposição de mecanismos de falha. Sendo assim, verifica-se que há uma superposição das delaminações com a propagação de fissuras na matriz. Devido à seqüência de empilhamento que contém mais camadas a $0^{\circ}$, é possível notar que há mais fissuras na matriz paralela às fibras orientadas a $0^{\circ}$ do que a $90^{\circ}$ bem como há uma tendência maior das delaminações se orientarem também a $0^{\circ}$ ("peanut shapes" em azul). Além disso, pode-se constatar que os laminados impactados a 5,91 J tiveram uma extensão maior do fenômeno de delaminação e de propagação das fissuras na matriz do que os laminados impactados a 2,36 J. Isto foi observado nos históricos de energia e foi confirmado pelos mapas de falha que apresentam áreas danificadas diferentes. No caso para as amostras impactadas a 5,91J, o programa da máquina de ultra-som calculou um valor igual $340 \mathrm{~mm}^{2}$ de área danificada. Em contra partida, para as amostras impactadas a 2,36 J, o programa da máquina de ultra-som calculou um valor igual $150 \mathrm{~mm}^{2}$ de área danificada para a região que foi varrida pelo "scanner".
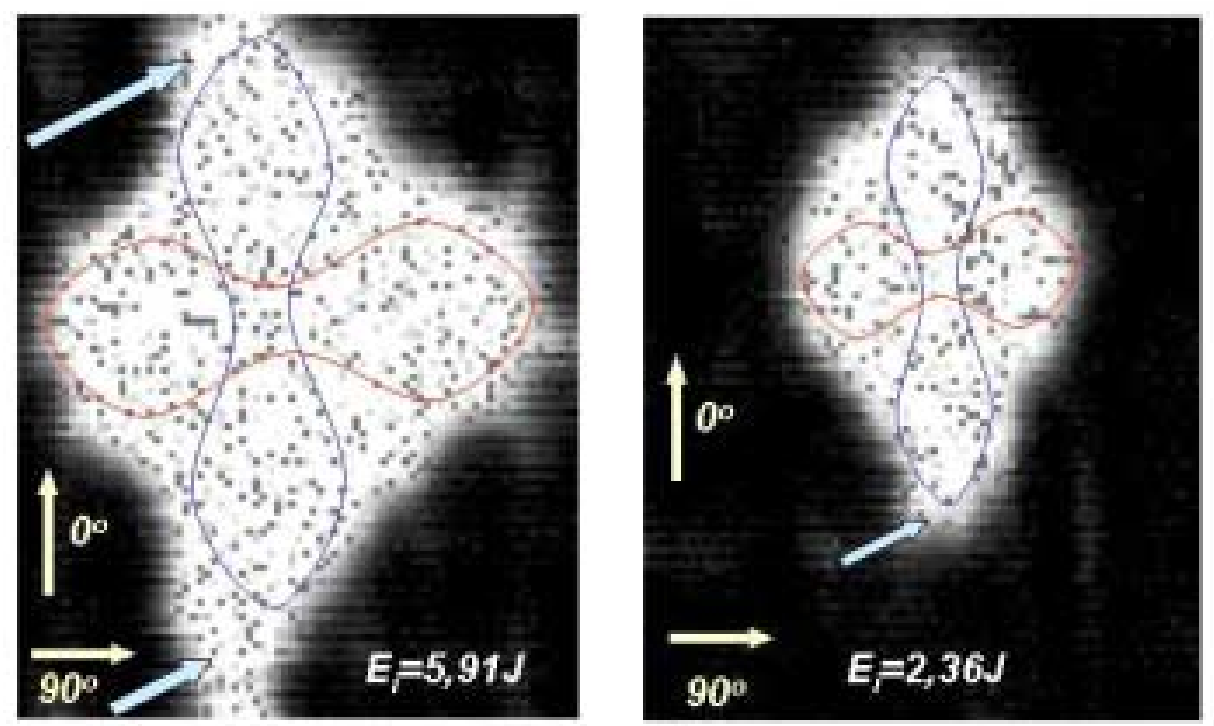

FIGURA 5.3.1-7 - Mapas de falha obtidos através da técnica de ultra-som C-Scan para lâminas orientadas a $[0 / 90 / 0 / 90 / 0]_{\mathrm{s}}$ 
A FIGURA 5.3.1-8 apresenta os históricos de força e de deslocamento do impactador para quatro diferentes níveis de energia de impacto quando este atinge amostras com lâminas orientadas a $[+45 /-45 /+45 / 0 / 90]_{\mathrm{s}}$.

Os históricos de força da FIGURA 5.3.1-8(a) demonstram claramente não apenas a influência da altura de impacto mas também da massa do impactador. Sendo assim, as amostras que foram atingidas por um impactador que foi colocado a $0,5 \mathrm{~m}$ de altura $\left(\mathrm{E}_{\mathrm{i}}\right.$ igual a 5,91 $\mathrm{J}$ ou igual a $10,82 \mathrm{~J}$ ) tiveram uma resposta diferente das amostras impactadas a uma altura de 0,2 $\mathrm{m}\left(\mathrm{E}_{\mathrm{i}}\right.$ igual a 2,36 J ou igual a 4,33 J). Além disso, as amostras impactadas sob uma altura maior tiveram picos de força maiores, sendo $3.300 \mathrm{~N}$ para $\mathrm{E}_{\mathrm{i}}$ igual a $5,91 \mathrm{~J}$ e $4.500 \mathrm{~N}$ para $\mathrm{E}_{\mathrm{i}}$ igual a $10,82 \mathrm{~J}$. É importante ressaltar a presença de inúmeras oscilações próximas desses picos de força, caracterizando assim a ocorrência de danificações. Neste caso, pode-se considerar a existência de diferentes mecanismos de danificação/falha, tal como, ruptura da matriz, delaminações entre as camadas $0^{\circ} / 90^{\circ}$ e $45^{\circ} / 0^{\circ}$, fratura de algumas fibras e deformações permanentes devido às lâminas $+/-45^{\circ}$. Por outro lado, as amostras impactadas sob uma altura menor tiveram picos de força menores, sendo $1.900 \mathrm{~N}$ para $\mathrm{E}_{\mathrm{i}}$ igual a 2,36 $\mathrm{J}$ e $2.500 \mathrm{~N}$ para $\mathrm{E}_{\mathrm{i}}$ igual a 4,33 J. Nota-se assim, apenas algumas oscilações próximas desses picos de força, caracterizando a ocorrência de poucas danificações.

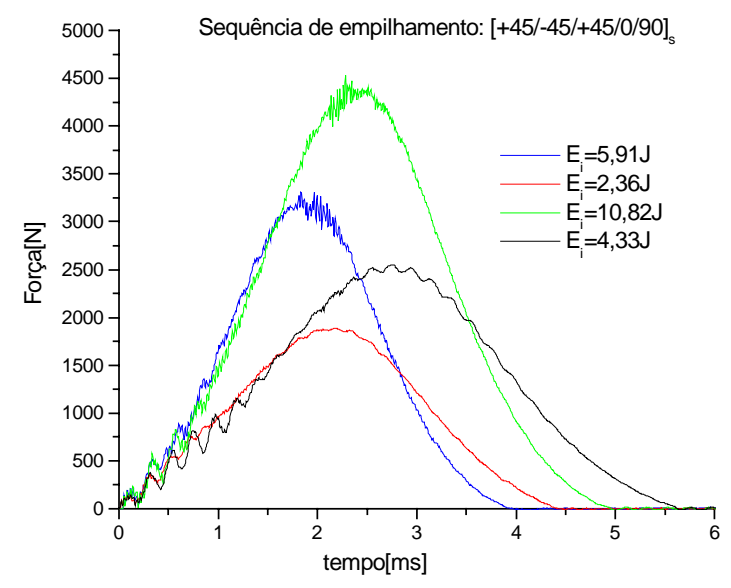

(a)

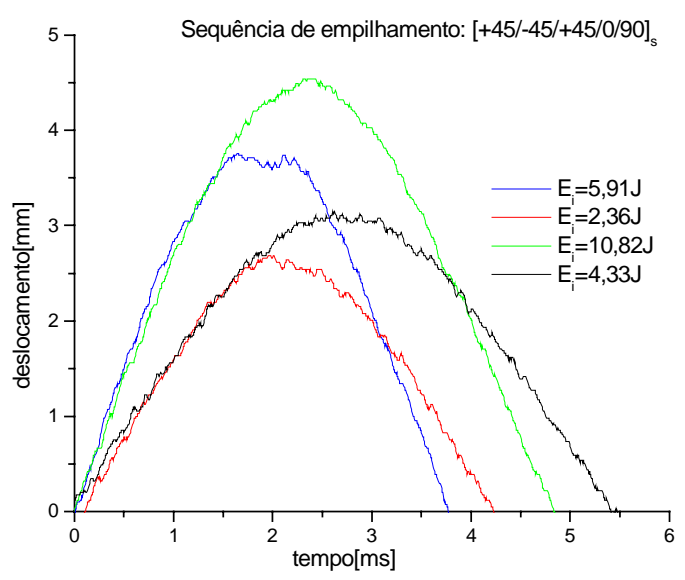

(b)

FIGURA 5.3.1-8 - Históricos para lâminas orientadas a [+45/-45/+45/0/90]s:

(a) Históricos de força; (b) Históricos de deslocamento

Por outro lado, as amostras que foram atingidas por uma massa maior tiveram o seu tempo de contato aumentado. Isto pode ser verificado nos históricos de força e 
confirmado nos históricos de deslocamento (FIGURA 5.3.1-8(b)). Nota-se que as amostras impactadas pela massa igual a $2,205 \mathrm{~kg}\left(\mathrm{E}_{\mathrm{i}}\right.$ igual a 4,33 $\mathrm{J}$ ou igual a $\left.10,82 \mathrm{~J}\right)$ tiveram um tempo de contato maior do que as amostras impactadas pela massa igual a $1,205 \mathrm{~kg}$. Além disso, verifica-se pelo histórico de deslocamento que quanto maior foi o nível de energia de impacto, maior foi o valor da penetração do impactador na amostra, sendo assim a energia transferida $\left(E_{t}\right)$ para estrutura também foi maior. Tudo isto pode ser confirmado através dos históricos de energia apresentados pela FIGURA 5.3.1-9.

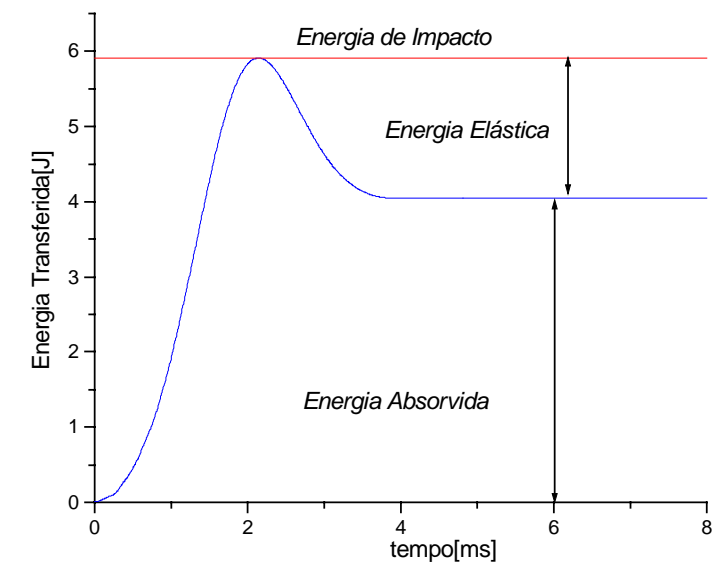

(a)

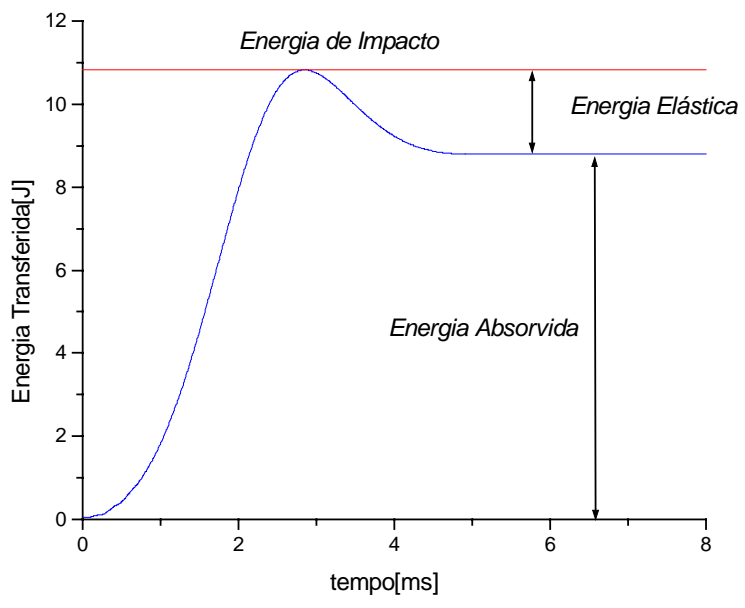

(c)

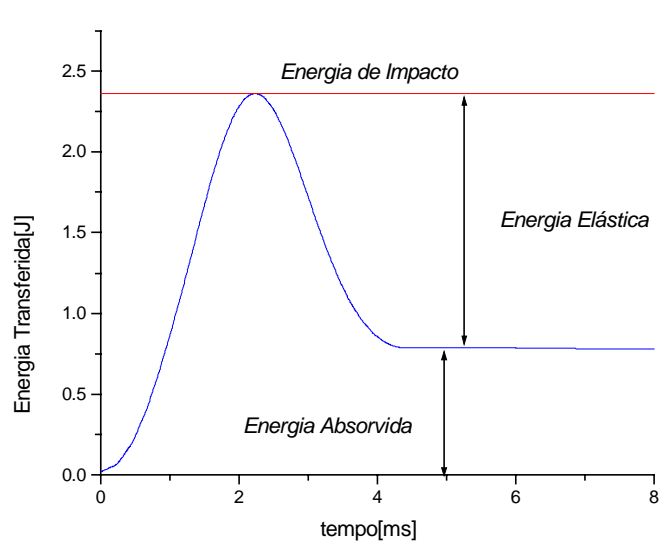

(b)

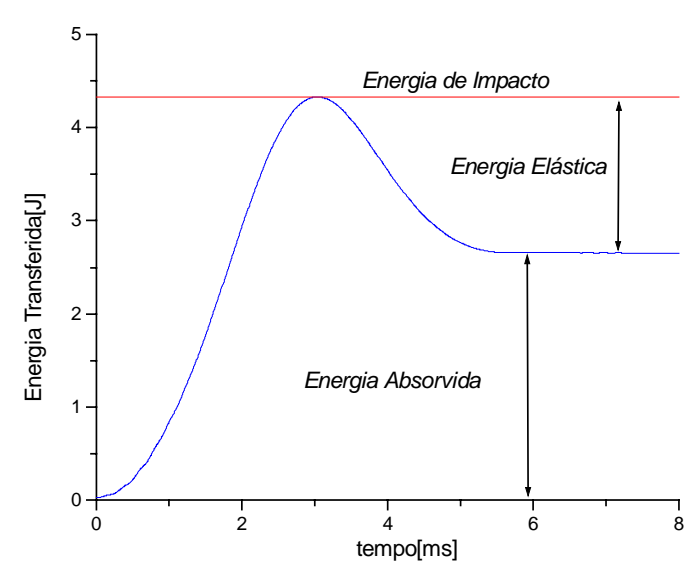

(d)

FIGURA 5.3.1-9 - Históricos de energia para lâminas orientadas a [+45/-45/+45/0/90]s:

(a) Energia de impacto igual a 5,91 J; (b) Energia de impacto igual a 2,36 J;

(c) Energia de impacto igual a 10,82 J; (d) Energia de impacto igual a 4,33 J

As amostras impactadas a 5,91 J, tiveram uma absorção de energia igual a 4,0J, transferindo de volta para o impactador $32 \%$ de toda a energia de impacto em forma de energia elástica de vibração (FIGURA 5.3.1-9(a)). No entanto, as amostras impactadas 
que mais absorveram energia foram aquelas que sofreram um nível de energia de impacto igual a 10,82 J (FIGURA 5.3.1-9(c)). Para essas amostras, foram absorvidos cerca de $8,8 \mathrm{~J}$, ou seja, mais de $80 \%$ da energia de impacto foi absorvida através de mecanismos de danificação. Em contra partida, as amostras impactadas a 2,36 J (FIGURA 5.3.1-9(b)), tiveram um nível de absorção de energia muito pequeno (0,8 J), retornando assim 66\% da energia de impacto em forma de vibrações elásticas para o impactador. Por fim, as amostras impactadas a 4,33 J apresentaram uma capacidade razoável de absorção de energia (2,6 J), devolvendo $40 \%$ da energia de impacto ao impactador. Dessa forma, tem-se a ocorrência de alguns mecanismos de danificação/falha que são elucidados com o auxílio dos mapas de falha obtidos através da técnica de ultra-som C-Scan (FIGURA 5.3.1-10).
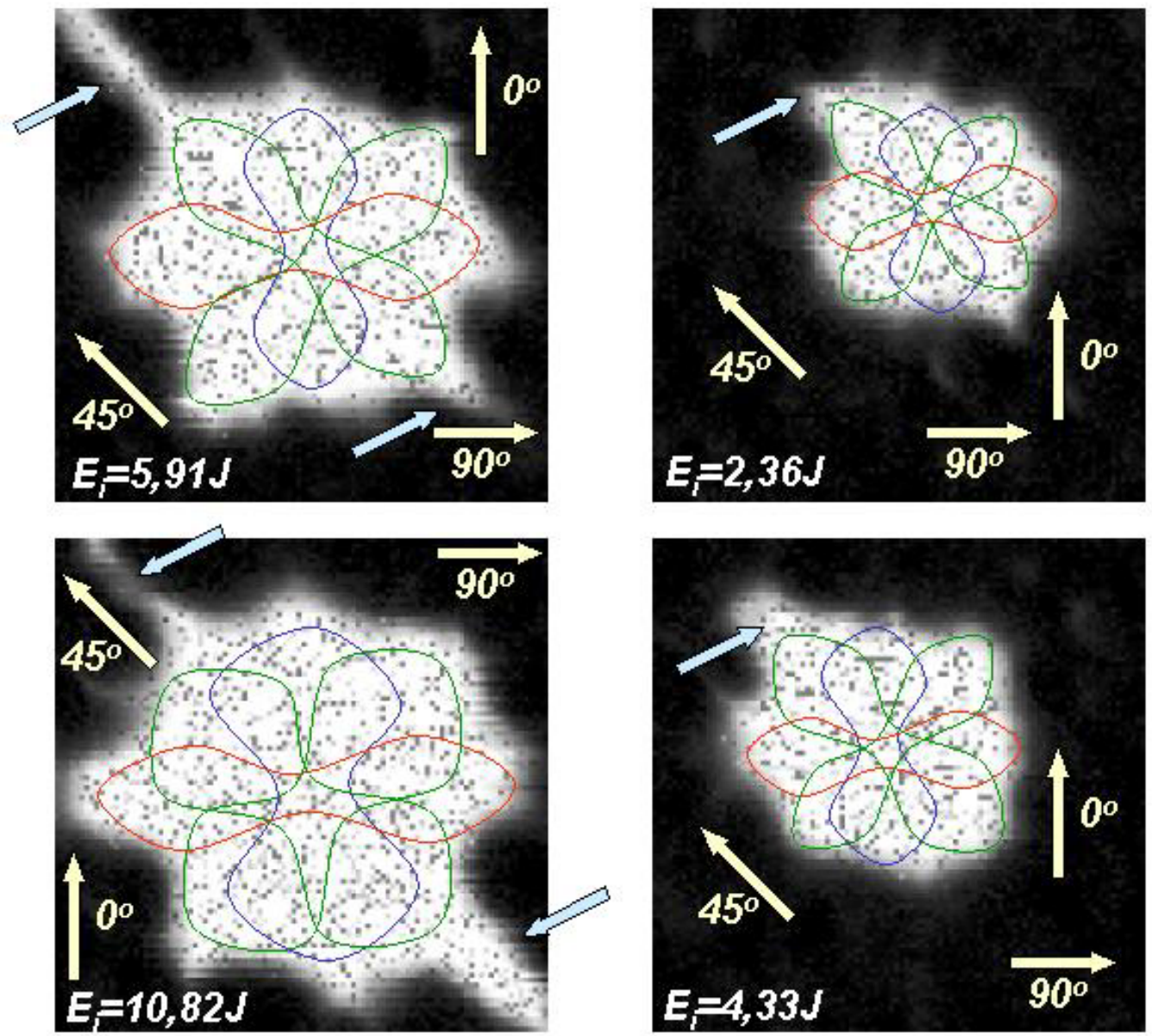

FIGURA 5.3.1-10 - Mapas de falha obtidos através da técnica de ultra-som C-Scan para lâminas orientadas a $[+45 /-45 /+45 / 0 / 90]_{\mathrm{s}}$

Na FIGURA 5.3.1-10 são apresentadas as formas de falha dos laminados provenientes da técnica $C$-Scan. Novamente, essas formas são constituídas pela 
superposição de mecanismos de danificação/falha. Sendo assim, verifica-se que há uma superposição das delaminações entre as camadas $0^{\circ} / 90^{\circ}, 45^{\circ} / 0^{\circ}$ e $+45^{\circ} / 45^{\circ}$ bem como a propagação de fissuras na matriz. Devido à seqüência de empilhamento conter mais camadas a $+45^{\circ}$, é possível notar que há mais fissuras na matriz paralela às fibras orientadas a $+45^{\circ}$ do que a $0^{\circ}$, a $-45^{\circ}$ ou a $90^{\circ}$. No entanto, as delaminações se orientam a $0^{\circ}$ ("peanut shapes" em azul) e a $90^{\circ}$ ("peanut shapes" em vermelho) devido às lâminas $0^{\circ} / 90^{\circ}$ e se orientam também a $+45^{\circ}$ e a $-45^{\circ}$ ("peanut shapes" em verde) devido às lâminas $+45^{\circ} /-45^{\circ}$ e $45^{\circ} \%^{\circ}$.

Além disso, pode-se constatar que os laminados impactados a um nível de energia maior tiveram uma extensão maior do fenômeno de delaminação e de propagação das fissuras na matriz, como mostra os mapas de falha dos laminados impactados a 5,91 J e 10,82 J. Isto foi observado nos históricos de energia e foi confirmado pelos mapas de falha que apresentam áreas danificadas diferentes. No caso para as amostras impactadas a 10,82 J, o programa da máquina de ultra-som calculou um valor igual $450 \mathrm{~mm}^{2} \mathrm{de}$ área danificada e um valor igual a $360 \mathrm{~mm}^{2}$ para as amostras impactadas a 5,91 J. Em contra partida, para as amostras impactadas a 2,36 J, o programa da máquina de ultrasom calculou um valor igual $165 \mathrm{~mm}^{2}$ de área danificada e para as amostras impactadas a 4,33 J, determinou-se um valor igual a $211 \mathrm{~mm}^{2}$.

Vale ressaltar que através dos históricos de energia bem como dos mapas de falha provenientes da técnica de C-Scan, pôde-se analisar com uma certa profundidade o comportamento mecânico de cada amostra separadamente. No entanto, torna-se interessante fazer uma comparação entre as diferentes amostras sob diferentes condições de ensaio. Para isso, recorreu-se ao gráfico de Energia Absorvida em função da Energia de Impacto (FIGURA 5.3.1-11).

Nota-se pela FIGURA 5.3.1-11 que a mesma pode ser dividida em três regiões:1, 2 e 3. Na Região 1, as amostras possuem um comportamento quase elástico, pois a porcentagem de absorção de energia é muito baixa devido à ocorrência de poucas danificações. Por outro lado, na Região 2 são encontradas amostras que sofreram basicamente fratura da matriz e delaminações entre as camadas com diferentes orientações de fibra. Por fim, a Região 3 contém amostras que sofreram falha por parte da matriz, por parte da fibra e/ou varias delaminações, possibilitando uma alta capacidade de absorção de energia o que caracteriza um comportamento altamente inelástico. É importante destacar que o modelo computacional utilizado deverá ser capaz de prever todos esses mecanismos de danificação/falha com precisão a fim de que 
o histórico de força numérico seja o mais próximo possível do histórico de força experimental.

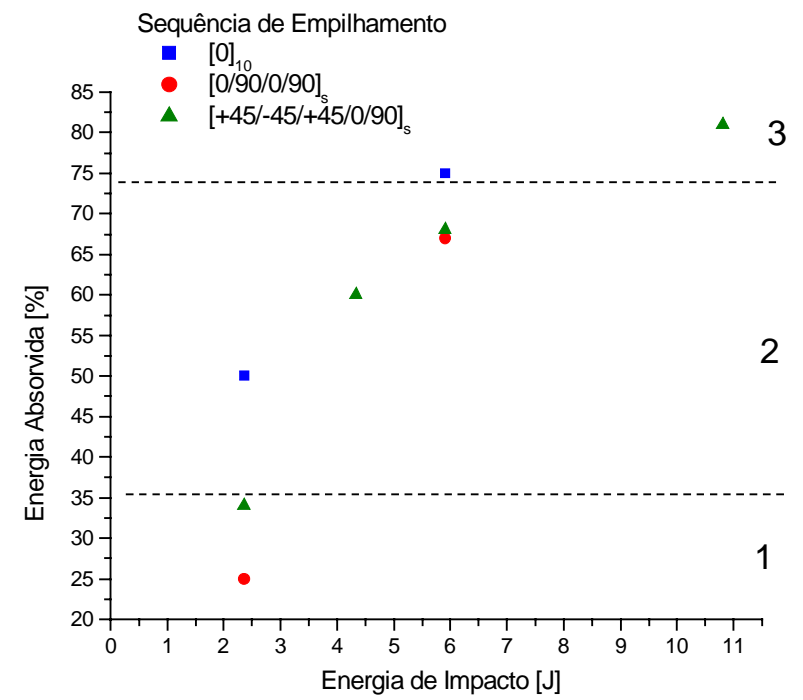

FIGURA 5.3.1-11 - Energia absorvida em função da energia de impacto

\section{$\underline{\text { Resultados dos Testes de Endentação }}$}

Como foi apresentado anteriormente, o valor último da força aplicado nos testes de endentação ("indentation test") deve ser baseado no pico de força encontrado nos testes de impacto (“drop test”). Com isso, a TABELA 5.3.1-1 traz as especificações para os testes de endentação, indicando a velocidade do carregamento (V), o valor último da força $(\mathrm{F})$ bem como o valor da Energia de Impacto $\left(\mathrm{E}_{\mathrm{i}}\right)$ correspondente no teste dinâmico.

TABELA 5.3.1-1 - Valores de força para os testes de endentação ( $\mathrm{L}=$ comprimento; $\mathrm{W}=$ largura; $\mathrm{H}=$ espessura)

\begin{tabular}{ccccccc}
\hline $\begin{array}{c}\text { Sequência de } \\
\text { Empilhamento }\end{array}$ & $\begin{array}{c}\mathbf{L} \\
{[\mathbf{m m}]}\end{array}$ & $\begin{array}{c}\mathbf{W} \\
{[\mathbf{m m}]}\end{array}$ & $\begin{array}{c}\mathbf{H} \\
{[\mathbf{m m}]}\end{array}$ & $\begin{array}{c}\mathbf{V} \\
{[\mathbf{m m} / \mathbf{m i n}]}\end{array}$ & $\begin{array}{c}\mathbf{F} \\
{[\mathbf{N}]}\end{array}$ & $\begin{array}{c}\mathbf{E}_{\mathbf{i}} \\
{[\mathbf{J}]}\end{array}$ \\
\hline$[0]_{10}$ & 120 & 120 & 1,8 & 10 & 2.250 & 5,91 \\
& 120 & 120 & 1,8 & 10 & 1.300 & 2,36 \\
\hline$[0 / 90 / 0 / 90 / 0]_{\mathrm{s}}$ & 120 & 120 & 1,8 & 10 & 3.000 & 5,91 \\
\hline$[+45 /-45 /+45 / 0 / 90]_{\mathrm{s}}$ & 120 & 120 & 1,8 & 10 & 1.750 & 2,36 \\
\hline & 120 & 120 & 1,8 & 10 & 3.300 & 5,91 \\
\hline
\end{tabular}


A FIGURA 5.3.1-12 apresenta os gráficos de força-deslocamento para o teste de endentação e para o teste de impacto em laminados que estão empilhados a $[0]_{10}$. Notase de uma maneira geral que durante a fase de carregamento, as curvas do teste de endentação e de impacto tiveram inicialmente quase a mesma inclinação, caracterizando assim, a não-linearidade do fenômeno de contato existente nos dois testes. Porém, os testes de endentação não são capazes de fornecer as oscilações de alta freqüência ocorridas no teste de impacto devido ao início do contato entre o impactador e a amostra. Além disso, ao final da fase de carregamento da curva de endentação, não é possível também verificar as oscilações encontradas na curva de impacto. É importante destacar que essas oscilações estão associadas em parte aos mecanismos de danificação/falha que ocorreram durante o teste. Isto faz com que, para um mesmo nível de carregamento, as amostras impactadas tenham um maior deslocamento do que as amostras endentadas devido à perda de rigidez. Sendo assim, verifica-se que as amostras endentadas possuem uma danificação/falha mais localizada (próxima do ponto de aplicação da força), ao passo que as amostras impactas possuem uma danificação/falha mais distribuída devido o comportamento dinâmico da estrutura. Isso é uma das causas para que durante a fase de descarregamento, as inclinações das curvas de impacto e de endentação sejam distintas.

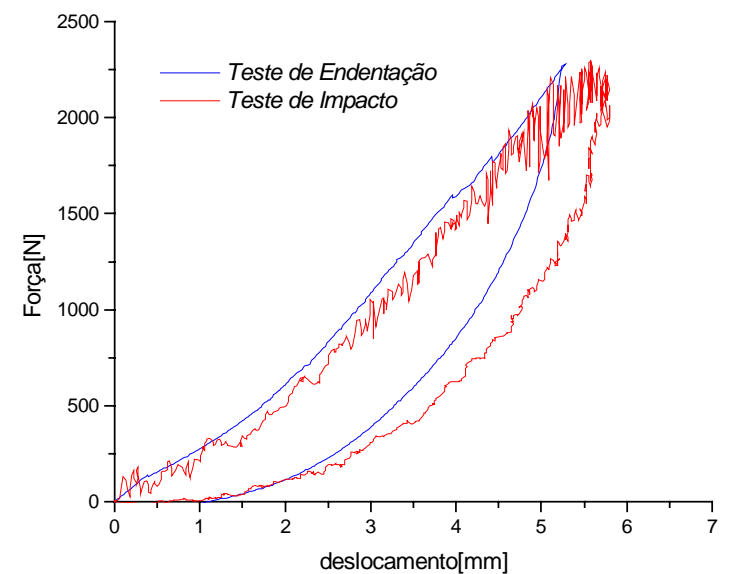

(a)

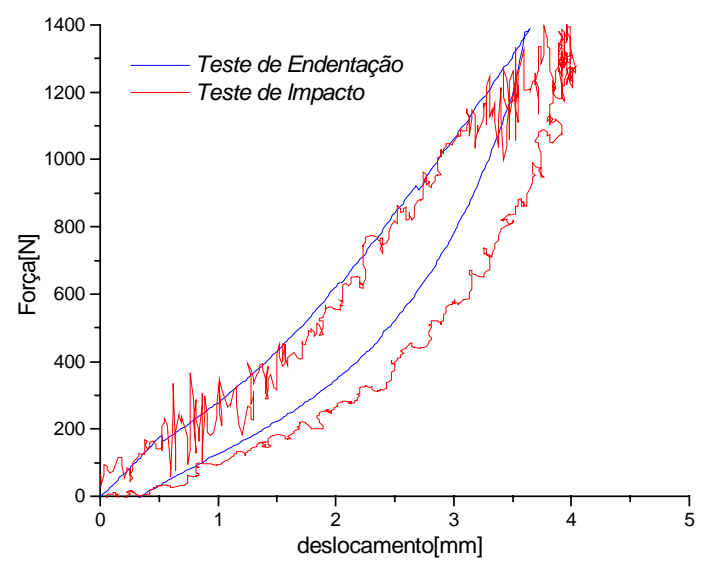

(b)

FIGURA 5.3.1-12 - Gráficos de força-deslocamento para lâminas orientadas a $[0]_{10}$ :

(a) Valor da força de $2.250 \mathrm{~N}$; (b) Valor da força de $1.300 \mathrm{~N}$

A FIGURA 5.3.1-13 apresenta os gráficos de força-deslocamento para o teste de endentação e para o teste de impacto em laminados que estão empilhados a 
[0/90/0/90/0] s. Nota-se na FIGURA 5.3.1-13(a) que no início da fase de carregamento, as curvas do teste de endentação e de impacto tiveram inicialmente quase a mesma inclinação, caracterizando assim, a não-linearidade do fenômeno de contato existente nos dois testes. No entanto, devido aos fenômenos de delaminação, as amostras continuam apresentando oscilações que não são registradas pelo teste de endentação. Novamente, verifica-se que as amostras endentadas possuem uma danificação/falha mais localizada, ao passo que as amostras impactas possuem uma danificação/falha mais distribuída devido ao comportamento dinâmico da estrutura. Isso pode explicar porque durante a fase de descarregamento, as inclinações das curvas de impacto e de endentação são distintas. No entanto, é importante ressaltar que a FIGURA 5.3.1-13(b) apresenta para o teste de endentação uma curva força-deslocamento relativamente próxima da curva força-deslocamento obtida no teste de impacto.

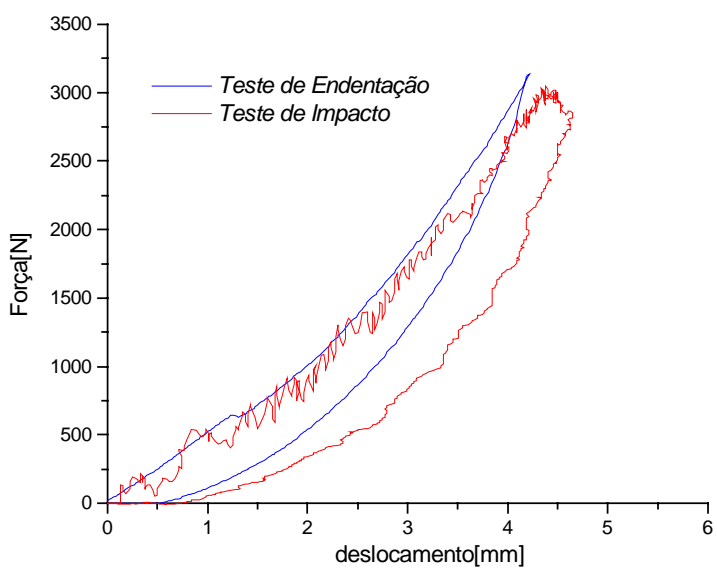

(a)

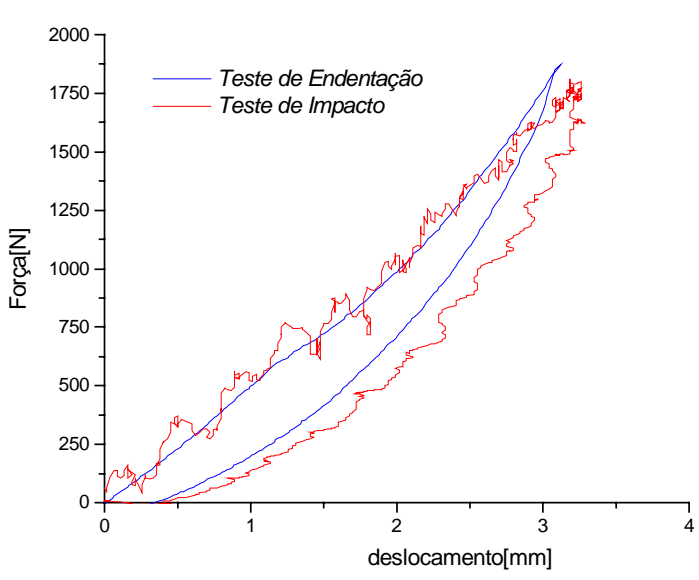

(b)

FIGURA 5.3.1-13 - Gráficos de força-deslocamento para lâminas orientadas a [0/90/0/90/0 $]_{\mathrm{s}}$ : (a) Valor da força de $3.000 \mathrm{~N}$; (b) Valor da força de $1.750 \mathrm{~N}$

A FIGURA 5.3.1-14 apresenta os gráficos de força-deslocamento para o teste de endentação e para o teste de impacto em laminados que estão empilhados a [+45/45/+45/0/90]s. Nota-se na FIGURA 5.3.1-14(a) que desde o início da fase de carregamento, a curva do teste de endentação e de impacto tiveram inclinações diferentes. Isto pode ser explicado, porque as amostras empilhadas a [+45/45/+45/0/90] apresentam vários mecanismos de danificação/falha (fratura da matriz, fratura da fibra, delaminações e deformações permanentes) quase que simultaneamente. No entanto, o teste de endentação promove uma resposta mais localizada, que faz com 
que durante a fase de descarregamento, as inclinações das curvas de impacto e de endentação sejam distintas. Por outro lado, a FIGURA 5.3.1-14(b) demonstra que a curva força-deslocamento proveniente do teste de endentação praticamente coincide com a curva proveniente do teste de impacto. Porém, no final da fase de carregamento nota-se que as curvas divergem, devido novamente ao problema de uma resposta ser mais localizada em quanto outra é mais distribuída. Por fim, durante a fase de descarregamento, verifica-se que as curvas não são tão distintas.

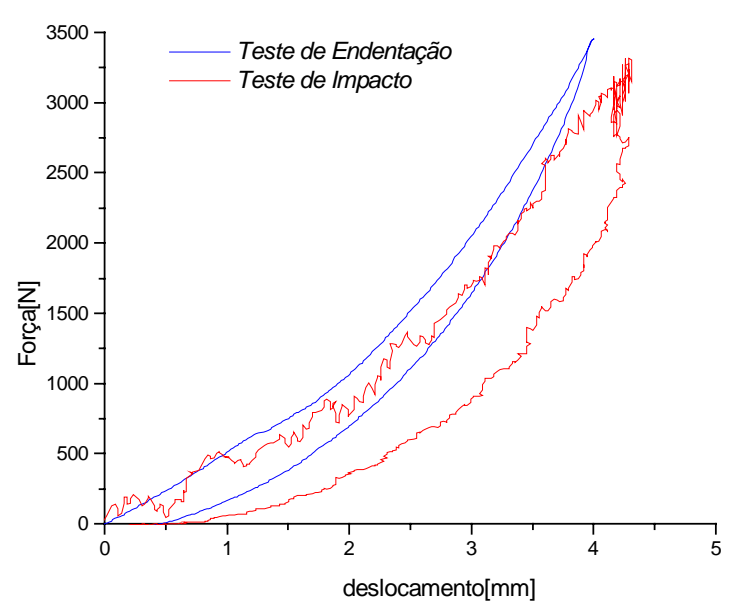

(a)

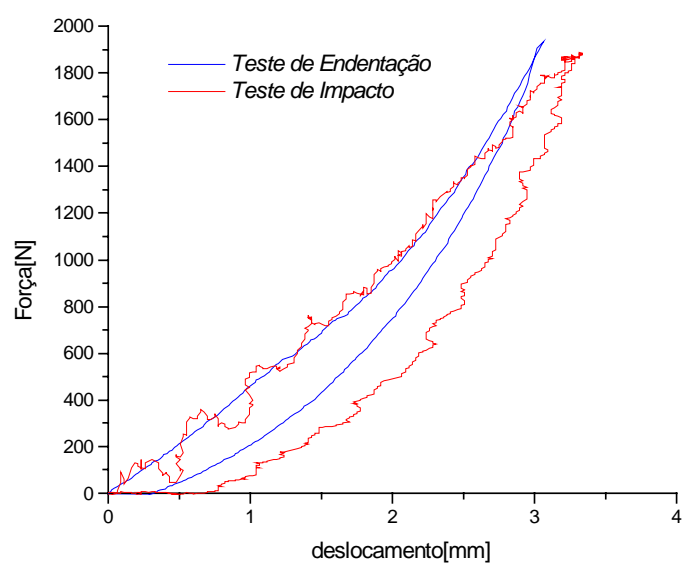

(b)

FIGURA 5.3.1-14 - Gráficos de força-deslocamento para lâminas orientadas a [+45/45/+45/0/90]s:(a) Valor da força de $3.300 \mathrm{~N}$; (b) Valor da força de $1.900 \mathrm{~N}$

Após todo esse processo de análise dos resultados experimentais segue-se para as simulações computacionais, a fim de verificar as potencialidades e limitações dos modelos de material implementados através de sub-rotinas UMAT. 


\subsubsection{Modelos computacionais}

De acordo com a estratégia de análise determinada, o modelo de material será avaliado e terá os seus parâmetros calibrados inicialmente por alguns testes de endentação e posteriormente por alguns testes de impacto. Como foi demonstrado nos ensaios experimentais, há alguns casos que as curvas de força-deslocamento são bem similares tanto na fase de carregamento como na fase de descarregamento para ambos os testes. Isto permite que uma análise computacional quase-estática possa em algumas situações fornecer resultados satisfatórios para um teste de impacto.

\section{Modelos para os Testes de Endentacão}

Para o segundo estudo de caso, tem-se que todos os modelos estão sendo desenvolvidos no ABAQUS ${ }^{\circledR}$. Deve-se destacar que a estratégia numérica necessária para solucionar tais modelos é um pouco diferente da estratégia para solucionar os modelos de flexão 3-pontos. Sendo assim, para que se possa prever com precisão o fenômeno localizado da endentação é necessário empregar um modelo de contato. Neste caso, deve-se incluir na equação de equilíbrio do corpo, o trabalho produzido pelas forças de contato $F_{c}$ na configuração atual sob a superfície de contato $S_{c}$ :

$$
\int_{v_{n-1}} S_{i j}^{n} \Delta E_{i j} d v-\int_{S_{\sigma}} \bar{T}_{i}^{n} \Delta u_{i} d a-\int_{S_{u}} S_{i j}^{n} n_{j} \Delta \bar{u}_{i} d a-\int_{S_{c}} F_{C_{i}}^{n} \Delta u_{i}^{C} d a=0
$$

Dessa forma, surge um novo problema que consiste em saber quando e onde ocorrerá o contato. De acordo com a FIGURA 5.3.2-1 é possível identificar as variáveis que estão associadas ao pares de contato.

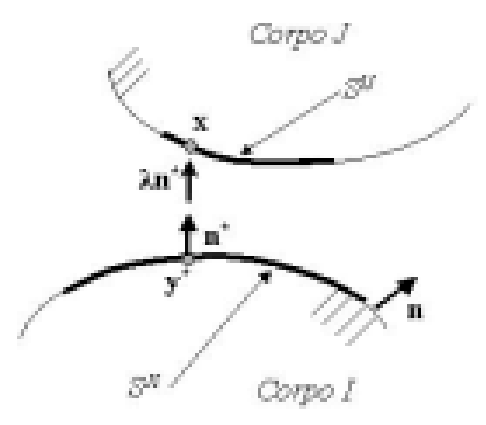

FIGURA 5.3.2-1 - Problema de contato entre dois corpos

(BATHE, 1996) 
Nota-se que a força de contato $F_{c}$ pode ser escrita em função do vetor $n$ que é normal à superfície de contato $\mathrm{S}^{\mathrm{JI}}$ :

$$
\mathrm{F}_{\mathrm{C}}^{\mathrm{n}}=\mathrm{F}_{\mathrm{IJ}}^{\mathrm{n}}=\lambda \mathrm{n}
$$

onde:

$$
\lambda=\text { força de tração na superfície de contato }
$$

Considere um ponto genérico $\mathrm{x}$ na superfície $\mathrm{S}^{\mathrm{IJ}}$ e um ponto $\mathrm{y}^{*}$ na superfície $\mathrm{S}^{\mathrm{JI}}$ tal que:

$$
\left\|\mathrm{x}-\mathrm{y}^{*}\right\|=\min \|\mathrm{x}-\mathrm{y}\| \text { tal que } \mathrm{y} \in \mathrm{S}^{\mathrm{JI}}
$$

Sendo assim, a distância de $\mathrm{x}$ até a superfície $\mathrm{S}^{\mathrm{JI}}$ pode ser calculada da seguinte forma:

$$
g(x, t)=\left(x-y^{*}\right)^{T} n^{*}
$$

onde:

$\mathrm{g}=$ função gap para os pares de contato

$\mathrm{n}^{*}=$ vetor "quase-normal” à superfície $\mathrm{S}^{\mathrm{JI}}$

E a força de contato normal será dada por:

$$
\mathrm{F}_{\mathrm{C}}^{\mathrm{n}}=\mathrm{F}_{\mathrm{IJ}}^{\mathrm{n}}=\lambda \mathrm{n}^{*}
$$

Portanto, a ocorrência do contato será checada a partir das seguintes condições:

$$
\mathrm{g} \geq 0 ; \quad \lambda \geq 0 ; \quad \mathrm{g} \lambda=0
$$

Ou seja,

Se $g=0$ então $\lambda>0 \rightarrow$ ocorrência de contato

Se $\mathrm{g}>0$ então $\lambda=0 \rightarrow$ não há contato 
Conseqüentemente, pode-se estabelecer uma função $\mathrm{w}$ de tal forma que se $\mathrm{w}$ for igual a zero tem-se que as condições de contato (5.3.2-7) foram satisfeitas. Essa função W será multiplicada pelas variações $\Delta \lambda$ a fim de que se tenha a chamada Equação de Restrição (“constraint equation”):

$$
\int_{\mathrm{S}^{\mathrm{I}}} \Delta \lambda \mathrm{W}(\mathrm{g}, \lambda) \mathrm{d} \mathrm{S}^{\mathrm{IJ}}=0
$$

onde:

$$
\Delta \lambda=\text { incremento dos multiplicadores de Lagrange }
$$

Segundo Bathe (1996), a equação de restrição deve ser utilizada em conjunto com as equações de equilíbrio do sistema a fim de que após a discretização do contínuo por um dado elemento finito tenha-se:

$$
\left[\begin{array}{cc}
\left(\mathrm{K}+\mathrm{K}_{\mathrm{uu}}^{\mathrm{C}}\right) & \mathrm{K}_{\mathrm{u} \tau}^{\mathrm{C}} \\
\mathrm{K}_{\tau \mathrm{u}}^{\mathrm{C}} & \mathrm{K}_{\tau \tau}^{\mathrm{C}}
\end{array}\right]\left[\begin{array}{c}
\Delta \mathrm{U} \\
\Delta \tau
\end{array}\right]=\left[\begin{array}{c}
\mathrm{R}-\mathrm{F}-\mathrm{R}_{\mathrm{C}} \\
\mathrm{F}_{\mathrm{C}}
\end{array}\right]
$$

onde:

$\mathrm{R}=$ vetor de forças externas

$\mathrm{F}=$ vetor de forças internas nodais equivalente

$\mathrm{R}_{\mathrm{c}}=$ vetor de forças de contato nodais

$\mathrm{F}_{\mathrm{c}}=$ vetor que contém as funções $\mathrm{w}(\mathrm{g}, \lambda)$

$\mathrm{K}=$ matriz de rigidez da estrutura impactada

$\mathrm{K}^{\mathrm{C}}=$ matrizes de rigidez que dependem das condições de contato

$\Delta \mathrm{U}=$ incremento do campo de deslocamentos

$\Delta \tau=$ incremento dos multiplicadores de Lagrange

Sendo assim, somente após o reconhecimento do contato é que o processo iterativo de Newton-Raphson será aplicado para avaliar o processo de falha do laminado. Portanto, durante cada iteração $\mathrm{m}$, deve-se verificar se houve contato, contabilizando assim, a influência dessas forças na análise.

Segue assim as descrições da geometria do modelo, da malha e das condições de contorno bem como dos modelos de material empregados nas análises computacionais de endentação. 


\section{$\underline{\text { Geometria do Modelo }}$}

A geometria do modelo segue basicamente as dimensões da amostra e do endentador especificados na FIGURA 5.3-1 e na TABELA 5.3-1. Vale ressaltar que os discos de aço de travamento não foram modelados. Sendo assim, tais peças foram substituídas por condições de contorno adequadas. No entanto, foi modelado o endentador bem como o contato entre o mesmo e a placa.

\section{Malha de elementos finitos com condiçoes de contorno}

Para este estudo de caso, foram desenvolvidos dois tipos diferentes de modelos. Inicialmente, criou-se um modelo constituído por elementos do tipo casca, designado Elemento S4 que contém 4 nós e 4 pontos de integração (ABAQUS, 2002) a fim de avaliar o laminado sob estado plano de tensões. Neste modelo, os nós pertencentes à periferia da placa possuem vinculações simulando os discos de travamento (FIGURA 5.3.2-2(a)). No entanto, deve-se ressaltar que o travamento dos discos utilizando somente quatro parafusos não garante uma condição de engastamento perfeito.

Posteriormente, criou-se um modelo constituído por elementos do tipo sólido, designado Elemento C3D8 que contém 8 nós e 4 pontos de integração (ABAQUS, 2002) a fim de avaliar o laminado sob estado triplo de tensões. A FIGURA 5.3.2-2(b) mostra que na espessura o sólido está dividido em 3 camadas, de tal forma que as duas camadas externas contém 3 lâminas (cada uma) ao passo que a camada interna possuí 4 lâminas. Sendo assim, para o laminado $[0 / 90 / 0 / 90 / 0]_{\mathrm{s}}$, as camadas externas possuem as lâminas $0^{\circ} / 90^{\circ} / 0^{\circ}$ e a interna contém as lâminas $90^{\circ} / 0^{\circ} / 0^{\circ} / 90^{\circ}$. Para o laminado [45/$45 / 45 / 0 / 90]_{\mathrm{s}}$, as camadas externas possuem as lâminas $45^{\circ} /-45^{\circ} / 45^{\circ}$ ao passo que a camada interna possui as lâminas $0^{\circ} / 90^{\circ} / 90^{\circ} / 0^{\circ}$.

Vale ressaltar que tanto para o modelo da placa em casca como em sólido, a superfície externa do endentador foi simulada como uma superfície rígida que entrará em contato com a região central da placa (FIGURA 5.3.2-2). Associada a esta superfície rígida de contato há um nó onde são atribuídas algumas vinculações, permitindo que o mesmo se desloque apenas na direção z (perpendicular à placa).

Por fim, para obter a resposta completa do teste de endentação foi necessário dividir a simulação em duas etapas. A primeira consiste da "etapa de carregamento", ou seja, o endentador parte da sua posição original e se desloca em direção à placa. A segunda consiste da "etapa de descarregamento", ou seja, o endentador retorna à sua posição original. 


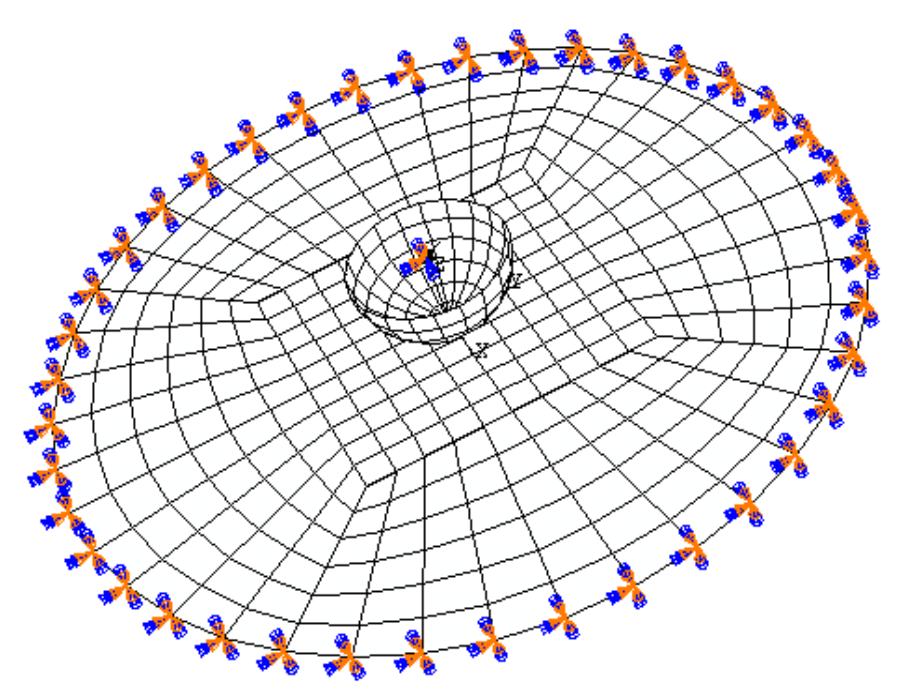

(a)

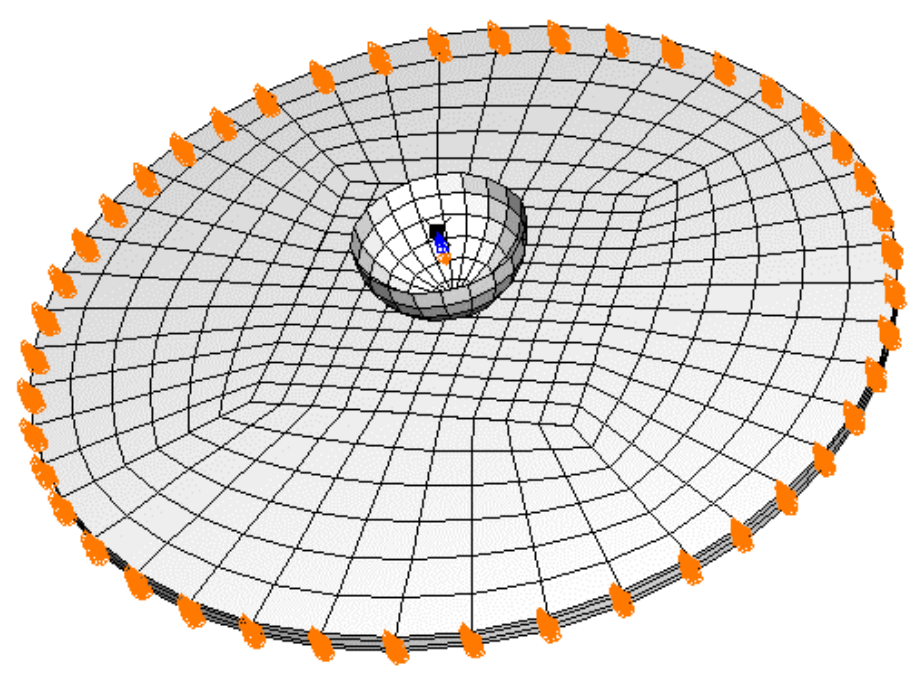

(b)

FIGURA 5.3.2-2- Modelos do teste de endentação:

(a) Modelo em Casca (Elemento S8R); (b) Modelo Sólido (Elemento C3D8R)

\section{Modelos de Material}

Inicialmente empregou-se um Modelo Elástico Ortotrópico já implementado no programa $\mathrm{ABAQUS}{ }^{\circledR}$, a fim de avaliar somente a não-linearidade de contato devido à interação entre o endentador e a placa. Posteriormente, avaliou-se o modelo de material II e III proposto no presente trabalho (TABELA 5.2.2-2) através da utilização de subrotinas UMAT. Além disso, com base nos resultados experimentais de tração e cisalhamento empregou-se o Critério de Plastificação de Hill que já está implementado no programa ABAQUS ${ }^{\circledR}$. Mais detalhes sobre o Critério de Plastificação de Hill podem ser encontrados nos manuais do programa (ABAQUS, 2002). Por fim, comparou-se os 
resultados do modelo de material proposto com os resultados fornecidos ao empregar o Critério de Hill

\section{Modelos para os Testes de Impacto}

Para o terceiro e último estudo de caso, tem-se que alguns modelos foram desenvolvidos utilizando $\mathrm{DYNA}^{\circledR}$ ao passo que outros foram desenvolvidos no ABAQUS $^{\circledR}$. Vale ressaltar que para representar o equilíbrio dinâmico de um corpo em movimento é necessário acrescentar os efeitos causados pelas forças de corpo ("body force" - b) que já poderiam ter sido incorporadas no problema quase-estático e além disso, os efeitos inerciais ( $\rho \ddot{u}$ ) e os efeitos dissipativos de amortecimento ( cù ):

$$
\begin{aligned}
& \int_{v_{n-1}} S_{i j}^{n} \Delta E_{i j} d v-\int_{S_{\sigma}} \bar{T}_{i}^{n} \Delta u_{i} d a-\int_{S_{u}} S_{i j}^{n} n_{j} \Delta \bar{u}_{i} d a-\int_{S_{c}} F_{C_{i}}{ }^{n} \Delta u_{i}^{C} d a \\
& -\int_{v_{n-1}}\left(b_{i}^{n}-\rho \ddot{u}_{i}-c \dot{u}_{i}\right) \Delta u_{i} d v=0
\end{aligned}
$$

Aplicando a relação constitutiva, impondo a equação de restrição devido ao problema de contato e discretizando o sistema contínuo através de um elemento finito, é possível chegar numa equação similar a eq. 5.3.2-9, porém com a presença de mais termos:

$$
\left[\begin{array}{cc}
\mathrm{M} & 0 \\
0 & 0
\end{array}\right]\left[\begin{array}{c}
\Delta \ddot{\mathrm{U}} \\
0
\end{array}\right]+\left[\begin{array}{cc}
\mathrm{C} & 0 \\
0 & 0
\end{array}\right]\left[\begin{array}{c}
\Delta \dot{\mathrm{U}} \\
0
\end{array}\right]+\left[\begin{array}{cc}
\left(\mathrm{K}+\mathrm{K}_{\mathrm{uu}}^{\mathrm{C}}\right) & \mathrm{K}_{\mathrm{u} \tau}^{\mathrm{C}} \\
\mathrm{K}_{\tau u}^{\mathrm{C}} & \mathrm{K}_{\tau \tau}^{\mathrm{C}}
\end{array}\right]\left[\begin{array}{c}
\Delta \mathrm{U} \\
\Delta \tau
\end{array}\right]=\left[\begin{array}{c}
\mathrm{R}-\mathrm{F}-\mathrm{R}_{\mathrm{C}}-\mathrm{R}_{\mathrm{B}} \\
\mathrm{F}_{\mathrm{C}}
\end{array}\right]
$$

onde:

$\mathrm{M}=\left[\mathrm{M}_{1 \beta \mathrm{j} \alpha}\right]=\int_{\mathrm{v}_{\mathrm{n}-1}} \mathrm{~N}_{\alpha, 1} \rho_{\mathrm{c}} \mathrm{N}_{\beta, \mathrm{j}} \mathrm{dv}=$ matriz de massa da estrutura impactada

$\mathrm{C}=\left[\mathrm{C}_{1 \beta \mathrm{j} \alpha}\right]=\int_{\mathrm{v}_{\mathrm{n}-1}} \mathrm{~N}_{\alpha, 1} \mathrm{c}_{\mathrm{c}} \mathrm{N}_{\beta, \mathrm{j}} \mathrm{dv}=$ matriz de amortecimento da estrutura impactada

$\Delta \dot{U}=$ incremento do campo de velocidades

$\Delta \ddot{\mathrm{U}}=$ incremento do campo de acelerações

$\mathrm{R}_{\mathrm{B}}=\mathrm{F}_{\mathrm{B}}-\mathrm{F}_{\mathrm{I}}$

$F_{B}=F_{B i \beta}=\int_{v_{n-1}} b_{i j} N_{\beta, j} d v=$ forças de corpo atribuídas à estrutura

$\mathrm{F}_{\mathrm{I}}=\mathrm{F}_{\mathrm{I} \mid \beta j \alpha}=\int_{\mathrm{v}_{\mathrm{n}-1}}\left(\mathrm{~N}_{\alpha, 1} \rho_{\mathrm{i}} \mathrm{N}_{\beta, \mathrm{j}}\right) \ddot{\mathrm{U}} \mathrm{dv}=$ forças de impacto 
onde: $\rho_{\mathrm{i}}=$ densidade do impactador; $\rho_{\mathrm{c}}=$ densidade do compósito; $\mathrm{c}_{\mathrm{c}}=$ propriedade dissipativa do compósito

Devido à complexidade da equação 5.3.2-11, muitos pesquisadores optam por desconsiderar os efeitos de amortecimento, pois os mesmos em alguns casos não são tão significativos. Isto faz com que o procedimento de solução seja razoavelmente simplificado.

Bathe (1996) descreveu uma série de estratégias numéricas para solucionar problemas dinâmicos não-lineares que não agregavam os efeitos de amortecimento. Dentre essas estratégias destacam-se as soluções explícitas baseadas no Método das Diferenças Centrais, as soluções implícitas baseadas no Método de Houbolt, no Método de Wilson ou no Método de Newmark bem como as soluções através da superposição de modos. No presente trabalho, tanto o programa DYNA ${ }^{\circledR}$ como o programa $\mathrm{ABAQUS}^{\circledR}$ solucionam tal problema utilizando um algoritmo de integração explícita no tempo.

Segue assim as descrições da geometria do modelo, da malha e das condições de contorno bem como dos modelos de material empregados nas análises computacionais.

\section{Geometria do Modelo}

A geometria do modelo segue basicamente as dimensões da amostra e do impactador especificados na FIGURA 5.3-1 e na TABELA 5.3-2. Vale ressaltar que os discos de aço de travamento não foram modelados. Sendo assim, tais peças foram substituídas por condições de contorno adequadas. No entanto, foi modelado o impactador bem como o contato entre o mesmo e a placa. Outro aspecto importante a ser destacado no presente modelo, é que toda massa de impacto foi atribuída ao impactador. Além disso, as condições iniciais (velocidade inicial) de cada análise foram especificadas em função da altura de impacto adotada nos respectivos experimentos.

\section{Malha de elementos finitos com condições de contorno}

Para o modelo em elementos finitos gerado no programa DYNA ${ }^{\circledR}$ utilizou-se elementos SHELL163 para discretizar a amostra e elementos SOLID164 para discretizar o impactador (FIGURA 5.3.2-3). Nota-se que as vinculações de engastamento impostas nos nós localizados na borda do modelo buscam representar o 
travamento da amostra pelos discos de aço. No entanto, deve-se ressaltar novamente que o travamento dos discos utilizando somente quatro parafusos não garante uma condição de engastamento perfeito.

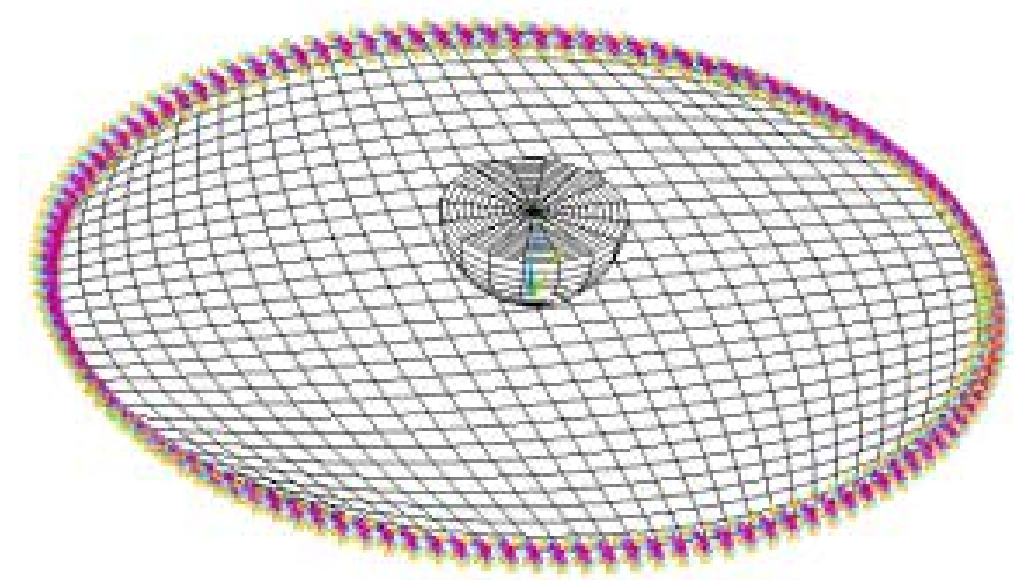

FIGURA 5.3.2-3 - Modelo do teste de impacto: programa DYNA ${ }^{\circledR}$

Para o modelo em elementos finitos gerado no programa ABAQUS/Explicit ${ }^{\circledR}$ utilizou-se elementos do tipo casca, designado Elemento S4R que contém 4 nós e 1 ponto de integração (ABAQUS, 2002) a fim de avaliar o laminado sob estado plano de tensões. Tal modelo é similar ao modelo de endentação, onde os nós pertencentes à periferia da placa possuem vinculações simulando os discos de travamento (FIGURA 5.3.2-2(a)). Vale destacar novamente que a superfície externa do impactador foi simulada como uma superfície rígida que entrará em contato com a região central da placa. Associada a esta superfície rígida de contato há um nó onde são atribuídas algumas vinculações, permitindo que o mesmo se desloque apenas na direção $\mathrm{z}$ (perpendicular à placa). Além disso, a este nó atribui-se o valor total da massa de impacto bem como a velocidade inicial de impacto.

\section{Modelos de Material}

Em se tratando das simulações realizadas com o programa DYNA ${ }^{\circledR}$, foi utilizado no presente trabalho um Modelo Elástico Ortotrópico bem como um Critério de Danificação Intralaminar baseado no trabalho de Chang e Chang (1987a), conhecido como Critério de Chang-Chang Modificado: 
$>$ Dano da matriz por tração (fratura): $\mathrm{F}_{\text {matriz }}=\left(\frac{\sigma_{2}}{\mathrm{Y}_{\mathrm{T}}}\right)^{2}+\bar{\tau}$

Dano da matriz por compressão: $F_{\text {comp }}=\left(\frac{\sigma_{2}}{2 S_{12}}\right)^{2}+\left[\left(\frac{Y_{C}}{2 S_{12}}\right)^{2}-1\right] \frac{\sigma_{2}}{Y_{C}}+\bar{\tau}$

$>$ Dano da fibra por tração (fratura): $\mathrm{F}_{\text {fibra }}=\left(\frac{\sigma_{1}}{\mathrm{X}_{\mathrm{T}}}\right)^{2}+\bar{\tau}$

$$
\text { onde: } \bar{\tau}=\frac{\frac{\sigma_{12}^{2}}{2 \mathrm{G}_{12}}+\frac{3}{4} \alpha \sigma_{12}^{4}}{\frac{\mathrm{S}_{12}^{2}}{2 \mathrm{G}_{12}}+\frac{3}{4} \alpha \mathrm{S}_{12}^{4}}
$$

Sendo F maior do que a unidade, tem-se a ocorrência do dano, e portanto o programa aplicará uma Lei de Degradação das Propriedades:

Caso haja danificação da matriz por tração $\left(\mathrm{F}_{\text {matriz }}>1\right)$, as constantes de material $\mathrm{E}_{22}$, $\mathrm{G}_{12}, \mathrm{v}_{12}$ e $\mathrm{v}_{21}$ são anuladas;

$>$ Caso haja danificação da matriz por compressão $\left(\mathrm{F}_{\text {comp }}>1\right)$, as constantes de material $\mathrm{E}_{22}, \mathrm{v}_{12}$ e $\mathrm{v}_{21}$ são anuladas;

Caso haja fratura da fibra por tração $\left(\mathrm{F}_{\text {fibra }}>1\right)$, as constantes de material $\mathrm{E}_{11}, \mathrm{E}_{22}$, $\mathrm{G}_{12}, v_{12}$ e $v_{21}$ são anuladas.

Tanto o Modelo Elástico Ortotrópico como o Critério de Chang-Chang Modificado já estão implementados no programa DYNA ${ }^{\circledR}$.

Em se tratando das simulações realizadas com o programa ABAQUS/Explicit ${ }^{\circledR}$, foi utilizado no presente trabalho um Modelo Elástico Ortotrópico já implementado no programa bem como o Modelo II descrito na TABELA 5.2.2-2. Deve-se destacar que este modelo foi implementado na forma de sub-rotina VUMAT, sendo posteriormente compilada com o programa ABAQUS/Explicit ${ }^{\circledR}$. Vale ressaltar que a VUMAT é um tipo de UMAT especificamente utilizada pelo programa ABAQUS/Explicit ${ }^{\circledR}$. Maiores detalhes podem ser encontrados no manual do programa (ABAQUS, 2002). 


\subsubsection{Resultados Numéricos}

\section{Resultados Numéricos dos Testes de Endentacão}

Os resultados computacionais para este estudo de caso serão apresentados em função da seqüência de empilhamento dos laminados, a fim de que se possa avaliar os problemas numéricos de cada situação de empilhamento.

\section{Seqüência de Empilhamento [Ol $_{10}$}

A FIGURA 5.3.3-1 compara as curvas de força-deslocamento da simulação e do teste de endentação para lâminas orientadas a $[0]_{10}$, ao empregar modelos de contato já implementados no programa ABAQUS ${ }^{\circledR}$.

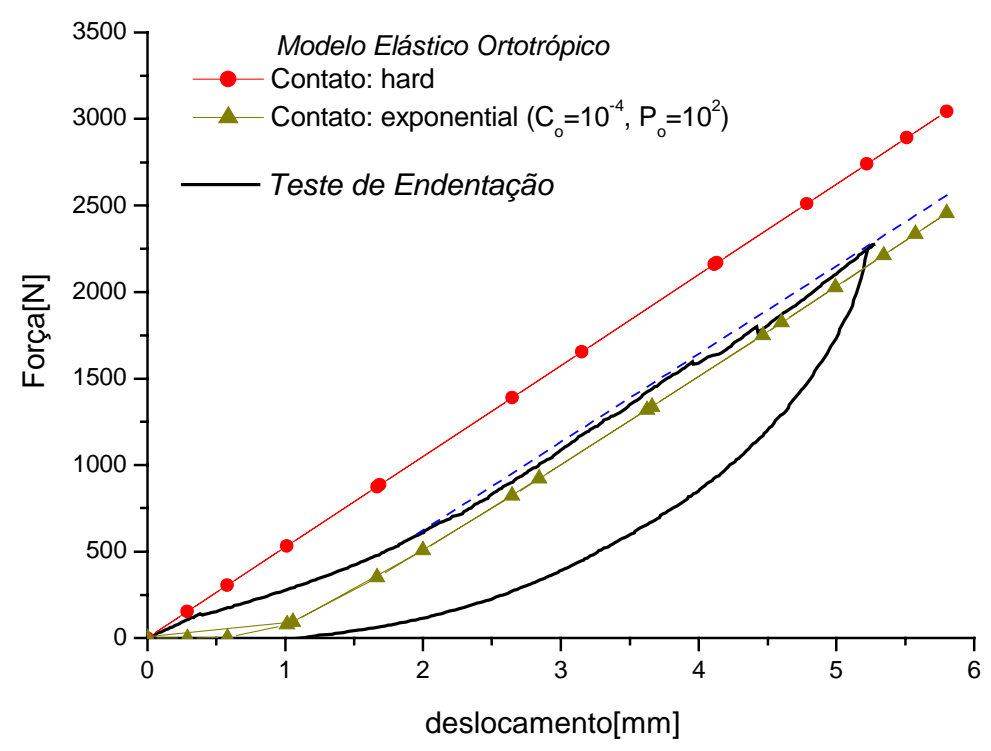

FIGURA 5.3.3-1 - Avaliação dos modelos de contato para o teste de endentação com lâminas orientadas a $[0]_{10}$

Nota-se que o tipo de modelo de contato utilizado influência fortemente na qualidade dos resultados numéricos para a simulação dos testes de endentação. $\mathrm{O}$ contato tipo "hard" impõem que as forças de contato agirão no momento em que o endentador e a placa entrarem em contato. Por outro lado, o contato tipo "exponential" impõem que as forças de contato passam a agir no momento em que o endentador penetrar na placa uma distância $\mathrm{C}_{\mathrm{o}}$ especificada pelo usuário. Neste instante, é aplicada sobre a placa uma pressão $\mathrm{P}_{\mathrm{o}}$ também definida pelo usuário. 
Com base nos ensaios experimentais, verifica-se que há uma fase inicial de acomodação do endentador até a placa deslocar-se cerca de 2,0 $\mathrm{mm}$. Somente após este valor de deslocamento é que se estabelece uma relação linear entre a força de contato e a deflexão da placa, como demonstra a linha azul tracejada paralela à resposta dada pelo modelo de contato tipo "hard" (FIGURA 5.3.3-1). Sendo assim, o modelo tipo "exponential" demonstra-se mais atrativo para simular tal fenômeno de acomodação do endentador na amostra. No entanto, os valores de $\mathrm{C}_{\mathrm{o}}$ e $\mathrm{P}_{\mathrm{o}}$ deverão ser reajustados em função do modelo de material empregado.

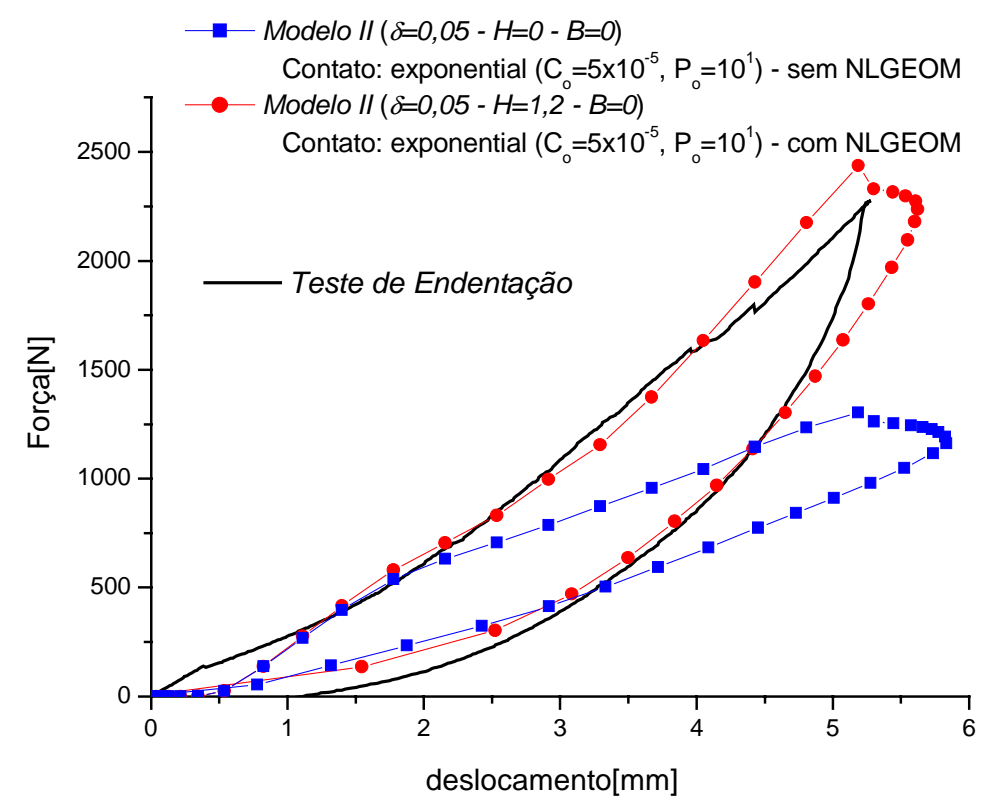

FIGURA 5.3.3-2 - Avaliação dos modelos de material para o teste de endentação com lâminas orientadas a $[0]_{10}$ : Modelo II (sub-rotina UMAT)

A FIGURA 5.3.3-2 mostra que ao empregar o Modelo II não são produzidos resultados satisfatórios caso o equilíbrio da estrutura seja feito na posição inicial, mesmo considerando apenas a ocorrência da falha da matriz polimérica $(\mathrm{H}=0$ e $\mathrm{B}=0)$. Caso contrário, se o equilíbrio da estrutura for realizado na posição deslocada, os resultados teóricos convergem para os resultados experimentais. Para tal, basta ativar a opção NLGEOM no programa $\mathrm{ABAQUS}^{\circledR}$ e após algumas simulações tem-se para o modelo da placa em casca que o parâmetro $\mathrm{H}$ deve ser igual a 1,2 ao passo que $\mathrm{B}$ deve ser igual a zero. Nota-se que os valores de $\mathrm{H}$ e B calibrados no teste de flexão 3-pontos são bem diferentes dos valores calibrados pelo teste de endentação. Diante desses resultados, tem-se que para o teste de flexão 3-pontos, a amostra está bi-apoiada e ao 
haver a aplicação da carga, as tensões são distribuídas ao longo da amostra fazendo com que ocorra vários tipos de mecanismos de danificação/falha. Por outro lado, durante a endentação verifica-se que além do fenômeno de contato também ocorre um fenômeno de esmagamento localizado na matriz polimérica produzido pelo endentador (FIGURA 5.3.3-3).

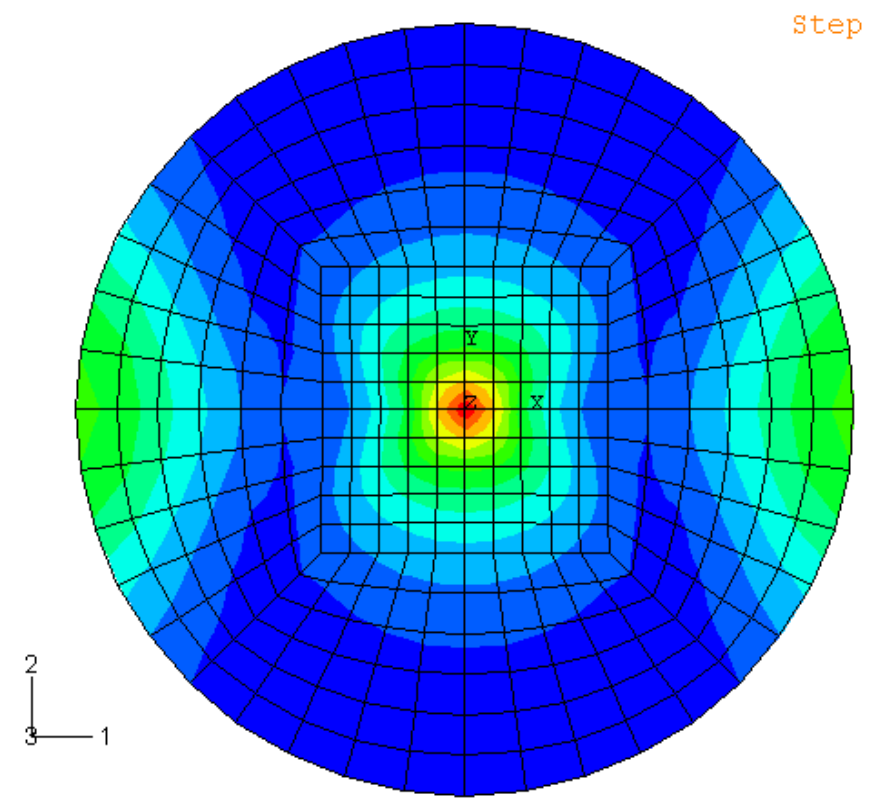

FIGURA 5.3.3-3 - Concentração de tensões próxima ao endentador para lâminas orientadas a $[0]_{10}$

O processo de esmagamento localizado da matriz polimérica faz com que haja na placa uma deformação residual após o término do descarregamento. No entanto, como foi descrito no Capítulo 4 (item 4.1), o modelo de material proposto não prevê a ocorrência de deformações plásticas. Sendo assim, os resultados teóricos do Modelo II sempre retornam ao valor de deslocamento igual a zero quando todo carregamento é removido (FIGURA 5.3.3-2). Dessa forma, optou-se por testar o emprego do Critério de Hill para verificar se o mesmo forneceria resultados melhores.

A FIGURA 5.3.3-4 mostra que o Critério de Hill produziu respostas mais satisfatórias ao final do descarregamento e ao fazer o equilíbrio na posição inicial (sem NLGEOM). Haja vista que este critério é capaz de representar as deformações residuais. No entanto, verifica-se ainda que o Modelo II apresentou de uma maneira geral um resultado mais consistente. Isto demonstra a necessidade da implementação de um modelo que envolva um critério de plastificação associado a um modelo de danificação. 
Porém, devido à anisotropia, este tipo de modelo necessita de um grande número de parâmetros para ser empregado. Uma alternativa seria incorporar na Lei de Contato a endentação permanente, como propuseram Yang e Sun (1982). Essa lei está fundamentada na Lei de Contato de Hertz, mas foi adequadamente ajustada com base nos resultados experimentais, visando assim a busca da representação fiel dos fenômenos descritos acima. Vale ressaltar que posteriormente, Tan e Sun (1985) modificaram esta Lei de Contato e obtiveram resultados mais precisos. Tal procedimento poderá ser futuramente adotado a fim de que o modelo computacional reproduza com mais fidelidade à resposta experimental. Além disso, poder-se-á realizar um estudo de investigação da influência da densidade da malha das regiões do endentador e da amostra que entram em contato.

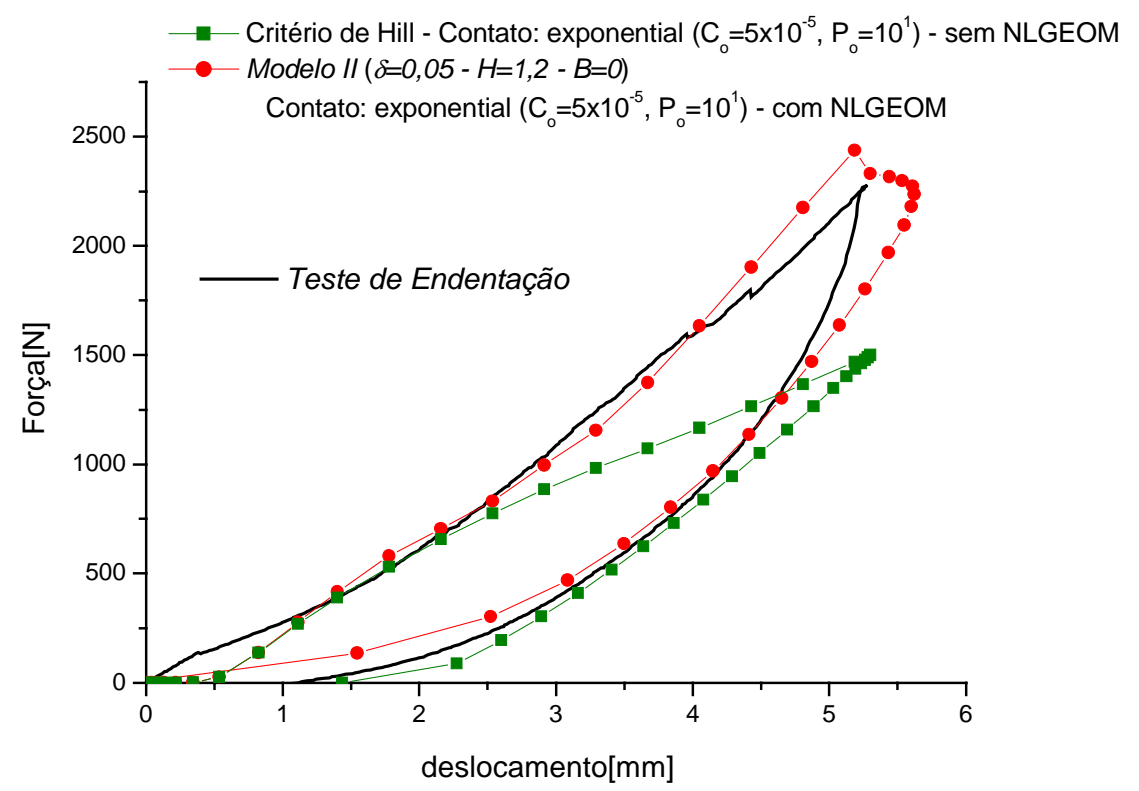

FIGURA 5.3.3-4 - Avaliação dos modelos de material para o teste de endentação com lâminas orientadas a $[0]_{10}$ : Critério de Hill x Modelo II (sub-rotina UMAT)

\section{Seqüência de Empilhamento /0/90/0/90/0]s}

A FIGURA 5.3.3-5 compara as curvas de força-deslocamento da simulação e do teste de endentação para lâminas orientadas a [0/90/0/90/0 $]_{\mathrm{s}}$, ao empregar o Modelo II de material juntamente com o modelo de contato já implementado no programa ABAQUS $^{\circledR}$ (tipo "exponential"). Constata-se que ao realizar o equilíbrio na posição inicial (sem NLGEOM), o processo de degradação da fibra juntamente com o da matriz faz com que a resposta teórica se afaste da resposta experimental quando $o$ 
deslocamento atinge $2,3 \mathrm{~mm}$ ao adotar 1,0 para o valor de $\mathrm{H}$ e zero para o valor de $\mathrm{B}$. Uma forma de obter resultados mais satisfatórios é realizar o equilíbrio na posição deslocada (com NLGEOM). Sendo assim, após algumas simulações verifica-se que o valor de $\mathrm{H}$ deve estar próximo de 1,6 e o valor de $\mathrm{B}$ ser igual a zero. Na fase de carregamento a resposta numérica se afasta um pouco da experimental entre $1,5 \mathrm{~mm}$ e 3,0 $\mathrm{mm}$ de deslocamento. Após este valor, tem-se que o resultado numérico converge para o experimental devido ao processo de degradação das propriedades ser ativado pelos respectivos critérios de degradação. No entanto, vale ressaltar que o empilhamento de lâminas $0^{\circ} / 90^{\circ}$ faz com que a estrutura apresente delaminações ao ser solicitada e o modelo de material implementado não contempla este tipo de falha. Constata-se também pela FIGURA 5.3.3-5 que o modelo computacional apresentou um resultado bem satisfatório durante a fase de descarregamento, apesar da resposta simulada convergir para zero quando há remoção completa da carga.

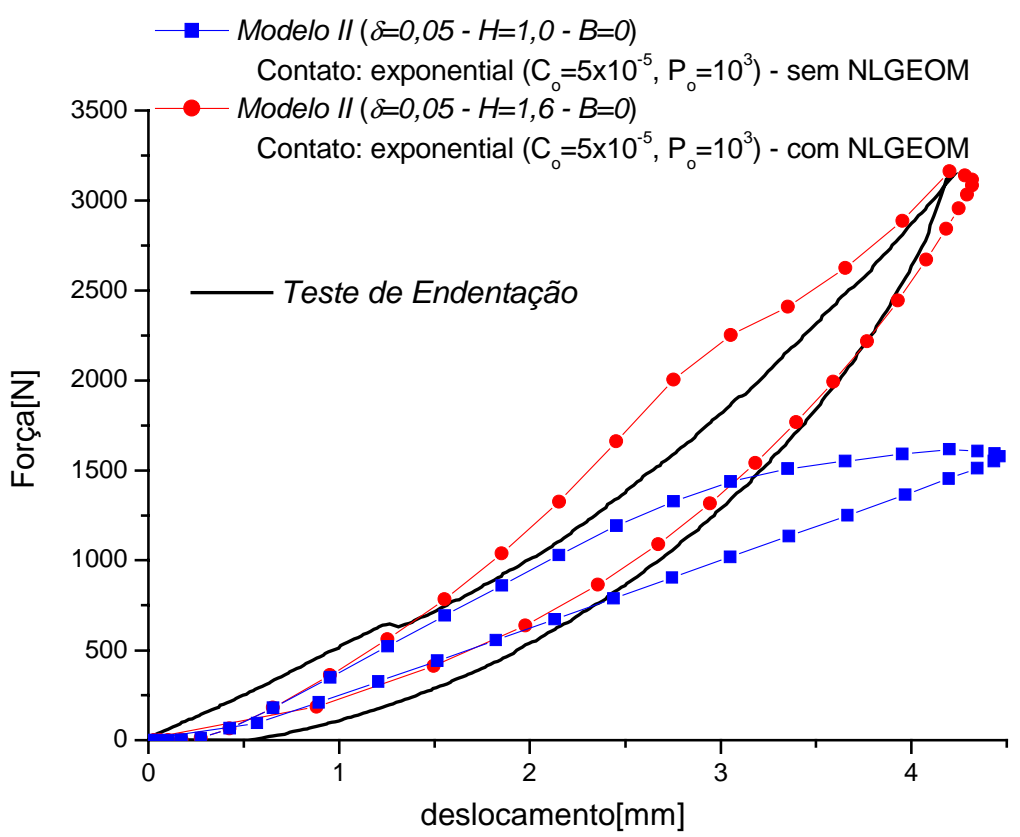

FIGURA 5.3.3-5 - Avaliação dos modelos de material para o teste de endentação com lâminas orientadas a [0/90/0/90/0 $]_{s}$ : Modelo II (sub-rotina UMAT)

Nota-se novamente pela FIGURA 5.3.3-5 que houve um processo de esmagamento localizado da matriz polimérica, pois após o término do descarregamento, o gráfico mostra que o deslocamento é diferente de zero. Dessa forma, a fim de simular essa deformação residual aplicou-se o Critério de Hill, visando obter resultados melhores. Após algumas simulações, é possível estabelecer que o melhor modelo de 
contato para utilizar nas simulações envolvendo o Critério de Hill, neste estudo de caso, é o modelo tipo "exponential" com $\mathrm{C}_{\mathrm{o}}$ igual a $5 \times 10^{-5}$ e $\mathrm{P}_{\mathrm{o}}$ igual a $10^{5}$. Como pode ser observado na FIGURA 5.3.3-6, o Critério de Hill produziu respostas mais satisfatórias ao final da fase de descarregamento, haja vista que este critério é capaz de representar as deformações permanentes devido ao esmagamento localizado causado pelo endentador. Sendo assim, reafirma-se a necessidade de desenvolver um modelo que possa contabilizar o processo de degradação da fibra e da matriz, bem como o processo de esmagamento localizado da resina polimérica.

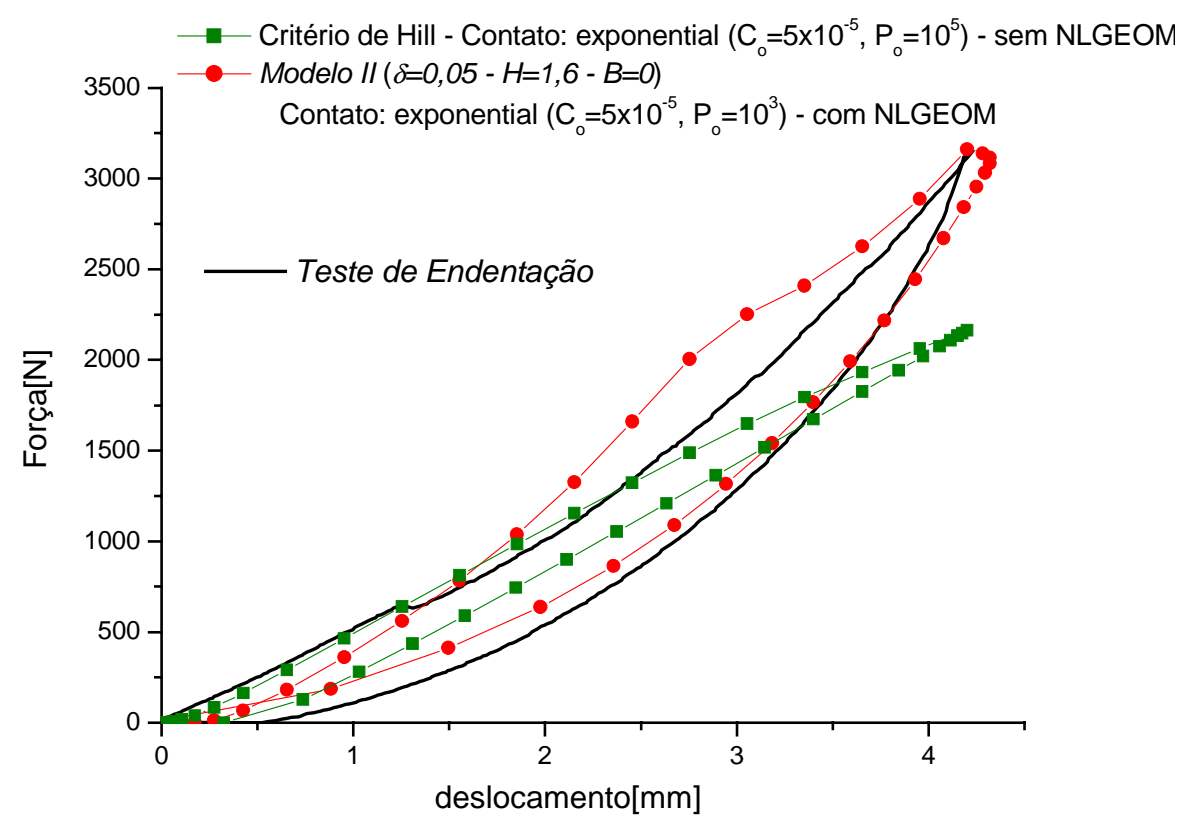

FIGURA 5.3.3-6 - Avaliação dos modelos de material para o teste de endentação com lâminas orientadas a [0/90/0/90/0]s: Critério de Hill x Modelo II (sub-rotina UMAT)

Além de utilizar o modelo em casca juntamente com o Modelo II da TABELA 5.2.2-2, para o presente estudo de caso, buscou-se também avaliar os resultados computacionais provenientes de um modelo sólido juntamente com o Modelo III da TABELA 5.2.2-2. Constata-se pela FIGURA 5.3.3-7 que o resultado utilizando o Modelo III pode apresentar resultados bem coerentes na fase de carregamento ao adotar 0,4 para o valor de $\mathrm{H}$ e zero para o valor de B. No entanto, durante a fase de descarregamento, o modelo em casca fornece um resultado melhor do que o modelo sólido. Isto se deve provavelmente à diferença de formulação existente entre esses dois elementos. Porém, de uma maneira geral, tanto o modelo em casca como o modelo 
sólido apresentam resultados satisfatórios. Vale ressaltar que o custo computacional do segundo é bem maior que o do primeiro devido ao emprego do estado triplo de tensão.

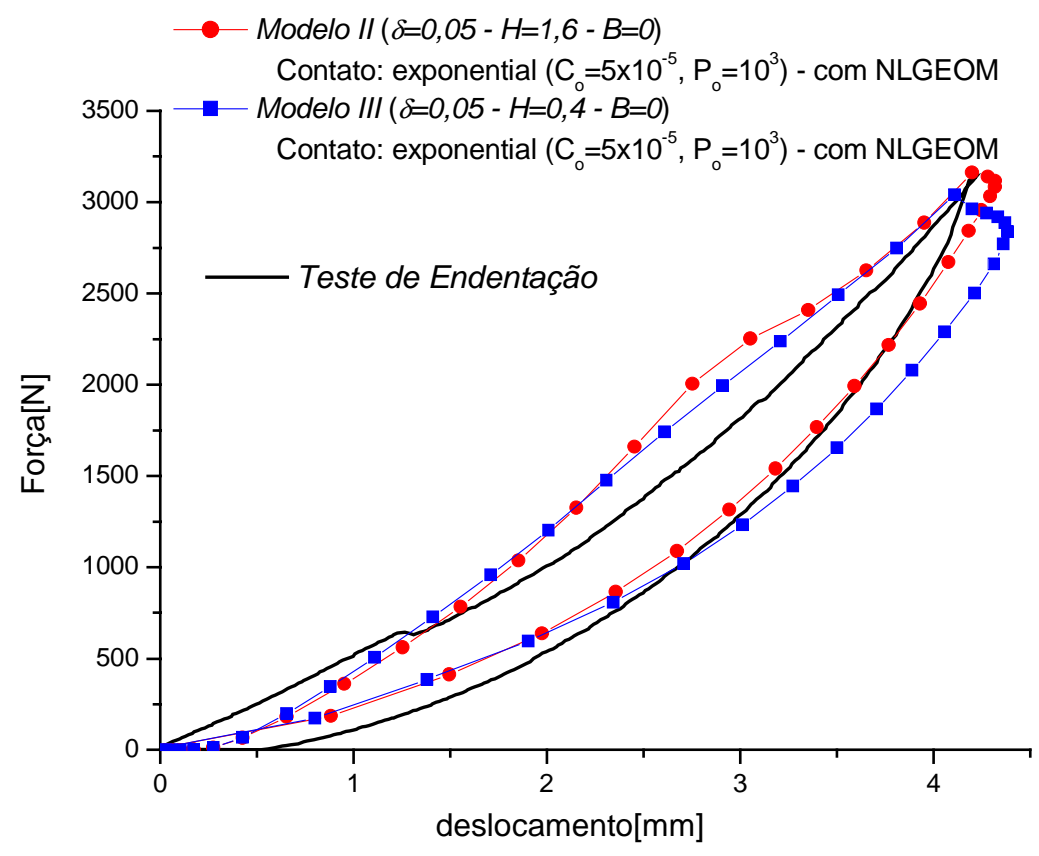

FIGURA 5.3.3-7 - Avaliação dos modelos de material para o teste de endentação com lâminas orientadas a [0/90/0/90/0 $]_{s}$ : Modelo II x Modelo III

\section{Seqüência de Empilhamento [+45/-45/+45/0/90]s}

A FIGURA 5.3.3-8 compara as curvas de força-deslocamento da simulação e do teste de endentação para lâminas orientadas a $[+45 /-45 /+45 / 0 / 90]_{\mathrm{s}}$, ao empregar o Modelo II de material juntamente com o modelo de contato já implementado no programa ABAQUS ${ }^{\circledR}$ (tipo “exponential”). Verifica-se que ao realizar o equilíbrio na posição inicial (sem NLGEOM), o processo de degradação da fibra juntamente com o da matriz faz com que a resposta teórica se afaste da resposta experimental quando o deslocamento atinge $2,0 \mathrm{~mm}$ ao adotar 0,5 para o valor de $\mathrm{H}$ e zero para o valor de $\mathrm{B}$. Uma alternativa para se obter resultados mais consistentes é realizar o equilíbrio na posição deslocada (com NLGEOM). Sendo assim, após algumas simulações verifica-se que o valor de $\mathrm{H}$ deve ser igual a 1,2 e o valor de B deve ser igual a zero. Na fase de carregamento a resposta numérica se afasta um pouco da experimental entre $1,5 \mathrm{~mm}$ e 3,2 $\mathrm{mm}$ de deslocamento. Após este valor, tem-se que o resultado numérico converge para o experimental devido ao processo de degradação das propriedades ser ativado pelos respectivos critérios de degradação. Verifica-se também pela FIGURA 5.3.3-8 que o modelo computacional apresentou um resultado bem satisfatório durante a fase de 
descarregamento, apesar da resposta simulada convergir para zero quando há remoção completa da carga. Diante deste tipo de fenômeno, optou-se por testar o emprego do Critério de Hill (FIGURA 5.3.3-8).

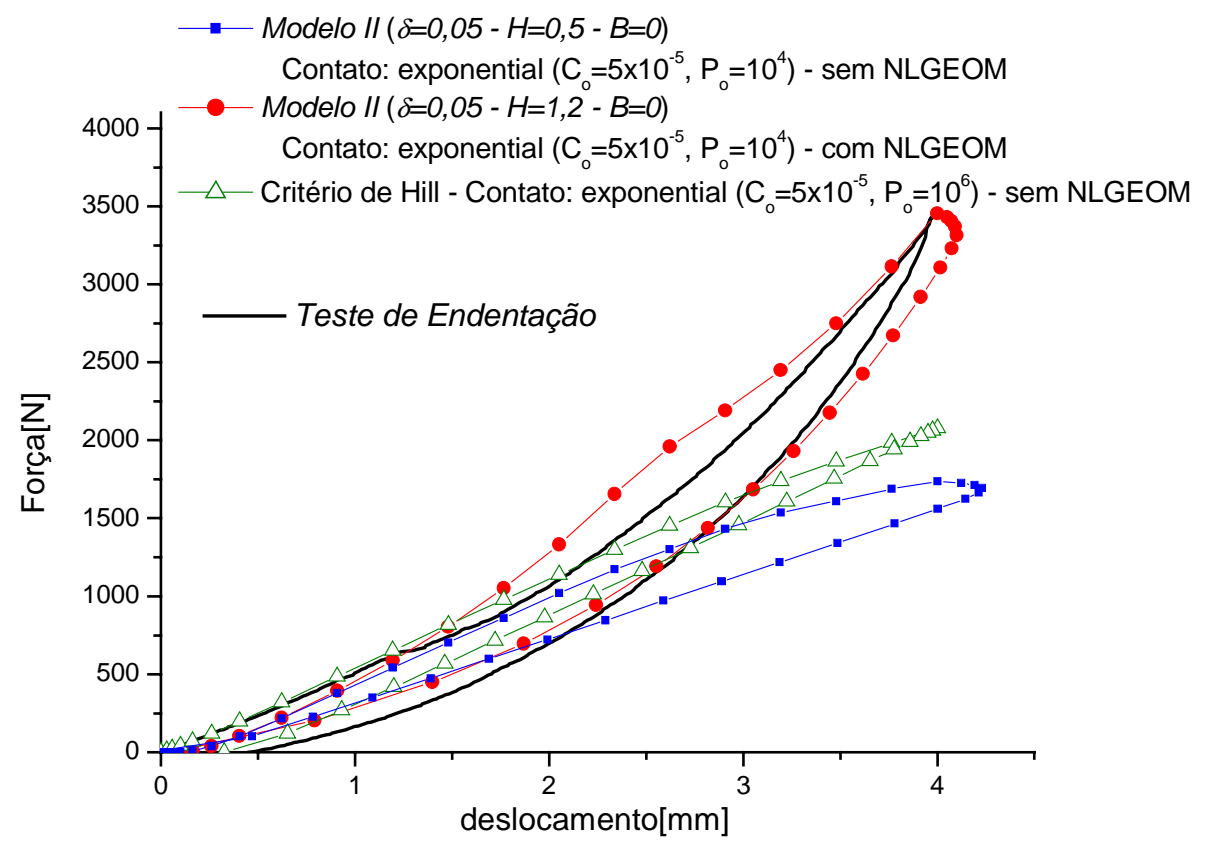

FIGURA 5.3.3-8 - Avaliação dos modelos de material para o teste de endentação com lâminas orientadas a [+45/-45/+45/0/90]s: Critério de Hill x Modelo II

Novamente, o Critério de Hill produziu respostas mais satisfatórias ao final da fase de descarregamento, pois o mesmo é capaz de representar as deformações permanentes devido ao esmagamento localizado causado pelo endentador.

Por fim, a FIGURA 5.3.3-9 compara os resultados numéricos provenientes do modelo em casca com do modelo sólido. Para o primeiro adota-se estado plano de tensão, utilizando o Modelo II da TABELA 5.2.2-2, ao passo que para o segundo, adota-se estado triplo de tensão ao empregar o Modelo III da TABELA 5.2.2-2. Constata-se que o modelo sólido apresenta resultados bem similares ao modelo em casca na fase de carregamento ao adotar 0,3 para o valor de $\mathrm{H}$ e zero para o valor de $\mathrm{B}$. Por outro lado, durante a fase de descarregamento, o modelo em casca fornece um resultado melhor do que o modelo sólido. Isto se deve provavelmente à diferença de formulação existente entre esses dois elementos. Sendo assim, o modelo em casca apresenta resultados melhores do que o modelo sólido. Além disso, vale ressaltar que o custo computacional do segundo é bem maior que o do primeiro devido ao emprego do estado triplo de tensão. 


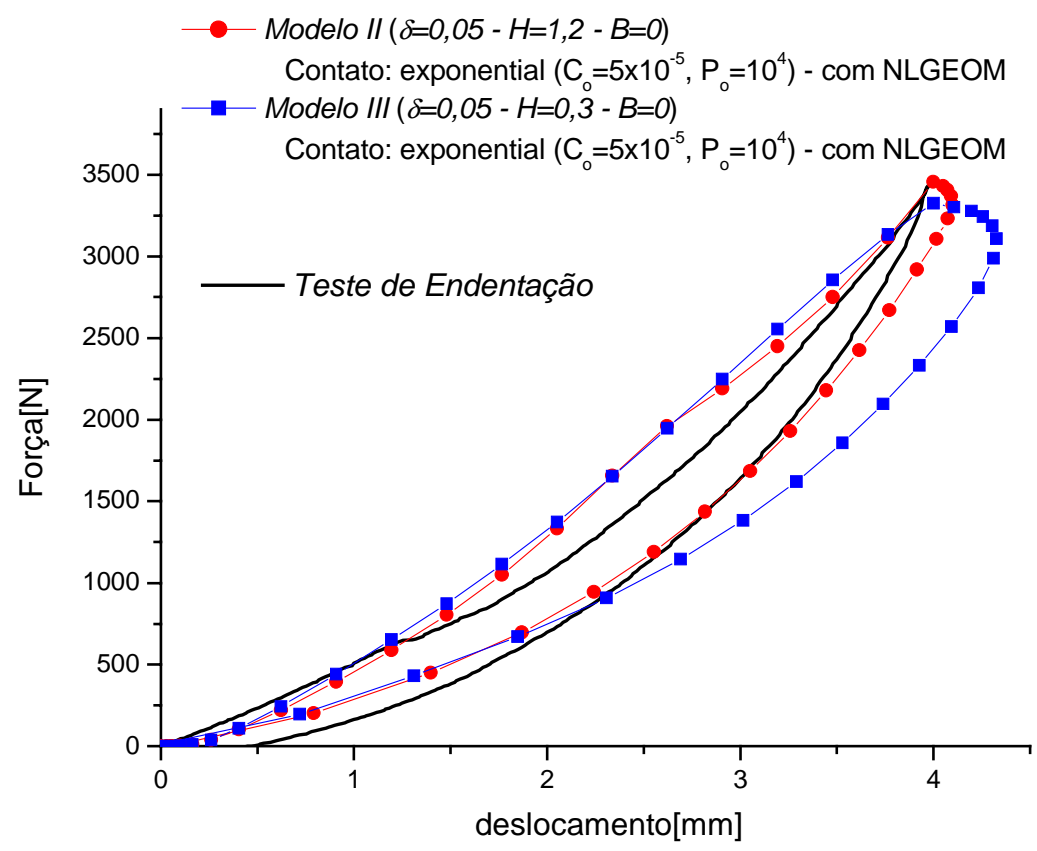

FIGURA 5.3.3-9 - Avaliação dos modelos de material para o teste de endentação com lâminas orientadas a [+45/-45/+45/0/90]s: Modelo II x Modelo III

\section{Resultados Numéricos dos Testes de Impacto}

Os resultados computacionais serão apresentados em função da seqüência de empilhamento dos laminados, a fim de que se possa avaliar os problemas numéricos de cada situação de empilhamento.

\section{Seqüência de Empilhamento [Ol $_{10}$}

A FIGURA 5.3.3-10 compara os históricos de força das simulações realizadas utilizando o programa DYNA ${ }^{\circledR}$ com os testes de impacto para lâminas orientadas a $[0]_{10}$. A FIGURA 5.3.3-10(a) mostra que o histórico proveniente da simulação utilizando o modelo elástico ortotrópico fornece um resultado pouco satisfatório para as amostras impactadas a 2,36 J. Isto ocorre, pois essas amostras tiveram um nível de absorção de energia igual a 1,2 J, retornando assim 1,16 J para o impactador (FIGURA 5.3.1-2(b)). Dessa forma, elas absorveram 50\% da energia de impacto em mecanismos de danificação e falha. Vale ressaltar que esses mecanismos são mais predominantes nas amostras impactadas a 5,91 J, como demonstrado pelas inspeções de ultra-som C-Scan (FIGURA 5.3.1-3). Além disso, o histórico de energia (FIGURA 5.3.1-2(a)) mostra que apenas $25 \%$ de toda a energia de impacto foi transformada em energia elástica de 
vibração, fazendo com que os resultados numéricos não sejam satisfatórios quando há o emprego do modelo elástico ortotrópico (FIGURA 5.3.3-10(b)). Sendo assim, torna-se necessária aplicação de um modelo de danificação/falha a fim de que a energia absorvida possa ser representada de forma coerente.

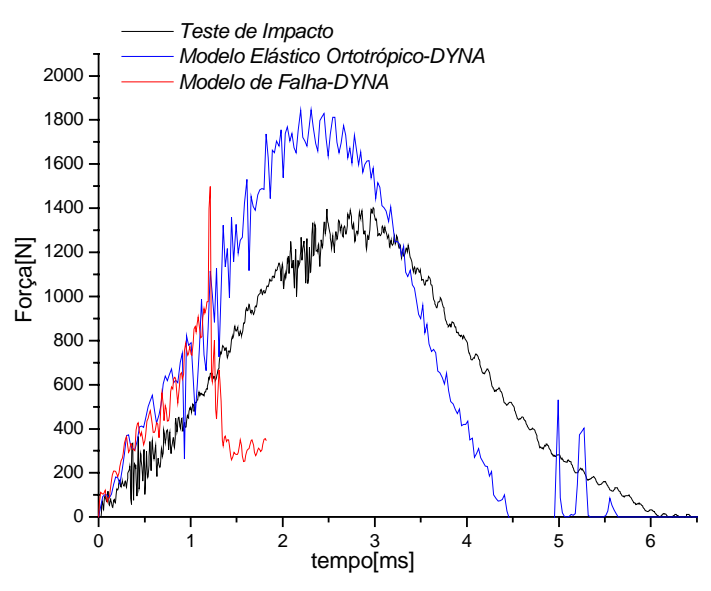

(a)

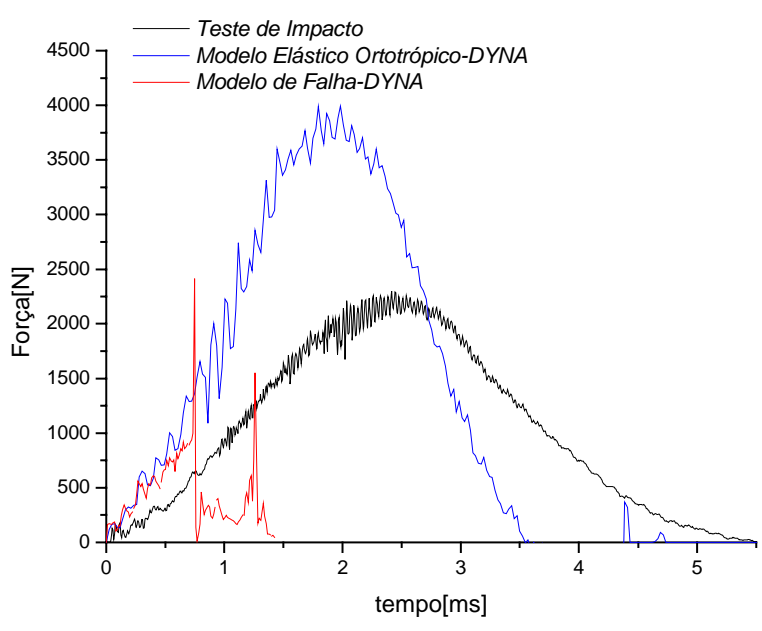

(b)

FIGURA 5.3.3-10 - Avaliação dos modelos de material para o teste de impacto com lâminas orientadas a $[0]_{10}$ : DYNA ${ }^{\circledR}$

(a) Energia de impacto igual a 2,36 J; (b) Energia de impacto igual a 5,91 J.

Com base nas FIGURAS 5.3.3-10(a) e 5.3.3-10(b), pode-se concluir que ou o Critério utilizado é inadequado e/ou a Lei de Evolução de Dano não está correta. Quanto ao Critério de Chang-Chang Modificado, tem-se que o mesmo é capaz de prever os mecanismos de danificação/falha desenvolvidos para lâminas orientadas a $[0]_{10}$. Quanto a Lei de Evolução de Dano tem-se que a mesma é muito severa, pois algumas propriedades são anuladas quando o dano é detectado, fazendo com que a rigidez do laminado seja reduzida drasticamente. Tal fato pode ser constatado nos históricos que revelam uma redução brusca da força após $0,8 \mathrm{~ms}$ quando a energia de impacto é igual a 5,91 J (FIGURA 5.3.3-10(a)) e após 1,2 ms quando a energia de impacto é igual a 2,36 J (FIGURA 5.3.3-10(b)).

A FIGURA 5.3.3-11 compara os históricos de força das simulações realizadas utilizando o programa DYNA ${ }^{\circledR}$ e o programa ABAQUS ${ }^{\circledR}$ com os testes de impacto para lâminas orientadas a $[0]_{10}$. Nota-se que o histórico proveniente da simulação utilizando o modelo elástico ortotrópico implementado no programa $\mathrm{ABAQUS}^{\circledR}$ depende do tipo de contato empregado. A FIGURA 5.3.3-11(a) mostra que a resposta numérica 
proveniente do $\mathrm{ABAQUS}^{\circledR}$ ao empregar o modelo de contato tipo "hard" se aproxima da resposta numérica proveniente do DYNA $^{\circledR}$ e são menos satisfatórias do que a resposta proveniente do ABAQUS ${ }^{\circledR}$ ao empregar o modelo de contato tipo "exponential". Para o caso em que a energia de impacto é igual a 5,91 J, tem-se resultados satisfatórios utilizando o modelo de contato tipo "exponential" com $\mathrm{C}_{\mathrm{o}}$ igual a $10^{-4}$ e $\mathrm{P}_{\mathrm{o}}$ igual a $10^{2}$ (FIGURA 5.3.3-11(a)). Entretanto, o pico de força do histórico simulado é maior que o pico de força do histórico experimental, confirmando assim a necessidade do emprego de um modelo de material que seja capaz de prever as danificações/falhas decorrentes do processo de impacto. Vale ressaltar que as análises foram realizadas com o equilíbrio na posição deslocada.

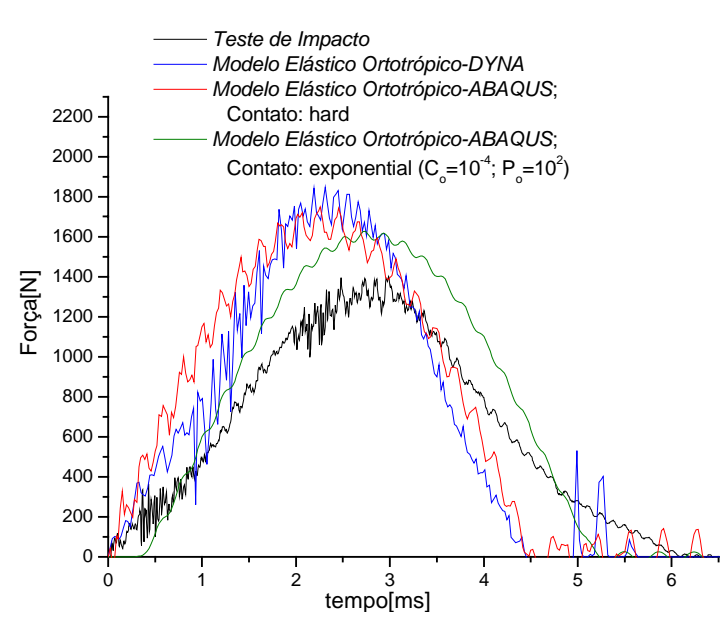

(a)

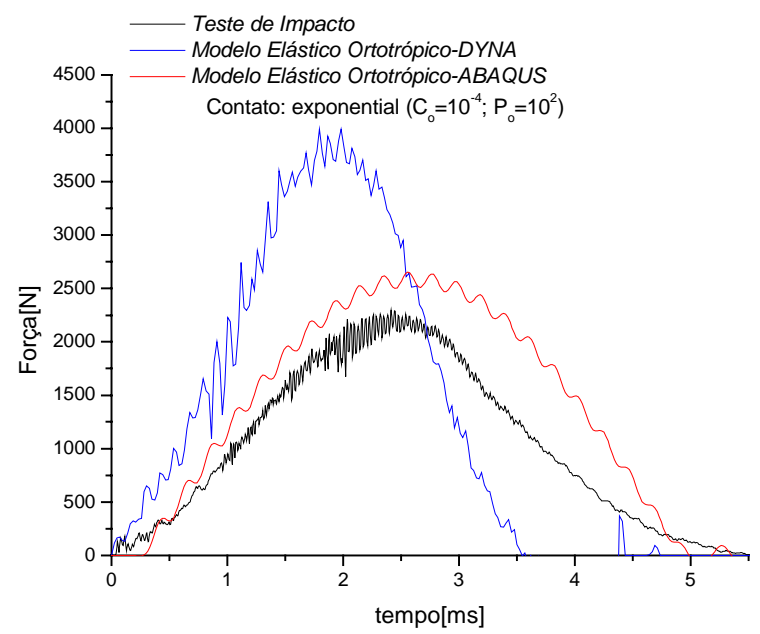

(b)

FIGURA 5.3.3-11 - Avaliação dos modelos de material para o teste de impacto com lâminas orientadas a $[0]_{10}$ : $\mathrm{DYNA}^{\circledR} \mathrm{x} \mathrm{ABAQUS}^{\circledR}$

(a) Energia de impacto igual a 2,36 J; (b) Energia de impacto igual a 5,91 J.

\section{Seqüência de Empilhamento /0/90/0/90/0]}

A FIGURA 5.3.3-12 compara os históricos de força das simulações realizadas utilizando o programa $\mathrm{ABAQUS}^{\circledR}$ com os testes de impacto para lâminas orientadas a

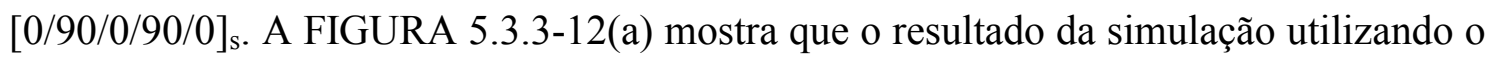
modelo elástico ortotrópico juntamente com o modelo de contato tipo "exponential" converge para o resultado experimental quando as amostras são impactadas a 2,36 J. Tal fato ocorre, pois tais amostras absorveram cerca de $0,58 \mathrm{~J}$, retornando para o impactador quase toda energia de impacto, ou seja, cerca de 75\% (FIGURA 5.3.1-5(b)). Dessa 
forma, essas amostras absorveram apenas $25 \%$ da energia de impacto em forma de danificações. Isto indica que ocorreram poucos mecanismos de danificação/falha, pois a estrutura apresentou uma resposta quase que totalmente elástica. Por outro lado, a FIGURA 5.3.3-12(b) demonstra que o histórico proveniente da simulação utilizando o modelo elástico ortotrópico juntamente com o modelo de contato tipo "exponential" fornece um resultado numérico não muito satisfatório. Isto ocorre, pois, as amostras empilhadas a $[0 / 90 / 0 / 90 / 0]_{\mathrm{s}}$ impactadas a 5,91 J apresentam fratura da matriz e delaminações, como pode ser visualizado nas FIGURAS 5.3.1-5(a) e 5.3.1-7. Verificase assim, que as amostras impactadas a 5,91 J tiveram uma absorção de energia igual a $3,96 \mathrm{~J}$, transferindo de volta para o impactador cerca de $33 \%$ de toda a energia de impacto. Dessa forma, torna-se necessária a aplicação de um modelo de danificação/falha a fim de representar com mais fidelidade os fenômenos envolvidos no processo de impacto. Vale destacar que as análises foram realizadas com o equilíbrio na posição deslocada.

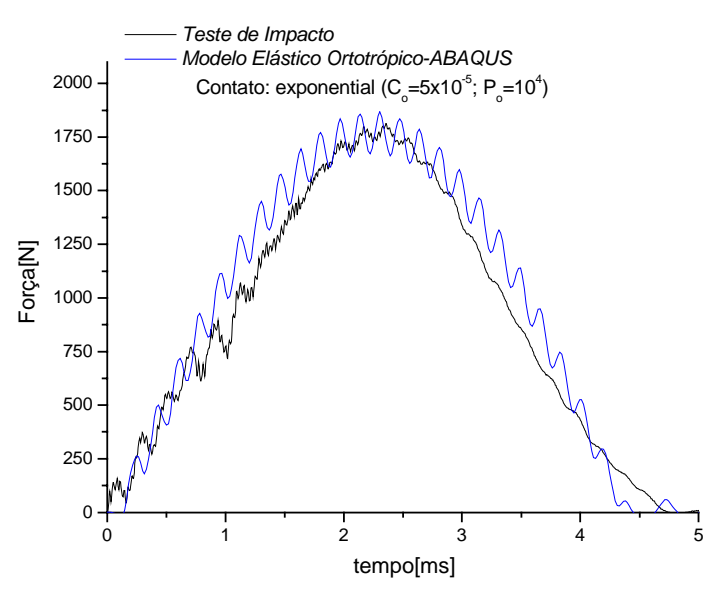

(a)

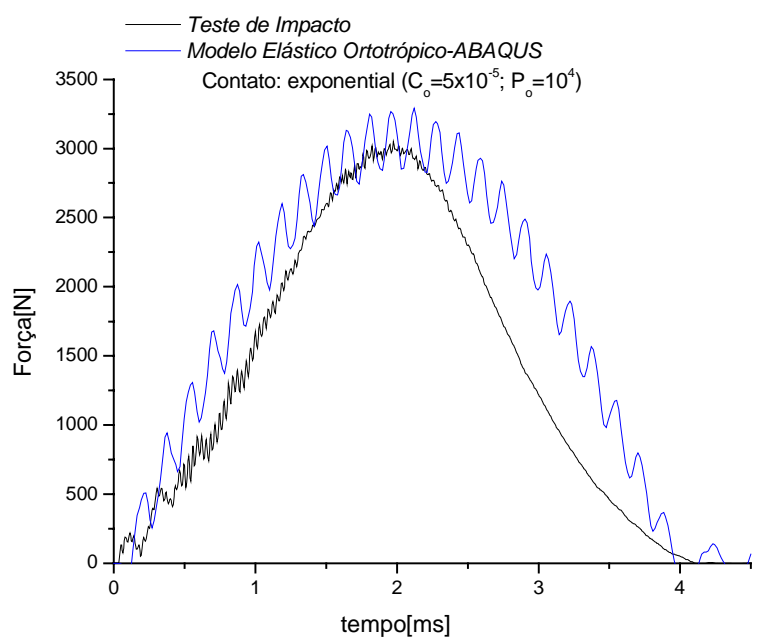

(b)

FIGURA 5.3.3-12- Avaliação dos modelos de material para o teste de impacto com lâminas orientadas a $[0 / 90 / 0 / 90 / 0]_{\mathrm{s}}$ : ABAQUS $^{\circledR}$

(a) Energia de impacto igual a 2,36 J; (b) Energia de impacto igual a 5,91 J.

Seqüência de Empilhamento $[+45 /-45 /+45 / 0 / 90]_{\underline{S}}$

A FIGURA 5.3.3-13 compara os históricos de força das simulações realizadas utilizando o programa $\mathrm{ABAQUS}^{\circledR}$ com os testes de impacto para lâminas orientadas a [+45/-45/+45/0/90]s. A FIGURA 5.3.3-13(a) mostra que o resultado da simulação 
utilizando o modelo elástico ortotrópico juntamente com o modelo de contato tipo "exponential" é satisfatório para o resultado experimental quando as amostras são impactadas a 2,36 J. Tal fato ocorre, pois tais amostras apresentaram um nível de absorção de energia muito pequeno $(0,8 \mathrm{~J})$, retornando assim $66 \%$ da energia de impacto em forma de vibrações elásticas para o impactador. Por outro lado, a FIGURA 5.3.3-13(b) demonstra que o histórico proveniente da simulação utilizando o modelo elástico ortotrópico juntamente com o modelo de contato tipo "exponential" fornece um resultado numérico não muito satisfatório. Isto ocorre, pois as amostras empilhadas a [+45/-45/+45/0/90 $]_{\mathrm{s}}$ impactadas a 5,91 J apresentam fratura da matriz, delaminações e deformações permanentes devido às tensões de cisalhamento que atuam nas camadas $+/-45^{\circ}$. Tanto a FIGURA 5.3.1-10 que apresenta os resultados de inspeção de ultra-som C-Scan como a FIGURA 5.3.1-9(a) que mostra o histórico de energia evidenciam a presença de tais mecanismos. Verifica-se assim, que as amostras impactadas a 5,91 $\mathrm{J}$ tiveram uma absorção de energia igual a 4,0 J, transferindo de volta para o impactador $32 \%$ de toda a energia de impacto em forma de energia elástica de vibração (FIGURA 5.3.1-9(a)). Sendo assim, torna-se necessário o emprego de um modelo de danificação/falha que represente de maneira consistente os fenômenos envolvidos no processo de impacto. Vale ressaltar que as análises foram realizadas com o equilíbrio na posição deslocada.

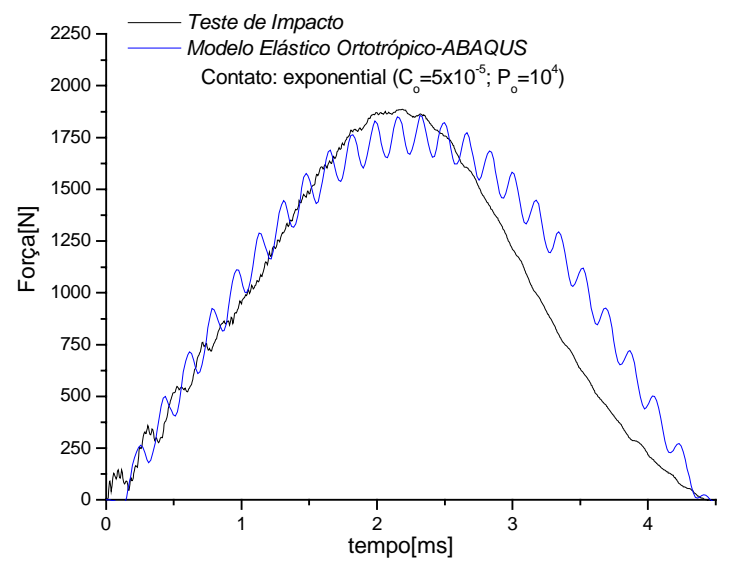

(a)

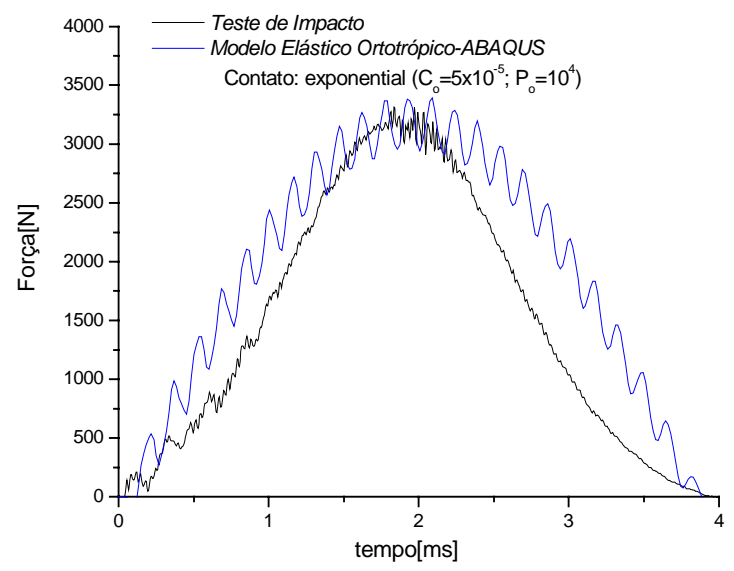

(b)

FIGURA 5.3.3-13- Avaliação dos modelos de material para o teste de impacto com lâminas orientadas a $[+45 / 45 /+45 / 0 / 90]_{\mathrm{s}}$ : ABAQUS $^{\circledR}$

(a) Energia de impacto igual a 2,36 J; (b) Energia de impacto igual a 5,91 J. 
A FIGURA 5.3.3-14 apresenta os resultados da simulação computacional ao empregar o Modelo II da TABELA 5.2.2-2. Vale ressaltar que este modelo teve de ser re-implementado em linguagem FORTRAN na forma de VUMAT que é uma "User MATerial Subroutine" utilizada especificamente pelo programa ABAQUS/Explicit ${ }^{\circledR}$ (ABAQUS, 2002).

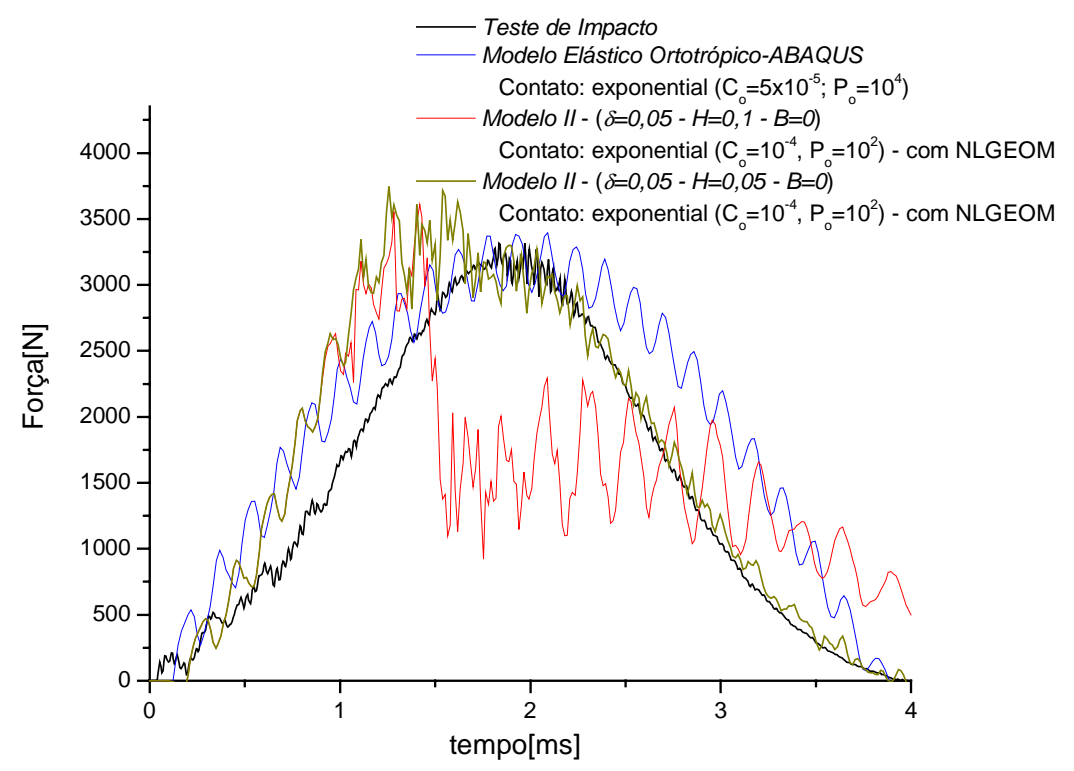

FIGURA 5.3.3-14- Avaliação dos modelos de material para o teste de impacto com lâminas orientadas a $[+45 / 45 /+45 / 0 / 90]_{\mathrm{s}}$ : Modelo II (VUMAT)

(Energia de impacto igual a 5,91 J)

Verifica-se que o modelo computacional é muito sensível ao parâmetro $\mathrm{H}$, de tal forma que uma diferença de apenas $0,05 \mathrm{fez}$ com que um resultado fosse muito mais próximo do experimental quando comparado ao outro. Isto demonstra que um estudo mais apurado torna-se necessário a fim de que sejam investigados possíveis erros numéricos. Além disso, a influência da taxa de deformação não foi contabilizada na presente análise e o modelo de contato implementado no programa ABAQUS/Explicit ${ }^{\circledR}$ também não é capaz de representar de forma adequada o fenômeno de esmagamento localizado causado pelo impactador. 


\section{Capítulo 6}

\section{METODOLOGIA PROPOSTA}

\subsection{METODOLOGIAS EMPREGADAS PARA AVALIAR IMPACTO EM COMPÓSITOS POLIMÉRICOS}

Como foi relatado anteriormente, os materiais compósitos poliméricos estão sendo ultimamente empregados no desenvolvimento de projetos de componentes mecânicos que devam possuir uma alta resistência ao impacto. Portanto, tais componentes devem ser capazes de absorver a máxima quantidade de energia proveniente de um carregamento impulsivo, sob um certo controle do colapso, sem ocasionar riscos para a vida humana e sem gerar altas desacelerações na estrutura. Por outro lado, foi visto no capítulo anterior que dependendo da incidência de determinados mecanismos de danificação intralaminar e falha interlaminar a estrutura pode ter uma maior ou menor resistência ao impacto. Sendo assim, como foi verificado no Capítulo 5, uma mesma estrutura pode ter respostas completamente distintas desde que mecanismos diferentes sejam acionados. Dessa forma, a resposta da estrutura depende de uma série de fatores, tais como:

Massa e velocidade do impactador;

Geometria do impactador;

$\checkmark$ Geometria da estrutura;

$\checkmark$ Tipo de compósito polimérico empregado;

Sequência de empilhamento utilizada na fabricação da estrutura.

Diante disso, tem-se que a previsão de resposta de um componente mecânico em CPR atingido por um carregamento impulsivo é algo relativamente complexo de ser 
realizado. Este desafio, fez com que vários pesquisadores apresentassem inúmeras contribuições.

Levy Neto e Al-Quereshi (1986) analisaram o bordo de ataque da aeronave EMB120 (Brasília) sob carregamento de impacto. Para tal, os autores inicialmente mediram o pico de força através de um teste de impacto e posteriormente realizaram uma análise quase-estática numérica, utilizando o Método dos Elementos Finitos (MEF). Nesta análise, o pico de força medido experimentalmente foi distribuído para alguns nós do modelo a fim de verificar a ocorrência de danos na estrutura com base no Critério de Tsai-Hill.

Oñate et al. (1991) formularam um modelo constitutivo para compósitos que foi posteriormente implementado em um programa de elementos finitos. Com isso tornouse possível simular o impacto da carroceria de um caminhão em compósito, analisando assim todo processo de danificação/falha desenvolvido.

Cairns e Lagace (1992) propuseram uma metodologia analítico-experimental onde inicialmente realizou-se uma análise do comportamento global da estrutura a fim de obter as regiões mais críticas, e posteriormente, fez-se uma análise local dessas regiões. Por fim, os autores com o auxílio de técnicas de inspeção de falha checaram a eficiência da metodologia proposta para alguns estudos de caso.

Farley e Jones (1992) apresentaram uma metodologia capaz de prever a capacidade de absorção de energia de estruturas em compósito (resina epóxi reforçada com fibra de carbono e resina epóxi reforçada com fibra de kevlar ${ }^{\circledR}$ ). Para tal, os autores utilizaram modelos em elementos finitos e puderam avaliar os fenômenos intra e interlaminares durante o esmagamento das estruturas. Vale ressaltar que outros pesquisadores, como Gautham e Ganesan (1994) e Hamada e Ramakrishna (1997) também utilizaram as potencialidades do Método dos Elementos Finitos (MEF) visando quantificar a energia absorvida por estruturas laminadas frente a carregamentos de impacto.

A Engineering Systems International (ESI) desenvolveu, com auxílio da Agência Espacial Européia, uma metodologia numérico-experimental capaz de quantificar a energia absorvida num processo de impacto por estruturas complexas fabricadas a partir de compósitos poliméricos reforçados. Haug e De Rouvray (1993) mostraram que a parte numérica da metodologia foi desenvolvida utilizando um pacote comercial de elementos finitos $\left(\mathrm{PAM}^{\circledR}\right)$. O PAM-FISS ${ }^{\circledR}$ é um programa criado pela ESI para realizar análises quase-estáticas não-lineares para vários tipos de materiais, inclusive materiais 
compósitos. O outro programa da mesma empresa é o PAM-CRASH ${ }^{\circledR}$ que realiza análises dinâmicas explícitas não-lineares, podendo assim obter respostas para componentes, sub-montagens e estruturas completas. Ambos programas trabalham em conjunto, pois o PAM-FISS ${ }^{\circledR}$ calibra o modelo constitutivo associado ao material, ao passo que o PAM-CRASH ${ }^{\circledR}$ executa uma análise dinâmica do modelo calibrado.

Belingardi, Gugliota e Vadori (1998) estudaram o problema de impacto em placas de compósito utilizando um Critério de Hashin Modificado associado a uma formulação de evolução de dano que foi implementada junto ao pacote comercial de elementos finitos DYNA-3D ${ }^{\circledR}$. Apesar da metodologia considerar comportamento linear elástico até a incidência do dano tem-se que a incorporação dos modos de danificação no equacionamento do critério e a evolução progressiva do dano proporcionaram uma boa convergência dos resultados numéricos quando comparados aos experimentais.

Collombet, Lalbin e Lataillade (1998) também apresentaram uma metodologia numérico-experimental a fim de avaliar os mecanismos de danificação/falha de laminados frente a carregamentos de impacto. Numa primeira abordagem, os autores optaram por modelar os mecanismos utilizando um "modelo de falha equivalente" associado a estratégias de contato. Numa segunda abordagem, optou-se por utilizar um simples critério para determinar a iniciação do dano causado pelo fraturamento da matriz ou pela delaminação. Vale ressaltar que os pesquisadores utilizaram técnicas de inspeção de falha para validar os modelos propostos.

Gottesman e Girshovich (1998) também utilizaram técnicas de inspeção de falha. Entretanto, os autores realizaram um procedimento inverso, ou seja, com base em imagens fornecidas pelas técnicas de inspeção, propuseram um modelo de material que empregado em conjunto com a Teoria Clássica de Laminados pode fornecer uma previsão de comportamento de estruturas laminadas.

Vicente, Béltran e Martínez (2000) apresentaram um trabalho com o objetivo de reproduzir de forma precisa a resposta não-linear e os mecanismos de colapso em estruturas aeronáuticas de compósitos sob carregamento de impacto. Assim, várias metodologias foram testadas, dentre as quais destacou-se o desenvolvimento de um modelo isótropo equivalente para representar o comportamento mecânico sob condições de interesse. Dessa forma, o primeiro passo da modelagem foi buscar uma alternativa para representar os modos de danificação intralaminar em compósitos. A metodologia escolhida baseou-se em capturar macroscopicamente a falha do laminado ao invés de representar todas as lâminas. Para tal, foi necessário desenvolver um modelo de material 
equivalente caracterizado por poucos parâmetros. Após vários testes, definiu-se um modelo constitutivo elasto-plástico associado a um critério com base na máxima deformação plástica equivalente. Tal modelo foi implementado num pacote comercial de elementos finitos $\left(\mathrm{ABAQUS}^{\circledR}\right.$ ) a fim de que as análises numéricas pudessem ser concretizadas.

Kindervater et al. (2000) realizaram simulações computacionais de impacto não somente em componentes aeronáuticos mas também em uma aeronave completa que viesse colidir contra água. Sendo assim, os pesquisadores desenvolveram uma metodologia numérico-experimental com uma abordagem local/global. Um dos primeiros objetivos do trabalho consistiu em avaliar os mecanismos de danificação/falha de componentes mecânicos em situações de impacto sob alta velocidade, tal como, o impacto de um pássaro numa aeronave. Sendo assim, novas leis constitutivas de material que consideram os efeitos das taxas de deformação foram implementadas e calibradas com o auxílio de experimentos. Posteriormente, um modelo constituído por elementos mola, massa e viga foi utilizado para simular o impacto de uma aeronave completa. Por fim, as rigidezes dos elementos viga e mola foram ajustadas em função das respostas obtidas pelos modelos de impacto dos componentes que foram calibrados experimentalmente.

Pérez Galán, Climent e Le Page (2000) realizaram simulações computacionais e testes experimentais da fuselagem completa e de sub-componentes da fuselagem da aeronave Airbus A320. Os autores criaram uma metodologia numérico-experimental que consiste basicamente de três etapas. $\mathrm{Na}$ primeira etapa busca-se avaliar o comportamento mecânico de sub-componentes da fuselagem frente a carregamentos quase-estáticos, calibrando o modelo com base nos resultados experimentais. $\mathrm{Na}$ segunda etapa, avalia-se o comportamento desses mesmos sub-componentes frente a carregamentos de impacto, calibrando o modelo com base em resultados provenientes de testes de impacto. Por fim, na terceira etapa, realiza-se inicialmente um teste de impacto da fuselagem completa, avaliando-se o comportamento da estrutura. Com base nessas avaliações e nos modelos calibrados nas etapas anteriores, constrói-se o modelo da fuselagem que demorou 6 dias para ser solucionado em um supercomputador CRAY YMP 232.

Tita e Carvalho (2001) utilizando o modelo de contato implementado num programa comercial de elementos finitos $\left(\mathrm{DYNA}^{\circledR}\right)$ investigaram o comportamento 
dinâmico de placas de compósitos simplesmente apoiadas que foram impactadas por uma pequena esfera de aço e obtiveram resultados satisfatórios.

Kostopoulos et al. (2002) apresentaram um estudo paramétrico sobre o desenvolvimento de projetos de capacetes. Para tal, os autores realizaram inúmeras simulações computacionais utilizando o pacote comercial de elementos finitos DYNA$3 \mathrm{D}^{\circledR}$. Sendo assim, pôde-se investigar a influência de diferentes de tipos de reforços (fibra de vidro, carbono ou kevlar ${ }^{\circledR}$ ) na resposta dinâmica de capacetes frente a carregamentos de impacto.

Lopresto e Caprino (2002) apresentaram uma metodologia analítico-experimental para avaliar problemas de impacto em compósito sob baixa velocidade. Vale ressaltar que a rigidez associada à flexão foi estimada com base no trabalho de Timoshenko de 1959 e na Teoria Clássica de Laminados. Por outro lado, a rigidez associada ao comportamento de membrana foi obtida com base em resultados experimentais.

Finalmente, essas são algumas das inúmeras contribuições que envolvem o estudo de impacto em compósitos poliméricos reforçados. Concluí-se assim que o problema de impacto em compósitos é um tema aberto para discussões, pois ainda não há uma metodologia geral capaz de representar de forma consistente todos os fenômenos envolvidos.

\subsection{PROPOSTA DE UMA METODOLOGIA}

Com base nos resultados apresentados no Capítulo 5, nota-se que para determinadas condições em que são realizados os testes de impacto (“drop-test"), temse que os mesmos podem ser representados por testes quase-estáticos de endentação. Isto pode ser confirmado através do trabalho de Olsson (2000) ao qual classifica a existência de 3 tipos de impacto em função da duração do contato entre o impactador e a estrutura impactada (FIGURA 6.2-1). Sendo assim, para impactos de curtíssima duração, a resposta da estrutura é dominada pela propagação de ondas ("dilatational waves") e pela ocorrência de mecanismos de danificação e falha mais localizados (próximos da região de impacto) (FIGURA 6.2-1(a)). Para impactos de curta duração, a resposta da estrutura é dominada pela propagação de ondas de flexão ("flexural waves") e pela ocorrência de mecanismos de danificação e falha mais distribuídos na estrutura (FIGURA 6.2-1(b)). Para impactos de longa duração, a resposta da estrutura é 
praticamente quase-estática e também há uma distribuição da incidência de mecanismos de danificação e falha na estrutura (FIGURA 6.2-1(c)).

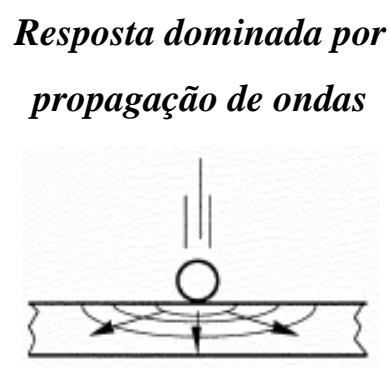

(a)

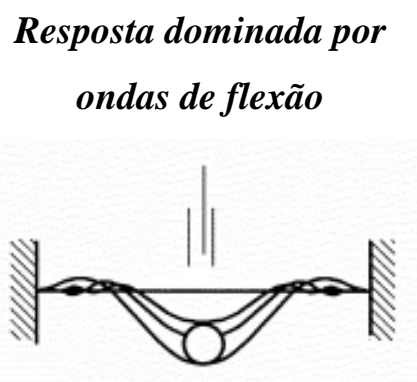

(b)

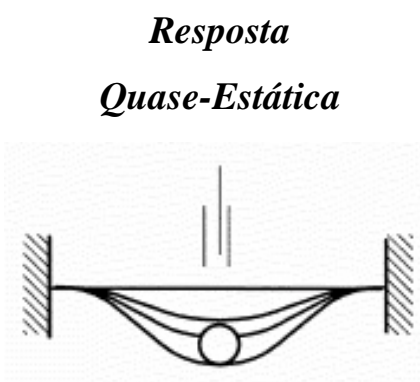

(c)

FIGURA 6.2-1 - Tipos de resposta de impacto em função do tempo de contato:

(a) curtíssimo tempo; (b) curto tempo; (c) longo tempo

(OLSSON, 2000)

Diante disso, foi proposta uma metodologia numérico-experimental para avaliar impacto a baixa velocidade em componentes mecânicos a base de compósitos poliméricos reforçados (CPR). A FIGURA 6.2-2 mostra uma metodologia que visa principalmente avaliar o modelo de material que está sendo empregado nas análises computacionais. Conseqüentemente, o modelo deverá ser avaliado frente a carregamentos quase-estáticos bem como frente a carregamentos dinâmicos (carregamentos de impacto) através de duas etapas:

$\checkmark$ Etapa 1 -Análises Quase-Estáticas: consiste em avaliar o modelo de material quando a estrutura é carregada gradativamente.

$\checkmark$ Etapa 2 - Análises Dinâmicas: consiste em avaliar o modelo de material quando a estrutura é carregada impulsivamente.

Na Etapa 1 são inicialmente realizados ensaios quase-estáticos para a obtenção das propriedades mecânicas e valores de resistência das lâminas ortotrópicas sob tração, compressão e cisalhamento. Os resultados obtidos alimentam um modelo de material implementado em um programa de elementos finitos. Com isso, realiza-se uma análise numérica de uma estrutura sob endentação. Os resultados numéricos dessa análise quase-estática são então comparados com os resultados experimentais dos testes de endentação ("indentation test”). Caso haja divergência entre estes resultados e considerando que os testes de caracterização mecânica sejam consistentes, pode-se 
concluir que o modelo de material adotado não é capaz de representar os mecanismos de danificação/falha ou que os parâmetros associados ao modelo precisam ser melhor calibrados. A checagem é repetida, calibrando os parâmetros do modelo com base nos resultados numéricos e experimentais.

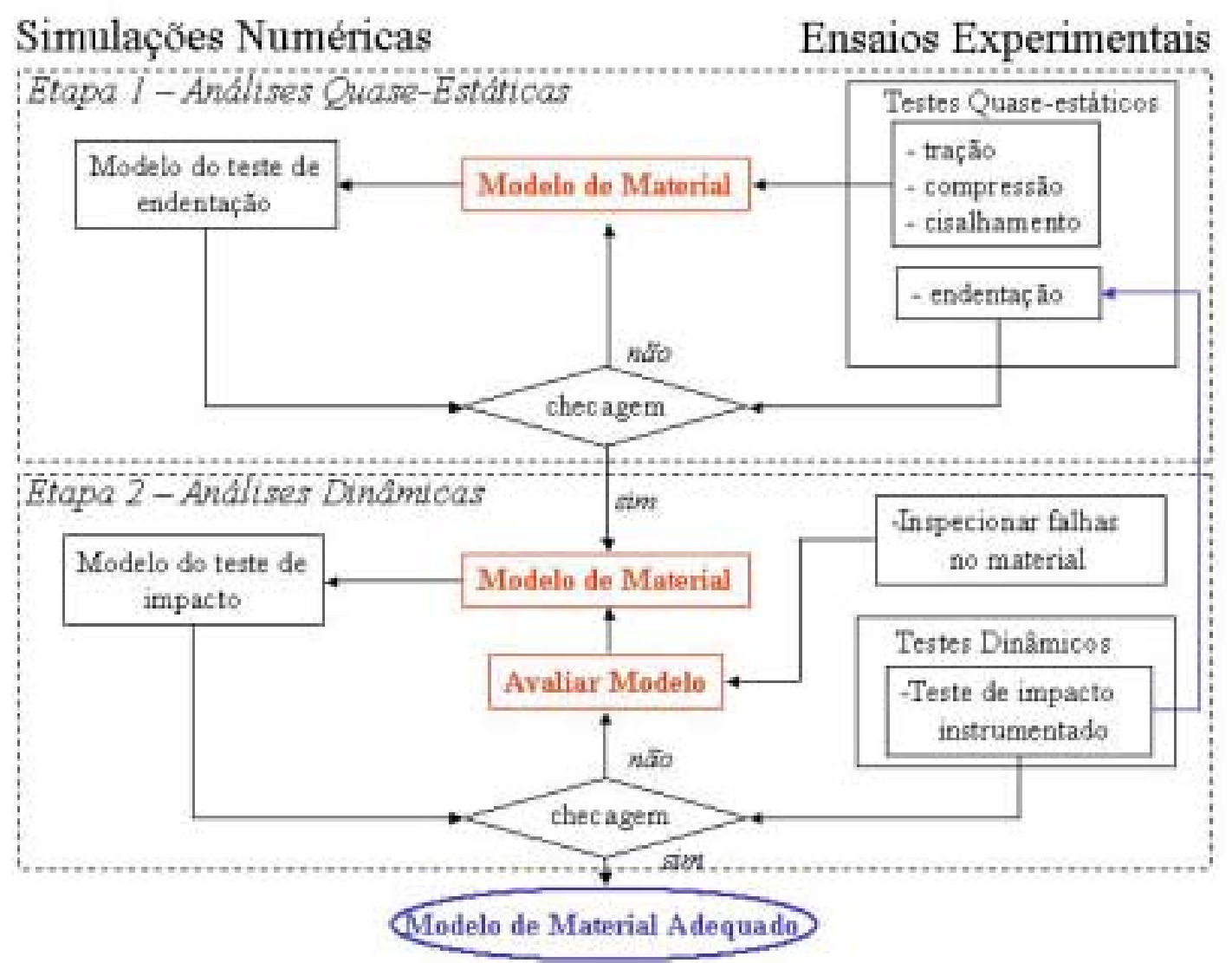

FIGURA 6.2-2 - Metodologia proposta

Sob posse dos parâmetros calibrados, segue-se para a Etapa 2, onde se faz um modelo em elementos finitos baseando-se no teste de impacto impacto (“drop-test”). Os resultados numéricos dessas análises dinâmicas são então comparados com os resultados gerados por uma máquina de teste de impacto instrumentada. Novamente, verifica-se a convergência entre o resultado teórico e o experimental. Para tal avaliação, propõe-se o cálculo de um parâmetro $\left(\mathrm{V}_{1}\right)$ baseado no Princípio da Conservação de Energia e com o auxílio de uma técnica de inspeção de falha (ultra-som C-Scan) tornase possível visualizar quais são os modos dominantes a fim de verificar o quanto o modelo de material empregado é capaz de representar os fenômenos envolvidos durante o processo de impacto da estrutura. 
Em se tratando do cálculo de $\mathrm{V}_{1}$, considera-se que o valor de força simulado computacionalmente necessita ser corrigido por este fator, tomando como referência os resultados experimentais tem-se:

$$
\mathrm{F}_{\text {sim }}=\mathrm{V}_{1} \mathrm{~F}_{\text {exp }}
$$

onde:

$$
\begin{aligned}
& F_{\text {sim }}=\text { força simulada computacionalmente } \\
& F_{\text {exp }}=\text { força medida experimentalmente }
\end{aligned}
$$

Além disso, tem-se que:

$$
\Delta \mathrm{E}_{\text {sim }}=\Delta \mathrm{E}_{\text {cin }}
$$

onde:

$$
\begin{aligned}
& \Delta \mathrm{E}_{\text {sim }}=\text { variação da energia simulada } \\
& \Delta \mathrm{E}_{\text {cin }}=\text { variação da energia cinética experimental }
\end{aligned}
$$

Sendo que a variação da energia cinética é dada por:

$$
\Delta \mathrm{E}_{\text {cin }}=\frac{\mathrm{m}\left(\mathrm{v}_{\mathrm{o}}^{2}-(\mathrm{v}(\mathrm{t}))^{2}\right)}{2}
$$

onde:

$$
\begin{aligned}
& \mathrm{v}_{\mathrm{o}}=\text { velocidade inicial de impacto do impactador } \\
& \mathrm{v}(\mathrm{t})=\text { velocidade do impactador }
\end{aligned}
$$

E a variação da energia simulada é dada por:

$$
\Delta \mathrm{E}_{\text {sim }}=\int_{\mathrm{t}_{\mathrm{o}}}^{\mathrm{t}_{\mathrm{f}}} \mathrm{F}_{\text {sim }} \mathrm{dx}=\mathrm{V}_{1} \int_{\mathrm{t}_{\mathrm{o}}}^{\mathrm{t}_{\mathrm{f}}} \mathrm{F}_{\text {exp }}\left(\mathrm{v}_{\mathrm{o}}+\Delta \mathrm{v}\right) \mathrm{dt}
$$

Nota-se que $\Delta \mathrm{v}$ pode ser obtido da seguinte forma:

$$
\Delta v=\int_{v_{o}}^{v_{f}} d v=\int_{t_{o}}^{t_{f}} a d t=\int_{t_{o}}^{t_{t}} \frac{F_{s i m}}{m} d t=\frac{V_{1}}{m} \int_{t_{o}}^{t_{t}} F_{e x p} d t
$$


Substituindo a equação (6.2-5) em (6.2-4) e utilizando (6.2-3) é possível chegar numa equação quadrática em função de $\mathrm{V}_{1}$ :

$$
V_{1} v_{o} \int_{t_{o}}^{t_{f}} F_{\exp } d t+V_{1}^{2} \int_{t_{o}}^{t_{f}} F_{\exp }\left(\int_{t_{o}}^{t_{f}} \frac{F_{\exp }}{m} d t\right) d t=\frac{m\left(v_{o}^{2}-v_{f}^{2}\right)}{2}
$$

Portanto,

$$
V_{1} v_{o} \int_{t_{0}}^{t} m \frac{d v(t)}{d t} d t+V_{1}^{2} \int_{t_{o}}^{t} m \frac{d v(t)}{d t}\left(\int_{t_{0}}^{t} \frac{m}{m} \frac{d v(t)}{d t} d t\right) d t-\frac{m\left(v_{o}^{2}-(v(t))^{2}\right)}{2}=0
$$

Continuando a dedução,

$$
\mathrm{V}_{1}^{2} \mathrm{~m} \int_{\mathrm{t}_{\mathrm{o}}}^{\mathrm{t}} \frac{\mathrm{dv}(\mathrm{t})}{\mathrm{dt}}\left(\mathrm{v}(\mathrm{t})-\mathrm{v}_{\mathrm{o}}\right) \mathrm{dt}+\mathrm{V}_{1} \mathrm{v}_{\mathrm{o}} \mathrm{m}\left(\mathrm{v}(\mathrm{t})-\mathrm{v}_{\mathrm{o}}\right)+\frac{\mathrm{m}\left((\mathrm{v}(\mathrm{t}))^{2}-\mathrm{v}_{\mathrm{o}}^{2}\right)}{2}=0
$$

Finalmente,

$$
\mathrm{V}_{1}^{2} \int_{\mathrm{v}_{\mathrm{o}}}^{\mathrm{v}}\left(\mathrm{v}(\mathrm{t})-\mathrm{v}_{\mathrm{o}}\right) \mathrm{dv}+\mathrm{V}_{1} \mathrm{v}_{\mathrm{o}}\left(\mathrm{v}(\mathrm{t})-\mathrm{v}_{\mathrm{o}}\right)+\frac{(\mathrm{v}(\mathrm{t}))^{2}-\mathrm{v}_{\mathrm{o}}^{2}}{2}=0
$$

Ou então:

$$
\mathrm{V}_{1}^{2}\left[\frac{\left((\mathrm{v}(\mathrm{t}))^{2}-\mathrm{v}_{\mathrm{o}}^{2}\right)}{2}-\mathrm{v}_{\mathrm{o}} \mathrm{v}(\mathrm{t})\right]+\mathrm{V}_{1}\left(\mathrm{v}_{\mathrm{o}} \mathrm{v}(\mathrm{t})-\mathrm{v}_{\mathrm{o}}^{2}\right)+\frac{(\mathrm{v}(\mathrm{t}))^{2}-\mathrm{v}_{\mathrm{o}}^{2}}{2}=0
$$

Onde $\mathrm{V}_{1}$ corresponde ao valor das raízes reais da equação de segundo grau acima. Nota-se pela equação (6.2-1) que se o valor de $\mathrm{V}_{1}$ estiver próximo da unidade, a força simulada computacionalmente estará próxima da força medida experimentalmente. Por outro lado, quanto mais o valor de $\mathrm{V}_{1}$ se afastar da unidade a força simulada estará longe de representar o teste experimental. Dessa forma, tem-se que o histórico de força 
da simulação deverá ser diferente para cada grupo de parâmetros associado ao modelo de material que está sendo calibrado.

Em resumo, de acordo com a metodologia, o modelo de material será inicialmente avaliado utilizando um teste de endentação que consiste de um teste quase-estático realizado em uma estrutura com as mesmas dimensões e vinculações empregadas no drop-test. No entanto, é importante destacar que o valor último da força aplicado deve ser baseado no pico de força encontrado no teste de impacto. Sendo assim, há necessidade de se realizar os testes de impacto antes dos testes de endentação. Após essa primeira etapa de avaliação (Etapa 1 - Análises Quase-Estáticas) segue-se para a avaliação dinâmica do modelo, onde serão utilizados os resultados provenientes da máquina de impacto (Etapa 2 - Análises Dinâmicas). Vale ressaltar que para alguns casos, quando a estrutura é impactada sob uma velocidade muito baixa, a análise computacional da primeira etapa é suficiente para fornecer resultados satisfatórios, dispensando assim as análises computacionais dinâmicas.

Conclui-se assim que a metodologia apresentada não é totalmente inovadora, no entanto, a determinação de $\mathrm{V}_{1}$ associado ao emprego dos modelos de material descritos no capítulo anterior (TABELA 5.2.2-2) é uma contribuição que demonstra uma alternativa para analisar problemas de impacto a baixa velocidade em estruturas de CPR. Pode-se considerar que a metodologia proposta vem sendo aplicada ao longo da execução do presente projeto de pesquisa. Em trabalhos futuros, os parâmetros associados aos modelos de material descritos no capítulo anterior (TABELA 5.2.2-2) poderão ser calibrados em função dos resultados do fator $\mathrm{V}_{1}$.

Por fim, a metodologia poderá ser aplicada para qualquer estrutura laminada, aconselhando-se apenas a realização de ensaios padronizados por normas técnicas para a obtenção das propriedades mecânicas e os valores de resistência, haja vista que na literatura as informações geralmente são escassas para o tipo específico de CPR que estiver sendo utilizado no projeto do componente. 


\section{Capítulo 7}

\section{CONCLUSÕES E PERSPECTIVAS FUTURAS}

O levantamento bibliográfico realizado para se obter um melhor entendimento do comportamento mecânico de materiais compósitos poliméricos foi de fundamental importância no desenvolvimento do presente projeto de pesquisa. Muitas contribuições científicas foram analisadas e estudadas para que se pudesse propor alguns modelos de material capazes de representar de forma coerente os mecanismos de danificação e falha existente em CPR. Além disso, o conhecimento de formas de abordagem (analítica e numérica) para prever o comportamento mecânico desses materiais forneceu subsídios para que as sub-rotinas USDFLD e UMAT fossem desenvolvidas.

A utilização de "prepregs" bem como a tecnologia de fabricação empregada para a obtenção das amostras foram fundamentais para os avanços conseguidos nesse projeto. Apesar do custo desse tipo de material, tem-se que a qualidade do mesmo é de extrema importância para que fossem obtidas amostras confiáveis. Além disso, o uso de uma autoclave automatizada permitiu controlar parâmetros de pressão, temperatura e vácuo durante a moldagem, seguindo assim as recomendações do fabricante do material $\left(\right.$ Hexcel $\left.^{\circledR}\right)$. Vale destacar também que o corte por ferramenta adiamantada (“diamond saw") garantiu que as amostras finais tivessem as dimensões esfecificadas pelas normas ASTM (American Society for Testing and Materials). Sendo assim, devido à qualidade do "prepreg" M10 (Hexcel ${ }^{\circledR}$ ) associado ao controle rigoroso dos parâmetros de processo, pode-se concluir que os corpos-de-prova confeccionados foram satisfatórios para que se pudesse obter resultados experimentais consistentes.

Quanto aos resultados experimentais quase-estáticos, deve-se ressaltar primeiramente que foi possível obter as propriedades mecânicas e os valores de resistência requisitados pelo modelo de material através dos testes de tração, 
compressão e cisalhamento devido ao aparato técnico existente no Leuven Composites Processing Centre (LCPC). A consistência desses resultados foi verificada comparando os mesmos com informações provenientes da literatura e com resultados provenientes de testes de flexão 3-pontos. Caso esses valores não fossem corretamente determinados, a avalição de um modelo de material proposto ficaria inviabilizada. Sendo assim, lançase a proposta de se criar no Brasil, centros de pesquisas tal como o LCPC, para que novos materiais possam ser desenvolvidos e testados.

A proposta de um modelo de material que fosse capaz de representar de forma coerente os fenômenos físicos intralaminares e interlaminares em compósitos poliméricos decorrentes da ação de carregamentos quase-estáticos foi um dos aspectos relevantes desta tese. $\mathrm{Na}$ verdade foram apresentados no Capítulo 4, dois critérios de degradação intralaminar, um critério de falha interlaminar e algumas leis de degradação caso houvesse danos na fibra ou na matriz, ou então falha interlaminar. Somado a isso, foi demonstrado como deveriam evoluir as tensões de cisalhamento no plano da lâmina devido à questão da não-linearidade de resposta. Diante desses aspectos e do levantamento bibliográfico realizado, conclui-se que a lei de degradação das propriedades em função dos parâmetros B e H é uma contribuição inédita e que pode ser aperfeiçoada em trabalhos futuros.

A implementação computacional de alguns modelos de material através de subrotinas USDFLD e UMAT (ABAQUS ${ }^{\circledR}$ ) foi fundamental para a avaliação dos critérios e leis de degradação apresentadas no Capítulo 4. Dentre os quatro modelos de material implementados, que estão especificados na TABELA 5.2.2-2, tem-se que tanto os Modelos II e III como o Modelo IV são inéditos. Pois, o emprego do Critério de Hashin Modificado associado com a lei de degradação das propriedades em função dos parâmetros B e H é uma contribuição inovadora.

O modelo de material foi inicialmente empregado para simular testes de tração e compressão com intuito de calibrar os parâmetros de material B e H e assim empregálos em simulações mais complexas como testes de flexão, endentação e impacto. No entanto, devido provavelmente à natureza anisótropa dos materiais compósitos poliméricos, observou-se que os parâmetros calibrados através da simulação dos ensaios de tração não poderiam ser utilizados em outros testes. Além disso, algumas simulações computacionais de testes de tração e de testes de flexão demonstraram que os modelos implementados até então, dependem da densidade da malha de elementos finitos, do tipo de elemento finito utilizado bem como do número de incrementos. Vale ressaltar 
que esses problemas foram investigados, apresentando assim, uma provável solução para os mesmos. No entanto, há necessidade de se realizar trabalhos futuros que venham corrigi-los a fim de que a simulação computacional produza resultados mais consistentes.

As simulações computacionais dos testes de flexão demonstraram de uma maneira geral que o Modelo I forneceu resultados mais pobres do que os Modelos II e III. Isso ocorreu porque o Modelo I possui uma lei de evolução de dano baseada num parâmetro constante de degradação, ao passo que os Modelos II e III possuem uma lei de evolução de dano baseada na função de degradação proposta no Capítulo 4. Conclui-se, que apesar dos problemas numéricos discutidos no Capítulo 5, os resultados mostram que os Modelos II e III, avaliados até então, são bem consistentes sob o ponto de vista da representação dos fenômenos físicos. Para a seqüência de empilhamento [45/45/45/0/90]s, o Modelo III obteve resultados mais satisfatórios, pois a análise foi realizada com base num modelo sólido. Quanto ao Modelo IV que inclui a previsão de falha por delaminação, tem-se que os resultados numéricos não apresentaram um ganho considerável de qualidade. Isto sugere que para melhor representar o fenômeno de propagação de fissuras interlaminares é necessário utilizar uma abordagem baseada em conceitos da Mecânica da Fratura.

As simulações computacionais dos testes de endentação demonstraram que os empregos dos Modelos II e III produziram resultados bem satisfatórios para representar os mecanismos de degradação que ocorrem neste tipo de ensaio. No entanto, vale ressaltar que tanto o fenômeno de contato como o esmagamento localizado da matriz polimérica pelo endentador precisam ser representados através de modelos mais completos. Portanto, esses modelos devem prever não somente o processo de degradação da fibra e da matriz, mas também a ocorrência de deformações permanentes.

As simulações computacionais dos testes de impacto utilizando os modelos de material implementados em programas comerciais $\left(\right.$ DYNA $^{\circledR}$ e ABAQUS $^{\circledR}$ ) mostraram que dependendo da energia de impacto, o modelo elástico ortotrópico pode fornecer resultados satisfatórios. Sendo assim, para os casos em que a energia de impacto é igual a 2,36 J, os mecanismos de degradação e falha não governam a resposta e assim a estrutura devolve uma parcela significativa dessa energia em forma de vibrações elásticas fazendo com que o modelo elástico ortotrópico apresente resultados numéricos satisfatórios. Por outro lado, para os casos em que a energia de impacto é igual a 5,91 J, os mecanismos de degradação e falha governam a resposta e assim a estrutura absorve 
uma parcela significativa dessa energia. Tudo isso pode ser confirmado com base em resultados experimentais, tais como históricos de força, velocidade e energia bem como imagens obtidas por ultra-som “C-Scan”. Sendo assim, tornou-se necessário o uso de modelos de degradação/falha, pois o modelo elástico ortotrópico não apresentou resultados numéricos satisfatórios. O Modelo de Chang-Chang Modificado implementado no programa DYNA ${ }^{\circledR}$ não foi capaz de representar de forma fiel os mecanismos de danificação/falha para os problemas de impacto avaliados, pois, apesar do modelo consistir de um Critério de Danificação associado a uma Lei de Degradação das Propriedades do Material, o mesmo não contempla falhas interlaminares (delaminações). Além disso, a lei de degradação das propriedades é muito rigorosa, fazendo com que a rigidez da estrutura seja reduzida drasticamente em pouco tempo. Por outro lado, os resultados obtidos com base no Modelo II através da VUMAT podem ser melhorados, desde que haja uma investigação mais detalhada dos problemas numéricos existentes. Além disso, ao incluir na formulação do modelo a influência das taxas de deformação do material bem como ao implementar um modelo de contato mais adequado pode-se levar a resultados mais satisfatórios.

Como perspetivas futuras, tem-se que os modelos de material implementados podem ser utilizados durante o desenvolvimento de projetos de componentes a fim de prever com maior precisão o comportamento mecânico das estruturas. Isso reflete diretamente na confiabilidade dos componentes fabricados, permitindo a utilização de coeficientes de segurança menores durante a fase de desenvolvimento de projeto, trazendo assim redução de custo sem comprometer a eficiência estrutural do mesmo. Vale ressaltar ainda, que essa capacidade de previsão de comportamento pode ser melhorada desde que a lei de evolução de dano intralaminar seja avaliada com base em ensaios de inspeção de falha (ultra-som "C-Scan") e que a lei de evolução de falha seja baseada em fundamentos da Mecânica da Fratura. Além disso, esses modelos foram avaliados apenas para resina epóxi reforçada por fibra de carbono unidirecional. No entanto, os mesmos poderão ser aplicados para outros tipos de compósitos poliméricos desde que os seus parâmetros sejam devidamente calibrados.

Com base nos resultados obtidos e na literatura estudada, apresentou-se a proposta de uma metodologia que fosse capaz de avaliar problemas de impacto a baixa velocidade de componentes mecânicos em CPR. Estabeleceu-se assim, um procedimento numérico-experimental contendo basicamente duas etapas: 1) Análises Quase-Estáticas; 2) Análises Dinâmicas. Nota-se, a primeira vista, que a metodologia 
proposta é um tanto quanto trabalhosa quando o material empregado não foi previamente caracterizado. Por outro lado, caso as propriedades mecânicas e os valores de resistência sejam conhecidos tem-se a necessidade apenas da realização dos testes de endentação e impacto para que haja a avaliação e a calibração do modelo de material. Apesar da metodologia apresentada não ser inovadora, tem-se que a contribuição mais relevante da mesma consiste no cálculo do fator $\mathrm{V}_{1}$ e no emprego dos Modelos de Material Propostos. Sendo assim, em trabalhos futuros, pode-se explorar uma relação entre o fator $\mathrm{V}_{1}$ e os parâmetros associados ao modelo de material, visando criar um procedimento mais atrativo de calibração desses parâmetros. Além disso, o modelo de material proposto poderá ser estendido para casos de impacto a alta velocidade, desde que seja realizado um estudo sobre a influência da taxa de carregamento na resposta do material. Por fim, a qualidade dos resultados numéricos pode ser melhorada através de uma investigação detalhada sobre a influência do tamanho do incremento, sobre a dependência da malha, sobre o tipo de elemento finito empregado e sobre o algoritmo de solução utilizado (Método de Newton-Raphson ou Método Dinâmico Explícito). Conclui-se, finalmente, que o presente trabalho poderá ser utilizado como ponto de partida para uma série de novos trabalhos.

\section{Sintese das conclusões e perspectivas futuras}

A utilização de "prepregs" bem como a tecnologia de fabricação empregada para a obtenção das amostras e os testes quase-estáticos e de impacto realizados foram fundamentais para os avanços conseguidos nesse projeto. Sendo assim, devido ao aparato técnico do Leuven Composites Processing Centre (LCPC) foi possível obter resultados experimentais consistentes.

Os modelos de material propostos no Capítulo 4 constituem uma contribuição inédita para o trabalho, pois, a combinação dada pela Relação Constitutiva associada com os Critérios de Danificação/Falha e com as Leis de Degradação das Propriedades é única. Além disso, os modelos de material propostos apresentam resultados muito satisfatórios para a previsão da primeira falha ("First Ply Failure").

A calibração dos parâmetros associados às Leis de Degradação demonstrou que resultados satisfatórios podem ser encontrados na fase "pós primeira falha". No entanto, os parâmetros calibrados na simulação dos testes de tração não puderam ser utilizados na simulação de outros testes (flexão e endentação). Isto se deve provavelmente à 
natureza anisotropa dos materiais compósitos poliméricos que promove um processo de falha complexo durante a fase "pós primeira falha".

A metodologia numérico-experimental proposta no Capítulo 6 é indédita e pode ser aplicada para estruturas mais complexas.

Por fim, a qualidade dos resultados numéricos pode ser melhorada através de uma investigação detalhada sobre a influência do tamanho do incremento, sobre a dependência da malha, sobre o tipo de elemento finito empregado e sobre o algoritmo de solução utilizado (Método de Newton-Raphson ou Método Dinâmico Explícito). Conclui-se, finalmente, que o presente trabalho poderá ser utilizado como ponto de partida para uma série de novos trabalhos. 


\section{Capítulo 8}

\section{REFERÊNCIAS BIBLIOGRÁFICAS}

ABAQUS Standard user's manual: theory. (2002). Pawtucket: Hibbitt, Karlsson \& Sorensen.

ABRATE, S. (1998). Impact on composite structures. London: Cambridge University Press.

AGARWAL, B.D.; BROUTMAN, L.J. (1990). Analysis and performance of fiber composites. New York: John Wiley.

SARACIBAR, C.A.; OÑATE, E. (1991). Modelado numérico de procesos de conformado de láminas metálicas. Barcelona: Centro Internacional de Métodos Numéricos en Ingeniería. Cap.5, p.5.1-5.80. (Monografia, 8).

ALVES, M. (1997). Mecânica do dano e falha em materiais e estruturas. São Paulo: EP/USP. Apostila.

ANDERSON, T.L. (1995). Fracture mechanics - fundamentals and applications. $2^{\text {nd }}$. ed. New York: CRC Press.

ANSYS user's manual: theory, procedures, elements. (1995). Houston: ANSYS.

ANSYS/LS-DYNA: theoretical manual. (1998). Livermore: Livermore Software Technology Corporation.

AMERICAN SOCIETY FOR TESTING AND MATERIALS (1995). D 3039/D 3039M-95a: standard test method for tensile properties of polymer matrix composite materials. Philadelphia. CD-ROM. 
AMERICAN SOCIETY FOR TESTING AND MATERIALS (1995). D 3410/D 3410_ 95: standard test method for compressive properties of polymer matrix composite materials with unsupported gage section by shear loading. Philadelphia. CD-ROM.

AMERICAN SOCIETY FOR TESTING AND MATERIALS (1994). D3518/D3518M94: standard practice for in-plane shear response of polymer matrix composite materials by tensile test of a $\pm 45^{\circ}$ laminate. Philadelphia. CD-ROM.

AMERICAN SOCIETY FOR TESTING AND MATERIALS (1996). D 790-96a: standard test method for flexural properties of unreinforced and reinforced plastics and electrical insulating materials. Philadelphia. CD-ROM.

AMERICAN SOCIETY FOR TESTING AND MATERIALS (1995). D 2344-84: standard test method for apparent interlaminar shear strength of parallel fiber composites by short-beam method. Philsdelphia. CD-ROM.

AMERICAN SOCIETY FOR TESTING AND MATERIALS (1996). D5628-96: standard test method for impact resistence of flat, rigid plastic specimens by means of a falling dart (tup or falling mass). Philadelphia. CD-ROM.

AMERICAN SOCIETY FOR TESTING AND MATERIALS (1993). D5379/D5379M93: standard test method for shear properties of composite materials by v-notched beam method. Philadelphia. CD-ROM.

BATHE, K.J. (1996). Finite element procedures. London: Prentice-Hall.

BELINGARDI, G.; GUGLIOTTA, A.; VADORI, R. (1998). Fragmentation of composite material plates submitted to impact loading: comparison between numerical and experimental results. Key Engineering Materials, Aedermannsdorf, v.144, p.75-88.

BOLZON, G.; GHILOTTI, D.; MAIER, G. (2002). Strength of periodic elastic-brittle composites evaluated through homogenization and parameter identification. European Journal of Mechanics A: solids, Montrouge, v.21, n.3, p.355-378.

BUCCHHOLZ, K. (1997). Chrysler CCV: four plastic body sections atop a steel chassis. Automotive Engineering, New York, v.105, n.11, p.67-68.

CAIRNS, D.S.; LAGACE, P.A. (1992). A Consistent engineering methodology for the treatment of impact in composite materials. Journal of Reinforced Plastics and Composites, Pennsylvania, v.11, 4, p.395-412, Apr. 
CALLISTER JR., W.D. (1985). Materials science and engineering. New York: John Wiley.

CANTWELL, W.J.; MORTON, J. (1991). The Impact resistence of composite materials - a review. Composites, Oxford, v.22, n.5, p.347-362.

CARLSSON, L.A.; PIPES, B. (1987). Experimental characterization of advanced composite materials. New Jersey: Prentice-Hall.

CARVALHO, J. (1996). Computer integrated design optimisation and manufacturing of filament wound parts. 198 p. Thesis (PhD) - Faculty of Applied Sciences, Division PMA, K.U. Leuven, Leuven, 1996.

CHANG, F.K.; CHANG, K.Y. (1987a). Post-failure analysis of bolted composite joints in tension or shear-out mode failure. Journal of Composite Materials, Thousand Oaks, v.21, n.9, p.809-833, Sept.

(1987b). A Progressive damage model for laminated composites containing stress concentrations. Journal of Composite Materials, Thousand Oaks, v.21, n.9, p.834-855, Sept.

CHANG, F.K.; SCOTT, R.A.; SPRINGER, G.S. (1984a). Failure of composite laminates containing a pin loaded holes - method of solution. Journal of Composite Materials, Thousand Oaks, v.18, n.3, p.255-278.

(1984b). Failure strength of nonlinearly elastic composite laminates containing a pin loaded hole. Journal of Composite Materials, Thousand Oaks, v.18, n.5, p.464477.

CHANG, F.K.; LESSARD, L.B. (1991). Damage tolerance of laminated composites containing an open hole and subjected to compressive loadings. Part I - analysis. Journal of Composite Materials, Thousand Oaks, v.25, n.1, p.2-43, Jan.

CHANG, K.Y.; LIU, S.; CHANG, F.K. (1991). Damage tolerance of laminated composites containing an open hole and subjected to tensile loadings. Journal of Composite Materials, Thousand Oaks, v.25, n.3, p.274-301, Mar.

CHRISTOFOROU, A.P.; SWANSON, S.R. (1991). Analysis of impact response in composite plates. International Journal of Solids Structures, New York, v.27, n.2, p.161-170. 
CHERESH, M.C.; McMICHAEL, S. (1987). Instrumented impact test data interpretation. In: KESSLER, S.L. Instrumented impact testing of plastics and composite materials. Philadelphia: ASTM. p.9-23. (ASTM - STP 936).

CHUN, L.; LAM, K.Y. (1997). Behavior of uniform anisotropic beams of rectangular section under transverse impact of a mass. Shock and Vibration, New York, v.4, n.2, p.125-141.

COLLOMBET, F.; LALBIN, X.; LATAILLADE, J.L. (1998). Damage prediction of laminated composites under heavy mass-low velocity impact. Key Engineering Materials, Aedermannsdorf, v.141-143, n.1, pt.1/2, p.743-776.

DAVIES, G.A.O. (1992). In-service behaviour of composites - impact. Leuven: European Postgraduate Education in Polymer and Composites Engineering (EUPOCO), K. U. Leuven. v.4, Module 5.

DÁVILA, C.G.; CAMANHO, P.P. (2001). Decohesion elements using two and threeparameter mixed-mode criteria. In: AHS INTERNATIONAL STRUCTURES SPECIALIST'S MEETING, 2001, Williamsburg. Proceedings... Williamsburg. 1 CDROM.

DÁVILA, C.G.; CAMANHO, P.P.; MOURA, M.F. (2001). Progressive damage analyses of skin/stringer debonding. In: AMERICAN SOCIETY OF COMPOSITES ANNUAL TECHINICAL CONFERENCE, 16., 2001, Blacksburg. Proceedings... Blacksburg: 1 CD-ROM.

DHARAN, C.K.H. (1979). Composite materials design and processes for automotive aplications. California: Ford Aerospace and Comunications.

DOTAN, A.L. (1997). Análise da rugosidade superficial de fibras de carbono e sua influência na interface fibra/matriz. Tese (Doutorado) - Instituto Tecnológico da Aeronáutica, São José dos Campos, 1997.

DUBEY, D.D.; VINZZINI, A.J. (1998). Energy absorption of composite plates and tubes. Journal of Composite Materials, Thousand Oaks, v.32, n.2, p.158-176.

ENGINEERED materials handbook. (1987). Metals Park: ASM International. v.1.

FARLEY, G.L. (1983). Energy absorption of composite materials. Journal of Composite Materials, Thousand Oaks, v.17, n.3, p.267-279. 
(1986). Effect of specimen geometry on the energy bsorption capability of composite materials. Journal of Composite Materials, Thousand Oaks, v.20, n.4, p.390400, July.

FARLEY, G.L.; JONES, R.M. (1992). Prediction of the energy absorption capability of composites type. Journal of Composite Materials, Thousand Oaks, v.26, n.3, p.388404.

FEIH, S.; SCHERCLIFF, H.R. (2000). 3-D Progressive damage modelling for ahesively bonded composite peel joints: implementation in a umat and related computaional issues. In: CONFERENCE ABAQUS - USER CONFERENCE, 2000, London. Proceedings... London. 1 CD-ROM.

GAO, S.L.; KIM, J.K. (1998). Three-dimensional characterization of impact damage in CFRPs. Key Engineering Materials, Aedermannsdorf, v.141-143, p.35-54.

GAUTHAM, B.P.; GANESAN, N. (1994). Finite element analysis of contact-impact between a shell of revolution and a rigid wall. International Journal for Numerical Methods in Engineering, New York, v.37, n.19, p.3251-3262, Oct.

GOTTESMAN, T.; GIRSHOVICH, S. (1998). Impact damage assessment and mechanical degradation of composites. Key Engineering Materials, Aedermannsdorf, v.141, n.1, pt.1/2, p.3-18.

GRESZCZUK, L.B. (1982). Damage in composite materials due to low velocity impact. In: ZUKAS, J.A. et al. Impact dynamics. New York: John Wiley. Cap.3, p.55-94.

HAHN, H.T.; TSAI, S.W. (1973). Nonlinear elastic behavior of unidirectional composite laminae. Journal of Composite Materials, Thousand Oaks, v.7, p.102-118, Jan.

. (1974). On The Behavior of composite laminates after initial failures. Journal of Composite Materials, Thousand Oaks, v.8, p.288-305, July.

HALLQUIST, J.O. (1993). LS-DYNA3D - theoretical manual. Livermore: Livermore Software Technology.

HAMADA, H.; RAMAKRISHNA, S. (1997). A FEM method for prediction of energy absorption capability os crashworthy polymer composite materials. Journal of Reinforced Plastics and Composites, Pennsylvania, v.16, n.3, p.226-241. 
HASHIN, Z. (1979). Analysis of properties of fiber composites with anisotropic constituents. Journal of Applied Mechanics, New York, v.46, n.3, p.543 -550, Sept. (1980). Failure criteria for unidirectional fiber composites. Journal of Applied Mechanics, Ne wYork, v.47, n.2, p.329 -334, June.

HAUG, E.; DE ROUVRAY, A. (1993). Crash response of composite structures. In: NORMAN, J.; TOMASZ, W. Structural crashworthiness and failure. London: Elsevier Science. Cap.7, p.237-294.

HILL, R. (1950). The Mathematical theory of plasticity. London: Oxford University Press.

HOLlMANN, M. (1986). Composite aircraft design. New York: Cupertino.

HULL, D. (1981). An Introduction to composite materials. London: Cambridge University Press.

HYER, M.W. (1998). Stress analysis of fiber-reinforced composite materials. Boston: McGraw-Hill.

JANG, B.Z. (1994). Advanced polymer composites. Metals Park: ASM International. JOHNSON, W. (1972). Impact strength of materials. London: Edward Arnold.

KARBHARI, V.M.; FALZON, P.J.; HERZBERG, I. (1997). Energy absorption characteristics of hybrid braided composite tubes. Journal of Composite Materials, Thousand Oaks, v.31, n.12, p.1164-1186.

KARBHARI, V.M.; LoCURCIO, A.P. (1997). Progressive crush response of hybrid felt/fabric composite structures. Journal of Reinforced Plastics and Composites, Pennsylvania, v.16, n.3, p.243-269.

KECMAN, D. (1997). An Engineering approach to crashworthiness of thin-walled beams and joints in vehicle structures. Thin-Walled Structures, Oxford, v.28, n.3/4, p.309-320.

KERMANIDIS, T. et al. (2000). Finite element modeling of damage accumulation in bolted composite joints under incremental tensile loading. In: EUROPEAN CONGRESS ON COMPUTATIONAL METHODS IN APPLIED SCIENCES AND ENGINEERING, 2000, Barcelona. Proceedings... Barcelona. 1 CD-ROM. 
KEUNINGS, R. (1992). Macromechanics of composites. Leuven: European Postgraduate Education in Polymer and Composites Engineering (EUPOCO), K. U. Leuven. v.2, Module 4.

KINDERVATER, C.M.; GEORGI, H. (1993). Composite strength and energy absorption as an aspect of structural crash resistence. In: NORMAN, J.; TOMASZ, W. Structural crashworthiness and failure. London: Elsevier Science. Cap.6, p.189-235.

KINDERVATER, C.M. et al. (2000). Crash and impact simulation of aircraft structures-hybrid and FE based approaches. In EUROPEAN CONGRESS ON COMPUTATIONAL METHODS IN APPLIED SCIENCES AND ENGINEERING. 2000, Barcelona. Proceedings... Barcelona. 1 CD-ROM.

KOSTOPOULOS, V. et al. (2002). Finite element analysis of impact damage response of composite motorcycle safety helmets. Composites: part B, Oxford, v.33, p.99-107.

LAVOIE, J.A.; KELLAS, S. (1996). Dynamic crush tests of energy-absorbing laminated composite plates. Composites: part A, Oxford, v.27, p.467-475.

LESSARD, L.B.; SHOKRIEH, M.M. (1995). Two-dimensional modelling of composite pinned-joint failure. Journal of Composite Materials, Thousand Oaks, v.29, n.5, p.671-697.

LEVY NETO, F. (1983). Estudo da falha ao impacto de uma estrutura de material conjugado usada em aeronaves. 252p. Dissertação (Mestrado) - Divisão de Engenharia Mecânica, Instituto Tecnológico da Aeronáutica, São José dos Campos, 1983.

LEVY NETO, F.; AL-QUERESHI, H.A. (1986). Aplicação do critério de falha de Tsai-Hill numa estrutura não-simétrica de material conjugado. In: CONGRESSO BRASILEIRO DE ENGENHARIA E CIÊNCIA DOS MATERIAIS, 7., 1986, Florianópolis. Anais... Florianópolis, p.389-392.

LIU, S.; KUTLU, Z.; CHANG, F.K. (1993). Matrix cracking and delamination in laminated composite beams subjected to a transverse concentrated line load. Journal of Composite Materials, Thousand Oaks, v.27, n.5, p.436-470.

LOPRESTO, V.; CAPRINO, G. (2002). Elastic response of circular CFRP plates under low-velocity impact. In: EUROPEAN CONFERENCE ON COMPOSITE MATERIALS, 10., 2002, Brugge. Proceedings... Brugge. 1 CD-ROM. 
MAGAGNIN FILHO, N. (1996). Placas laminadas em materiais compostos de fibras longas: propriedades termoelásticas dos materiais constituintes; propriedades equivalentes das lâminas; critérios de ruptura e análise pelo método dos elementos finitos. 147 p. Dissertação (Mestrado) - Escola de Engenharia de São Carlos, Universidade de São Paulo, São Carlos, 1996.

MAITI, D.K.; SINHA, P.K. (1995). Impact behavior of thick laminated composite beams. Journal of Reinforced Plastics and Composites, Pennsylvania, v.14, p.255-279, Mar.

MALVERN, L.E. (1969). Introduction to the mechanics of a continuous medium. New Jersey: Prentice-Hall.

MAMALIS, A.G. et al. (1996). Analysis of failure mechanisms observed in axial collapse of thin-walled circular fibreglass composite tubes. Thin-Walled Structures, Oxford, v.24, n.4, p.335-352.

- (1996a). The Static and dynamic axial collapse of fibreglass composite automotive frame rails. Composite Structures, Oxford, v.34, n.1, p.77-90, Jan.

. (1997). Crashworthy capability of composite material structures. Composite Structures, Oxford, v.37, n.2, p.109-134, Feb.

(1997a). Analytical modelling of the static and dynamic axial collapse of thinwalled fibreglass composite conical shells. International Journal of Impact Engineering, Oxford, v.19, n.5-6, p.477-492.

MARKOPOULOS, Y.P.; KOSTOPOULOS, V. (2002). On the low velocity impact response of laminated composite plates utilizing the p-version ritz method. In: EUROPEAN CONFERENCE ON COMPOSITE MATERIALS, 10., 2002, Brugge. Proceedings... Brugge. $1 \mathrm{CD}-\mathrm{ROM}$.

MATTEWS, F.L.; RAWLINGS, R.D. (1994). Composite materials: engineering and science. New York: Chapman-Hall

MATZENMILLER, A.; LUBLINER, J.; TAYLOR, R.L. (1995). A Constitutive model for anisotropic damage in fiber-composites. Mechanics of Materials, Amsterdam, v.20, n.2, p.125-152, Apr.

McCRUM, N.G.; BUCKLEY, C.P.; BUCKNALL, C.B. (1992). Principles of polymer engineering. New York: Oxford Science. 
MITTAL, R.K.; JAFRI, M.S. (1995). Influence of fibre content and impactor parameters on transverse of uniaxially reinforced composite plates. Composites, Oxford, v.26, n.12, p.877-886, Dec.

NUISMER, R.J.; TAN, S.C. (1988). Constitutive relations of a cracked composite lamina. Journal of Composite Materials, Thousand Oaks, v.22, n.4, p.306-321, Apr.

OLSSON, R. (2000). Mass criterion for wave controlled impact response of composite plates. Composites: part A, Oxford, v.31, p.879-887.

OÑATE, E. et al. (1991). Métodos avanzados de cálculo de estructuras de materiales compuestos. Barcelona: Centro Internacional de Métodos Numéricos en Ingeniería. (Monografia, 3).

PANDITA, S.; FALCONET, D.; VERPOEST, I. (2002). Impact properties of weft knitted fabric reinforced composites. Composites Science and Technology, Oxford, v.62, n.7/8, p.1113-1123, June.

PARÍS, F. (2001). A Study of failure criteria of fibrous composite materials. NASA. Report n.CR-2001-210661/March 2001.

PÉREZ GALÁN, J.L.; CLIMENT, H.; LE PAGE, F. (2000). Non-linear response of metallic and composite aeronautical fuselage structures under crash loads and comparison with full scale test. In: EUROPEAN CONGRESS ON COMPUTATIONAL METHODS IN APPLIED SCIENCES AND ENGINEERING. 2000, Barcelona. Proceedings... Barcelona. 1 CD-ROM.

PERUGINI, P.; RICCIO, A.; SCARAMUZZINO, F. (2001). Three-dimensional progressive damage analysis of composite joints. In: INTERNATIONAL CONFERENCE ON CIVIL AND STRUCTURAL ENGINEERING COMPUTING, 8., 2001, Stirling. Proceedings... 1 CD-ROM.

PETIT, P.H.; WADDOUPS, M.E. (1969). A Method of predicting the nonlinear behavior of laminated composites. Journal of Composite Materials, Thousand Oaks, v.3, p.2-19, Jan.

PIERSON, M.O.; VAZIRI, R. (1996). Analytical solution for low-velocity impact response of composite plates. AIAA Journal, Easton, v.34, n.8, p.1633-1640, Aug.

PRIOLO, P.; BUCCHIONI, A.; AYMERICH, F. (1998). Impact behaviour of quasiisotropic graphite-peek laminates. Key Engineering Materials, Aedermannsdorf, v.144, p. 63-74. 
PROENÇA, S.P.B. (1997). Análise não-linear de estruturas. São Carlos: EESC/USP. Apostila.

REINDL, J.C. (1987). Commercial and automotive applications. In: ENGINEERED materials handbook. Metals Park: ASM International. v.1, section 12, p.832-836.

ROCHE, J.L.; KAKARALA, S.N. (1987). Methodology for selecting impact tests of composite materials in automotive applications. In: KESSLER, S.L. Instrumented impact testing of plastics and composite materials. Philadelphia: ASTM. p.24-43. (ASTM -STP 936).

(1987a). Experimental comparison of several impact test methods. In:

KESSLER, S.L. Instrumented impact testing of plastics and composite materials. Philadelphia: ASTM. p.144-162. (ASTM-STP 936).

ROWLANDS, R.E. (1985). Strength (failure) theories and their experimental correlation. In: SIH, G.C.; SKUDRA, A.M. Failure mechanics of composite. Amsterdam: North-Holland. Cap.2, p.71-127.

RUBERT, J.B. (1997). Grandes deformações e anisotropia por tensores de mapeamento aplicados a problemas de materiais compostos e na conformação de metais. 228 p. Tese (Doutorado) - Escola de Engenharia de São Carlos, Universidade de São Paulo, São Carlos, 1997.

SANDHU, R.S. (1976). Nonlinear behavior of unidirectional and angle ply laminates. Journal of Aircraft, New York, v.13, n.2, p.104-111.

SHAHID, I.; CHANG, F.K. (1995). An Accumulative damage model for tensile and shear failures of laminated composite plates. Journal of Composite Materials, Thousand Oaks, v.29, n.7, p.926-981.

SHIVAKUMAR, K.N.; ELBERT, W.; ILLG, W. (1985). Prediction of low-velocity impact damage in thin circular laminates. AIAA Journal, Easton, v.23, n.3, p.442-449.

SIERAKOWSKI, R.L. (1997). Strain rate effects in composites. ASME (American Society of Mechanical Engineers, local, v.50, n.11, p.741-761.

SUN, C.T.; CHEN, J.K. (1985). On The Impact of initially stressed composites laminates. Journal of Composite Materials, Thousand Oaks, v.19, n.6, p.490-504.

TAN, S.C. (1991). A Progressive failure model for composite laminates containing openings. Journal of Composite Materials, Thousand Oaks, v.25, n.5, p.556-577, May. 
TAN, S.C.; NUISMER, R.J. (1989). A Theory for progressive matrix cracking in composite laminates. Journal of Composite Materials, Thousand Oaks, v.23, n.10, p.1029-1047, Oct.

TAN, T.M.; SUN, C.T. (1985). Use of statical indentation laws in the impact analysis of laminated composite plates. Transactions of ASME, New York, v.52, p.6-12.

TARANTOLA, A. (1987). Inverse problem theory. Methods for data fitting and model parameter etimation. Southampton: Elsevier Applied Science.

THOM, H. (1998). A Review of the biaxial strength of fibre-reinforced plastics. Composites: part A, Oxford, v.29, p.869-886.

THORNTON, P.H. (1979). Energy absorption in composite structures. Journal of Composite Materials, Thousand Oaks, v.13, p.247-262, July.

TITA, V. (1999). Análise dinâmica teórica e experimental de vigas fabricadas a partir de materiais compósitos poliméricos reforçados. 119 p. Dissertação (Mestrado) Escola de Engenharia de São Carlos, Universidade de São Paulo, São Carlos, 1999.

TITA, V.; CARVALHO, J.; LIRANI, J. (2001). A Procedure to estimate the dynamic damped behavior of fiber reinforced composite beams submitted to flexural vibrations. Materials Research, São Carlos, v.4, n.4, p.315-321.

TITA, V.; CARVALHO, J. (2001). Impact study on composite materials using finite element method. In: INTERNATIONAL CONFERENCE ON COMPOSITE MATERIALS, 13., 2001, Bejing. Proceedings... Bejing. 1 CD-ROM.

TITA, V.; CARVALHO, J.; SANTOS, N.C. (2002). Modelagem do comportamento mecânico de materiais compósitos utilizando o método dos elementos finitos. In: CONGRESSO NACIONAL DE ENGENHARIA MECÂNICA, 2., 2002, João Pessoa. Anais... João Pessoa. 1 CD-ROM.

TROWBRIDGE, D.A.; GRADY, J.E.; AIELLO, R.A. (1991). Low velocity impact analysis with NASTRAN. Computers \& Structures, New York, v.40, n.4, p.977-984.

TSAI, S.W. (1986). Composites design. United States Air Force Materials Laboratory. Dayton: Think Composites.

TSAI, S.W.; HAHN, H.T. (1980). Introduction to composite materials. Lancaster: Technomic Publishing. 
TSAI, S.W.; WU, E.M. (1971). A General theory of strength for anisotropic materials. Journal of Composite Materials, Thousand Oaks, v.5, p.58-80, Jan.

UCHIKAWA,Y.; ITABASHI, M.; KAWATA, K. (1997). On Crashworthiness of FRP thin-walled circular tubes under dynamic axial compression. Advanced Composite Materials, Netherlands, v.6, n.3, p.239-252.

VARNA, J. (2002). Effective properties of damaged laminated composites reinforced with continues ud fibers. In: EUROPEAN CONFERENCE ON COMPOSITE MATERIALS, 10., 2002, Brugge. Proceedings... Brugge. 1 CD-ROM.

VICENTE, J.L.S.; BÉLTRAN, F.; MARTÍNEZ, F. (2000). Simulation of impact on composite fuselage structures. In: EUROPEAN CONGRESS ON COMPUTATIONL METHODS IN APPLIED SCIENCES AND ENGINEERING, 2000, Barcelona. Proceedings... Barcelona. 1 CD-ROM.

VINSON, J.R.; SIERAKOWSKI, R.L. (1986). Behavior of structures composed of composite materials. Dordrecht: Martins Nijhoff.

WILLIAMS, J.G. (1973). Stress analysis of polymers. London: Longman Group.

WILLIAMS, K.V.; VAZIRI, R. (2001). Application of a damage mechanics model for predicting the impact response of composite materials. Computer \& Structures, New York, v.79, n.10, p.997-1011, Apr.

WHITNEY, J.M.; DANIEL, I.M.; PIPES, R.B. (1984). Experimental mechanics of fiber reinforced composite materials. New Jersey: Prentice-Hall.

YAMADA, S.E.; SUN, C.T. (1978). Analysis of laminate strength and its distribution. Journal of Composite Materials, Thousand Oaks, v.12, p.275-284, July.

YANG, S.H.; SUN, C.T. (1982). Identation law for composite laminates. In: WHITCOMB, J.D. Composite materials: testing and design. Philadelphia: ASTM. p.425-449. (ASTM - STP 787).

YIGIT, A.S.; CHRISTOFOROU, A.P. (1995). Impact dynamics of composite beams. Composite Structures, Oxford, v.32, n.1/4, p.187-195.

YOUNG, R.J.; LOVELL, P.A. (1991). Introduction to polymers. $2^{\text {nd }}$ ed. London: Chapman \& Hall.

ZUKAS, J.A. et al. (1982). Impact dynamics. New York: John Wiley. 


\section{Apêndice A}

\section{Sub-rotinas USDFLD e UMAT}

\section{MODELO I}

SUBROUTINE USDFLD (F IELD, STATEV, PNEWDT, DIRECT, T, CELENT, TIME, DTIME,

1 CMNAME, ORNAME, NF IELD, NSTATV, NOEL, NPT, LAYER, KSPT, KSTEP, KINC,

2 NDI, nshr, coord, jmac, jmtyp, mat layo, laccflg)

C

INCLUDE 'ABA_PARAM.INC'

C

$\mathrm{C}$

PROPRIEDADES ELÁSTICAS E VALORES DE RESISTÊNCIA

PARAMETER $(\mathrm{XT}=1400 \mathrm{D} 6, \mathrm{YT}=47 \mathrm{D} 6, \mathrm{XC}=930 \mathrm{D} 6, \mathrm{YC}=130 \mathrm{D} 6, \mathrm{SC} 12=53 \mathrm{D} 6, \mathrm{SC} 23=8$ 9D 6$)$

PARAMETER $(\mathrm{G} 12=5.4 \mathrm{D} 9, \mathrm{ALPHA}=3.98 \mathrm{D}-24)$

$\mathrm{C}$

CHARACTER $* 80$ CMNAME, ORNAME

CHARACTER $* 8$ FLGRAY (15)

DIMENSION FIELD (NFIELD), STATEV (NSTATV), DIRECT $(3,3), \mathrm{T}(3,3), \operatorname{TiME}(2)$,

* $\operatorname{coord}(*), j \operatorname{jmac}(*), j \operatorname{jmtyp}(*)$

DIMENSION ARRAY (15), JARRAY (15)

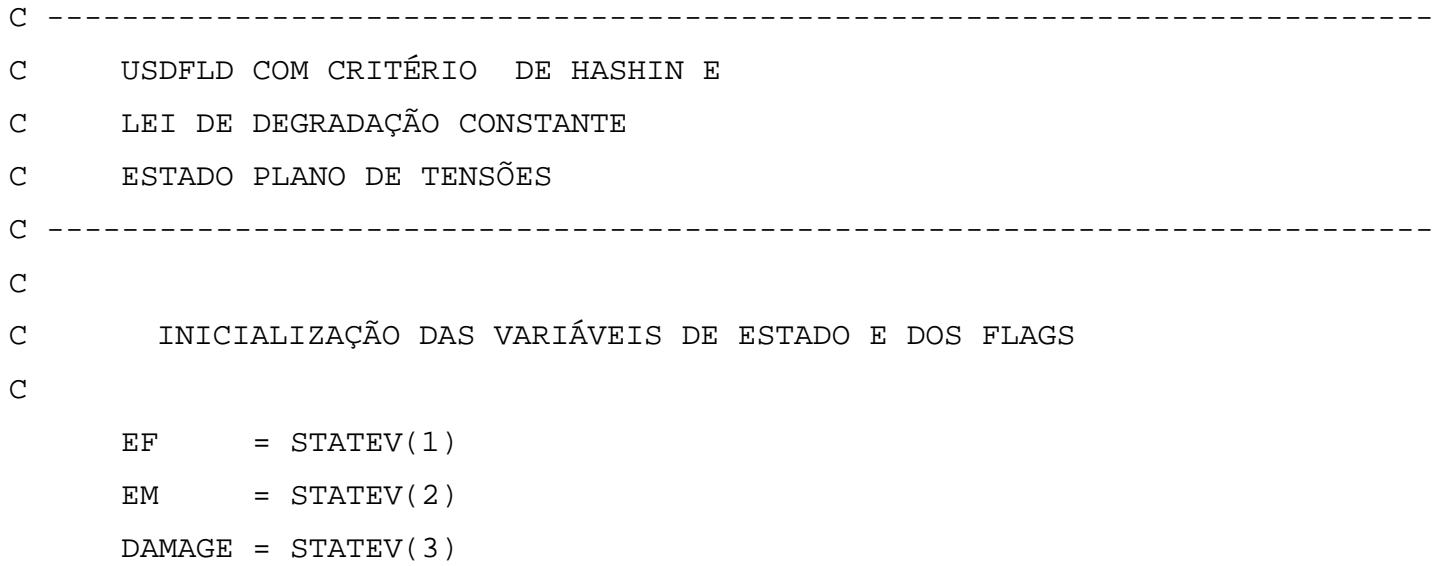


C

C

CALL GETVRM('S' , ARRAY, JARRAY, FLGRAY, jrCd,

\$ jmac, jmtyp, matlayo, laccflg)

$\mathrm{S} 11=\operatorname{ARRAY}(1)$

S22 = ARRAY (2)

$\mathrm{S} 12=\operatorname{ARRAY}(4)$

CALL GETVRM('E', ARRAY, JARRAY, FLGRAY, jrCd,

\$ jmac, jmtyp, matlayo, laccflg)

$\mathrm{E} 12=\operatorname{ARRAY}(4)$

C

$\mathrm{C}$

C

IF (E12.NE.0) THEN

DAMAGE $=(3 \cdot \mathrm{D} 0 * \mathrm{ALPHA} * \mathrm{G} 12 * \mathrm{~S} 12 * * 2-2 \cdot \mathrm{D} 0 * \mathrm{ALPHA} *(\mathrm{~S} 12 * * 3) / \mathrm{E} 12) /$

1

$\left(1 . \mathrm{D} 0+3 . \mathrm{D} 0 * \mathrm{ALPHA}{ }^{\mathrm{G}} 12{ }^{*} \mathrm{~S} 12 * \star 2\right)$

ELSE

DAMAGE $=0$. DO

ENDIF

C

$\mathrm{F} 1=\mathrm{S} 12 * * 2 /(2 . \mathrm{D} 0 * \mathrm{G} 12)+0.75 \mathrm{D} 0 * \mathrm{ALPHA} * \mathrm{~S} 12 * * 4$

$\mathrm{F} 2=\mathrm{SC} 12 * \star 2 /(2 . \mathrm{D} 0 * \mathrm{G} 12)+0.75 \mathrm{D} 0 * \mathrm{ALPHA} * \mathrm{SC} 12 * \star 4$

$\mathrm{C}$

C

IF (EF .LT. 1.DO) THEN

IF (S11 .LT. O.DO) THEN

$\mathrm{EF}=\mathrm{ABS}(\mathrm{S} 11 / \mathrm{XC})$

ELSE

$\mathrm{EF}=\operatorname{SQRT}((\mathrm{S} 11 / \mathrm{XT}) \star \star 2+(\mathrm{F} 1 / \mathrm{F} 2))$

ENDIF

$\operatorname{STATEV}(1)=\mathrm{EF}$

ENDIF

C

C

C

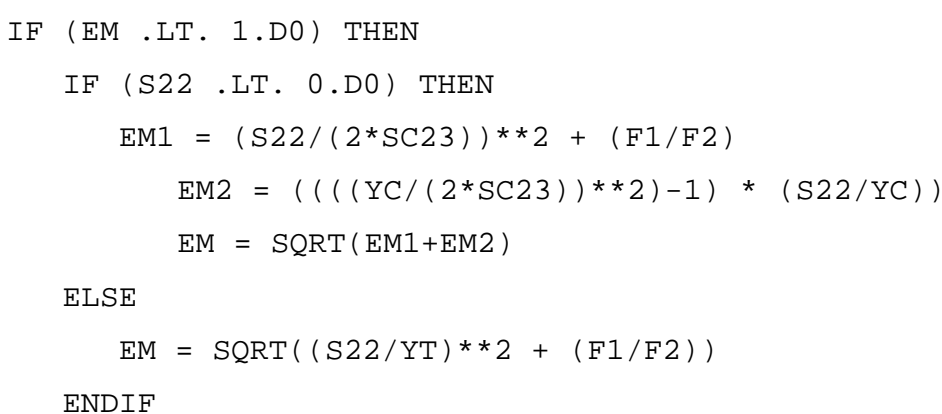




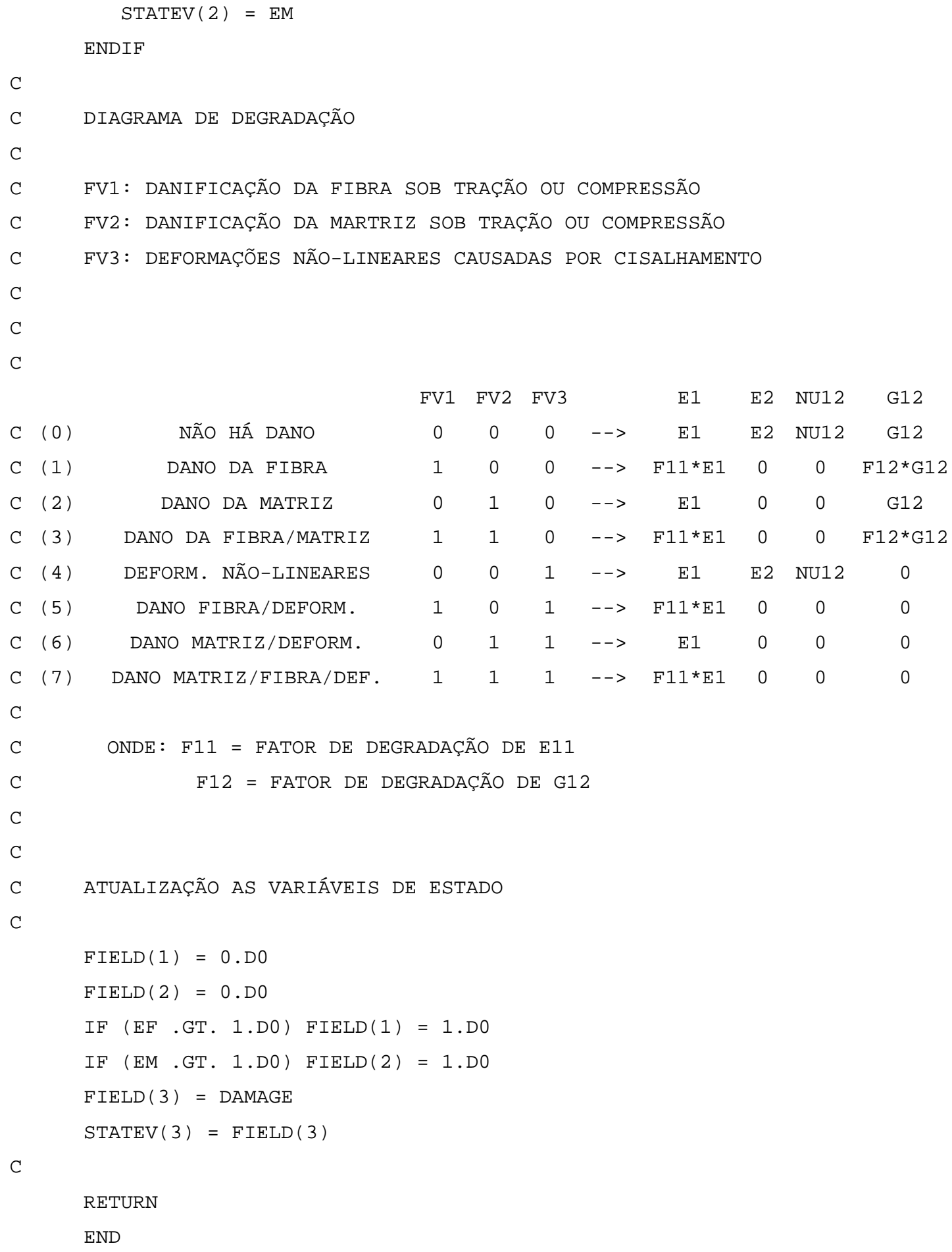




\section{MODELO II}

SUBROUTINE UMAT (STRESS, STATEV, DDSDDE, SSE, SPD, SCD,

1 RPL, DDSDDT, DRPLDE, DRPLDT , STRAN, DSTRAN,

2 TIME, DT IME, TEMP, DTEMP, PREDEF, DPRED, MATERL, NDI, NSHR, NTENS,

3 NSTATV, PROPS, NPROPS, COORDS, DROT, PNEWDT, CELENT,

4 DFGRD0, DFGRD1, NOEL, NPT, KSLAY, KSPT, KSTEP, KINC)

C

INCLUDE 'ABA_PARAM.INC'

C

CHARACTER $* 80$ MATERL

DIMENSION STRESS (NTENS), STATEV (NSTATV),

1 DDSDDE (NTENS, NTENS), DDSDDT (NTENS), DRPLDE (NTENS),

2 STRAN (NTENS), DSTRAN (NTENS), TIME (2), PREDEF (1), DPRED (1),

3 PROPS (NPROPS), COORDS (3), DROT $(3,3)$,

$4 \operatorname{DFGRDO}(3,3), \operatorname{DFGRD} 1(3,3)$

C

INTEGER FLAG

PARAMETER (XT=1400D 6, YT=4 7D 6, XC=930D 6, YC=130D 6, SC12=53D 6, SC23=89D 6)

PARAMETER (ALPHA $=3.98 \mathrm{D}-24, \mathrm{AGA}=0.2, \mathrm{AZERO}=2.5 \mathrm{D}-3$ )

$\mathrm{C}$

UMAT COM CRITÉRIO DE HASHIN E

LEI DE DEGRADAÇÃO DE CHANG MODIFICADA

ESTADO PLANO DE TENSÕES

PROPS (1) - E11

PROPS (2) - E22

PROPS (3) - E33

PROPS (4) - V12

PROPS (5) - V13

PROPS (6) - V23

PROPS (7) - G12

PROPS (8) - G13

PROPS (9) - G23

CARREGA OS VALORES DAS VARIÁVEIS DE ESTADO

$\mathrm{EF}=\operatorname{STATEV}(1)$

$E M=S T A T E V(2)$

FLAG $=S T A T E V(3)$

E11NOVO=STATEV (4)

E22NOVO=STATEV (5)

G12NOVO=STATEV (6)

$\mathrm{V} 12 \mathrm{NOVO}=\operatorname{STATEV}(7)$

$\mathrm{B}=\operatorname{STATEV}(8)$

C

$\mathrm{C}$

$\mathrm{C}$ 
$\mathrm{C}$$$
\text { c- }
$$

$\mathrm{C}$

C

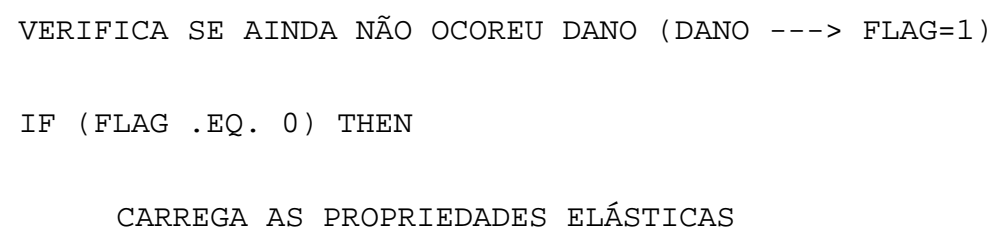

C

$\mathrm{V} 21=\mathrm{V} 12 \star \mathrm{E} 22 / \mathrm{E} 11$

C

C

RIGIDEZ ELÁSTICA

"ZERA" OS COMPONENTES DO TENSOR CONSTITUTIVO

DO $20 \mathrm{~K} 1=1,6$

DO $10 \mathrm{~K} 2=1,6$

$\operatorname{DDSDDE}(\mathrm{K} 2, \mathrm{~K} 1)=0.0$

10 CONTINUE

20

CONT INUE

$\mathrm{C}$

C

C

C

MONTAGEM DO TENSOR CONSTITUTIVO ELÁSTICO

$\operatorname{DDSDDE}(1,1)=\mathrm{E} 11 /(1-(\mathrm{V} 12 * \mathrm{~V} 21))$

$\operatorname{DDSDDE}(2,2)=\mathrm{E} 22 /(1-(\mathrm{V} 12 * \mathrm{~V} 21))$

$\operatorname{DDSDDE}(1,2)=(\mathrm{V} 21 * \mathrm{E} 11) /(1-(\mathrm{V} 12 * \mathrm{~V} 21))$

$\operatorname{DDSDDE}(2,1)=(\mathrm{V} 21 * \mathrm{E} 11) /(1-(\mathrm{V} 12 * \mathrm{~V} 21))$

IF (STRAN (3) .NE. 0) THEN $\operatorname{DDSDDE}(3,3)=(1+(2 * \operatorname{ALPHA} *(\operatorname{STRESS}(3) * \star 3) /(\operatorname{STRAN}(3)))) /$

1 $((1 /$ G12 $)+(3 * A L P H A *(\operatorname{STRESS}(3) * \star 2)))$

ELSE

$\operatorname{DDSDDE}(3,3)=\mathrm{G} 12$

ENDIF

C

C

PROPRIEDADES ELÁSTICAS SÃO CARREGADAS NAS VARIÁVEIS DE ESTADO

C 
ENDIF

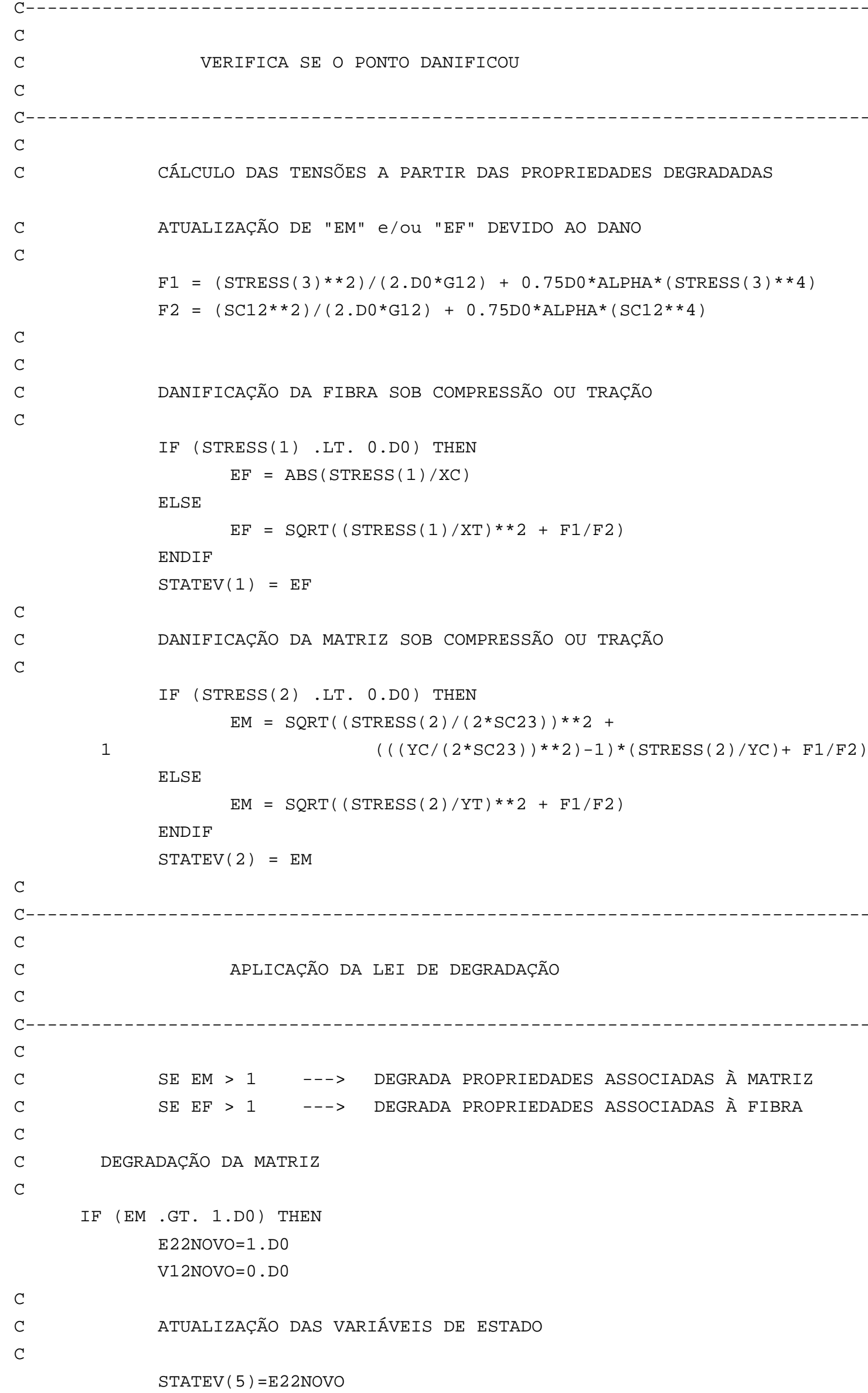


$\operatorname{STATEV}(7)=\mathrm{V} 12 \mathrm{NOVO}$

C

1

ENDIF

C

$\mathrm{C}$

C

C
ATUALIZAÇÃO DE V21 CASO AS PROPRIEDADES DEGRADEM

$\mathrm{V} 21 \mathrm{NOVO}=\mathrm{V} 12 \mathrm{NOVO} * \mathrm{E} 22 \mathrm{NOVO} / \mathrm{E} 11 \mathrm{NOVO}$

MONTAGEM DO NOVO TENSOR CONSTITUTIVO DEGRADADO

$\operatorname{DDSDDE}(1,1)=\mathrm{E} 11 \mathrm{NOVO} /(1-(\mathrm{V} 12 \mathrm{NOVO} * \mathrm{~V} 21 \mathrm{NOVO}))$

$\operatorname{DDSDDE}(2,2)=\mathrm{E} 22 \mathrm{NOVO} /(1-(\mathrm{V} 12 \mathrm{NOVO} * \mathrm{~V} 21 \mathrm{NOVO}))$

$\operatorname{DDSDDE}(1,2)=(\operatorname{V1} 2 \mathrm{NOVO} * \mathrm{E} 22 \mathrm{NOVO}) /(1-(\mathrm{V} 12 \mathrm{NOVO} * \mathrm{~V} 21 \mathrm{NOVO}))$

$\operatorname{DDSDDE}(2,1)=(\operatorname{V1} 2 \mathrm{NOVO} * \mathrm{E} 22 \mathrm{NOVO}) /(1-(\mathrm{V} 12 \mathrm{NOVO} * \mathrm{~V} 21 \mathrm{NOVO}))$

IF (STRAN (3) .NE. 0) THEN

$\operatorname{DDSDDE}(3,3)=(1+(2 * \operatorname{ALPHA} *(\operatorname{STRESS}(3) * \star 3) /(\operatorname{STRAN}(3)))) /$

$((1 / \mathrm{G} 12 \mathrm{NOVO})+(3 * \mathrm{ALPHA} *(\operatorname{STRESS}(3) * * 2)))$

ELSE

$\operatorname{DDSDDE}(3,3)=\mathrm{G} 12 \mathrm{NOVO}$

ENDIF

DEGRADAÇÃO DA FIBRA

IF (EF . GT . 1.DO) THEN

$\mathrm{E} 22 \mathrm{NOVO}=1 . \mathrm{DO}$

$\mathrm{V} 12 \mathrm{NOVO}=0 . \mathrm{DO}$

LEI DE DEGRADAÇÃO EXPONENCIAL

$\mathrm{FATOR}=0.5 \mathrm{D} 9$

$\mathrm{I} 1=1 \mathrm{D} 2 *(\operatorname{STRAN}(1)+\operatorname{STRAN}(2))$

$I 2=1 \mathrm{D} 4 *((\operatorname{STRAN}(1) * \operatorname{STRAN}(2))-(0.25 *(\operatorname{STRAN}(3) * \star 2)))$

$\mathrm{J} 2=(0.33333 *(\mathrm{I} 1 * \star 2))-\mathrm{I} 2$

ÁREA DEGRADADA=1/4 AREA DO ELEMENTO

$\mathrm{A}=\mathrm{B}+3.03 \mathrm{D}-2$

$\mathrm{FACT}=\mathrm{FATOR} * \mathrm{~J} 2$

$\mathrm{E} 11 \mathrm{NOVO}=\left(\mathrm{E} 11 / \mathrm{EXP}\left((\mathrm{A} / \mathrm{AZERO}){ }^{*} \mathrm{AGA}\right)\right)-\mathrm{FACT}$

$\mathrm{G} 12 \mathrm{NOVO}=(\mathrm{G} 12 / \mathrm{EXP}((\mathrm{A} / \mathrm{AZERO}) * \mathrm{AGA}))-\mathrm{FACT}$

ATUALIZAÇÃO DAS VARIÁVEIS DE ESTADO

$\operatorname{STATEV}(4)=\mathrm{E} 11 \mathrm{NOVO}$

$\operatorname{STATEV}(5)=\mathrm{E} 22 \mathrm{NOVO}$

$\operatorname{STATEV}(6)=$ G12NOVO

$\operatorname{STATEV}(7)=\mathrm{V} 12 \mathrm{NOVO}$

$\operatorname{STATEV}(8)=\mathrm{A}$

ATUALIZAÇÃO DE V21 CASO AS PROPRIEDADES DEGRADEM

$\mathrm{V} 21 \mathrm{NOVO}=\mathrm{V} 12 \mathrm{NOVO} * \mathrm{E} 22 \mathrm{NOVO} / \mathrm{E} 11 \mathrm{NOVO}$ 
$\operatorname{DDSDDE}(3,3)=\mathrm{G} 12 \mathrm{NOVO}$

ENDIF

IF (STRAN (3) .NE. 0) THEN

MONTAGEM DO NOVO TENSOR CONSTITUTIVO DEGRADADO

$\operatorname{DDSDDE}(1,1)=\mathrm{E} 11 \mathrm{NOVO} /(1-(\mathrm{V} 12 \mathrm{NOVO} * \mathrm{~V} 21 \mathrm{NOVO}))$

$\operatorname{DDSDDE}(2,2)=\mathrm{E} 22 \mathrm{NOVO} /(1-(\mathrm{V} 12 \mathrm{NOVO} * \mathrm{~V} 21 \mathrm{NOVO}))$

$\operatorname{DDSDDE}(1,2)=(\operatorname{V1} 2 \mathrm{NOVO} * \mathrm{E} 22 \mathrm{NOVO}) /(1-(\mathrm{V} 12 \mathrm{NOVO} * \mathrm{~V} 21 \mathrm{NOVO}))$

$\operatorname{DDSDDE}(2,1)=(\operatorname{V1} 2 \mathrm{NOVO} * \mathrm{E} 22 \mathrm{NOVO}) /(1-(\mathrm{V} 12 \mathrm{NOVO} * \mathrm{~V} 21 \mathrm{NOVO}))$

$\operatorname{DDSDDE}(3,3)=(1+(2 * \operatorname{ALPHA} *(\operatorname{STRESS}(3) * \star 3) /(\operatorname{STRAN}(3)))) /$

$((1 / \mathrm{G} 12 \mathrm{NOVO})+(3 * \operatorname{ALPHA} *(\operatorname{STRESS}(3) * \star 2)))$

ENDIF

A LÂMINA JÁ DEGRADOU, MAS NA ITERAÇÃO ATUAL NEM A FIBRA E NEM A MATRIZ DEGRADAM

(FLAG .EQ. 1) THEN

IF (EM .LE. 1.DO .AND. EF .LE. 1.DO) THEN

1

MONTAGEM DO NOVO TENSOR CONSTITUTIVO DEGRADADO

$\operatorname{DDSDDE}(1,1)=\mathrm{E} 11 \mathrm{NOVO} /(1-(\mathrm{V} 12 \mathrm{NOVO} * \mathrm{~V} 21 \mathrm{NOVO}))$

$\operatorname{DDSDDE}(2,2)=\mathrm{E} 22 \mathrm{NOVO} /(1-(\mathrm{V} 12 \mathrm{NOVO} * \mathrm{~V} 21 \mathrm{NOVO}))$

$\operatorname{DDSDDE}(1,2)=(\mathrm{V} 12 \mathrm{NOVO} * \mathrm{E} 22 \mathrm{NOVO}) /(1-(\mathrm{V} 12 \mathrm{NOVO} * \mathrm{~V} 21 \mathrm{NOVO}))$

$\operatorname{DDSDDE}(2,1)=(\mathrm{V} 12 \mathrm{NOVO} * \mathrm{E} 22 \mathrm{NOVO}) /(1-(\mathrm{V} 12 \mathrm{NOVO} * \mathrm{~V} 21 \mathrm{NOVO}))$

IF (STRAN (3) .NE. 0) THEN

$\operatorname{DDSDDE}(3,3)=(1+(2 \star \operatorname{ALPHA} *(\operatorname{STRESS}(3) \star \star 3) /(\operatorname{STRAN}(3)))) /$

$((1 / \mathrm{G} 12 \mathrm{NOVO})+(3 * \operatorname{ALPHA} *(\operatorname{STRESS}(3) * \star 2)))$

ELSE

$\operatorname{DDSDDE}(3,3)=\mathrm{G} 12 \mathrm{NOVO}$

ENDIF

ENDIF

ENDIF

ATUALIZAÇÃO DAS TENSÕES

$\operatorname{STRESS}(1)=(\operatorname{DDSDDE}(1,1) *(\operatorname{STRAN}(1)+\operatorname{DSTRAN}(1)))+$

$(\operatorname{DDSDDE}(1,2) *(\operatorname{STRAN}(2)+\operatorname{DSTRAN}(2)))+$

2

$(\operatorname{DDSDDE}(1,3) *(\operatorname{STRAN}(3)+\operatorname{DSTRAN}(3)))$

C

$\operatorname{STRESS}(2)=(\operatorname{DDSDDE}(2,1) *(\operatorname{STRAN}(1)+\operatorname{DSTRAN}(1)))+$

$(\operatorname{DDSDDE}(2,2) *(\operatorname{STRAN}(2)+\operatorname{DSTRAN}(2)))+$

$(\operatorname{DDSDDE}(2,3) *(\operatorname{STRAN}(3)+\operatorname{DSTRAN}(3)))$

C

$\operatorname{STRESS}(3)=(\operatorname{DDSDDE}(3,1) *(\operatorname{STRAN}(1)+\operatorname{DSTRAN}(1)))+$

$(\operatorname{DDSDDE}(3,2) *(\operatorname{STRAN}(2)+\operatorname{DSTRAN}(2)))+$

$(\operatorname{DDSDDE}(3,3) *(\operatorname{STRAN}(3)+\operatorname{DSTRAN}(3)))$ 
C

C ACIONAMENTO DO FLAG DE DANO

$\mathrm{C}$

IF (EM .GT. 1.DO .OR. EF .GT. 1.DO) THEN

$F L A G=1$

$\operatorname{STATEV}(3)=\mathrm{FLAG}$

ENDIF

C

$\mathrm{C}$

C

C FIM DA SUBROTINA UMAT

C

RETURN

END 


\section{MODELO IV}

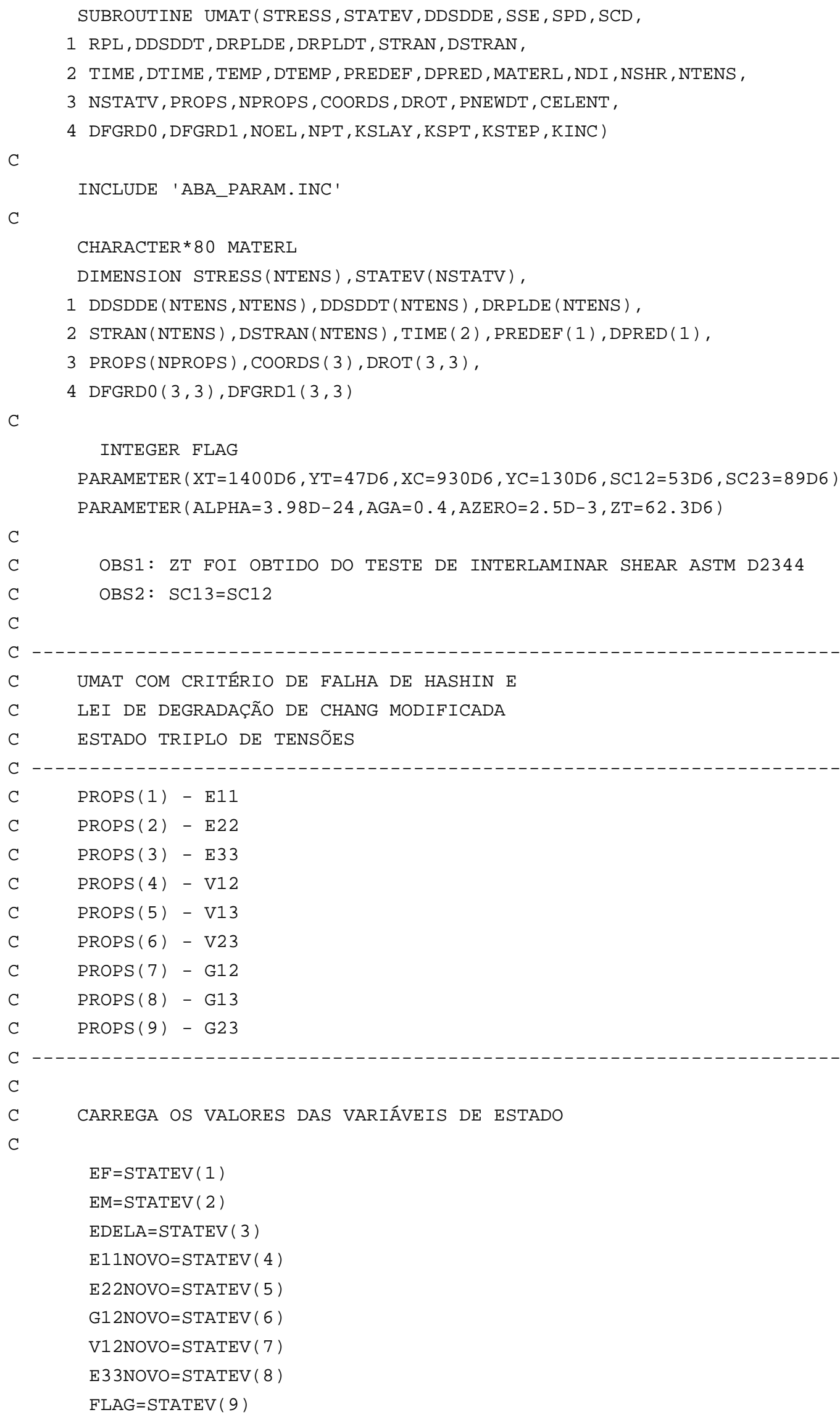




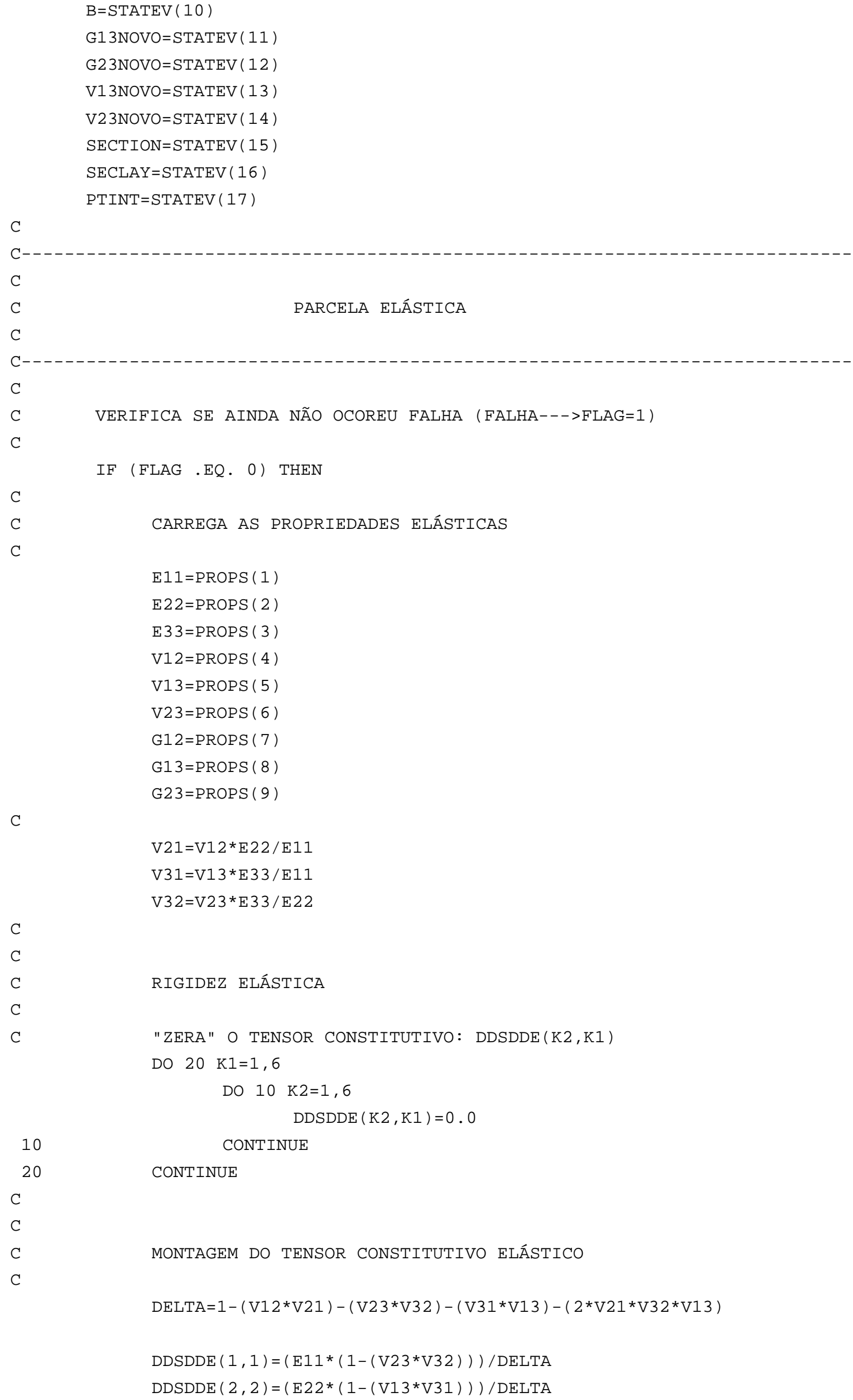




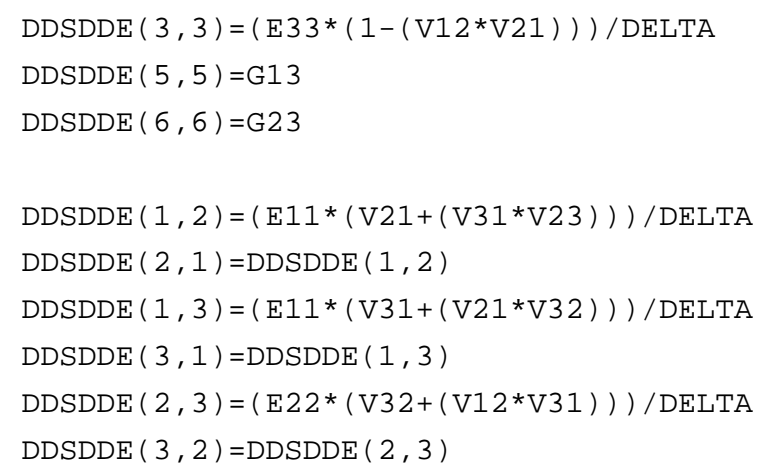

IF (STRAN (4) .NE. 0) THEN $\operatorname{DDSDDE}(4,4)=(1+(2 * \operatorname{ALPHA} *(\operatorname{STRESS}(4) * \star 3) /(\operatorname{STRAN}(4)))) /$

ELSE

$$
\operatorname{DDSDDE}(4,4)=\mathrm{G} 12
$$

ENDIF

C

C

ENDIF

C

C

C

C

C

C

ATUALIZAÇÃo DE "EM" e/ou "EF" e/ou "EDELA"

C-

C

$\mathrm{F} 1=(\operatorname{STRESS}(4) * \star 2) /(2 . \mathrm{D} 0 * \mathrm{G} 12)+0.75 \mathrm{D} 0 * \operatorname{ALPHA} *(\operatorname{STRESS}(4) * \star 4)$

$\mathrm{F} 2=(\mathrm{SC} 12 * \star 2) /(2 . \mathrm{D} 0 * \mathrm{G} 12)+0.75 \mathrm{D} 0 * \mathrm{ALPHA} *(\mathrm{SC} 12 * \star 4)$

$\mathrm{C}$

C

C

FALHA DA FIBRA SOB TRAÇÃO/COMPRESSÃO

$\mathrm{C}$

IF (STRESS (1) .LT. O.DO) THEN

$\mathrm{EF}=\mathrm{ABS}(\mathrm{STRESS}(1) / \mathrm{XC})$ 


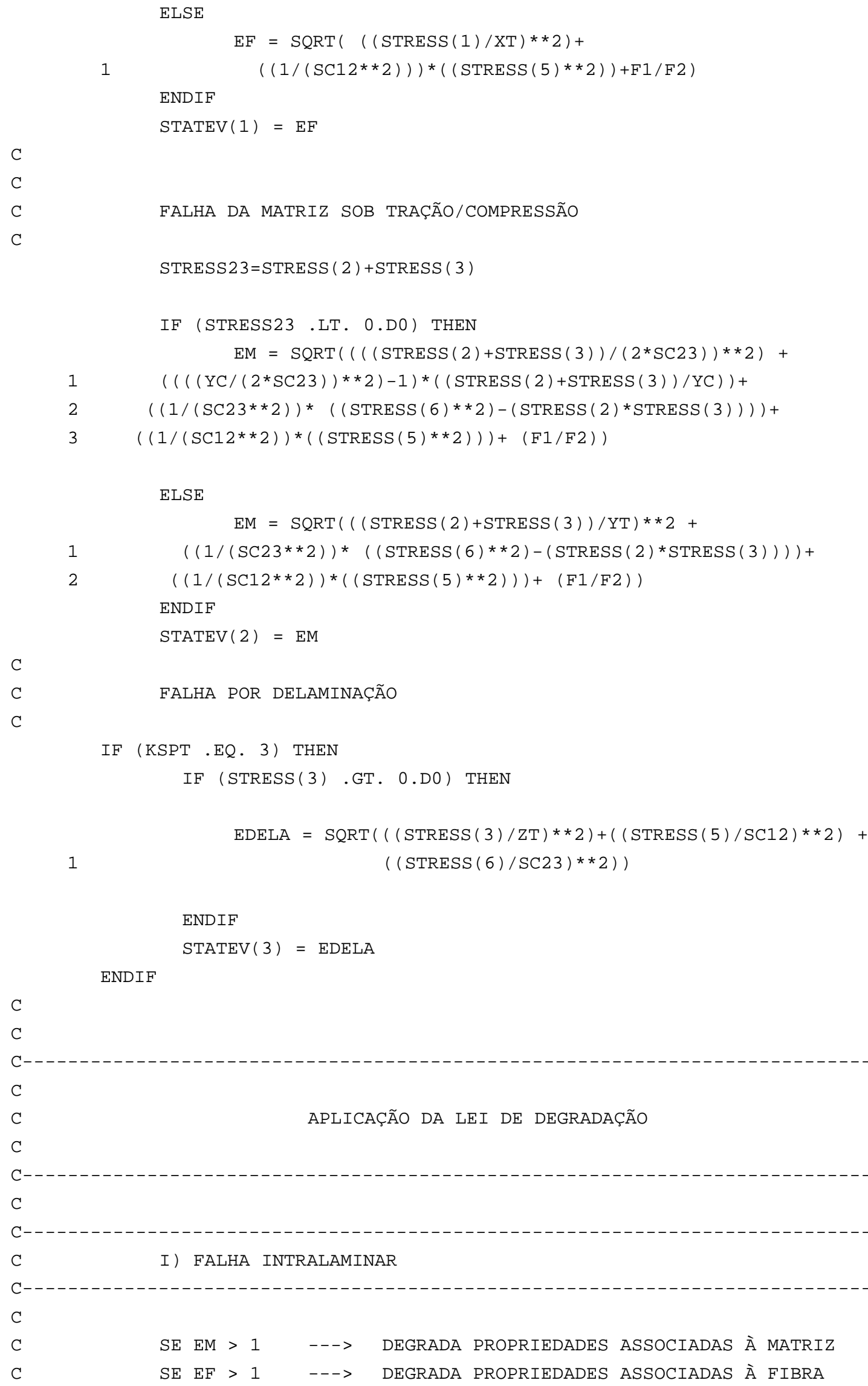


C

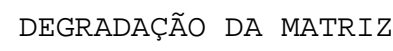

C 
1

2

C

C

C

$\mathrm{C}$

$\mathrm{C}$

$\mathrm{C}$

C

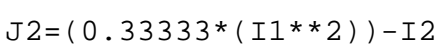

ENDIF 


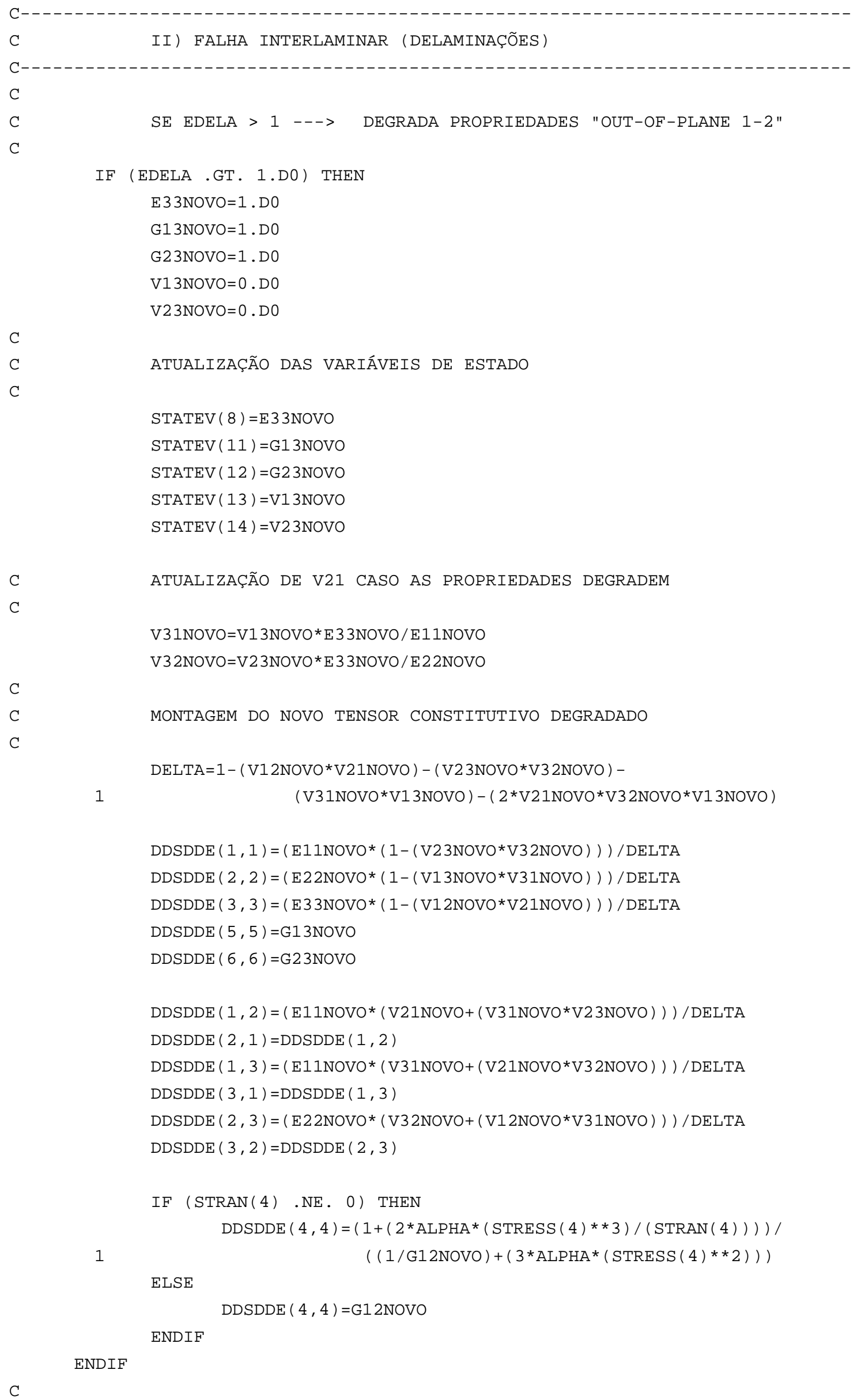


c

c

c

1

A LÂMINA JÁ FALHOU, MAS NO INCREMENTO ATUAL NEM A FIBRA E NEM

A MATRIZ FALHAM E NÃO HÁ DELAMINAÇÃO

(FLAG EQ. 1) THEN

IF (EM .LE. 1.DO .AND. EF .LE. 1.DO .AND. EDELA . LE. 1.DO) THEN

ATUALIZAÇÃO DE V21 CASO AS PROPRIEDADES DEGRADEM

V21NOVO=V12NOVO *E22NOVO/E11NOVO

MONTAGEM DO NOVO TENSOR CONSTITUTIVO DEGRADADO

DELTA $=1-(\mathrm{V} 12 \mathrm{NOVO} * \mathrm{~V} 21 \mathrm{NOVO})-(\mathrm{V} 23 \mathrm{NOVO} * \mathrm{~V} 32 \mathrm{NOVO})-$

(V31NOVO*V13NOVO) $-(2 * V 21$ NOVO*V32NOVO*V13NOVO $)$

$\operatorname{DDSDDE}(1,1)=($ E11NOVO* $(1-(\mathrm{V} 23 \mathrm{NOVO} * \mathrm{~V} 32 \mathrm{NOVO}))) / \operatorname{DELTA}$

$\operatorname{DDSDDE}(2,2)=($ E22NOVO* $(1-(\mathrm{V} 13 \mathrm{NOVO} * \mathrm{~V} 31 \mathrm{NOVO}))) /$ DELTA

$\operatorname{DDSDDE}(3,3)=($ E33NOVO $*(1-(\mathrm{V} 12 \mathrm{NOVO} * \mathrm{~V} 21 \mathrm{NOVO}))) /$ DELTA

$\operatorname{DDSDDE}(5,5)=$ G13NOVO

$\operatorname{DDSDDE}(6,6)=\mathrm{G} 23 \mathrm{NOVO}$

$\operatorname{DDSDDE}(1,2)=(\mathrm{E} 11 \mathrm{NOVO} *(\mathrm{~V} 21 \mathrm{NOVO}+(\mathrm{V} 31 \mathrm{NOVO} * \mathrm{~V} 23 \mathrm{NOVO}))) / \mathrm{DELTA}$

$\operatorname{DDSDDE}(2,1)=\operatorname{DDSDDE}(1,2)$

$\operatorname{DDSDDE}(1,3)=($ E11NOVO $*(\mathrm{~V} 31 \mathrm{NOVO}+(\mathrm{V} 21 \mathrm{NOVO} * \mathrm{~V} 32 \mathrm{NOVO}))) / \mathrm{DELTA}$

$\operatorname{DDSDDE}(3,1)=\operatorname{DDSDDE}(1,3)$

$\operatorname{DDSDDE}(2,3)=(\mathrm{E} 22 \mathrm{NOVO} *(\mathrm{~V} 32 \mathrm{NOVO}+(\mathrm{V} 12 \mathrm{NOVO} * \mathrm{~V} 31 \mathrm{NOVO}))) / \mathrm{DELTA}$

$\operatorname{DDSDDE}(3,2)=\operatorname{DDSDDE}(2,3)$

IF (STRAN (4) .NE. 0) THEN

$\operatorname{DDSDDE}(4,4)=(1+(2 \star \operatorname{ALPHA} *(\operatorname{STRESS}(4) * \star 3) /(\operatorname{STRAN}(4)))) /$

1 $((1 /$ G12NOVO $)+(3 * A L P H A *(\operatorname{STRESS}(4) * * 2)))$

ELSE

$\operatorname{DDSDDE}(4,4)=\mathrm{G} 12 \mathrm{NOVO}$

ENDIF

ENDIF

ENDIF

1

2

C

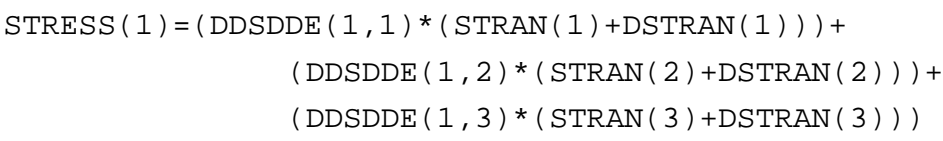

ATUALIZAÇÃO DAS TENSÕES $(\operatorname{DDSDDE}(2,2) *(\operatorname{STRAN}(2)+\operatorname{DSTRAN}(2)))+$ $(\operatorname{DDSDDE}(2,3) *(\operatorname{STRAN}(3)+\operatorname{DSTRAN}(3)))$ 


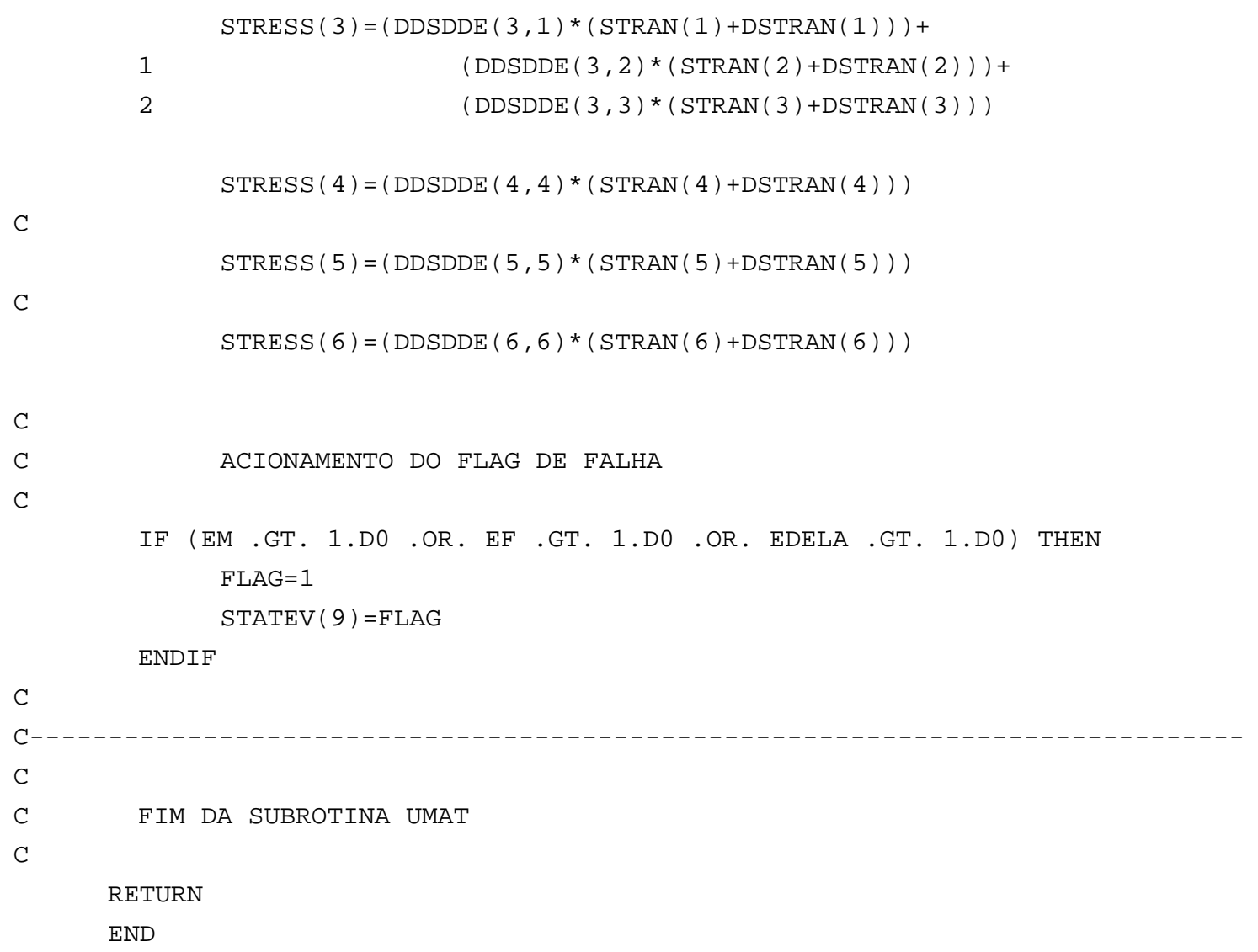

